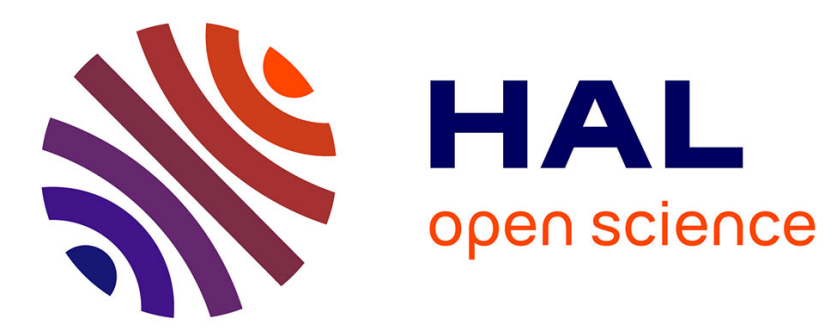

\title{
Contribution to the optimization of energy withdrawn from a PV panel using an Embedded System
}

\author{
Saad Motahhir
}

\section{To cite this version:}

Saad Motahhir. Contribution to the optimization of energy withdrawn from a PV panel using an Embedded System. Electric power. Université Sidi Mohamed Ben Abdellah Fès (Maroc), 2018. English. NNT: . tel-02471764

\section{HAL Id: tel-02471764 \\ https://hal.science/tel-02471764}

Submitted on 11 Apr 2020

HAL is a multi-disciplinary open access archive for the deposit and dissemination of scientific research documents, whether they are published or not. The documents may come from teaching and research institutions in France or abroad, or from public or private research centers.
L'archive ouverte pluridisciplinaire HAL, est destinée au dépôt et à la diffusion de documents scientifiques de niveau recherche, publiés ou non, émanant des établissements d'enseignement et de recherche français ou étrangers, des laboratoires publics ou privés. 
جامعة سيدي محمد بن عبد عامد الله

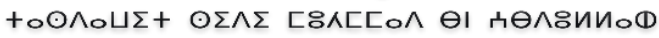
Université Sidi Mohamed Ben Abdellah

$\mathrm{N}^{\circ}$ d'ordre : $11 / 2018$

\section{THESE DE DOCTORAT}

Présentée par

Mr: Saad MOTAHHIR

Spécialité : Génie électrique

Sujet de la thèse

\section{«Contribution to the optimization of energy withdrawn from a PV panel using an Embedded System»}
«Contribution à l'optimisation de l'énergie soutirée des panneaux photovoltaïques par un système embarqué »

Thèse présentée et soutenue le 31/03/2018 devant le jury composé de :

\begin{tabular}{|l|c|l|l|}
\hline Nom Prénom & Titre & \multicolumn{1}{|c|}{ Etablissement } & \\
\hline Pr. Ali BENBASSOU & PES & Ecole Supérieure de Technologie de Fès & Président \\
\hline Pr. Tarik KOUSKSOU & PES & Université de Pau et des Pays de l'Adour France & Rapporteur \\
\hline Pr. Miloud RAHMOUNE & PES & Ecole Supérieure de Technologie de Meknès & Rapporteur \\
\hline Pr. Jamil ABDELMAJID & PH & Ecole Supérieure de Technologie de Fès & Rapporteur \\
\hline Pr. Rachid SAADANI & PES & Ecole Supérieure de Technologie de Meknès & Examinateur \\
\hline $\begin{array}{l}\text { Pr. Abdelaziz EL GHZIZAL } \\
\text { Pr. Aziz DEROUICH }\end{array}$ & PES & Ecole Supérieure de Technologie de Fès & Directeurs de thèse \\
\hline
\end{tabular}

Laboratoire d'accueil : Laboratoire Productique, des Energies et de Développement Durable.

Etablissement : Ecole Supérieure de Technologie de Fès. 


\section{To my beloved} parents

for their enduring

love,

motivation and

support. 


\section{ACKNOWLEDGEMENT}

Alhamdulillah, I am greatly indebted to Allah SWT for His mercy and blessing for making this research successful.

I would like to take this opportunity to express my deepest gratitude and thanks to my project supervisors, Prof. Dr. Abdelaziz El ghzizal and Prof. Dr. Aziz Derouich for their constant guidance, assistance and support as well as all the knowledge they shared during this research.

Mr. Ali BENBASSOU, the Director of the High School of Technology for accepting to be the president of the reading committee of my thesis.

The rest of the reading committee members: Mr. Abdelmajid JAMIL, Mr. Rahmoune Miloud, Mr. Tarik KOUSKSOU and Mr. Rachid Saadani for their helpful comments and their valuable suggestions. Mr. Frederic Compagnon Chopin Director at Zodiac Aerospace Maroc for his testimony as the guest of honor.

Mr. Mustapaha IJJAALI, the Dean of the Faculty of Sciences and Techniques of Fez and Mr. El Mestafa EL HADRAMI, the Director of Doctoral Studies Centre "Science and Engineering Techniques" for their efforts in ensuring the accomplishment of this doctoral thesis in the best conditions.

I sincerely thank all the professors who have taught me, for the lesson that has been delivered. Not to mention, to my fellow researchers, friends, especially Aboubakr El Hammoumi, Abdelilah Chalh, Ayoub Aoune, Mohammed Boussetta, Amine Allouhi, Moustapha Errouha and Mohamed Benslimane, thank you for helping me in my research, sharing useful ideas, information and moral support during the course of study.

To my closer friends, especially Adnane Touati, Salah Eddine Hebaz and Aderdor Zouhir, I express my gratitude for their unconditional friendship, support and patience throughout these years.

Last but not least I would like to express my appreciation and gratitude to my parents Latifa and Mohamed, uncles and aunts and their wives and husbands, especially my uncle Abderahim and his wife for all the supports and encouragements they provide during my studies. 
 \\ Centre d'Etudes Doctorales : Sciences et Techniques de I'Ingénieur}

\section{ABSTRACT}

Considering the high initial capital cost of photovoltaic (PV) panels and their low conversion efficiency, it is imperative to operate the PV system at the maximum power point (MPP). In this context, our goal in this thesis is to develop and improve the PV system, by contributing to the optimization of energy withdrawn from PV panel using an embedded system. For this purpose, in order to simulate and test MPPT algorithm, the model of the PV panel should be first studied in accordance with the real behavior of the PV panel. Therefore, the single diode model of the PV panel is introduced in Matlab/Simulink and PSIM. Moreover, for the first time, the PV panel model is developed in Proteus; an experimental test bench was built to validate the developed model. On the other hand, this work proposes a modified incremental conductance (INC) algorithm to improve the MPP tracker (MPPT) capability for PV system when the irradiation is suddenly modified. Three modifications are made in the INC algorithm, which are described as follows:

(1) A check to identify the increase in irradiation and make a correct decision.

(2) Eliminate the all-division computations in the INC algorithm and make the algorithm structure simpler allowing the algorithm to be easily implemented by a low-cost embedded system.

(3) A modified variable step INC algorithm is used, which can reduce the steady-state oscillations and improve the tracking speed under sudden irradiance variation.

The first modification is simulated using PSIM through "Software in the Loop" test and the results show that the modified algorithm provides an accurate response to a sudden variation of solar irradiation with an efficiency of $98.8 \%$. The second modification is simulated using the PV panel model proposed in Proteus. For verification, a hardware test bench is implemented by using the Arduino Uno board in which the low-cost Atmega328 microcontroller is integrated. This has led to a low-cost PV system with an efficiency of $98.5 \%$. The third modification is developed following the techniques employed in the automotive and aeronautical embedded systems. This is done by following the V-cycle development process, which means that our controller will be validated using "Model in the Loop/Software in the Loop/Processor in the Loop" tests. In this sense, integrating the MPPT embedded system in the automotive or aeronautical area will be possible. It should be mentioned that Matlab/Simulink is used for MIL/SIL/PIL tests, thus STM32F4 board is used for PIL test. 
 \\ Centre d'Etudes Doctorales : Sciences et Techniques de l'Ingénieur}

On the other side, if minimizing the cost of the PV system is not essential than guarantying a very high level of robustness and efficiency, it is required to use a ${ }^{2}$ more robust method. Therefore in this thesis, we design and implement MPPT based on Kalman Filter. The expected outcome of this proposal is an efficient MPPT method which presents a very high level of robustness, reliability and accuracy. The obtained results clearly highlight the superiority of the proposed method; it yields an efficiency of $99.38 \%$, which is almost $3 \%$ higher than the conventional INC method.

In a nutshell, this thesis proposed two solutions, the first one is for low-cost applications with a good performance using the modified INC, and the second is for higher performance and critical applications by using Kalman filter.

Keywords: PV Panel, Proteus, modified incremental conductance, fast change of irradiance, embedded system, low-cost PV system, Kalman filter-based MPPT, Reliable and robust PV system.

اليوم، أصبح من الضروري الانخر اط في استخدام موارد الطاقة المتجددة لتغطية الطلب المتزايد على الطاقة وتقليل الاعتماد على الوقود الأحفوري. الطاقة الثمسية الكهروضوئية (PV) هي واحدة من مصادر الطاقة المتجددة الأكثر استعمالا في

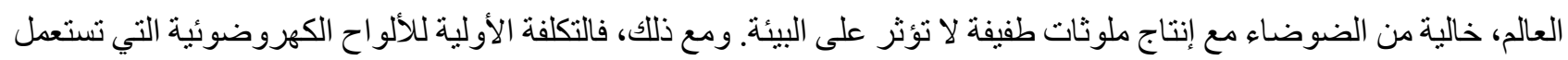
لتوليد الطاقة الكهربائية من الطاقة الثمسية تبقى مرتفعة، بالإضافة إلى كفاءة تحويلها المنخفضة. كما أن الطاقة المحصلة غير خطية و التي تقدم نقطة واحدة لاستخر اج الطاقة القصوى. أمام هذه التحديات، من الضروري تشغيل النظام الكهروضوئي عند نقطة الطاقة القصوى (MPP). في هذا السياق، هدفنا في هذه الأطروحة هو تطوير وتحسين النظم الكهروضوئية، وذلك عن طريق المساهمة في

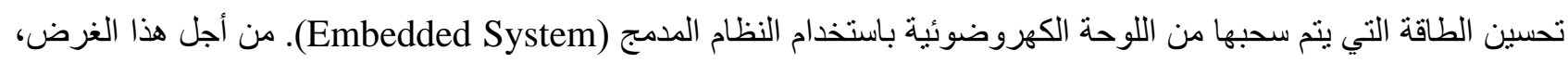

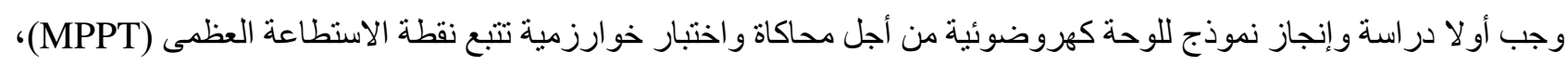

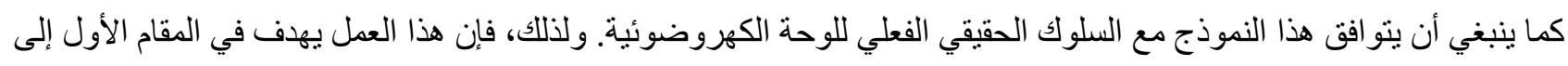
اقتر اح نموذج للوحة الكهروضوئية في برنامج Proteus. و هكذا، تم إعداد اختبار تجريبي بككونات حقبقية للتحقق من صحة هدا النموذج. من ناحية أخرى، يقترح هذا العمل خوارزمية زيادة الناقلية (INC) معدَّلة لتحسين قدرة تحكم المتتبع نقطة الاستطاعة

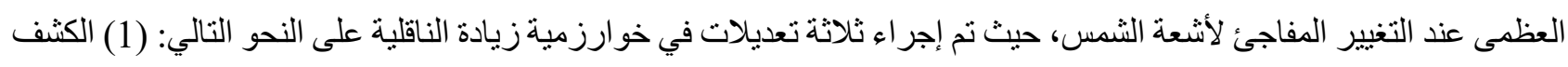
عن التغيير المفاجئ لأشعة الثمس و اتخاد القرار الصحيح. في هذه الحالة (2) إلغاء جميع حسابات القسمة في خوارزمية زيادة الناقلية وتبسيط هيكلها لجعلها تبرمج بسهولة في المتحكمات الدقيقة (Microcontrollers) منخفضة التكلفة. وبالتالي، تقديم نظام كهروضوئي منخفض التكلفة. (3) اقتر اح خطوة متغيرة جديدة لخوارزمية زيادة الناقلية من أجل الحد من التذبذبات في النظام المستقر

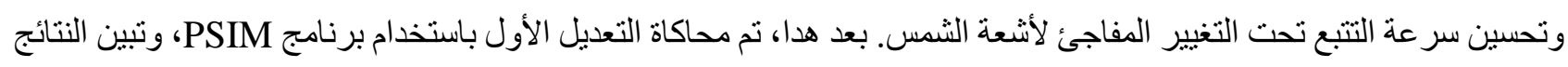

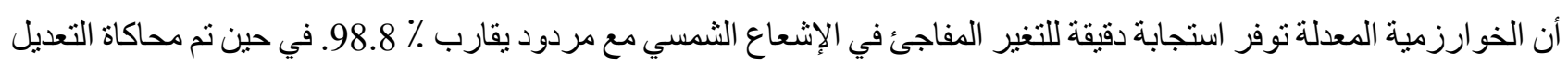


 \\ Centre d'Etudes Doctorales : Sciences et Techniques de l'Ingénieur}

الثاني باستخدام النموذج المقترح للوحة الكهروضوئية في برنامج Proteus. من أجل التحقق العملي، نم إعداد الاختبار التجريبي باستخدام لوحة أردوينو 1 (Arduino Uno) مع متحكم دقيق Atmega328 مدمج فيها. وبالتالي، تقديم نظام كهروضوئي منخفض

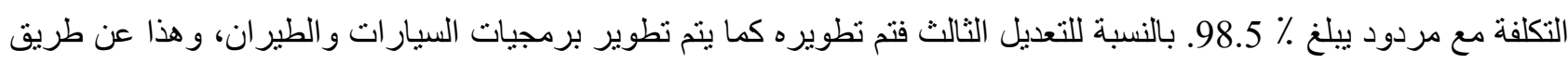
اتباع نموذج V، مما يعني أنه تم التحقق من أداء وصحة متحكمنا باستخدام الاختبار بات التالية: (Model in the Loop/Software in the Loop/Processor in the Loop) الاستطاعة العظمى في مجالات السيارات و الطيران. وتجدر الإشارة إلى أنه تم استخدام برنامج Matlab/Simulink لإجراء الاختبار ات MIL/SIL/PIL، و أيضا استخدمت لوحة STM32F4 للاختبار PIL. من ناحية أخرى، إذا كان خفض التكاليف ليس مهما أمام ضمان مستوى عال جدا من منانة وكفاءة النظام الكهروضوئي، فمن الضروري استخدام طريقة قوية وفعالة. لذلك في هذه الأطروحة، تم تصميم وتتفيذ خوارزمية متتبع نقطة الاستطاعة العظمى باستخدام مرشح كالمان (Kalman filtre)، وهي طريقة

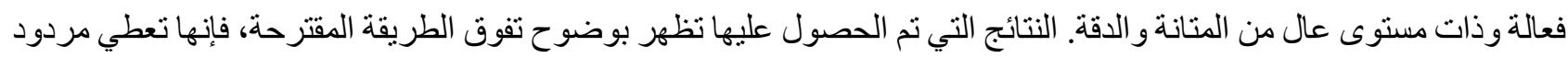
يقدر ب \% 99.38، و هذا أعلى بنسبة ٪ 3 بالمقارنة مع الطريقة زيادة الناقلية التقليدية (INC). وبتالي في هذه الأطروحة تم اقتراح

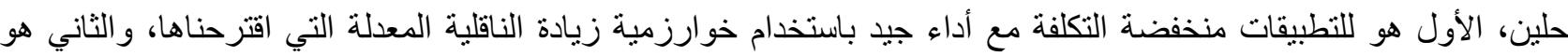
للنطبيقات الأكثر كفاءة ومنانة باستخدام مرشح كالمان.

الكلمات المفتاحية: اللوحة الكهروضوئية، برنامج Proteus، خو ارزمية زيادة الناقلية المعدلة، التغير السريع في الإشعاع الثمسي، النظام المدمج، نظام كهروضوئي منخفض التكلفة، متتبع نقطة الاسنطاعة العظمى باستخدام مرشح كالمان، نظام كهروضوئي ذو رئو

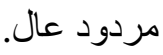

\section{RÉSUMÉ}

$\mathrm{Vu}$ la forte sensibilité des panneaux photovoltaïques (PV) aux l'irradiation solaire et à la température, leur faible rendement et leur coût élevé, il est impératif de les faire fonctionner au point de puissance maximale (MPP). Dans ce contexte, l'objectif de ce travail est de développer, améliorer et optimiser l'énergie soutirée du panneau PV en utilisant les techniques des systèmes embarqués. Il s'agit donc, dans une première étape d'étudier et de simuler le modèle du panneau PV dans le but d'avoir un modèle fiable décrivant correctement le comportement réel de ce dernier qui sera utilisé par la suite pour simuler et tester les algorithmes MPPT.

Dans cette thèse le modèle du panneau PV à une seule diode a été retenu et simulé dans deux environnements connus, Matlab/Simulink et PSIM. De plus, une procédure de simulation d'un panneau PV a été réalisée dans l'environnement Proteus. Les résultats de simulation et expérimentaux ont été confrontés. Dans une deuxième étape de ce travail des modifications à l'algorithme d'incrémentation de la conductance (INC) classique ont été apporté afin d'améliorer la 
capacité du contrôleur MPPT pendant les variations brusque de l'irradiation solaire. Trois modifications proposées et exécutées pour cet algorithme à savoir :

(1) L'ajout d'une condition permettant de détecter cette variation de l'irradiation solaire et par conséquent d'assurer un suivi MPP correct.

(2) L'élimination de tous calculs de divisions dans l'algorithme (INC) afin de simplifier sa structure et facilité son implémentation et par conséquent réduire le temps de réponse et le cout du système photovoltaïque.

(3) Adopté un pas variable pour réduire les oscillations en régime permanent et améliorer la vitesse de poursuite sous des variations soudaines d'irradiations solaires.

La première modification a été simulée avec le logiciel PSIM en utilisant le test "Software in the Loop", les résultats ont montré que l'algorithme modifié fournit une réponse précise avec un rendement de 98,8\%. La deuxième modification a été simulée à l'aide du modèle du panneau photovoltaïque élaboré sous Proteus et validée au laboratoire au moyen d'un émulateur solaire et une carte Arduino (Uno intégrant un microcontrôleur Atmega328) justifiant ainsi le faible coût du système avec une efficacité de 98,5\%. La troisième modification a été développée en guise de la manière adoptée par l'industrie automobile et aéronautique dans le but d'une éventuelle intégration dans ces domaines. Le cycle de développement en V sera donc suivi, et notre contrôleur MPPT va se soumettre aux trois tests à savoir les tests : Model In the Loop, Software In the Loop et Processor In the Loop. Ces trois tests du cycle ont été exécutés et testés avec Matlab/Simulink, et la carte STM32F4 a été utilisée pour le test PIL.

Par ailleurs, nous avons aussi envisagé d'implémenter un algorithme MPPT très puissant basé sur le filtre de Kalman dans le cas où la précision, la robustesse et l'efficacité du système priment sur son prix. Les résultats de simulation de cet algorithme montrent clairement sa supériorité par rapport aux algorithmes classiques. Le rendement obtenu avoisine 100\% $(99,38)$.

En résumé de ce travail, nous pouvons dégagés deux idées majeures : La première, pour des applications à faible coût avec des bonnes performances nous proposons l'utilisation de l'algorithme INC modifié. La seconde, pour des applications plus performantes et critiques nous proposons l'algorithme basé sur le filtre de Kalman.

Mots clés: panneau PV, Proteus, INC modifié, changement rapide de l'irradiation solaire, système embarqué, système PV à faible coût, MPPT, filtre de Kalman, système PV fiable et robuste. 


\section{TABLE OF CONTENTS}

List of figures

List of tables .

Nomenclatures 7

Greek letters. 7

Abbreviations 7

Chapter 1 : Introduction 8

1. Overview 9

2. Objective and Importance of Research........................................................................................ 12

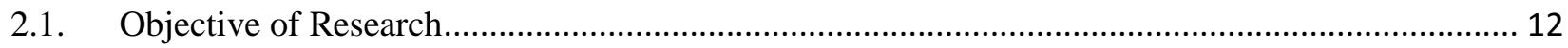

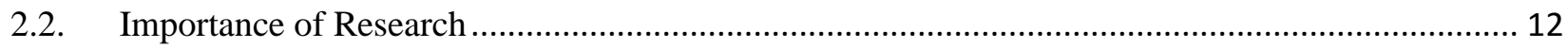

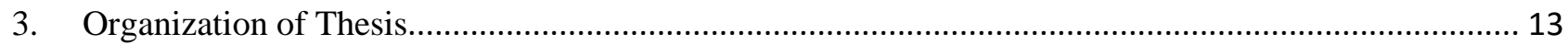

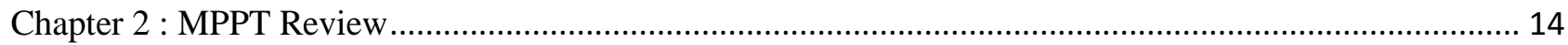

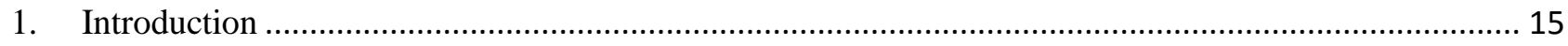

2. Description of MPPT Based PV System for DC-DC Application ……............................................. 15

2.1. Current or Voltage Based MPPT controller ........................................................................... 15

2.2. Duty Cycle Control Based MPPT System ............................................................................... 16

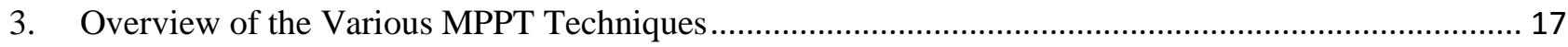

3.1. Group 1: Conventional/Popular Techniques (direct)........................................................... 17

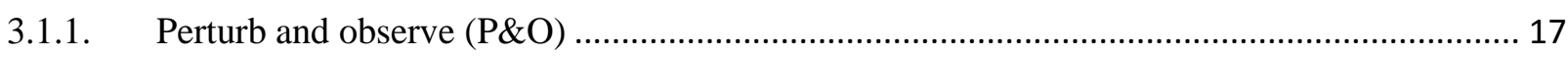

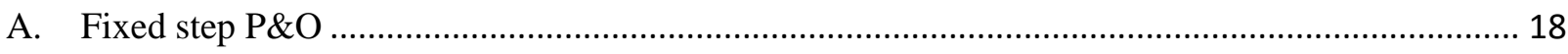

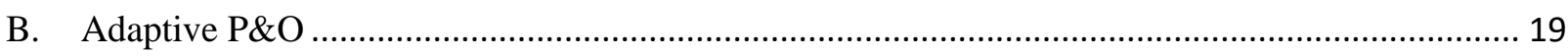

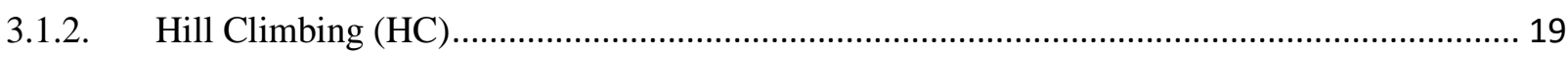

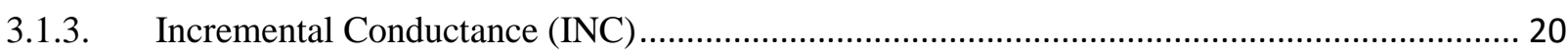

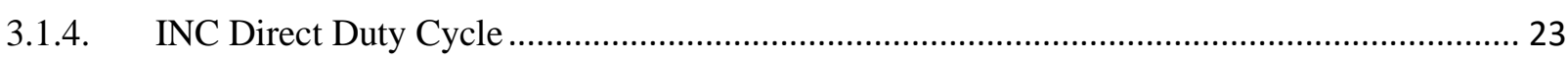

3.2. Group 2: MPPT Based on PV Panel and Power Converter Characteristics ................................. 23

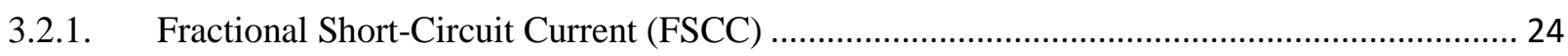

3.2.2. Fractional Open-Circuit Voltage (FOCV) ..................................................................... 25

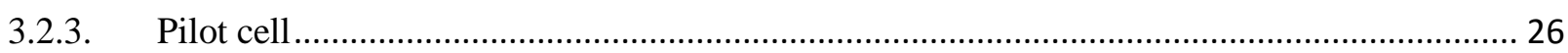

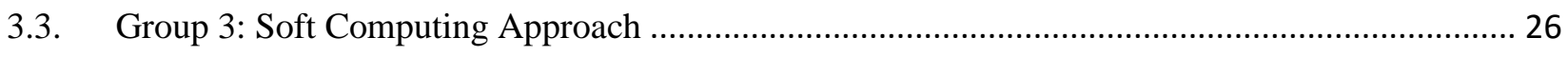

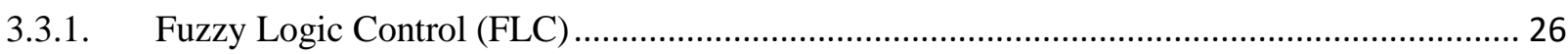

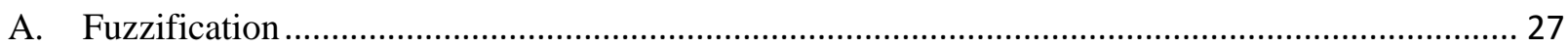

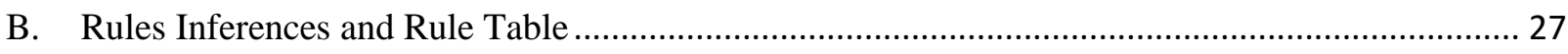

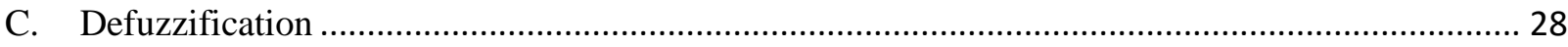

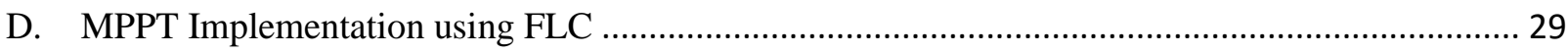

3.3.2. Artificial Neural Network (ANN) based MPPT ................................................................ 29

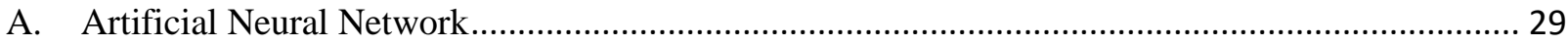




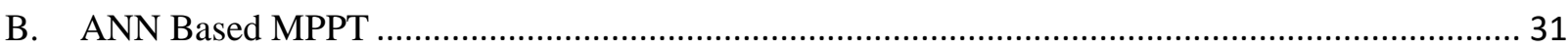

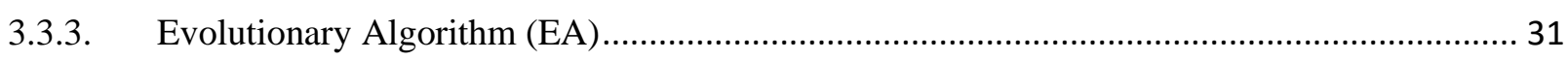

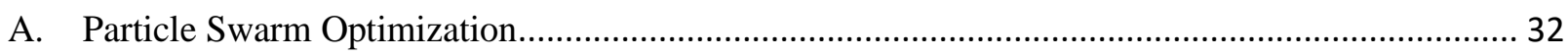

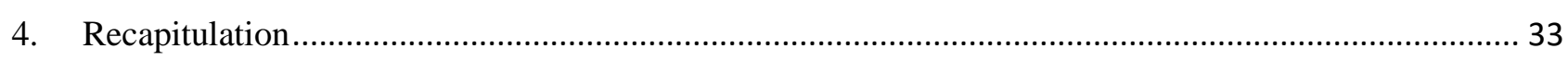

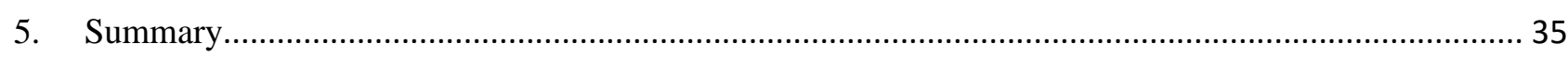

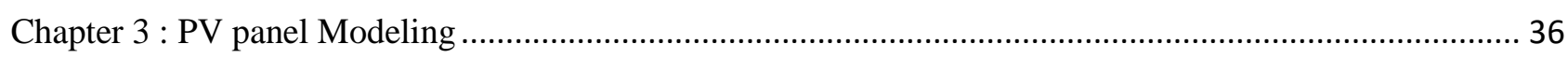

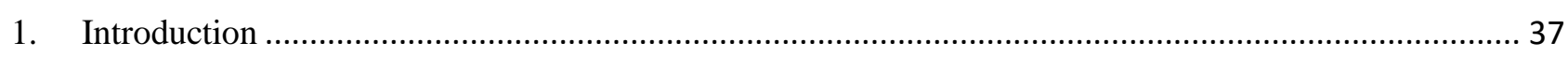

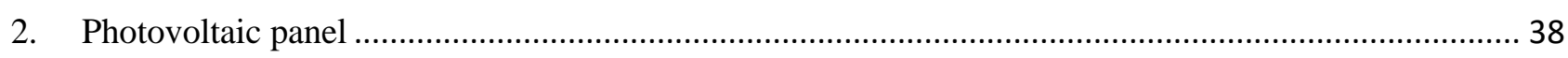

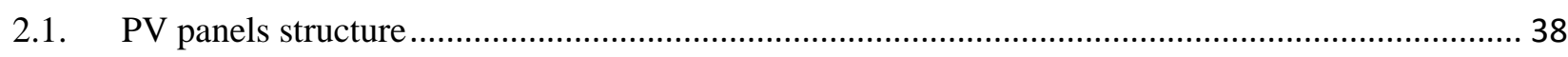

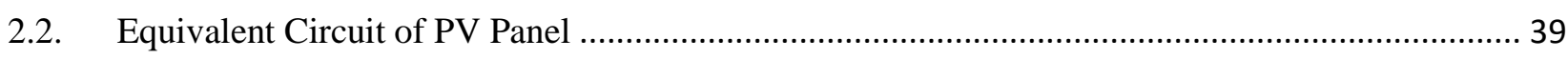

3. MATLAB/Simulink Based Modelling of Photovoltaic Panel .......................................................... 40

3.1. Extract the lacked parameters of a PV panel .......................................................................... 40

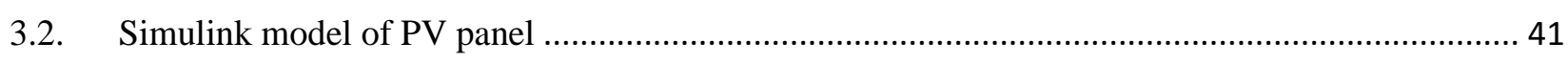

4. PSIM Based Modelling of Photovoltaic Panel ........................................................................... 42

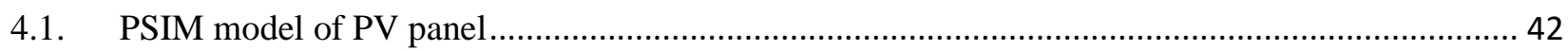

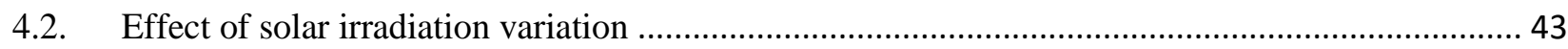

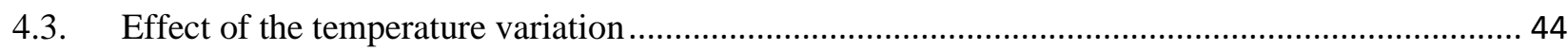

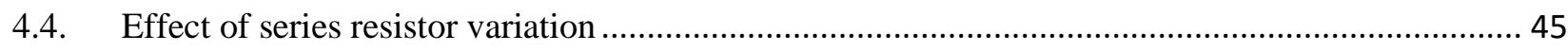

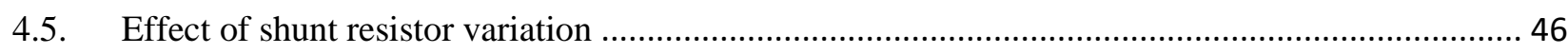

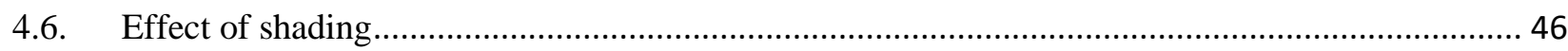

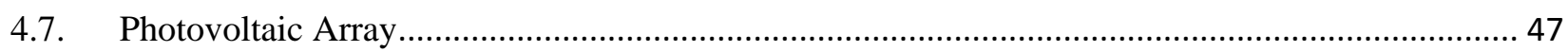

5. Proteus Based Modelling of Photovoltaic Panel ….......................................................................... 48

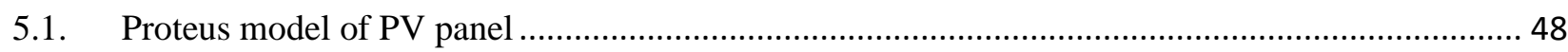

5.2. Experimental validation of the Proteus model of PV panel ...................................................... 50

6. Summary

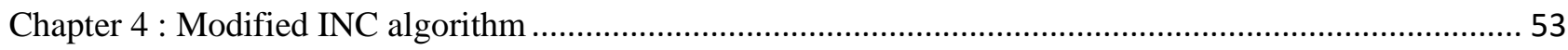

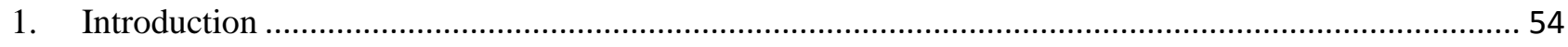

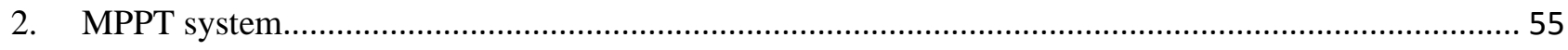

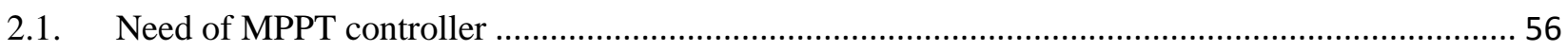

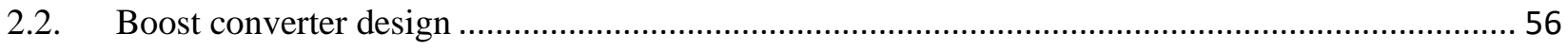

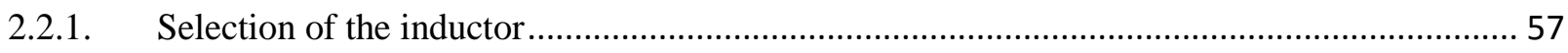

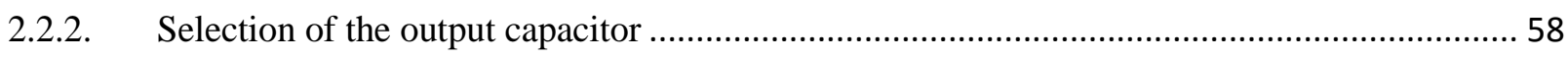

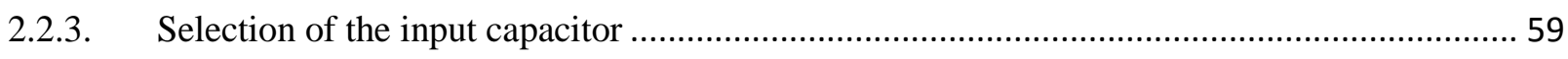

3. Modified Incremental Inductance algorithm for fast change of solar irradiance.................................. 60

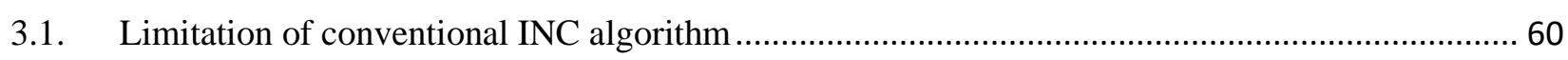

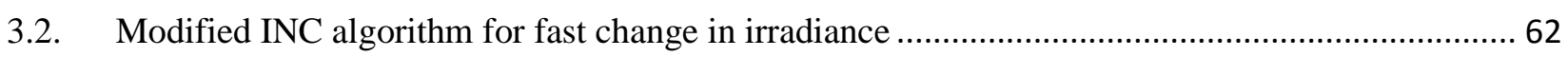

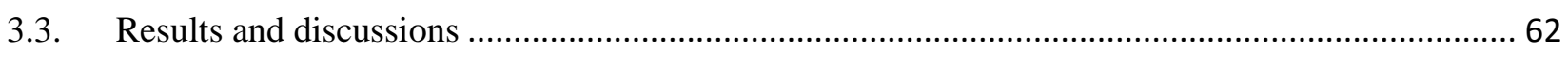


Contribution to the optimization of energy withdrawn from a PV panel using an Embedded System

3.4. Problem of MPPT algorithm under partial shading .............................................................. 64

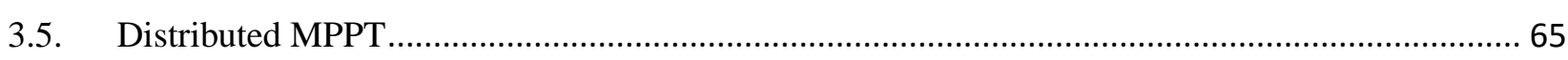

4. Low-cost Embedded system based control for PV system by using a modified division-free Incremental conductance algorithm. .67

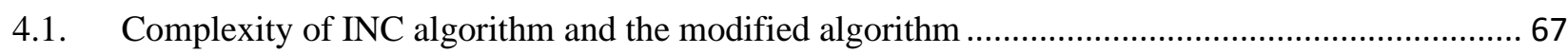

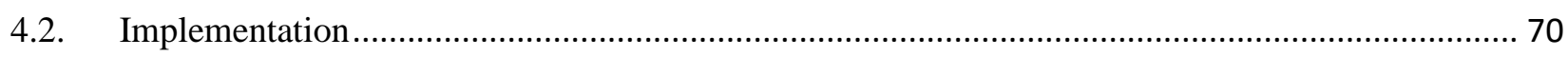

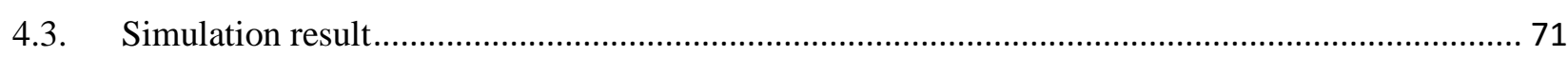

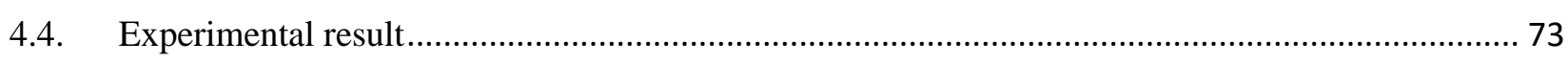

5. MIL and SIL and PIL Tests for a modified variable step size INC algorithm ................................... 76

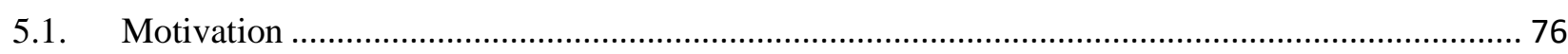

5.2. Modified variable step Incremental Conductance algorithm..................................................... 78

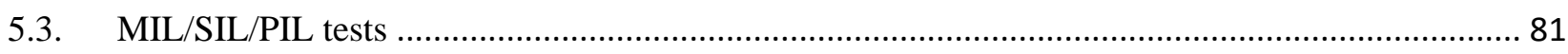

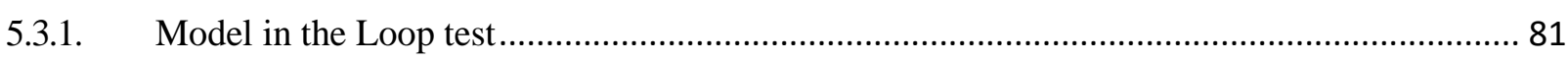

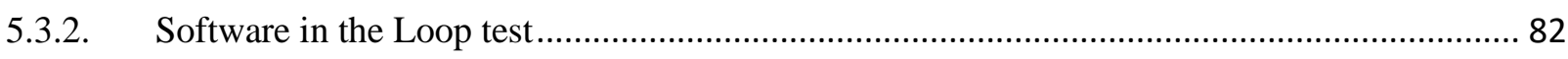

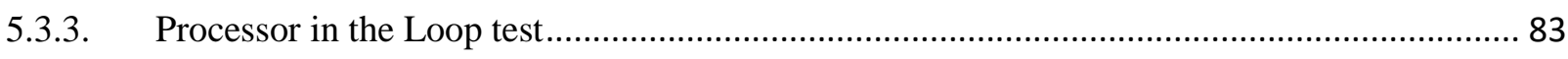

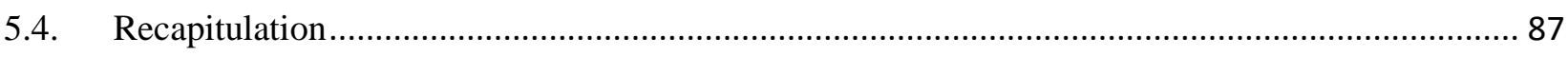

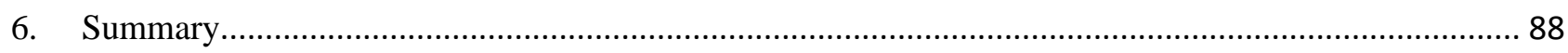

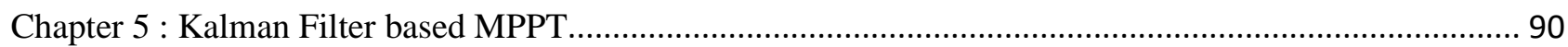

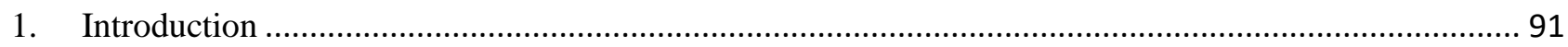

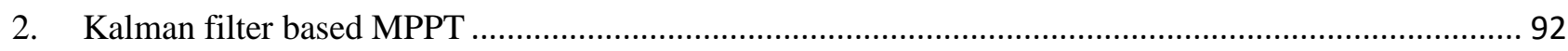

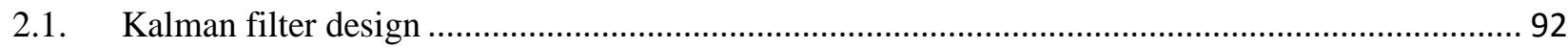

2.2. Design the MPPT algorithm using Kalman filter ..................................................................... 94

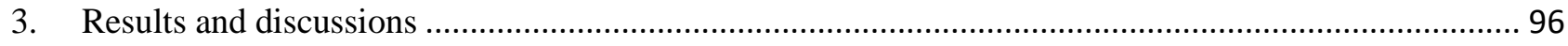

3.1. Tests under standard test conditions …………....................................................................... 96

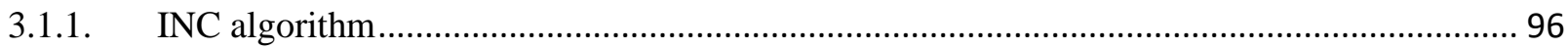

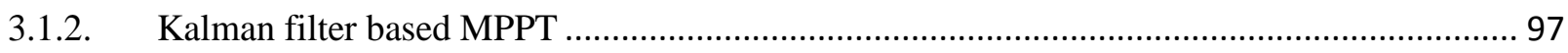

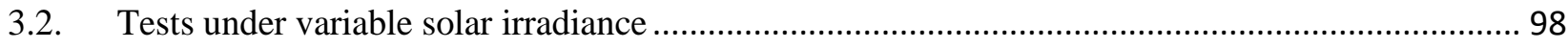

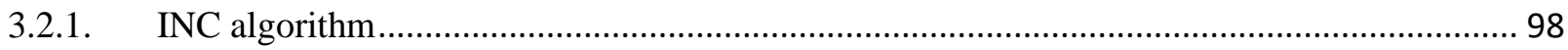

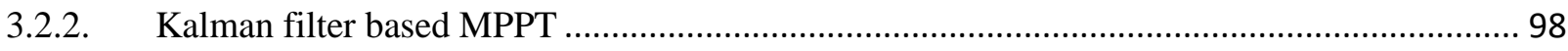

3.3. Tests under variable temperature and fixed solar irradiance $\left(500 \mathrm{~W} / \mathrm{m}^{2}\right)$.................................. 99

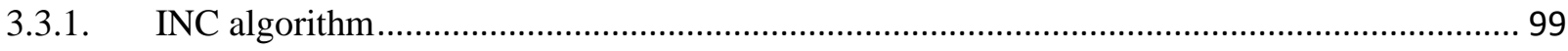

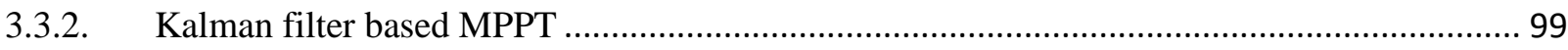

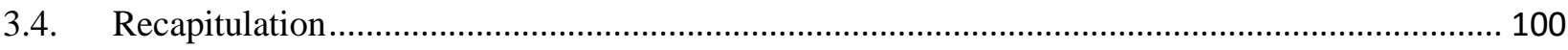

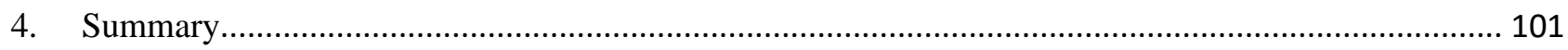

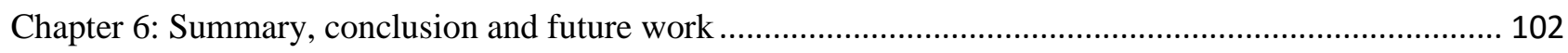

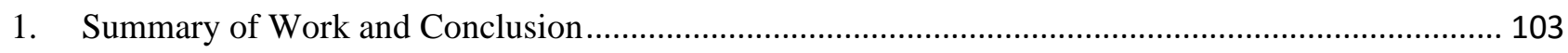

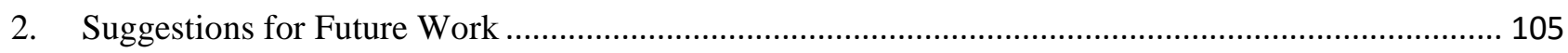


2.1. Design an improved MPPT method for tracking the MPP under partial shading condition ............. 105

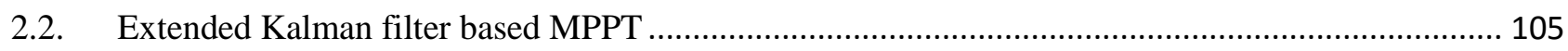

2.3. Automatic cleaning system for the PV panel, solar tracker and PV system as a connected object... 105

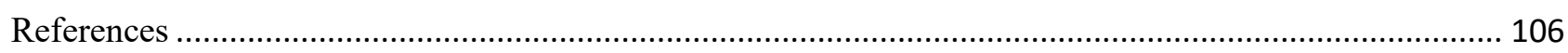

\section{LIST OF FIGURES}

Figure 2.1. Current or voltage based MPPT controller. .......................................................................... 16

Figure 2.2. A typical direct duty cycle based MPPT system.................................................................... 16

Figure 2.3. Flowchart of conventional Perturb and Observe (P\&O) method............................................. 17

Figure 2.4. The movement of operating point in MPP tracking operation. (a) For large perturbation. (b) For

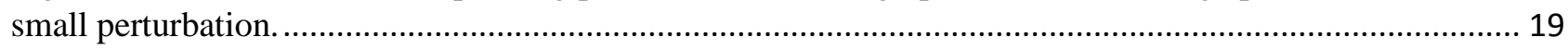

Figure 2.5. Basic Flowchart of Hill Climbing (HC) method................................................................. 20

Figure 2.6. P-V characteristics for the basis of INC method.................................................................... 21

Figure 2.7. The basic flow chart of the voltage based INC method. ........................................................ 21

Figure 2.8. The P-I characteristic for the current based INC method............................................................ 22

Figure 2.9. Basic flowchart of INC based direct duty cycle approach. ....................................................... 23

Figure 2.10. The 3-D plot of ISC and IMP for insolation and temperature variations................................ 24

Figure 2.11. 3D plot of VOC and VMP for insolation and temperature variations. ...................................... 25

Figure 2.12. Block diagram of Fuzzy logic control (FLC) ................................................................ 27

Figure 2.13. Fuzzy membership functions used in the fuzzification process.......................................... 27

Figure 2.14. A typical three layer feed-forward ANN structure ................................................................ 30

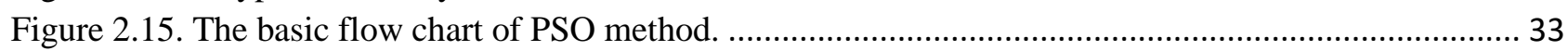

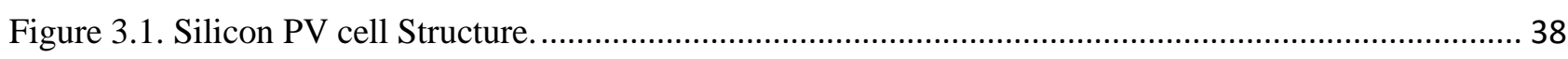

Figure 3.2. Solar Cells, Panels, and Arrays configuration types.............................................................. 39

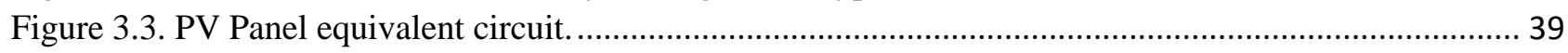

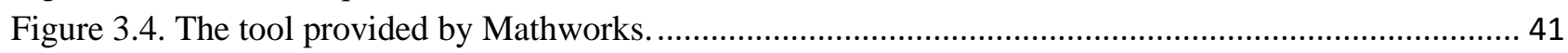

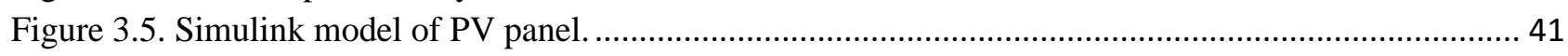

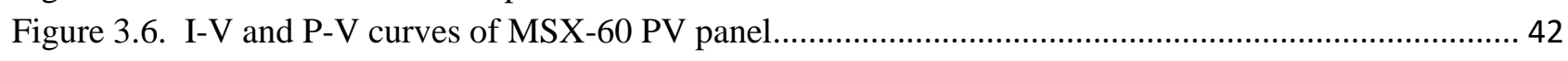

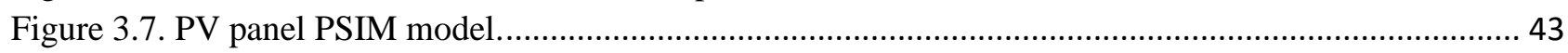

Figure 3.8. I-V and P-V characteristics of model and experimental data................................................. 43

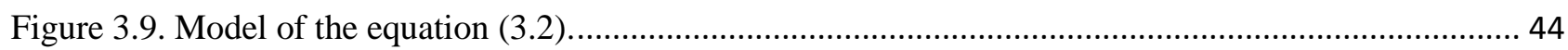

Figure 3.10. I-V and P-V characteristics for different values of irradiance. .......................................... 44

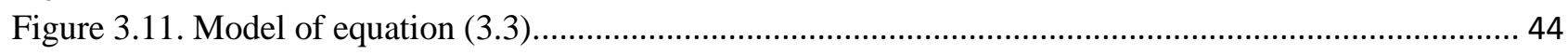

Figure 3.12. I-V and P-V curves for different values of temperature....................................................... 45

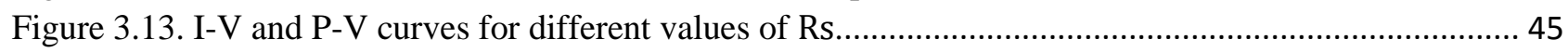

Figure 3.14. I-V and P-V curves for different values of Rsh ............................................................... 46

Figure 3.15. PV panel under non-uniform irradiation. ....................................................................... 46

Figure 3.16. I-V and P-V characteristics of the PV panel under non-uniform irradiation. .......................... 47

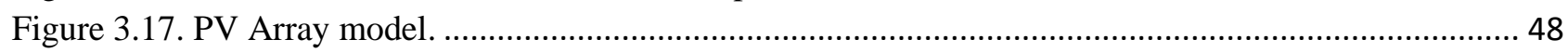

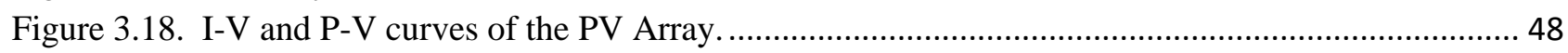

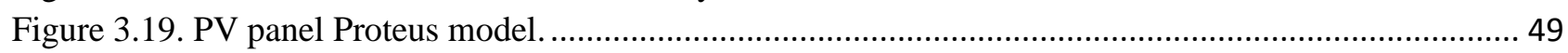

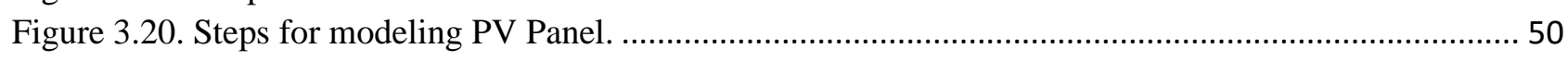

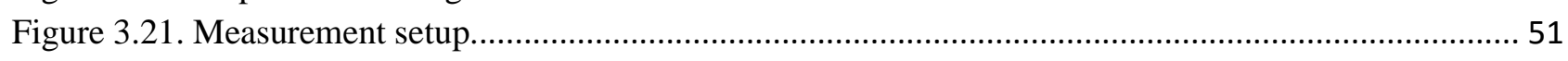

Figure 3.22. I-V and P-V model curves and experimental data. ........................................................ 51 


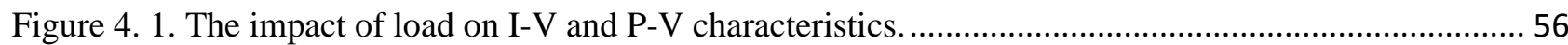

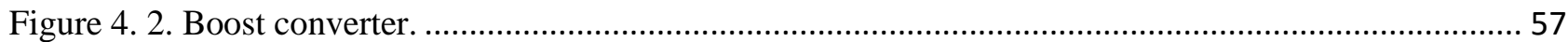

Figure 4. 3. Current waveforms of the input capacitor and inductor in CCM......................................... 58

Figure 4. 4. Current waveforms of the input capacitor in CCM.............................................................. 59

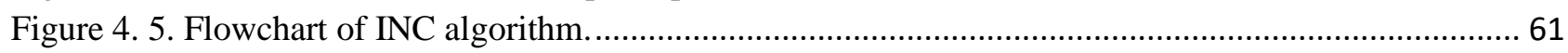

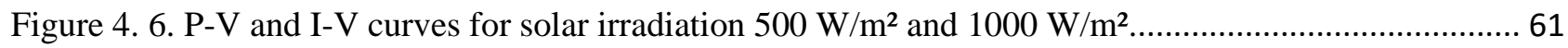

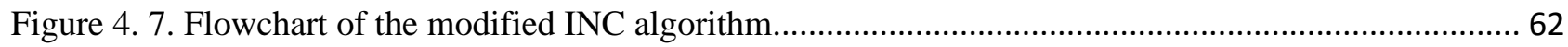

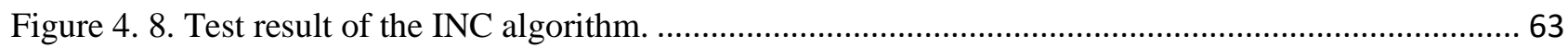

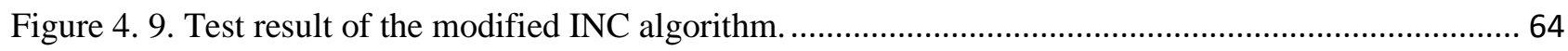

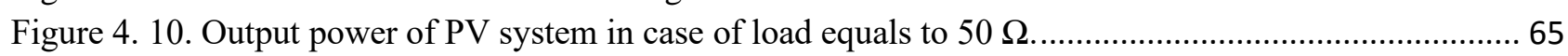

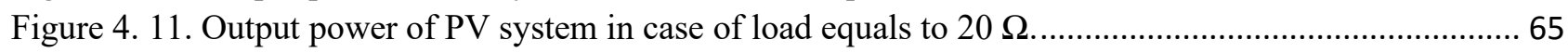

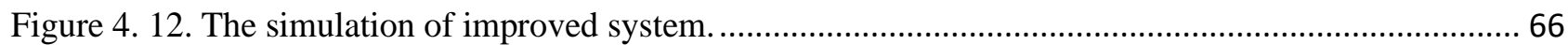

Figure 4. 13. Output power of PV system in case of load equals to $50 \Omega$ using DMPPT............................ 66

Figure 4. 14. Output power of PV system in case of load equals to $20 \Omega$ using DMPPT............................. 66

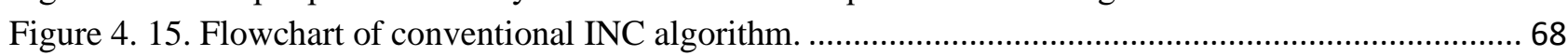

Figure 4. 16. Flowchart of the modified INC algorithm........................................................................... 70

Figure 4. 17. Low-cost embedded system based control Proteus for PV system on Proteus........................ 71 Figure 4. 18. (a): Execution time of the conventional algorithm program, (b): Execution time of the modified

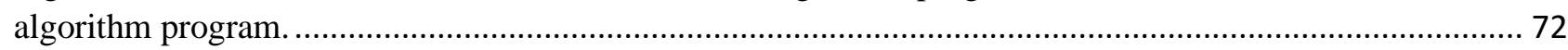
Figure 4. 19. (a): Simulation result of the conventional INC algorithm, (b): Simulation result of the modified

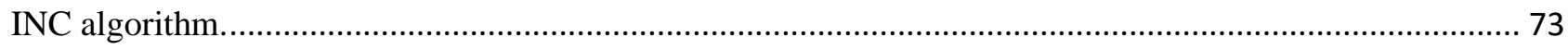

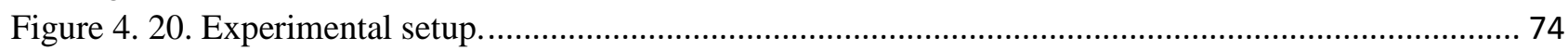

Figure 4. 21. Experimental result of the conventional INC algorithm, (b): Experimental result of the modified

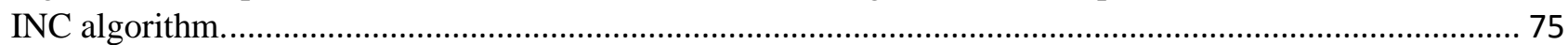

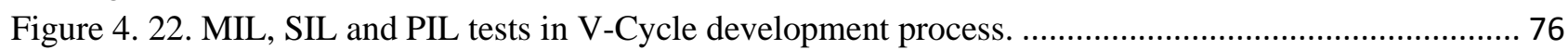

Figure 4. 23. The behavior of PV voltage under irradiance variation. .......................................................... 79

Figure 4. 24. Flow process diagram of modified INC control method for Boost........................................ 80

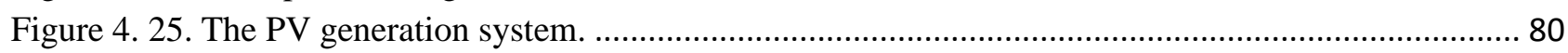

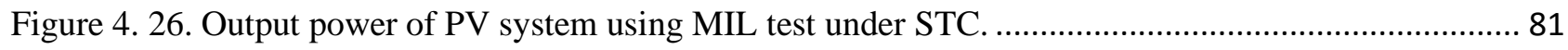

Figure 4. 27. Output power of PV system using MIL test under irradiance change. ...................................... 82

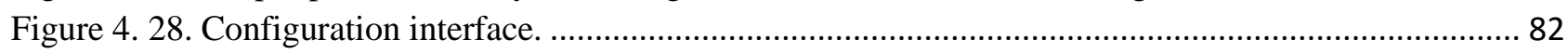

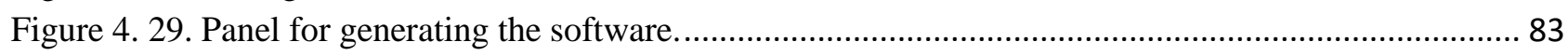

Figure 4. 30. The PV generation system using SIL block. ..................................................................... 83

Figure 4. 31. Output power of PV system using SIL test under irradiance change...................................... 83

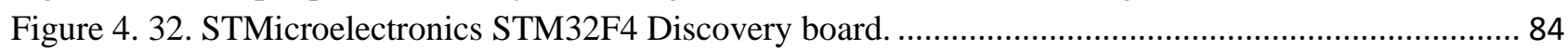

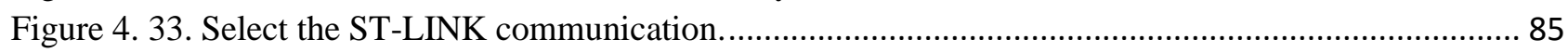

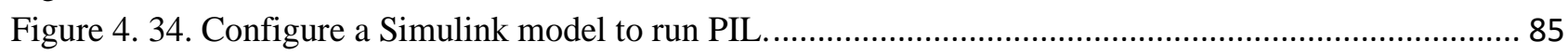

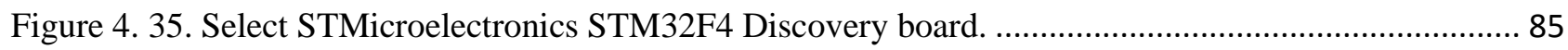

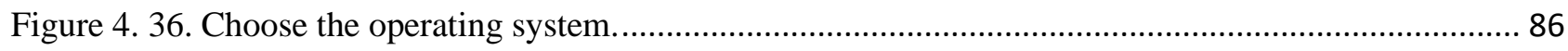

Figure 4. 37. The PV generation system using PIL block. ................................................................ 86

Figure 4. 38. Output power of PV system using PIL test under irradiance change....................................... 87

Figure 5.1. The architecture of the PV system.

Figure 5.2. Software-in-the-loop test for the Kalman filter based MPPT on PSIM....................................... 96

Figure 5.3. The output powers for INC algorithm under STC. ................................................................... 96

Figure 5.4. Zoom in the output powers for INC algorithm under STC .................................................. 97

Figure 5.5. The output powers for Kalman filter based MPPT under STC................................................ 97

Figure 5.6. Zoom in the output powers for Kalman filter based MPPT under STC...................................... 98

Figure 5.7. The output powers for INC algorithm under variable solar irradiance. ........................................ 98

Figure 5.8. The output powers for Kalman filter based MPPT under variable solar irradiance..................... 99 
Figure 5.9. The output powers for INC algorithm under variable temperature. 99

Figure 5.10. The output powers for Kalman filter based MPPT under variable temperature. 100

\section{LIST OF TABLES}

Table 2.1. Fuzzy rule table. 28

Table 2.2. Review of the most used MPPT algorithms. 34

Table 3.1. Specifications of Solarex MSX-60 PV panel at STC. 40

Table 3.2. The TDC-M20-36 panel characteristics at STC.

Table 4.1. Design of the Boost converter. 59

Table 4.2. Comparison of the proposed algorithm with other improved incremental conductance algorithms proposed in the scientific literature. 64

Table 4.3. Comparison between our proposal and some experimental works published recently. 75

Table 4.4. Parameters of the boost converter. .81

Table 4.5. Comparison between the proposed work and some existing works in the area of PV systems. ...

Table 5.1. Results comparison between the proposed method and INC algorithm at temperature $298.15 \mathrm{~K}$.

Table 5.2. Results comparison between the proposed method and INC algorithm at irradiance $500 \mathrm{~W} / \mathrm{m}^{2} .100$ 


\section{NOMENCLATURES}

- $\mathrm{a}:$ is the diode's ideality factor

- $\mathrm{F}$ : is switching frequency $[\mathrm{Hz}]$

- $\quad$ ID : is the diode current $[\mathrm{A}]$

- $\quad \mathrm{I}$ : is the panel output current $[\mathrm{A}]$

- $\mathrm{I}_{\mathrm{S}}$ : is the panel reverse saturation current $[\mathrm{A}]$

- $\mathrm{I}_{\mathrm{ph}}$ : is the panel photocurrent $[\mathrm{A}]$

- Io : is the output current of the Boost converter [A]

- $\mathrm{K}$ : is the constant of Boltzmann [J.K $\left.\mathrm{K}^{-1}\right]$

- $\mathrm{N}_{\mathrm{s}}$ : is the number of cells connected in series

- $\mathrm{q}$ : is the electron charge [C]

- $\mathrm{R}_{\mathrm{S}}$ : is the series resistance $[\Omega]$

- $\mathrm{R}_{\mathrm{sh}}$ : is the shunt resistance $[\Omega]$

- $\mathrm{R}$ : is the load $[\Omega]$

- $\mathrm{T}$ : is the junction temperature $[\mathrm{K}]$

- $\mathrm{V}_{\mathrm{D}}$ : is the diode voltage $[\mathrm{V}]$

- $\quad \mathrm{V}$ : is the panel output voltage [V]

- Vo : is the output voltage of the Boost converter [V]

- $\Delta \mathrm{V}$ : input voltage ripple of the Boost converter [V]

- $\Delta \mathrm{V}_{\mathrm{o}}$ : output voltage ripple of the Boost converter [V]

- $\Delta \mathrm{I}_{\mathrm{L}}$ : inductor current ripple $[\mathrm{A}]$

\section{GREEK LETTERS}

- $\alpha$ : is the duty cycle

\section{ABBREVIATIONS}

- CAN : Controller Area Network

- FLC: Fuzzy Logic Control

- FSCC: Fractional Short-Circuit Current

- FOCV: Fractional Open-Circuit Voltage

- INC : Incremental Conductance

- LCD: Liquid Crystal Display

- MBD : Model-Based Design

- MIL : Model In the Loop

- DMPP: distributed MPP

- DMPPT: distributed MPPT

- GMPPT: global MPPT

- MPP : Maximum Power Point

- MPPT : Maximum Power Point Tracking

- $\quad$ P \& O : Perturb and observe

- PIL : Processor In the Loop

- PV : Photovoltaic

- PWM : Pulse Width Modulation

- RE : Renewable Energy

- SIL : Software In the Loop

- STC: Standard Test Conditions

- USB : Universal Serial Bus 


\section{Chapter 1}

\section{Introduction}

- Overview

- Objective and Importance of Research

- Organization of Thesis 


\section{Overview}

With the rapid growth in population, the unabated usage of technology, frequent human movement and the ever-increasing level of lifestyle, the world energy demand have been subjected to a tremendous strain. This phenomenon has resulted in two major concerns, namely energy sustainability and environmental concerns. The latter, which manifests itself in the form of climate change, is seriously jeopardizing the earth civilization. The challenge today is to tackle the climate change and greenhouse warming by utilizing clean and affordable renewable energy (RE) sources [1].

Energy generated from renewable natural resources, such as solar, wind, rainfall, tidal, geothermal heat, etc have been applied for electric power generation. Compared to conventional fossil energy sources (coal, oil and natural gas), RE sources have the following major advantages (1) they are refilled from natural resources; therefore they are sustainable and will never run out, (2) when generating, they emit little or no carbon dioxide. It can be concluded that RE appears to be the ideal and effective solution to deal with the environmental problems.

For the past several decades, solar photovoltaic (PV) energy has emerged as one of the preferable RE sources. The sun radiates an enormous amount of energy onto the earth's surface every day, which, if properly harvested, would be more than sufficient to provide the demand of the whole world [2]. The main advantages of PV power system can be attributed to its low operational cost, almost maintenance-free and environmentally friendly. Regardless of the high cost of solar panels, PV power generation systems, in particular the grid-connected type, have been commercialized in many countries due to its potential medium and long-term economic prospects [3]. Furthermore, generous financial schemes, for example, the feed-in tariff [4] and subsidized policies [5], have been introduced by various countries, resulting in rapid growth of the industry.

However, despite these tangible benefits, the main hindrance for public acceptance of PV system is still apparent, i.e. the high capital investment. This is primarily due to the high panel price. Although the price per watt has declined rapidly over the past decade, PV power remains considerably above the cost of conventional electricity. Grid-parity, i.e. the point at which the price of PV power per unit is less than or equal to the price of the electricity provided by the power utility companies, is still a long way to go. With regards to this concern, it is imperative that whatever available energy captured by the panels to be the optimally processed. An enormous amount of work has been carried out to enhance the solar cell design and its fabrication technologies [6]-[9]. Whilst these efforts are crucial, it is equally important to continually improve the overall performance at the system level. One area of immense interest is the maximum power point tracker (MPPT). MPPT 
aims to ensure that at any environmental condition (particularly solar insolation and temperature), the maximum power is extracted from the PV panels by matching its I-V operating point with the load.

Due to the non-linear I-V characteristics of the PV source, the tracking of the maximum power point (MPP) at various environmental conditions can sometimes be a challenging task. Researchers have proposed different MPPT algorithms to maximize PV power, namely FSCC, FOCV, Fuzzy Logic, Neural Network, P\&O, and INC [10], [11]. FSCC and FOCV are the simplest MPPT algorithms, which are based on the linearity of short-circuit current or open-circuit voltage to the maximum power point current or voltage respectively. However, these methods isolate the PV panel to measure shortcircuit current or open-circuit voltage. Therefore, the loss of energy is increased due to the periodic isolation of the panel [12]. On the other side, Fuzzy Logic and Artificial Neural Network are knowledge-based controllers where they require detailed knowledge while implementing them. Fuzzy Logic and ANN are effective in tracking MPP and they obtain a consistent MPPT algorithm due to their ability to treat the nonlinearity of the PV Panel. But they require large memory for rules implementation (FLC) or training (ANN). In particular, the fuzzy logic method requires the designer to have some prior knowledge of how the output responds qualitatively to the inputs, and it suffers from a severe drawback that the rules cannot be changed, once it is defined. ANN presents many disadvantages like the fact that the data needed for the training process has to be specifically acquired for every PV panel and location, also the PV characteristics change with time, so the neural network has to be periodically trained. Hence, since the amount of training involved is quite high for this algorithm, it makes its implementation even more complex [13]. On the other side, P\&O and INC are mostly used. These methods are based on the (P-V) curve of the PV panel. For P\&O, steady-state oscillations occur after the MPP is found due to the perturbation made by this algorithm to maintain the MPP, which in turn increases the loss of power [14]. For INC, it is founded in the fact that slope of $\mathrm{P}-\mathrm{V}$ characteristic is zero at the maximum power, and theoretically, there is no perturbation after the MPP is found. Therefore, oscillations are minimized. However, the INC algorithm can make an inaccurate response when the irradiation is suddenly increased [15]. Therefore in this thesis, we will present and implement a modified INC algorithm that can overcome the wrong response made by the conventional INC algorithm when the irradiance is suddenly increased. Nevertheless, INC is more complicated in structure compared to $\mathrm{P} \& \mathrm{O}$ since it contains several mathematical divisions that complicate the calculation process and require a stronger microcontroller which reduces the opportunity to use a low-cost embedded board [16]. Therefore, P\&O algorithm is extensively employed in PV autonomous systems for its simplicity [17]-[19] because in this kind of PV systems, it is preferred to implement MPPT algorithms by using a low-cost microcontroller in order to reduce the system cost. Thus, the P\&O algorithm, being an algorithm with no arithmetic-division [20]-[24], 
is a suitable choice to be implemented by a low-cost microcontroller. However, based on the abovementioned analysis, INC is capable of tracking the MPP correctly with less steady-state oscillations and faster response when compared to P\&O algorithm [25]-[28]. Therefore in this thesis, the INC algorithm is improved by eliminating the all-division computations and make the algorithm structure simpler. This decreases the real-time processing which in turn enables the algorithm to be easily implemented by a low-cost embedded board. Hence, the modified algorithm is implemented by using Arduino Uno board in which the low-cost Atmega328 microcontroller is integrated; as a result, reduce the system cost.

On the other hand, to improve the efficiency of MPPT algorithm, a variable step-size (VSS) is proposed [14]. However, this variable step can show poor performance in case of sudden irradiance variation. In addition, it can increase steady-state power oscillations [29]. Therefore, an improved variable step-size is presented in this thesis. Then we offer a guidelines to develop this VSS INC controller as automotive and aeronautical embedded systems are developed, this by following the Vcycle development process, which means that our controller will be validated by using "Model In the Loop (MIL)/ Software In the Loop (SIL)/ Processor In the Loop (PIL)” tests. In this sense, integrating the MPPT embedded system in the automotive or aeronautical area will be possible. On the other hand PIL test can be used as a low-cost option to test the hardware implementation of the MPPT algorithm. It should be mentioned that Matlab/Simulink is used for MIL/SIL/PIL tests, thus STM32F4 board is used for PIL test.

On the other side, if minimizing the cost is not important than guarantying a very high level of robustness and efficiency of our PV system, it is required to use a powerful method. Therefore in this thesis, Kalman filter based MPPT algorithm is proposed since it can provide an efficient computational (recursive) solution of the least-squares method. The filter is very powerful in several aspects: it supports estimations of past, present, and even future states, and it can do so even when the precise nature of the modeled system is unknown [30]. Hence, this filter can be used to respond accurately to rapid environmental changes.

In order to simulate the performance of such MPPT algorithm, several researchers have modeled the PV panel either in Matlab/Simulink or PSIM tools [52], [62], [64]; however, these tools don't provide a microcontroller or an electronic board in which our algorithm can be implemented and tested as made during the hardware implementation. Consequently, we can't rely on these tools to validate and guarantee the excellent performance of such MPPT algorithm. On the other hand, Proteus is the best simulation software for various designs with electronics and microcontrollers. It is mainly popular because of availability of almost all microcontrollers in it. However, it does not contain a PV panel model. Hence in this thesis, a PV panel is modeled in Proteus and this model is 
validated by using a laboratory test bench. Therefore, by using Proteus, MPPT algorithm can be implemented on the electronic boards and consequently, this solution can be used as a low-cost PV simulator.

\section{Objective and Importance of Research}

\subsection{Objective of Research}

The objectives of this research are:

(i) Propose a new Proteus model of PV panel.

(ii) Propose, design and implement an improved INC algorithm that can make an accurate response when the irradiation is suddenly modified. Also, eliminate the all-division computations in INC algorithm and make the algorithm structure simpler, allowing the algorithm to be easily implemented by a low-cost embedded system; as a result, propose a low-cost PV system.

(iii) Develop the MPPT controller as the automotive and aeronautical embedded systems are developed. In this sense, take advantage of safety level integrated into these areas, and integrating the MPPT embedded system in the automotive or the aeronautical area will be possible.

(iv) Propose, design and implement MPPT based on Kalman Filter through "Software In the Loop" test. The expected outcome of this proposal is an efficient MPPT method which presents a very high level of robustness, reliability and accuracy.

\subsection{Importance of Research}

Due to the non-linear characteristics I-V of the PV panel, the tracking of the maximum power point (MPP) at various environmental conditions can sometimes be a challenging task. The issue becomes more complicated when the irradiance is suddenly increased. The drawback of the conventional MPPT is that for the majority of the cases, the algorithm is likely to make an inaccurate response. Consequently, this slows the tracking speed and leads to high oscillation level. This problem can be overcome by employing the proposed INC algorithm. Also, some modifications are involved in the INC algorithm structure seeking to avoid the mathematical division calculations, allowing the algorithm to be easily implemented by a low-cost embedded system and as a result, reduce the system cost.

On the other side, if it is required to guarantee a very high level of robustness, reliability and efficiency of our PV system, the proposed Kalman filter based MPPT algorithm is a suitable choice. 


\section{Organization of Thesis}

This thesis is organized into six chapters. Their contents are outlined as follows:

(i) Chapter 2 provides an extensive review of the most used MPPT algorithms. They are categorized into various groups, namely direct, indirect and soft computing methods. The merits and drawbacks of each method are highlighted.

(ii) Chapter 3 introduces the modeling strategy for PV panel in considerable detail. The modeling approach is very simple, fast and accurate. The model is done in Matlab and PSIM. Furthermore, a PV panel model is proposed in Proteus.

(iii) Chapter 4 describes the proposed INC algorithm for tracking the MPP of PV system. System simulation, hardware implementation and performance evaluation under fast change of irradiance are elaborated. This is performed in comparison to conventional INC algorithm. Comparison between our proposal and some experimental works published recently is also presented.

(iv) Chapter 5 describes the design and implementation of Kalman filter based MPPT algorithm. System simulation and performance evaluation under fast change of irradiance and temperature are elaborated. This is performed in comparison to conventional INC algorithm.

(v) Chapter 6 concludes the works undertaken and highlights the contributions of this research. Several suggestions are given for possible directions for future works. 


\section{Chapter 2}

\section{MPPT Review}

- Introduction

- Description of MPPT Based PV System for DC-DC Application

- Overview of the Various MPPT Techniques

- Recapitulation

- Summary 


\section{Introduction}

Maximum power point tracking (MPPT) is a power conversion system with an appropriate control algorithm to extract the maximum power from the PV source irrespective of the changes in the operating conditions. The maximization of the delivered power can be achieved by regulating the voltage or current of $\mathrm{PV}$ panel to ensure the converter operates at (or near) the maximum power point (MPP) on the P-V curve [31].

Over the years, numerous MPPT algorithms have been proposed to track the maximum power of PV system. Even if these algorithms are designed for the same aim, they differ markedly in terms of efficiency, tracking speed, steady-state oscillations, complexity, cost and range of effectiveness. Moreover, each method may work best in certain conditions while not in others. For instance, some MPPT methods yield better performance under stable irradiance but under fast change of irradiance, the results are found to be unsatisfactory [12].

This chapter presents a strategic review of MPPT techniques that have been prominently used in PV systems. The objective of the review is to provide an overview of various MPPT methods: describing their principles of operations and highlighting their advantages and limitations. This would be useful for the reader who requires a comprehensive background of MPPT methods, as well as keeping abreast with the latest development in this area. From here, the ultimate goal of this literature review is to search for the gap in the existing methods. This gap shall be the basis for the research that shall be carried out in this thesis.

\section{Description of MPPT Based PV System for DC-DC Application}

\subsection{Current or Voltage Based MPPT controller}

Figure 2.1 presents the MPPT controller in conjunction with the DC/DC converter. It can be seen that only DC system is presented here. However, it can be extended to a grid-connected PV system with the addition of more power electronic devices such as inverter and grid components [32].

Typically, voltage or current based MPPT method operates by measuring the voltage and current information of PV panel, as shown in Figure 2.1. Using this information, the duty cycle is computed through the PI or hysteresis controller and consequently DC/DC converter is forced to extract the MPP from the PV panel. 


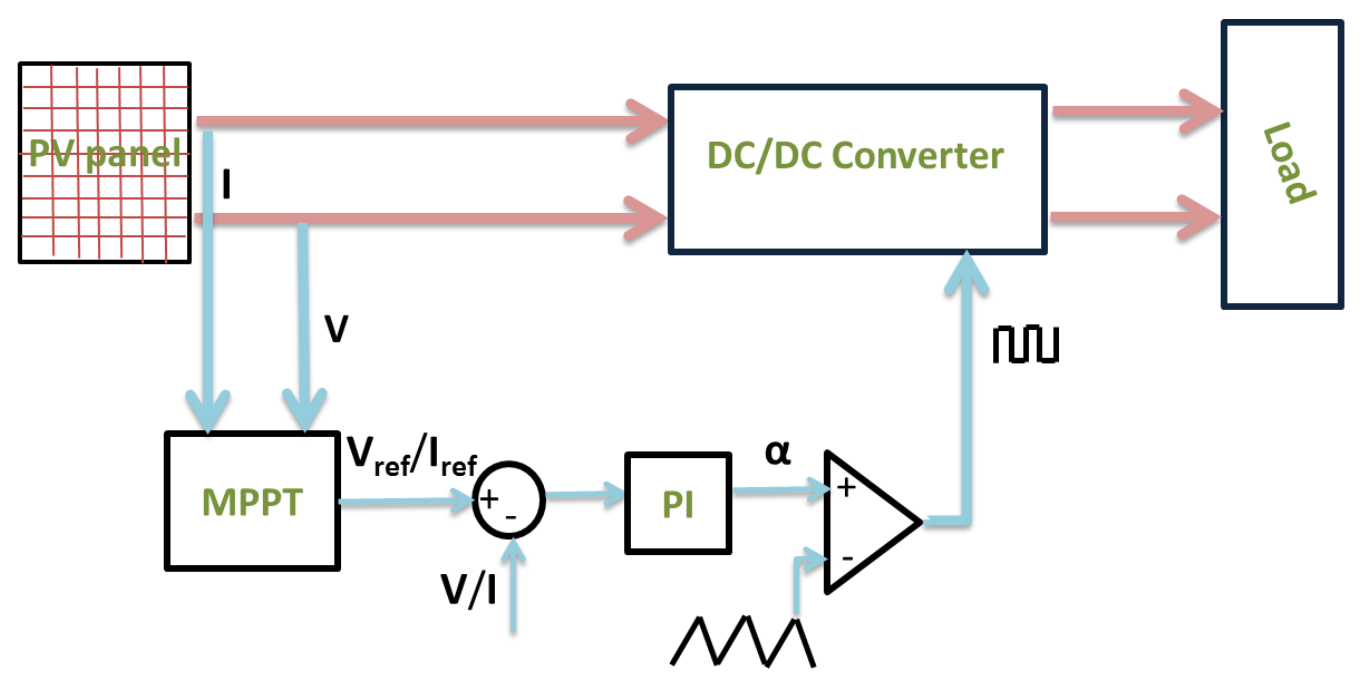

Figure 2.1. Current or voltage based MPPT controller.

\subsection{Duty Cycle Control Based MPPT System}

In contrast to Figure 2.1, another popular category of MPPT method is based on duty cycle control of DC/DC converter. This type is defined as the direct MPPT control system; the controller is shown in Figure 2.2. The PI block (Figure 2.1) is not used and duty cycle is computed directly by the controller. The advantages of this solution are: (1) the MPPT design becomes simple, (2) the computation time is decreased and (3) no tuning effort is necessary for the PI gains. Hence, it offers MPPT system with a simplified control while maintaining the optimal results [32]. Therefore, this method is used in our research.

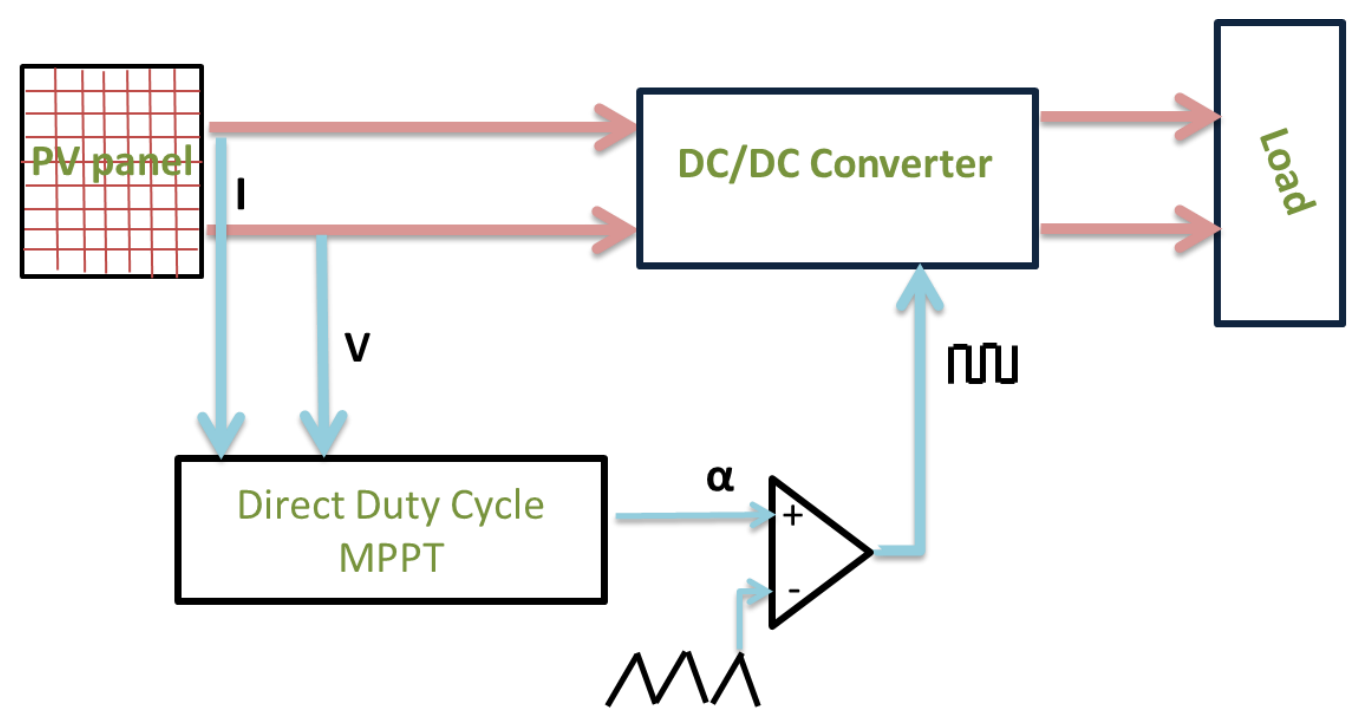

Figure 2.2. A typical direct duty cycle based MPPT system. 


\section{Overview of the Various MPPT Techniques}

For a better understanding of the various approaches used for MPPT, the various techniques are categorized into three groups. The first group, which comprises the most popular methods; they are based on specific observations by applying a control signal to the power converter. This is also known as the conventional MPPTs and direct control techniques, which include the Perturb and Observe (P\&O), the Hill Climbing (HC), and Incremental Conductance (INC) methods. The second group is categorized by MPPT that exploits the characteristics of PV panel, this is also known as the indirect control techniques. The last group involves more recent techniques, which are based on soft computing approaches. This includes the Fuzzy Logic Controller (FLC), Artificial Neural Network (ANN) and Particle Swarm Optimization (PSO) which is one of the Evolutionary Algorithms (EA) [12].

\subsection{Group 1: Conventional/Popular Techniques (direct)}

\subsubsection{Perturb and observe (P\&O)}

Due to the simplicity of the algorithm, Perturb \& Observe $(\mathrm{P} \& \mathrm{O})$ is the most widely used MPPT method. The working principle of $\mathrm{P} \& \mathrm{O}$ is presented by the flowchart in Figure 2.3. As the name suggests, it works by introducing a perturbation (offset) in the operating voltage or current of PV panel and accordingly the change in operating power is observed using the samples of voltage $(\mathrm{V}(\mathrm{k}))$ and current $(\mathrm{I}(\mathrm{k}))$.

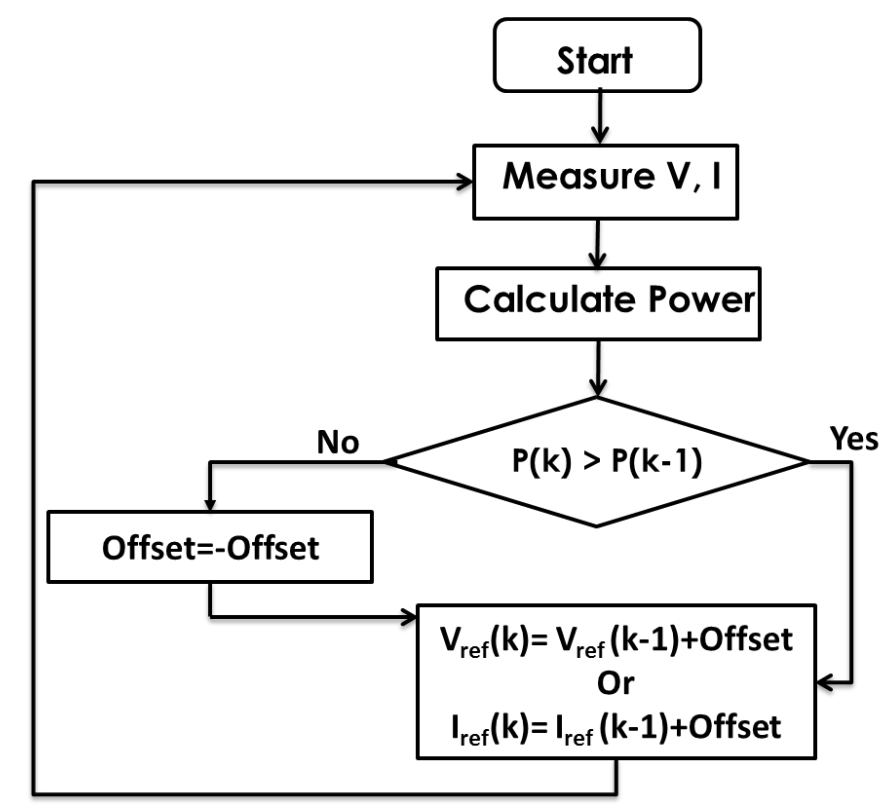

Figure 2.3. Flowchart of conventional Perturb and Observe (P\&O) method.

The increment in operating power means that the system is getting closer to the MPP. Therefore, in the next sampling cycle, the direction (slope) of perturbation is maintained and the 
reference voltage/current is further increased by an amount of 'offset'. Conversely, when the power decreases, the reference value is reduced by changing the sign of the slope.

The amount of perturbation value 'offset' depends upon the nature of algorithm: it can be constant or varying. About this fact, two further groups of $\mathrm{P} \& \mathrm{O}$ method are reported in the literature, namely fixed-step $\mathrm{P} \& \mathrm{O}$ and adaptive step $\mathrm{P} \& \mathrm{O}$ methods. These are discussed in the following sections.

\section{A. Fixed step P\&O}

In this method, fixed step size is employed to generate a reference signal for the PI control loop, as shown in Figure 2.1. The perturb signal is either the reference PV voltage or current. Figure 2.4 (a) shows the movement of operating power in the MPPT process. Starting from the point A, the operating power is gradually increasing with a fixed value of 'offset'. Once the operating point reaches point $\mathrm{D}$, the $\mathrm{P} \& \mathrm{O}$ observes the decrease in panel power. Consequently, the slope of the 'offset' is changed and reference voltage is made to increase from point $\mathrm{D}$ to $\mathrm{C}$ to cater for the loss in panel power. However, due to the same direction of 'offset', the reference voltage is further increased until a decrease in power is detected at point B. Once again, the reference value will be altered based on 'offset'. Hence, due to the nature of $\mathrm{P} \& \mathrm{O}$ as described in preceding lines, the operating power will continuously oscillate between D to B. The perturbation step 'offset' is selected according to the system designer usually by hit and trial approach. Therefore, the solution provided by this method is system dependent, hence not generic. It can also be observed in Figure 2.4 (a), the oscillation at the MPP region as shown by dotted circle is totally dependent on the value of step size. In the case of large perturbation step (Figure 2.4 (a)), faster tracking results in significant oscillations at the steady-state (from point D to B). On the other hand, a smaller value of 'offset', the steady-state oscillations are reduced as shown by dotted circle in Figure 2.4 (b) but tracking is significantly slower compared to Figure 2.4 (a). Therefore, $\mathrm{P} \& \mathrm{O}$ method with fixed perturbation suffers an inherent tracking -oscillations trade-off problem. 


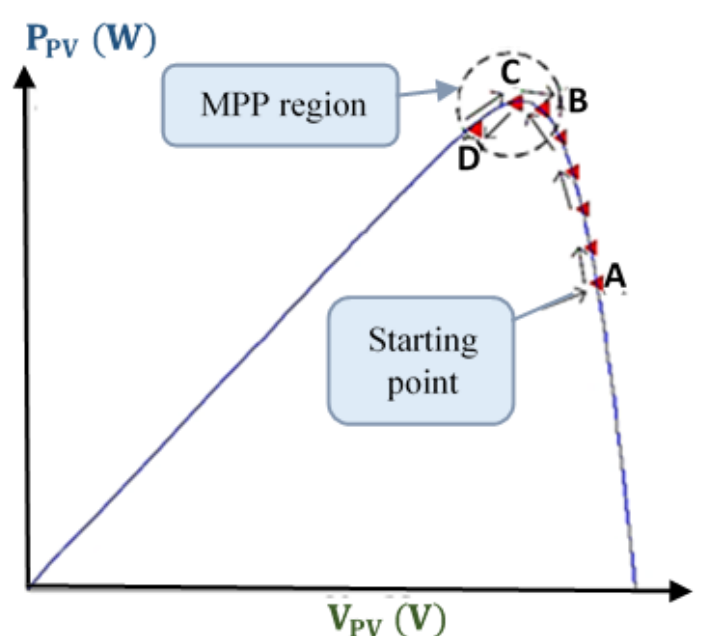

(a)

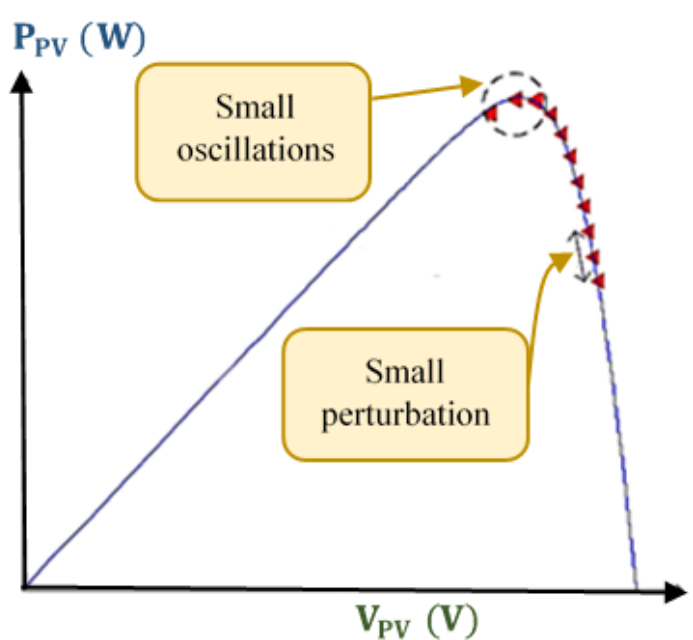

(b)

Figure 2.4. The movement of operating point in MPP tracking operation. (a) For large perturbation. (b) For small perturbation.

\section{B. Adaptive P\&O}

In the fixed step $\mathrm{P} \& \mathrm{O}$ algorithm, the amount of perturbation size is designed according to the accuracy at steady-state and the response time of the MPPT. Thus, the trade-off between the response time and steady-state accuracy has to be addressed by the corresponding design. To solve this dilemma, a variable $\mathrm{P} \& \mathrm{O}$ method is usually employed [33].

In this method, the perturbation step is adjusted usually by using the derivative of power to voltage $(\mathrm{dP} / \mathrm{dV})$ or current $(\mathrm{dP} / \mathrm{dI})$ of a PV panel. This approach is fully adaptive as it works based on the P-V or P-I characteristics, which always results in $\mathrm{dP} / \mathrm{dV}$ or $\mathrm{dP} / \mathrm{dI}$ factor near to zero at MPP. Therefore, step size can be made relatively small as $\mathrm{dP} / \mathrm{dV}$ approaches to zero and the panel operates in the vicinity of MPP. Thus, the adaptive P\&O has an excellent tracking speed as well as accuracy at steady state [33].

\subsubsection{Hill Climbing (HC)}

The $\mathrm{HC}$ method is presented in Figure 2.5. Its working principle is like $\mathrm{P} \& \mathrm{O}$, but the operating point of the PV panel is updated by perturbing the duty cycle, instead of perturbing the voltage or current [33].

The HC method periodically updates the duty cycle $\alpha(\mathrm{k})$ by a fixed perturbation (offset) with the direction of increasing power. The perturbation direction is reversed when the change of power is negative; that means that the tracking is not moving towards the MPP [33].

Since it works based on the perturbation mechanism; this method can be based on a fixed or adaptive step. 


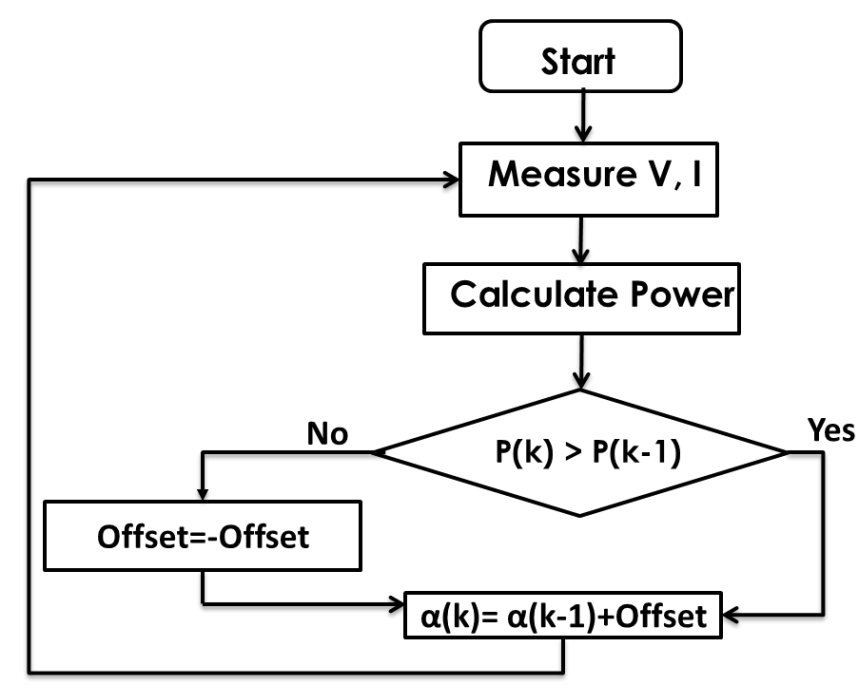

Figure 2.5. Basic Flowchart of Hill Climbing (HC) method.

\subsubsection{Incremental Conductance (INC)}

The P\&O method has two major shortcomings [34]. (1) Due to a fixed amount of perturbation at the steady-state, a small power variation around the MPP is always there which contributes to some power losses. (2) Under rapid fluctuations of environment, the operating point is most likely to diverge from the true MPP. The Incremental Conductance (INC) method was proposed in [34] to circumvent the above drawbacks.

The INC is based on the fact that at MPP, the derivative of $(\mathrm{dP} / \mathrm{dV})$ is zero. Mathematically, it can be written as:

$$
\frac{d P}{d V}=\frac{d(I V)}{d V}=V \frac{d I}{d V}+I=0
$$

Equation (2.1) can be written in the following form:

$$
-\frac{I}{V}=\frac{d I}{d V} \cong \frac{\Delta I}{\Delta V}
$$

where $\Delta \mathrm{V}$ and $\Delta \mathrm{I}$ are the increments of $\mathrm{PV}$ voltage and current, respectively. The working principle of INC can thus be derived from the P-V curve, as shown in Figure 2.6 and can be written as:

$$
\begin{aligned}
& \frac{d I}{d V}=-\frac{I}{V} \text { at MPP } \\
& \frac{d I}{d V}>-\frac{I}{V} \text { left to MPP } \\
& \frac{d I}{d V}<-\frac{I}{V} \text { right to MPP }
\end{aligned}
$$




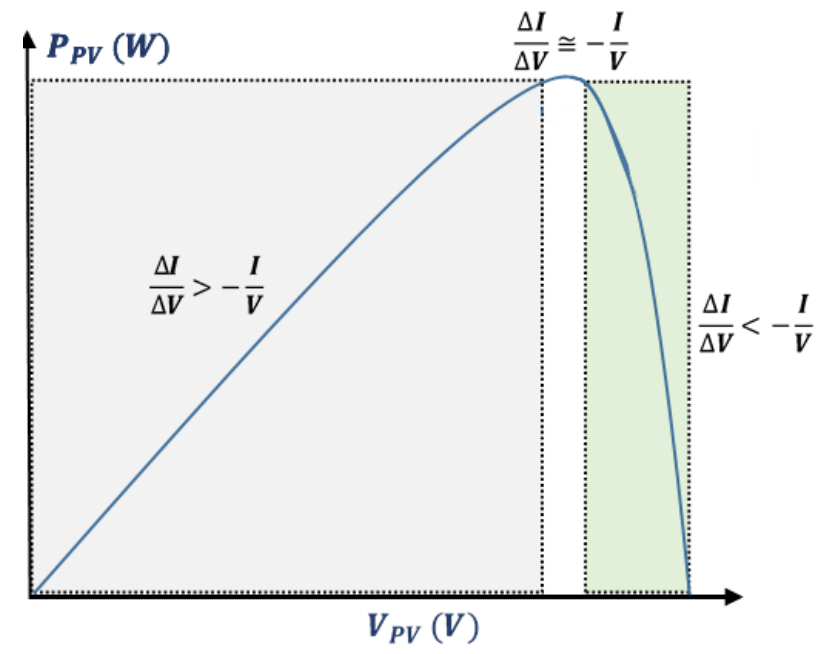

Figure 2.6. P-V characteristics for the basis of INC method.

Hence, the basic idea of INC method is incrementally comparing the ratio of derivative of conductance with the instantaneous conductance [34]. Using the rules as stated in equations (2.3)(2.5), the basic flow chart of INC method is depicted in Figure 2.7.

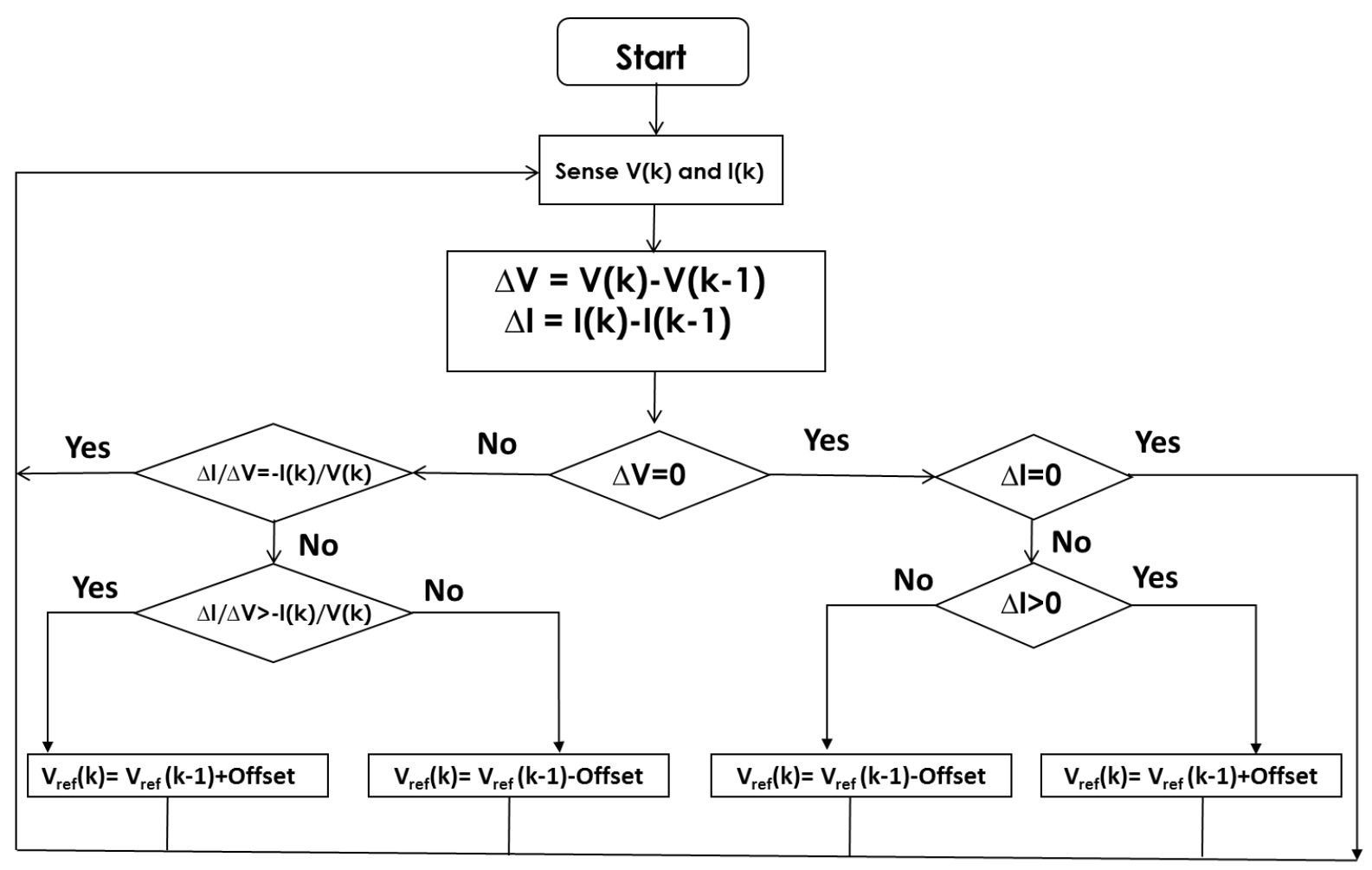

Figure 2.7. The basic flow chart of the voltage based INC method. 
It can be noticed in Figure 2.7 that the reference signal is based on voltage. Since the rules in equations (2.3)-(2.5) are derived using P-V curve, the current cannot be used as a final output of the INC method. To use INC method with respect to current P-I characteristics curve can be used, as shown in Figure 2.8.

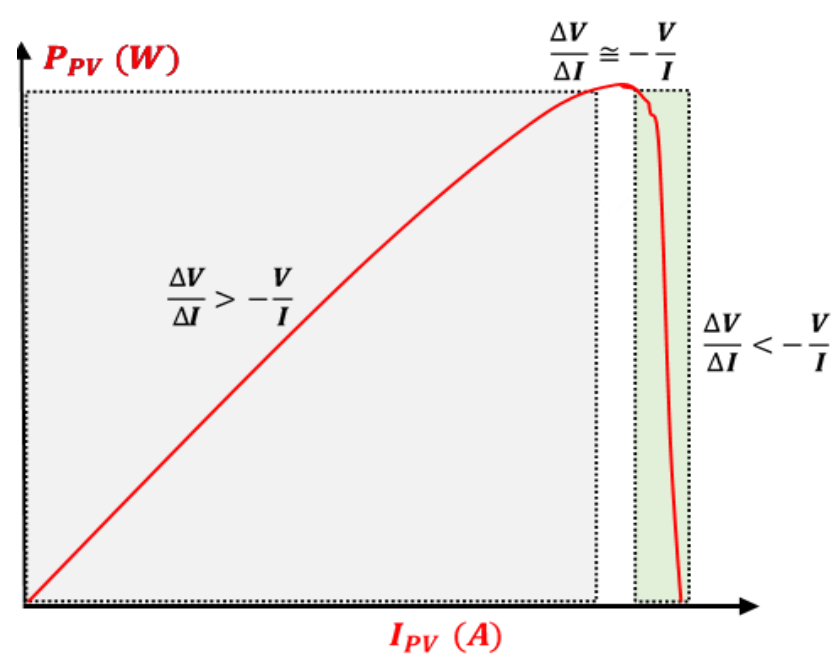

Figure 2.8. The P-I characteristic for the current based INC method.

To design INC as a current based MPPT, the equation (2.1) can be rewritten as:

$$
\frac{d P}{d I}=\frac{d(V I)}{d I}=I \frac{d V}{d I}+V=0
$$

Accordingly, the rules in equations. (2.3)-(2.5) will be transformed by

$$
\begin{aligned}
& \frac{d V}{d I}=-\frac{V}{I} \text { at MPP } \\
& \frac{d V}{d I}>-\frac{V}{I} \text { left to MPP } \\
& \frac{d V}{d I}<-\frac{V}{I} \text { right to MPP }
\end{aligned}
$$

Using rules defined in equations (2.7)-(2.9), the flowchart in Figure 2.7 can be modified to current based INC method by interchanging $\mathrm{V}$ with $\mathrm{I}, \Delta \mathrm{V}$ with $\Delta \mathrm{I}$ and $\mathrm{V}(\mathrm{k})$ with $\mathrm{I}(\mathrm{k})$. Therefore, the algorithm will be defined by incremental resistance (ICR) not INC.

Similar to P\&O method, INC also depends on the perturbation value 'offset'. The large value of 'offset' will result in fast-tracking but the system may possibly oscillate at MPP; the incremental conductance $(\Delta \mathrm{I} / \Delta \mathrm{V})$ is not exactly equal to instantaneous inductance $(\mathrm{I} / \mathrm{V})$. However, a smaller value of 'offset' can overcome this problem but tracking will get slower; so the trade-off is still there, similar to the P\&O method. In the same way, two subgroups of INC method can be characterized 
based on fixed and adaptive value of 'offset'. These are not discussed separately because of the same objective as that of $\mathrm{P} \& \mathrm{O}$ algorithm.

\subsubsection{INC Direct Duty Cycle}

Similar to HC, another method of direct duty cycle control is based on INC algorithm. In this method, the duty cycle is updated according to the flowchart scheme depicted in Figure 2.9, this algorithm can use fixed or variable perturbation. The latter scheme can be included to achieve a better tracking speed and reduced steady-state oscillations.

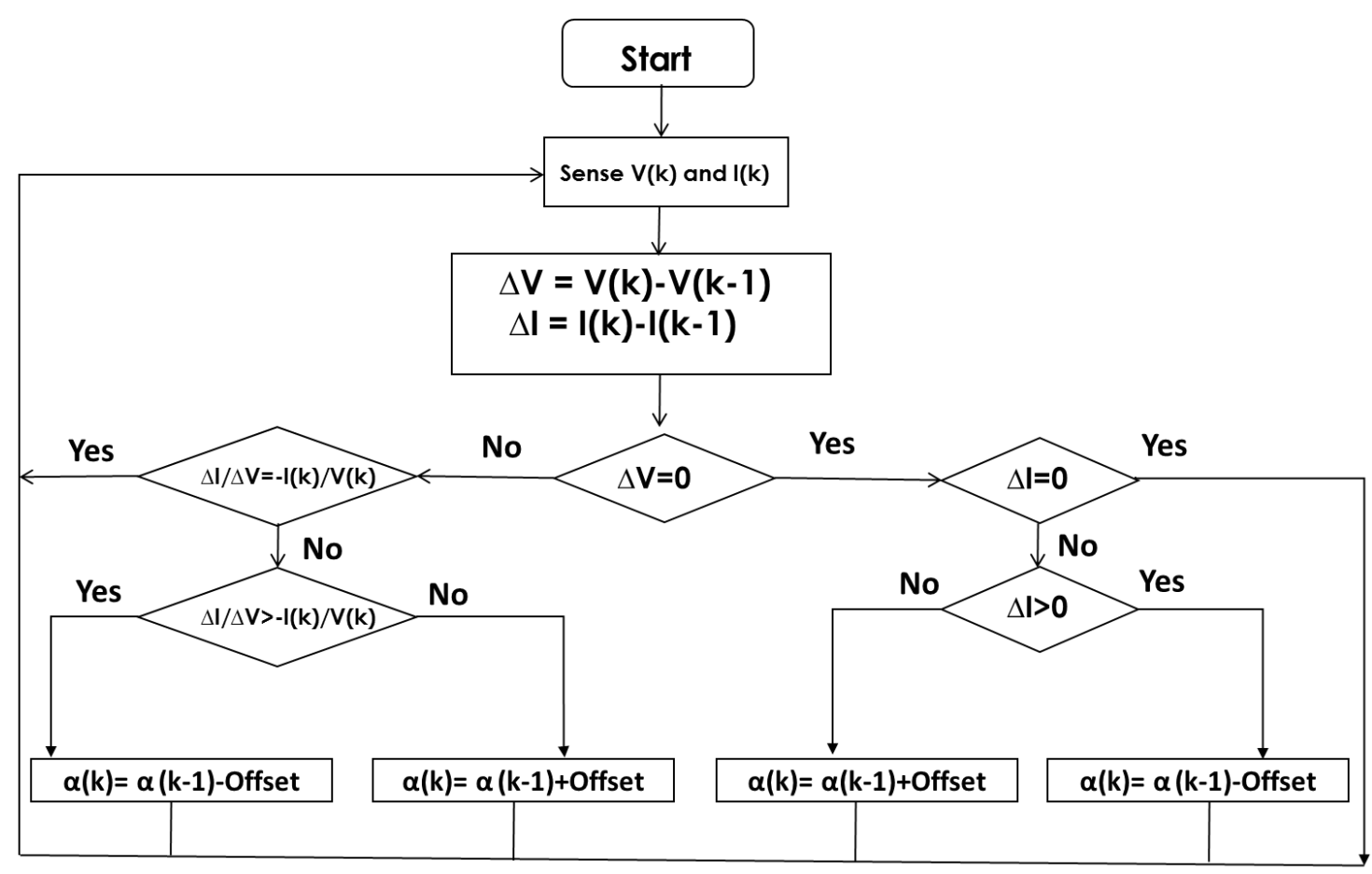

Figure 2.9. Basic flowchart of INC based direct duty cycle approach.

\subsection{Group 2: MPPT Based on PV Panel and Power Converter Characteristics}

The methods that fall under this category exploit the inherent behavior of different panel parameters with respect to temperature and insolation variations. Among these, one method is characterized by its current characteristics and commonly known as Fractional Short-Circuit Current (FSCC) method. The other takes advantage of its voltage characteristics and recognized as Fractional Open- Circuit Voltage (FOCV). There is another method which is based on the FOCV or FSCC algorithm called pilot cell. These are discussed in the following subsections [12]. 


\subsubsection{Fractional Short-Circuit Current (FSCC)}

The Basic idea for the FSCC method is derived from the relationship between the values of a short circuit $\left(I_{S C}\right)$ and maximum power current $\left(I_{m p}\right)$ of PV panel, as shown in Figure 2.10. It shows the 3D plot of $I_{S C}$ and $I_{m p}$ for MSX-60 PV panel for the operating points of insolation level (100$\left.1000 \mathrm{~W} / \mathrm{m}^{2}\right)$ and temperature $\left(10-75^{\circ} \mathrm{C}\right)[32]$.
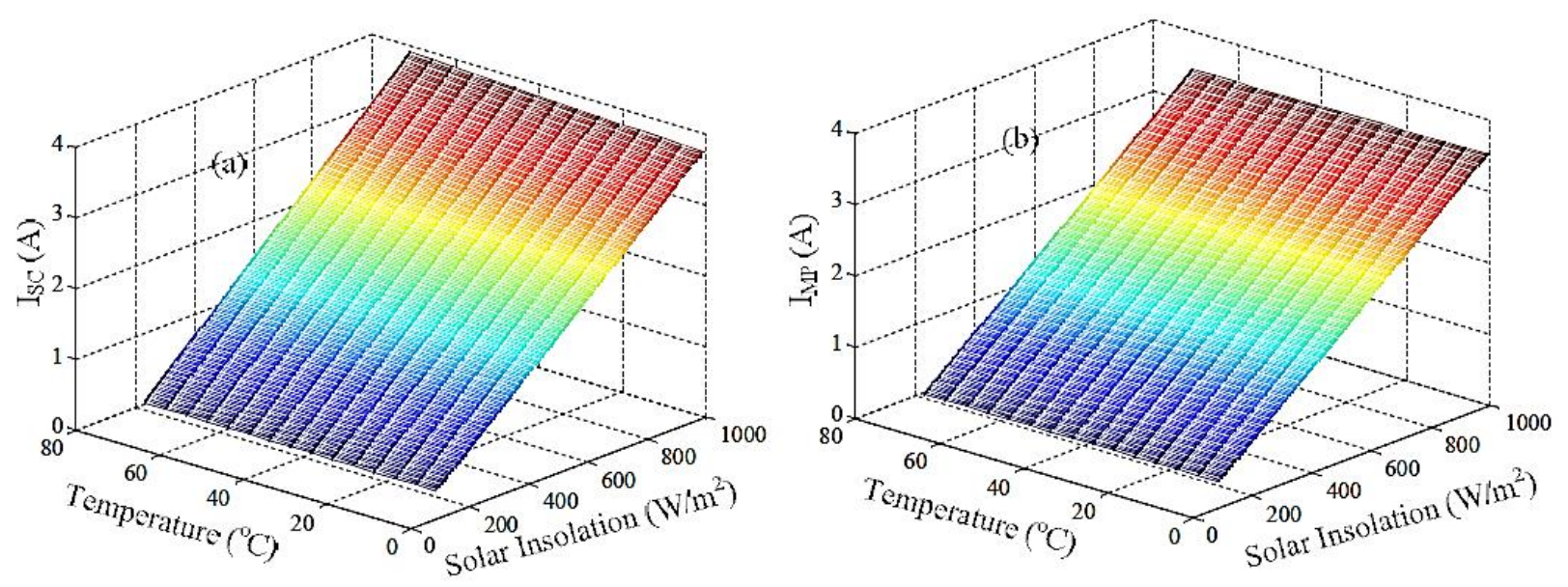

Figure 2.10. The 3-D plot of $\mathbf{I}_{\mathbf{S C}}$ and $\boldsymbol{I}_{\boldsymbol{m} \boldsymbol{p}}$ for insolation and temperature variations.

It can be clearly seen that there exists a linear relationship between the $I_{S C}$ and $I_{m p}$ which can be written as:

$$
I_{m p}=K_{i} \times I_{s c}
$$

where $K_{i}$ is a proportionality constant. Since $K_{i}$ is characterized by the characteristics of the PV panel under consideration, it needs to be determined in advance by empirically determining $I_{m p}$ and $I_{S C}$ at different insolation and temperature levels. Thereafter, the ratio of $I_{m p}$ and $I_{S C}$ such as in Figure 2.10 gives the value of $K_{i}$. It can be noted that $K_{i}$ can be computed experimentally or using simulation studies. However, the former is preferable as it will result in more realistic value. Nevertheless, due to the availability of PV simulators, now it is possible to obtain accurate value of $K_{i}$ using simulation tools. Generally, for most of the PV panels, the factor $K_{i}$ has been found to be between 0.78-0.92.

Several authors [35]-[38] utilized equation (2.10) to track the MPP of PV panel. However, the main problem lies in the measurement of $I_{S C}$ during the MPP operation. To measure $I_{S C}$, an extra switch is introduced to the power converter which periodically shorts the PV panel terminal so that $I_{S C}$ can be measured. However, this additional circuitry increases the components and hence the cost. Furthermore, the available power might be significantly reduced due to the rough estimation of Ki in equation (2.10), which does not ensure the perfect matching of true MPP. To avoid extra circuitry, 
authors in [36] used a boost converter, in which the switch of the converter itself was used to short the PV panel. Despite these efforts, the extracted power is reduced while finding the value of $I_{S C}$ as well as due to the approximate value of $K_{i}$. To overcome this issue, authors in [38] proposed a compensation method for $K_{i}$ such that the MPP is better tracked under environmental variations.

\subsubsection{Fractional Open-Circuit Voltage (FOCV)}

The variations of $V_{O C}$ and $V_{m p}$ voltages are depicted in Figure 2.11 for the insolation level $\left(100-1000 \mathrm{~W} / \mathrm{m}^{2}\right)$ and temperature $\left(10-75^{\circ} \mathrm{C}\right)$. Each PV panel shows different characteristics with changing irradiation conditions especially around the MPP points. For the insolation levels between 100 and $1000 \mathrm{~W} / \mathrm{m}^{2}$ at a constant cell temperature of $50{ }^{\circ} \mathrm{C}$, the $V_{m p}$ of MSX-60 increases almost proportionally with irradiance levels [32].
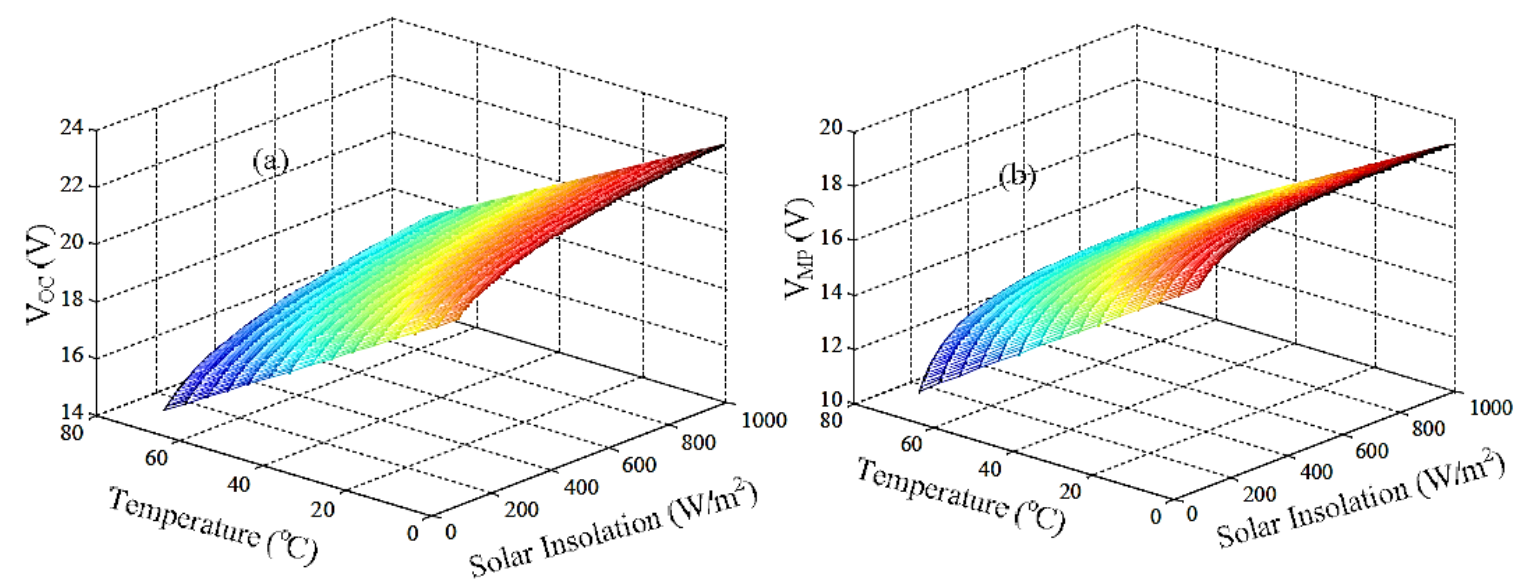

Figure 2.11.3D plot of $\boldsymbol{V}_{\boldsymbol{O C}}$ and $\mathbf{V}_{\mathbf{m p}}$ for insolation and temperature variations.

Similar to the FOC method, a linear relationship between the $V_{O C}$ and $V_{m p}$ can be approximated using equation (2.11):

$$
V_{m p}=K_{v} \times V_{o c}
$$

where $K_{v}$ is a proportionality constant. Like $K_{i}$, the constant $K_{v}$ also needs to be determined using the relationship between $V_{m p}$ and $V_{O C}$ at different insolation and temperature levels. Most of the occasion, $K_{v}$ has reported being between $0.71-0.84$.

Various works [39]-[42] have attempted to exploit equation (2.11) for MPP tracking. Unfortunately, Similar to FSCC to achieve this, $V_{O C}$ need to be measured periodically. This, in turn deteriorates the MPPT dynamic efficiency. To avoid the temporary loss due to the measurement, the pilot cells were proposed in [35] to obtain the value of $V_{O C}$. However, the specification of each PV cell is not generic; therefore, these cells must be carefully selected to closely represent the 
characteristics of the PV panel. Interestingly, in [39], it was stated that the voltage resulted by cell diodes is approximately $75 \%$ of the $V_{O C}$ and hence measuring the open-circuit voltage is not necessary. By approximating of $V_{m p}$ as a reference value from equation (2.11), a closed-loop control then was employed to follow the reference value $V_{m p}$.

Similar to FSCC, equation (2.11) is the only estimation and technically the PV panel never operates at the MPP. Another point worth noting is that the increasing insolation does not always cause an increase in the MPP voltage for other PV technologies [43], for example, US-21 and FS-50 PV panel. Therefore, the relation in equation (2.11) does not hold for such type of PV panels. Therefore, if FOCV scheme is employed in these mentioned panels, the MPPT accuracy will be severely compromised.

\subsubsection{Pilot cell}

The pilot cell method is based on the FOCV or FSCC algorithm, but the measurements of the Voc or Isc is done by using a small PV cell, called a pilot cell, the latter must have the same characteristics as the cells in the big PV panel. Then the MPPT uses the measurement to extract MPP from the main PV panel. As a result, the loss of energy during the $V_{O C}$ or $I_{S C}$ measurement is eliminated. However, the lack of a constant $\mathrm{K}$ value is still present. Also, the characteristics of the pilot cell must be according to those of the main PV panel [44].

\subsection{Group 3: Soft Computing Approach}

\subsubsection{Fuzzy Logic Control (FLC)}

The powerful computing capability of existing microprocessors allowed fuzzy logic control (FLC) to be employed in MPPT controller. Using FLC, the system model is not mandatory. This in itself is an essential advantage because the changes in operating point, non-linearities and the uncertainties such as unmodeled physical quantities can be excellently dealt with it. Nevertheless, the designer must have some prior knowledge of how the output responds qualitatively to the inputs.

The process of a FLC controller is presented in Figure 2.12. It is composed of three functional blocks namely fuzzification, rules inferences and defuzzification. Moreover, there is a database in which the designed rules are stored. This is referred to as the rule table. The process in which FLC performs the calculation based on the rule table to generate the output is called fuzzy inference [33]. 


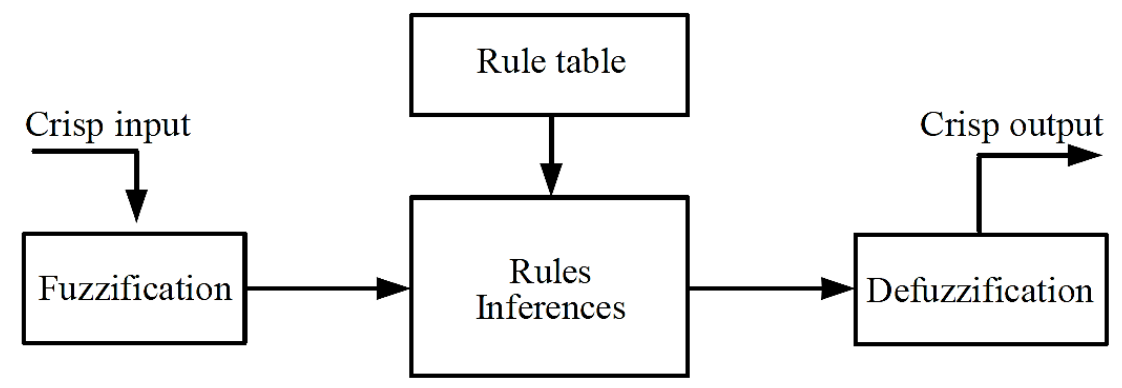

Figure 2.12. Block diagram of Fuzzy logic control (FLC)

\section{A. Fuzzification}

The fuzzification process is used to transform numerical input variables (crisp input) into linguistic variables based on a membership function as shown in Figure 2.13. Five membership are shown: NL (negative large), NS (negative small), Z (zero), PS (positive small), and PL (positive large).

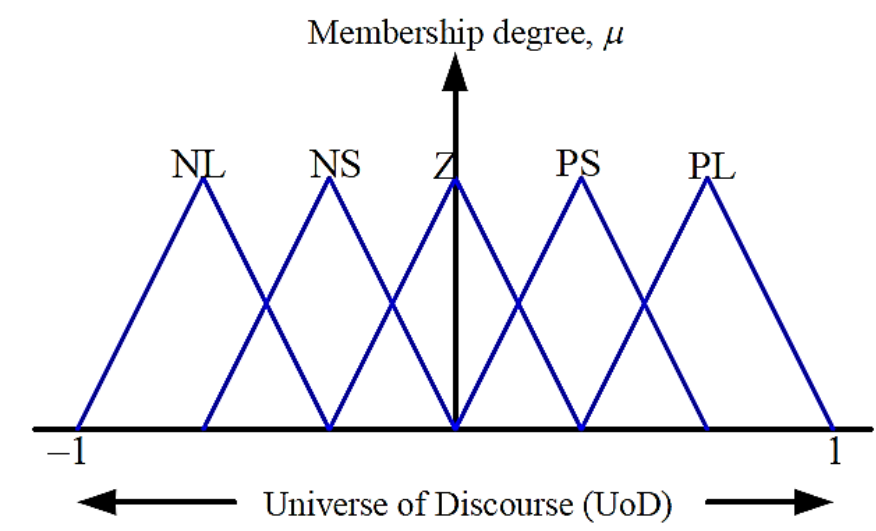

Figure 2.13. Fuzzy membership functions used in the fuzzification process.

\section{B. Rules Inferences and Rule Table}

The rules inferences process is the workhorse in the FLC structure. This is the block where the control decisions are carried out. It is analogous to control gains or control laws in a conventional controller. In FLC, the equivalent term is known as the rule and it's linguistic. A typical rule structure can be written as follows:

\section{$R k$ : If $\mathrm{x}$ is $A i$ and $\mathrm{dx}$ is $B i$ Then Output is $C i$}

In equation (2.12), $\mathrm{Rk}$ is the kth rule while $\mathrm{x}$ and $\mathrm{dx}$ are the input variables for FLC. Variables $\mathrm{Ai}, \mathrm{Bi}$ and $\mathrm{Ci}$ are the linguistic labels for the inputs and the output, respectively. To evaluate the rule, the fuzzy set theory is used. One of the main challenges of FLC is to write rules that can relate the 
input variables to the output. These rules are written with the syntax of the equation (2.12). These rules are grouped to form a fuzzy rule table. Unfortunately, there is no accurate method to design the control rules. It mainly relies on the intuitive knowledge gained from the practical experience. As expected, this approach produces results that are rather subjective. Table 2.1 shows a typical rule table for the case of five linguistics variables. In general, more rules yield accurate results at the expense of computation time.

Table 2.1. Fuzzy rule table.

\begin{tabular}{|c|l|l|l|l|l|}
\hline \multicolumn{1}{|c|}{$\mathrm{E}$} & PL & PS & Z & NS & NL \\
\hline NL & Z & NS & NL & NL & NL \\
\hline NS & PS & Z & NS & NL & NL \\
\hline$Z$ & PL & PS & Z & NS & NL \\
\hline PS & PL & PL & PS & Z & NS \\
\hline PL & PL & PL & PL & PS & Z \\
\hline
\end{tabular}

\section{Defuzzification}

At this stage, the linguistic-based data is converted back to crisp data. Numerous methods of defuzzification exist, e.g. Bisector of Area (BoA), Mean of Maxima (MoM), Centre of Gravity (CoG) and Centre of Gravity for Singleton (CoGS) [45]. The selection of defuzzification method is a compromise between accuracy and computational intensity. The most used is the Centre of Gravity method $(\mathrm{CoG})$, which is presented by the equation:

$$
u=\frac{\sum_{i=1}^{n} \mu\left(x_{i}\right) x_{i}}{\sum_{i=}^{n} x_{i}}
$$

In equation (2.13), variable $\mathrm{n}$ represents the number of output membership function while $\mu\left(x_{i}\right)$ is the degree of membership function and $x_{i}$ is the peak location of the membership function. The output expression can be interpreted as the weighted average of the elements.

Compared to previous MPPT techniques, the dynamic performance of FLC is very efficient [46]. In addition, FLC offers a high degree of freedom to tune its control parameters. This allows for easy modifications, thus making it compatible with different types of linear and non-linear controllers [47]. 


\section{MPPT Implementation using FLC}

As can be seen in Table 2.1, the inputs of the FLC based MPPT controller are usually an error $\mathrm{E}$ and a change in error $\Delta \mathrm{E}$. The designer has the flexibility of choosing how to calculate $\mathrm{E}$ and $\Delta \mathrm{E}$. For instance, both inputs can be computed by the following equations [33]:

$$
\begin{aligned}
& E(k)=\frac{P(k)-P(k-1)}{V(k)-V(k-1)} \quad \text { Or } \quad E(k)=\frac{P(k)-P(k-1)}{I(k)-I(k-1)} \\
& \Delta E=E(k)-E(k-1)
\end{aligned}
$$

Once $\mathrm{E}$ and $\triangle \mathrm{E}$ are calculated and transformed into the linguistic variables, the output of FLC can also be defined linguistically in terms of duty cycle, voltage or current, such as shown in Figure 2.12. Thus, the output signal is based on fuzzy rules presented in Table 2.1. The linguistic variables for the output signal are usually assigned based on prior knowledge of the particular PV panel being employed. For instance, if the operating point is far to the right of the MPP (Figure 2.6), that is E is $\mathrm{NL}$, and $\Delta \mathrm{E}$ is $\mathrm{Z}$, then the output signal of the converter should be PL to reach towards the MPP [33].

\subsubsection{Artificial Neural Network (ANN) based MPPT}

\section{A. Artificial Neural Network}

Artificial neural network (ANN) is an interconnection of processing units known as neurons. Generally, ANN is not programmed to perform some specific tasks; instead, it is trained with respect to data sets until it is able to figure out (learn) the imposed patterns used as inputs. Once trained, it can predict or classify these input patterns, which are usually tested in the validation step. A well trained ANN can handle a variety of inputs with excellent results [43].

Figure 2.14 shows a typical three-layer feed-forward ANN structure. It can be seen that it consists of various neurons (represented by circles) arranged in layers with forward connections to other neurons in the subsequent layers. Each neuron is associated with a particular weight. The first is the input layer (h), which is then distributed to the subsequent layers. In the next layer, which is the hidden layer (j), each neuron carries out following tasks: (1) addition of its inputs with the bias or threshold term and (2) the results of (1) is passed through a nonlinear function to produce the final output. This nonlinear function is called the activation function of the neuron. The output layer units often have linear activations. The layers squeezed in between the input and output layer are called hidden layers and accordingly, the neurons in these layers are known as hidden neurons. 
Layer $h$

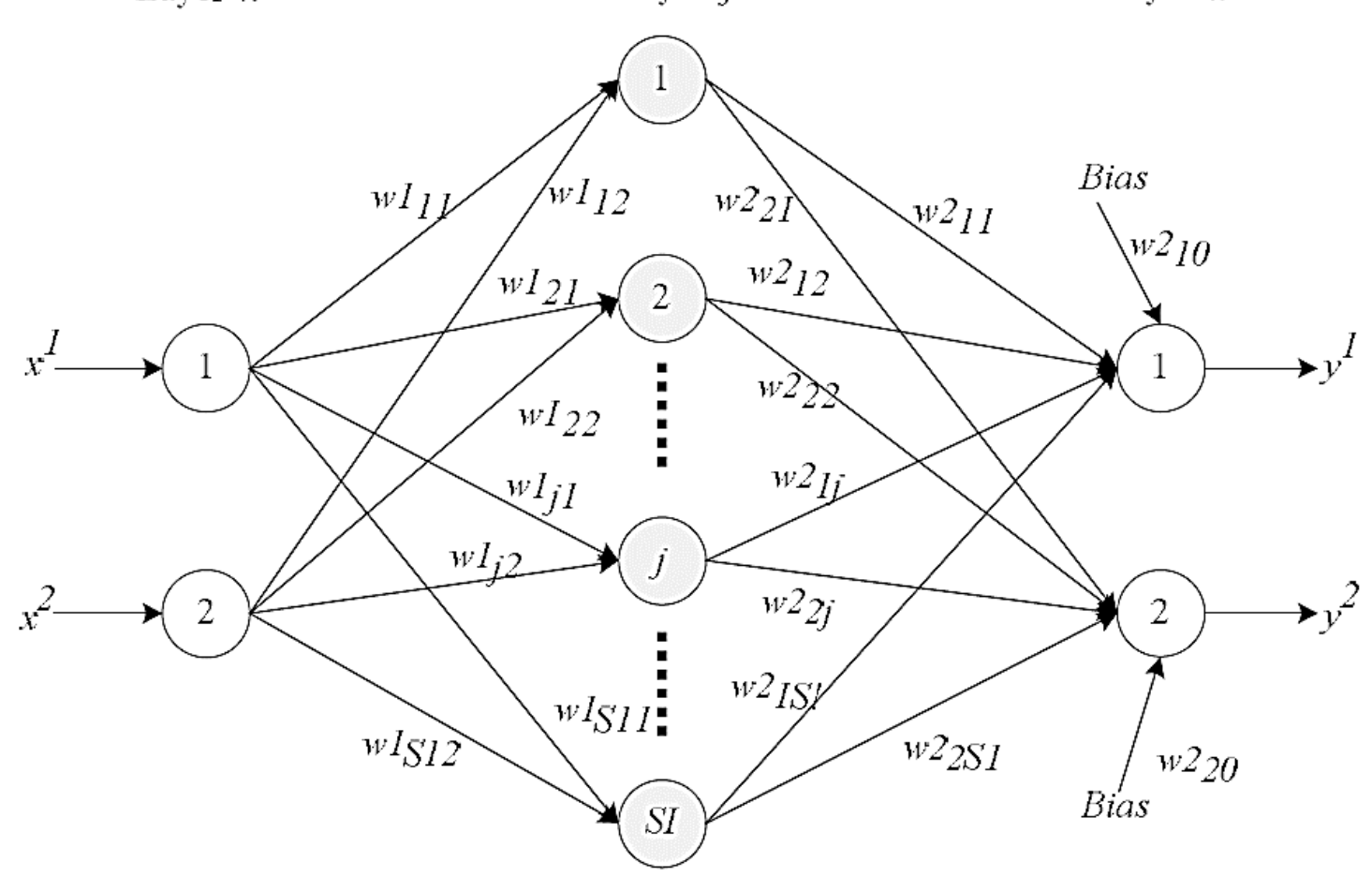

Figure 2.14. A typical three layer feed-forward ANN structure.

In the figure, S1 represents the total number of neurons in the hidden layer, $\mathrm{w}$ are the adaptive weights and biases and $\mathrm{x}$ and $\mathrm{y}$ represent the ANN input and output respectively. Let the neurons in layers $\mathrm{h}$ and $\mathrm{k}$ use linear activation while those in layer $\mathrm{j}$ use sigmoid activation functions, respectively. Thus, the output of Figure 2.14 in terms of its input can be written as:

Using equations (2.16) and (2.17), a generalized output equation can be written as:

$$
\begin{aligned}
& y^{1}=w 2_{10}+w 2_{11} z_{1}+w 2_{12} z_{2}+\ldots+w 2_{1 S 1}=\sum_{j=0}^{S 1} w 2_{1 j} z_{j} \\
& y^{2}=w 2_{20}+w 2_{21} z_{1}+w 2_{22} z_{2}+\ldots+w 2_{2 S 1}=\sum_{j=0}^{S 1} w 2_{2 j} z_{j}
\end{aligned}
$$

Using equations (2.16) and (2.17), a generalized output equation can be written as:

$$
y^{k}=\sum_{j=0}^{S 1} w 2_{k j} z_{j} \text { and } Z_{0}=1
$$

Where

$$
Z_{j}=f\left(a_{j}\right)=\frac{1}{1+e^{a_{j}}}
$$




$$
a_{j}=\sum_{h=1}^{2} w 1_{j h} x^{h}
$$

The mapping error can be written as:

$$
E^{k}(w)=\left(y^{k}\left(x_{i}, w\right)-t_{i}^{k}\right)^{2}
$$

The goal of the ANN 'learning' is how to find a set of weights, w, such that the error, $E^{k}(\mathrm{w})$ in Equation (2.21) is minimized. A relatively simple but effective method known as backpropagation (BP) algorithm is generally employed to compute the associated weights in ANN.

\section{B. ANN Based MPPT}

As discussed earlier that ANN exhibits excellent performance for recognizing and estimating unknown parameters. This feature has greatly inspired research community to employ it for MPPT. The inputs of ANN-based MPPT can be PV panel characteristics like $V_{O C}$ and $I_{S C}$, environmental data such as irradiation and temperature, or any combination of these. The output can be either the duty cycle, voltage or current. The tracking performance (accuracy and speed) of the MPPT depends on the employed method for the hidden layer and the appropriate training of ANN [33].

To achieve the MPP, the associated weights have to be carefully computed through a comprehensive training process. Accordingly, PV panel is tested extensively for a certain period of time. This can prolong to months or even years.

Then, the resulting patterns between the input(s) and output(s) of the ANN are stored. Once the ANN is trained comprehensively, the ANN can estimate the MPP and give the reference value $\left(V_{m p}\right.$ or $\left.I_{m p}\right)$ to the MPPT controller. Accordingly, any MPPT method such as FLC can be utilized to maintain the PV panel at the reference signal given by ANN.

\subsubsection{Evolutionary Algorithm (EA)}

An alternative method to track the global peak (GP) by employing the evolutionary algorithm (EA). EA methods have been widely used due to its ability to handle nonlinear functions without requiring derivatives information. It is a stochastic optimization method that appears to be very efficient in optimizing real-valued multi-modal objective functions [48], [49]. With these advantages, EA is envisaged to be very effective in dealing with MPPT problem. Since the technique is based on search optimization, it should be able to find the MPP for any P-V characteristics regardless of environmental variations. 
Various types of EA methods are found in the literature; the most used are genetic algorithm (GA), differential evolution (DE) and particle swarm optimization (PSO). Although each technique (GA, DE and PSO) can be effectively employed to track the MPP, PSO appears to be the preferable one. This is due to its simple structure, easy implementation and fast computation capability [50]. Therefore, PSO based MPPT is described in this chapter, whereas discussions on other EA MPPT techniques can be found elsewhere [49].

\section{A. Particle Swarm Optimization}

Particle swarm optimization (PSO) is a stochastic, population-based search method, modeled after the behavior of bird flocks [51]. A PSO algorithm maintains a swarm of individuals (called particles), where each particle represents a candidate solution. Particles follow a simple behavior: emulate the success of neighboring particles, and achieve their own successes. The position of a particle is therefore influenced by the best particle in a neighborhood, as well as the best solution found by the particle. Particle position, xi, are adjusted using:

$$
x_{i}^{k+1}=x_{i}^{k}+v_{i}^{k+1}
$$

Where the velocity component, $v_{i}$, represents the step size. The velocity is calculated by:

$$
v_{i}^{k+1}=w v_{i}^{k}+c_{1} r_{1}\left(P_{b e s t i}-x_{i}^{k}\right)+c_{2} r_{2}\left(G_{b e s t}-x_{i}^{k}\right)
$$

where $\mathrm{w}$ is the inertia weight, $c_{1}$ and $c_{2}$ are the acceleration coefficients, $r_{1}, r_{2} \in \mathrm{U}(0,1), P_{b e s t i}$ is the personal best position of particle i, and $G_{b e s t}$ is the neighborhood best position of particle $\mathrm{i}$. The inertia weight $w$ plays a vital role in balancing the global search and local search. A large w facilitates a global search while a small inertia weight improves a local search. It can be a positive constant or a positive decreasing linear function of iteration index $\mathrm{j}$.

Figure 2.15 depicts the basic flow chart of the PSO method. 


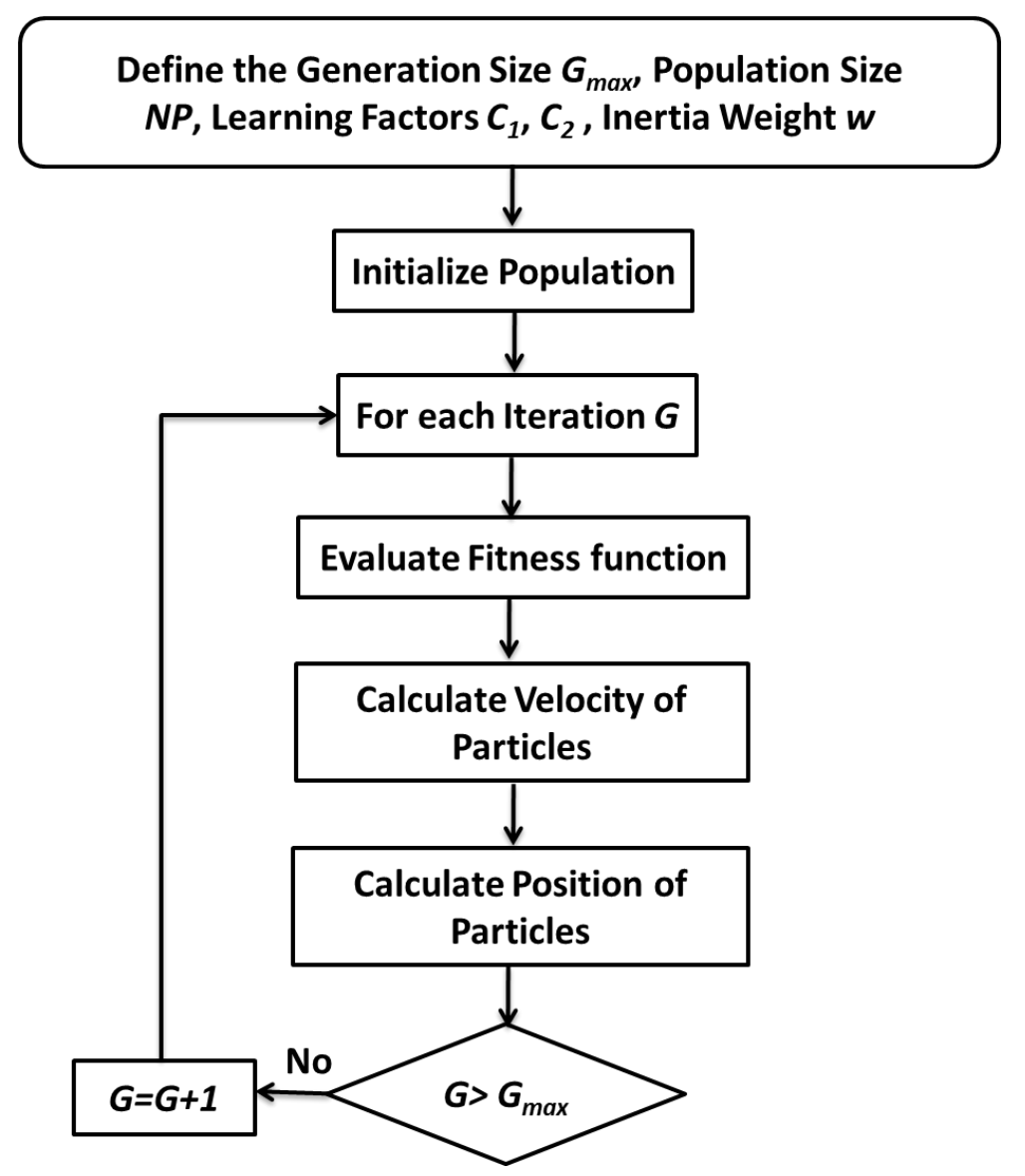

Figure 2.15. The basic flow chart of PSO method.

\section{Recapitulation}

Since there are several MPPT algorithms available in the literature, it is mandatory to compare them and then select the most suitable MPPT for a particular application. In this chapter a comparative assessment of the most MPPT used has been done on the following criteria: category (direct, indirect, soft computing), True MPPT (The MPPT method can operate at MPP or not), tracking Speed, sensors used, analog or digital implementation, Steady-state oscillations level, algorithm complexity, cost and efficiency. A comparison of MPPT methods according to these criteria is presented in Table 2.2. 
Table 2.2. Review of the most used MPPT algorithms.

\begin{tabular}{|c|c|c|c|c|c|c|c|c|c|}
\hline MPPT & Category & True MPPT & $\begin{array}{l}\text { Steady-state } \\
\text { oscillations }\end{array}$ & Efficiency & $\begin{array}{l}\text { Tracking } \\
\text { Speed }\end{array}$ & Analog/digital & $\begin{array}{l}\text { Implementation } \\
\text { Complexity }\end{array}$ & Sensors & Cost \\
\hline $\begin{array}{l}\text { Fractional Short Circuit } \\
\text { Current }\end{array}$ & Indirect [12] & No [103] & No [110] & Low [11] & Fast [12] & Both [12] & Simple [12] & I [112] & Cheap [12] \\
\hline $\begin{array}{l}\text { Fractional open circuit } \\
\text { voltage }\end{array}$ & Indirect [12] & No [103] & No [110] & Low [11] & Fast [12] & Both [12] & Simple [12] & V [112] & Cheap [12] \\
\hline Pilot cell & Indirect [12] & No [103] & No [110] & Low [11] & Fast [12] & Both [12] & Simple [12] & V or I [44] & Cheap [12] \\
\hline $\begin{array}{l}P \& O \text { and hill climbing } \\
\text { method }\end{array}$ & Direct [12] & Yes [103] & Yes [111] & $\begin{array}{l}\text { Medium } \\
{[11]}\end{array}$ & Slow [12] & Both [12] & Simple [12] & $\begin{array}{c}\text { I and V } \\
{[112]}\end{array}$ & Medium [12] \\
\hline $\begin{array}{l}\text { Incremental conductance } \\
\text { method }\end{array}$ & Direct [12] & Yes [103] & $\begin{array}{l}\text { Sometimes } \\
{[111]}\end{array}$ & Good [11] & $\begin{array}{c}\text { Medium } \\
{[12]}\end{array}$ & Digital [12] & Medium [12] & $\begin{array}{c}\text { I and V } \\
{[112]}\end{array}$ & $\begin{array}{c}\text { Expensive } \\
{[113]}\end{array}$ \\
\hline Fuzzy logic & $\begin{array}{c}\text { Soft computing } \\
{[12]}\end{array}$ & Yes [103] & No [110] & $\begin{array}{l}\text { Very good } \\
\text { [11] }\end{array}$ & Fast [12] & Digital [12] & Complex [12] & $\begin{array}{l}\text { I and V } \\
{[112]}\end{array}$ & $\begin{array}{c}\text { Very } \\
\text { Expensive } \\
{[12]} \\
\end{array}$ \\
\hline Neural network & $\begin{array}{c}\text { Soft computing } \\
\text { [12] }\end{array}$ & Yes [103] & No [110] & $\begin{array}{l}\text { Very good } \\
\quad[11]\end{array}$ & Fast [12] & Digital [12] & Complex [12] & $\begin{array}{l}\text { Varies } \\
{[112]}\end{array}$ & $\begin{array}{c}\text { Very } \\
\text { Expensive } \\
{[12]}\end{array}$ \\
\hline PSO based MPPT & $\begin{array}{c}\text { Soft computing } \\
{[12]}\end{array}$ & Yes [103] & No [110] & $\begin{array}{l}\text { Very good } \\
\quad[11]\end{array}$ & Fast [12] & Digital [12] & Complex [12] & $\begin{array}{c}\text { I and V } \\
{[12]}\end{array}$ & $\begin{array}{c}\text { Very } \\
\text { Expensive } \\
{[12]} \\
\end{array}$ \\
\hline
\end{tabular}




\section{Summary}

In this chapter, the most MPPT algorithms used for tracking the MPP of PV panel have been extensively reviewed. Based on the review, all methods have their own advantages and disadvantages. Some of the methods show very effective results such as soft computing techniques but the methodologies used were complicated. The methods which are simple in implementation such as FOCV, FSCC and pilot cell method are less accurate. Perturb and observe method is commonly used method because its implementation circuitry is not complicated but it shows high level of steady-state oscillations. To overcome this problem incremental conductance method was proposed, however, this method is more complex than $\mathrm{P} \& \mathrm{O}$ due to the mathematical division calculations used in its construction and requires a controller with division capabilities resulting in high cost of the system. In addition, INC algorithm may fail to track the new MPP in case of fast increasing in solar irradiance. Therefore, in this thesis a modified INC is presented, the latter can overcome the wrong response made by the conventional INC algorithm when the irradiance is suddenly increased, also the modified INC is designed without any mathematical division calculations to propose a low-cost PV system. 


\section{Chapter 3}

\section{$\underline{\text { PV Panel Modeling }}$}

- Introduction

- Photovoltaic panel

- MATLAB/Simulink Based Modelling of Photovoltaic Panel

- PSIM Based Modelling of Photovoltaic Panel

- Proteus Based Modelling of Photovoltaic Panel

- Summary 


\section{Introduction}

The energy generated by the PV systems depends on various parameters, either environmental as temperature and irradiance or internal parameters of the PV panel, namely, the series and shunt resistors [52], [53]. Thus, the load imposes its own characteristic on the output power [20]. Therefore, in order to predict and analyze the effect of these parameters on the PV power, the model of the PV panel should be previously studied and achieved, and this model should be in accordance with the real comportment of the PV panel. Therefore, different models were proposed in the literature, in [54] a single diode model is used, in [55] a two diodes model is proposed to illustrate the influence of the recombination of carriers, and in [56] a model of three diodes is used to present the effects which are neglected by the two diodes model. However, the single-diode model is the most adopted due to its good simplicity and accuracy [57]. However, manufacturers of PV panels offer only some characteristics, and other characteristics required to model PV panel are lacked in the datasheet, namely the photocurrent, the diode saturation current, the series and shunt resistors, and the ideality factor [58]. Hence, in [48], [57]-[59] researchers have proposed different methods to extract the lacked characteristics based on the datasheet values, but these methods require an implementation and this can increase the time spent in the development of a PV application. Therefore in this chapter, the parameters lacked in the manufacturers' datasheet are extracted by using a simple tool provided by Mathworks [60] and then the PV panel is model by MATLAB and PSIM. The single diode model is used in this thesis because it gives a high compromise between accuracy and simplicity [61] and several researchers have used it in their works [27], [62]. In addition, the effect of parameters that may change the performance of the PV panel is presented.

Nevertheless, several researchers have modeled the PV panel either in Matlab/Simulink or PSIM tools [52], [62], [64]. However, these tools don't provide a microcontroller or an embedded board in which our algorithm can be implemented and tested as made using the hardware implementation. Consequently, we can't rely on these tools to validate and guarantee the excellent performance of such MPPT algorithm. On the other hand, Proteus is the best simulation software for various designs with electronics and microcontrollers. It is mainly popular because of availability of almost all microcontrollers in it. But, it does not provide a PV panel model. Hence in this chapter, a PV panel is modeled in Proteus and this model is validated using an experimental test bench. Therefore, by using Proteus, MPPT algorithm can be implemented on embedded boards and consequently, this solution can be used as a low-cost PV simulator. 


\section{Photovoltaic panel}

\subsection{PV panels structure}

The principal component used to convert the solar energy to the electrical one is the solar cell that is not other than a diode. When the photons that have lengths waves hit the cell, the pairs electrons-holes are created if the energy of each photon is greater than the energy of the semiconductor material's gap. Consequently, thanks to the existence of the junction's electrical field as seen in Figure 3.1, these pairs electrons-holes are separated and collected to form a current, generally called, photo-current or current photo-generated [65].

\section{Photon}

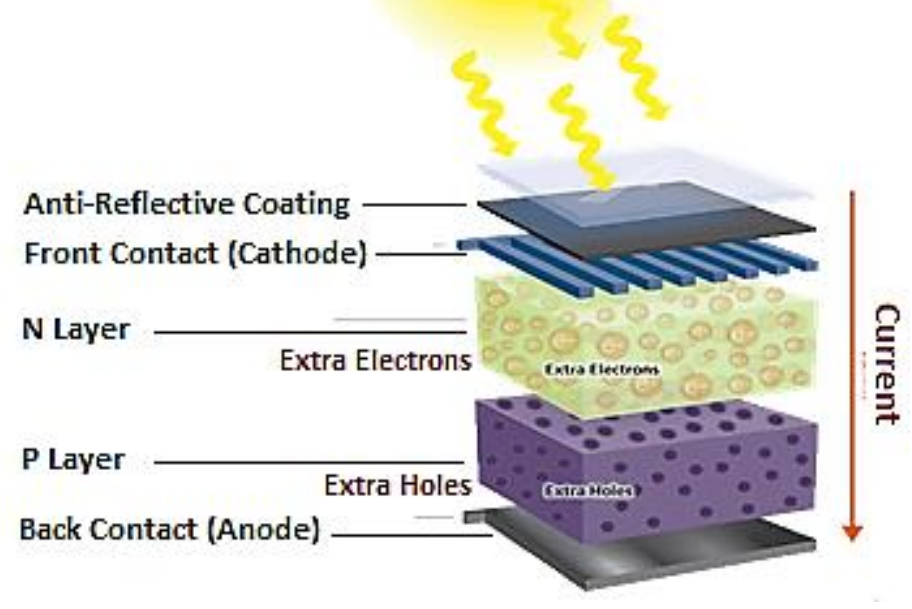

Figure 3.1. Silicon PV cell Structure.

Figure 3.2 shows the difference between solar cells, panels and arrays and their configuration types. PV array is composed of several PV panels [66]. The PV panel contains numbers of solar cells connected in parallel or series. This connection depends totally on the application whether a large voltage or current is required for the load [67]. Therefore, the voltage and current level are referred to the PV panel, and not in individual PV cell. A series connection can be used when the operating voltage is low (at millivolts) and the current is high. Thus, a series arrangement helps to increase the output voltage by adding the voltage of each cell for each string. On the other hand, a parallel cell connection is used to increase the current in the PV panel because it will add the current for each cell, which is less common [67]. 


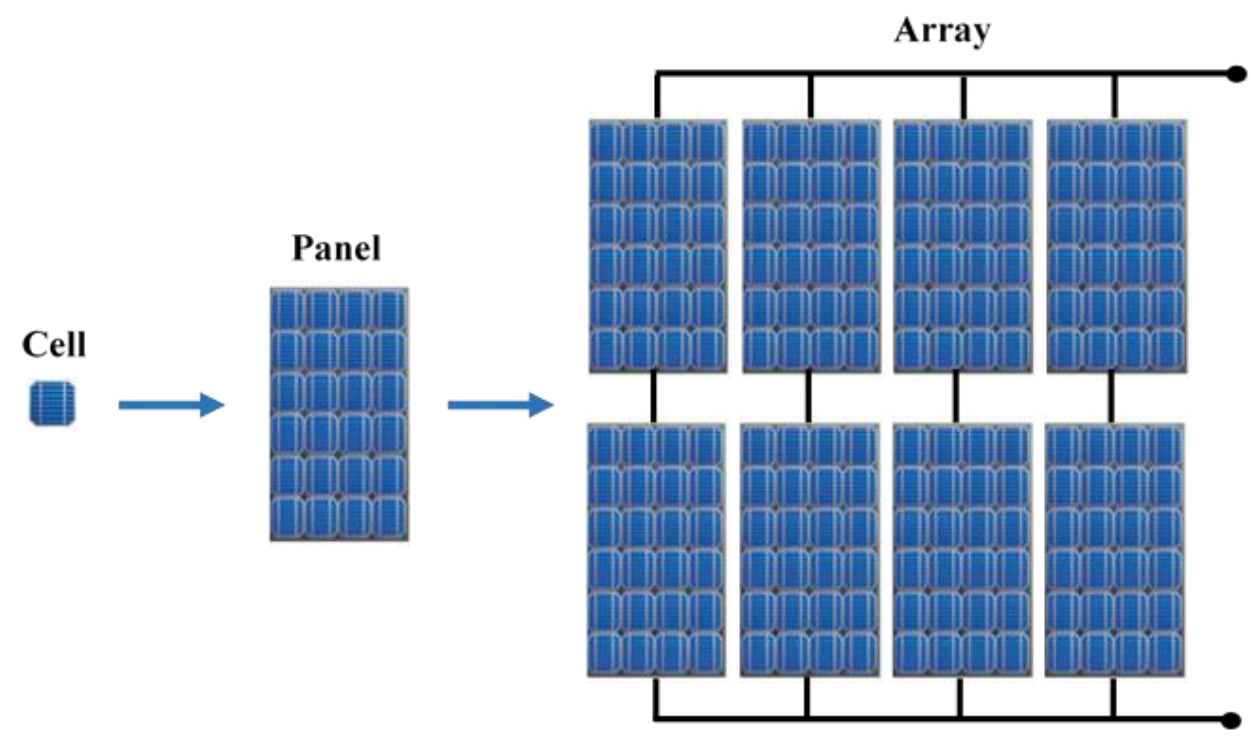

Figure 3.2. Solar Cells, Panels, and Arrays configuration types.

\subsection{Equivalent Circuit of PV Panel}

A PV panel is a component that can convert a solar energy into direct current electricity by using semiconducting materials that exhibit the PV effect. In order to model mathematically a PV panel, we derive the fundamental equation from the equivalent circuit of the PV panel shown in Figure 3.3 [53], [68].

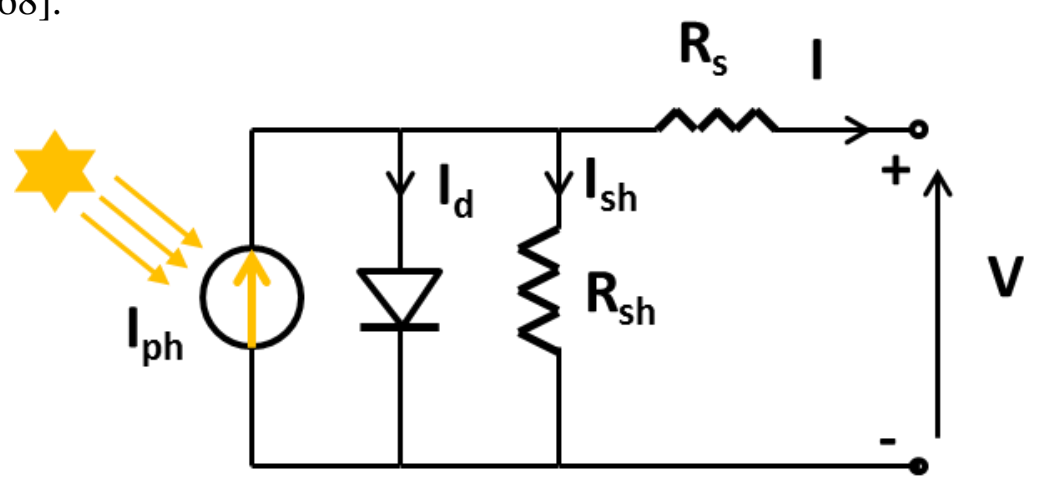

Figure 3.3. PV Panel equivalent circuit.

The current generated by the panel can be given as [53], [68]:

$$
I=I_{p h}-\mathrm{I}_{\mathrm{s}}\left(\exp \frac{\mathrm{q}\left(\mathrm{V}+R_{\mathrm{s}} \mathrm{I}\right)}{\mathrm{aKTN}_{\mathrm{s}}}-1\right)-\frac{\left(V+I R_{\mathrm{s}}\right)}{R_{\mathrm{sh}}}
$$

Where:

$$
I_{p h}=\left(\mathrm{I}_{\mathrm{SC}}+K_{i}(T-298.15)\right) \frac{G}{1000}
$$




$$
\mathrm{I}_{\mathrm{S}}=\frac{\mathrm{I}_{\mathrm{SC}}+K_{i}(T-298.15)}{\exp \left(\frac{q\left(V_{O C}+K_{V}(T-298.15)\right)}{a K T N_{S}}\right)-1}
$$

Based on equations (3.1)-(3.3), the physical behavior of the PV panel depends on the shunt and series resistances, solar irradiation and temperature. Hence, in order to predict and analyze the effect of these parameters on the PV characteristics, the model of the PV panel should be previously studied and achieved, and this model should be in accordance with the real comportment of the PV panel.

\section{MATLAB/Simulink Based Modelling of Photovoltaic Panel}

\subsection{Extract the lacked parameters of a PV panel}

In this study, the MSX-60 panel is used, and as shown in Table 3.1, manufacturers of PV panel offer only some parameters. Hence, several parameters mandatory for modeling PV panel are missed in the manufacturers' specification, namely the diode saturation current, the light-generated current, the diode ideality factor and the series and shunt resistances. Therefore, many researchers have worked on the adjustment of these parameters [57]-[59], actually thanks to Mathworks that provides in the new version of Simulink (2016) a tool (PV Array) that can help us to extract these parameters [60]. Therefore, as shown in Figure 3.4, once the parameters mentioned in manufacturer specifications are provided to this tool, the latter adjusts and displays the missing parameters.

Table 3.1. Specifications of Solarex MSX-60 PV panel at STC.

\begin{tabular}{|l|c|}
\hline Characteristics & MSX-60 \\
\hline Maximum power, Pmax & $60 \mathrm{~W}$ \\
\hline Voltage at Pmax, Vmp & $17.1 \mathrm{~V}$ \\
\hline Current at Pmax, Imp & $3.5 \mathrm{~A}$ \\
\hline Short-circuit current, Isc & $3.8 \mathrm{~A}$ \\
\hline Open-circuit voltage, Vco & $21.1 \mathrm{~V}$ \\
\hline $\begin{array}{l}\text { Temperature coefficient of } \\
\text { open-circuit voltage Voc, } \mathbf{K v}\end{array}$ & $-80 \mathrm{mV} /{ }^{\circ} \mathrm{C}$ \\
\hline $\begin{array}{l}\text { Temperature coefficient of } \\
\text { short-circuit current Isc, } \mathbf{K i}\end{array}$ & $2.4 \mathrm{~mA} /{ }^{\circ} \mathrm{C}$ \\
\hline The number of cells & 36 \\
\hline
\end{tabular}




\begin{tabular}{|c|c|c|}
\hline Parameters Advanced & & \\
\hline \multirow{2}{*}{\multicolumn{2}{|c|}{$\begin{array}{l}\text {-Array data } \\
\text { Parallel strings }\end{array}$}} & Display I-V and P-V characteristics of ...- \\
\hline & & array @ 1000 W/m2 \& specified temperatures \\
\hline \multicolumn{2}{|l|}{1} & \\
\hline \multicolumn{2}{|l|}{ Series-connected modules per string } & - \\
\hline \multicolumn{2}{|l|}{1} & Plot \\
\hline \multicolumn{2}{|l|}{ Module data- } & Model parameters - \\
\hline \multicolumn{2}{|l|}{ Module: User-defined } & Light-generated current IL (A) \\
\hline Maximum Power (W) & Cells per module (Ncell) & 3.8128 \\
\hline 59.85 & 36 & Diode saturation current I0 (A) \\
\hline Open circuit voltage Voc (V) & Short-circuit current Isc (A) & $2.5245 e-10$ \\
\hline 21.1 & 3.8 & Diode ideality factor \\
\hline & & 0.97484 \\
\hline Voltage at maximum power point Vmp (V) & Current at maximum power point $\operatorname{Imp}(\mathrm{A})$ & Shunt resistance Rsh (ohms) \\
\hline 17.1 & 3.5 & 153.5644 \\
\hline Temperature coefficient of Voc (\%/deg.C) & Temperature coefficient of Isc (\%/deg.C) & Series resistance Rs (ohms) \\
\hline-0.38 & 0.065 & 0.38572 \\
\hline
\end{tabular}

Figure 3.4. The tool provided by Mathworks.

\subsection{Simulink model of PV panel}

Based on the equations (3.1), (3.2) and (3.3), below is the model developed by Matlab/Simulink tool:

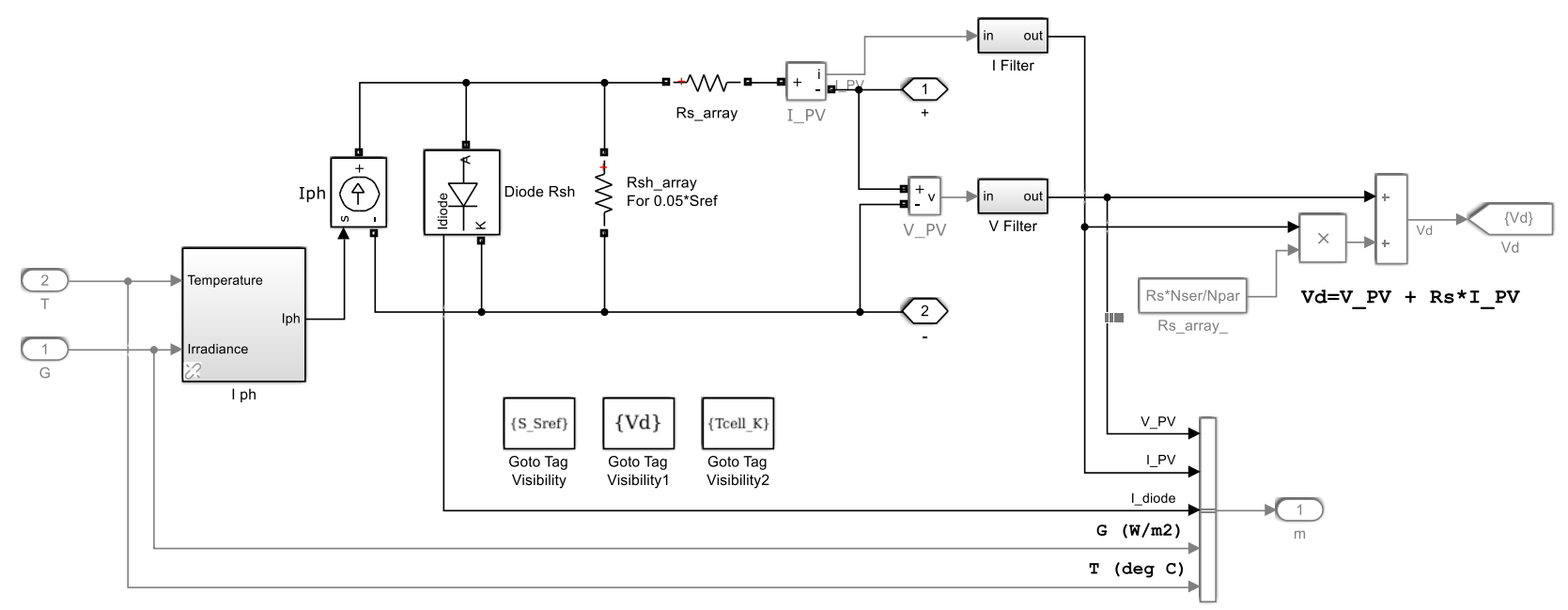

Figure 3.5. Simulink model of PV panel.

Figure 3.6 presents the I-V and P-V curves obtained by the PV Panel Simulink model. 

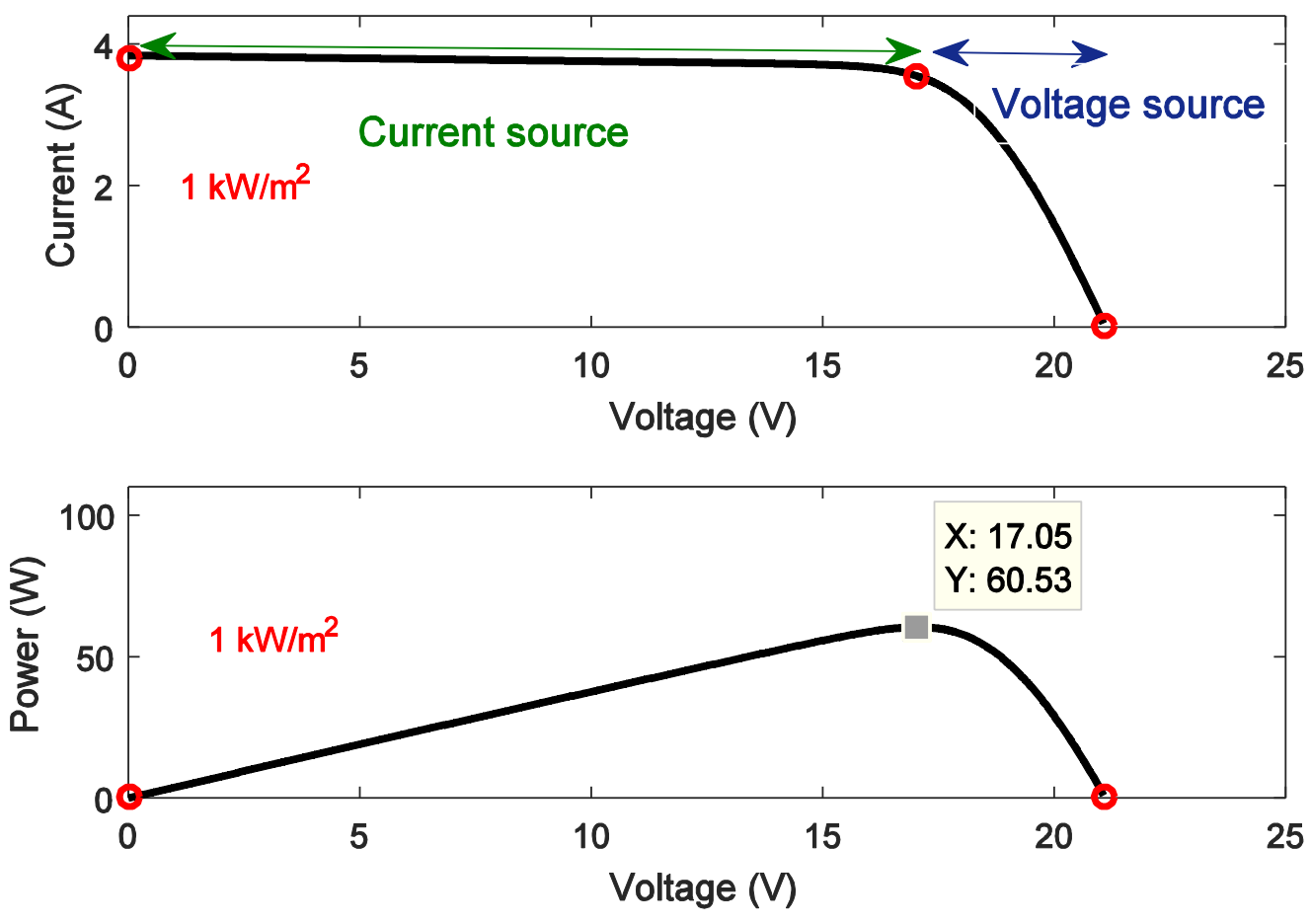

Figure 3.6. I-V and P-V curves of MSX-60 PV panel.

As presented in P-V curve (Figure 3.6), the point where the power drawn from the panel is the highest is called MPP. This characteristic is depending on the temperature and solar irradiation. Also, the own characteristic of the load is usually different from the MPP. Therefore, the MPPT controller is used to remove this mismatch between the load and MPP. Thus, to operate the PV panel at this point, the Boost converter controlled by the MPPT algorithm is inserted between the PV panel and the load [69].

\section{PSIM Based Modelling of Photovoltaic Panel}

\subsection{PSIM model of PV panel}

Equations (3.1)-(3.3) are modeled using PSIM tool, and Figure 3.7 presents the PSIM model.

Figure 3.8 shows the I-V and P-V curves of experimental and PSIM model under STC. The experimental data P (V) and I (V) are got from the manufactured datasheet [70]. And as presented, the model data are in accordance with the experimental data both in the current and power curves.

Based on equations (3.1)-(3.3), the physical behavior of the PV panel depends on the shunt and series resistances, solar irradiation and temperature. Therefore, in this chapter, the impact of these parameters on the output of the PV panel is investigated. 

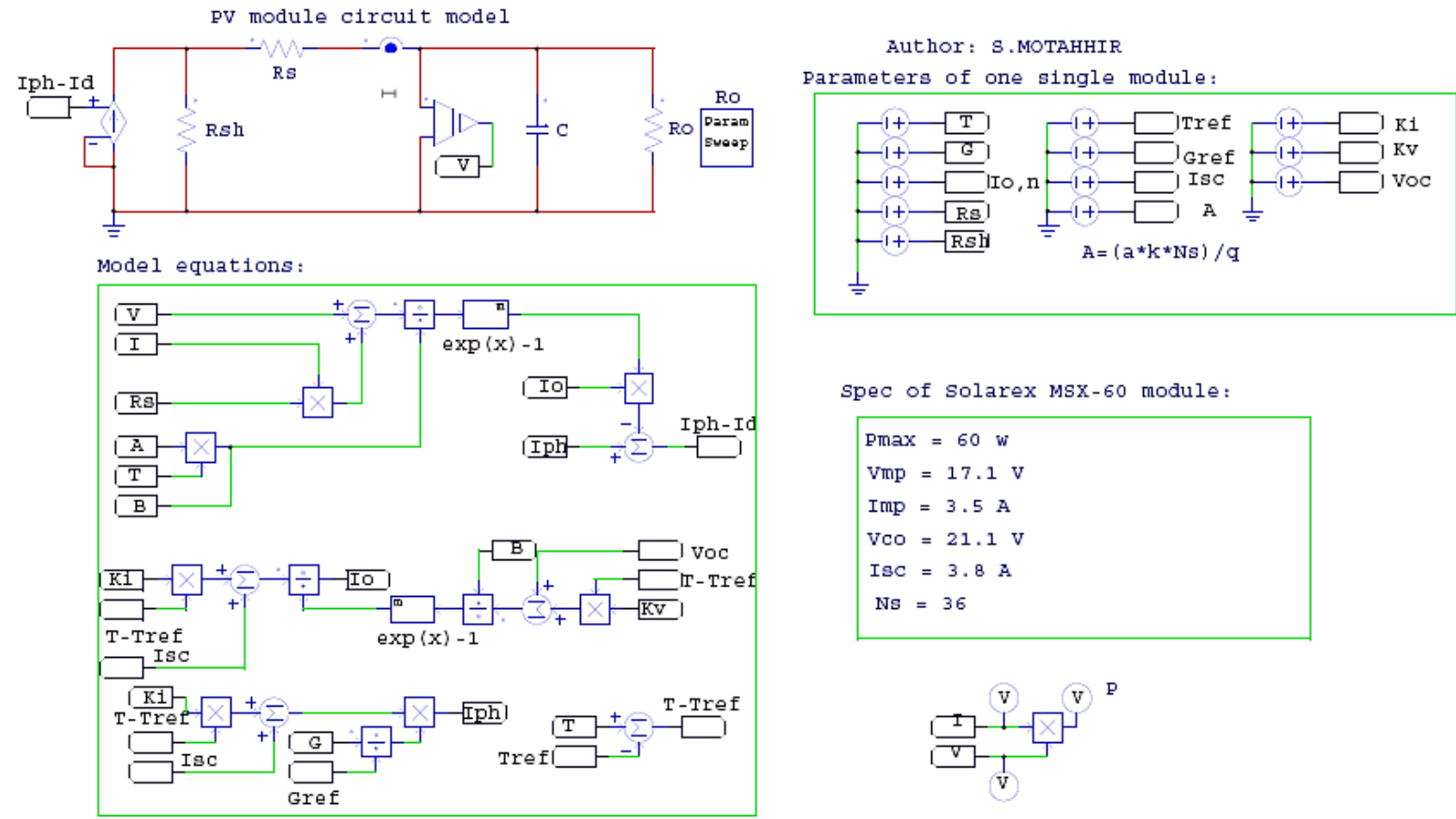

Figure 3.7. PV panel PSIM model.
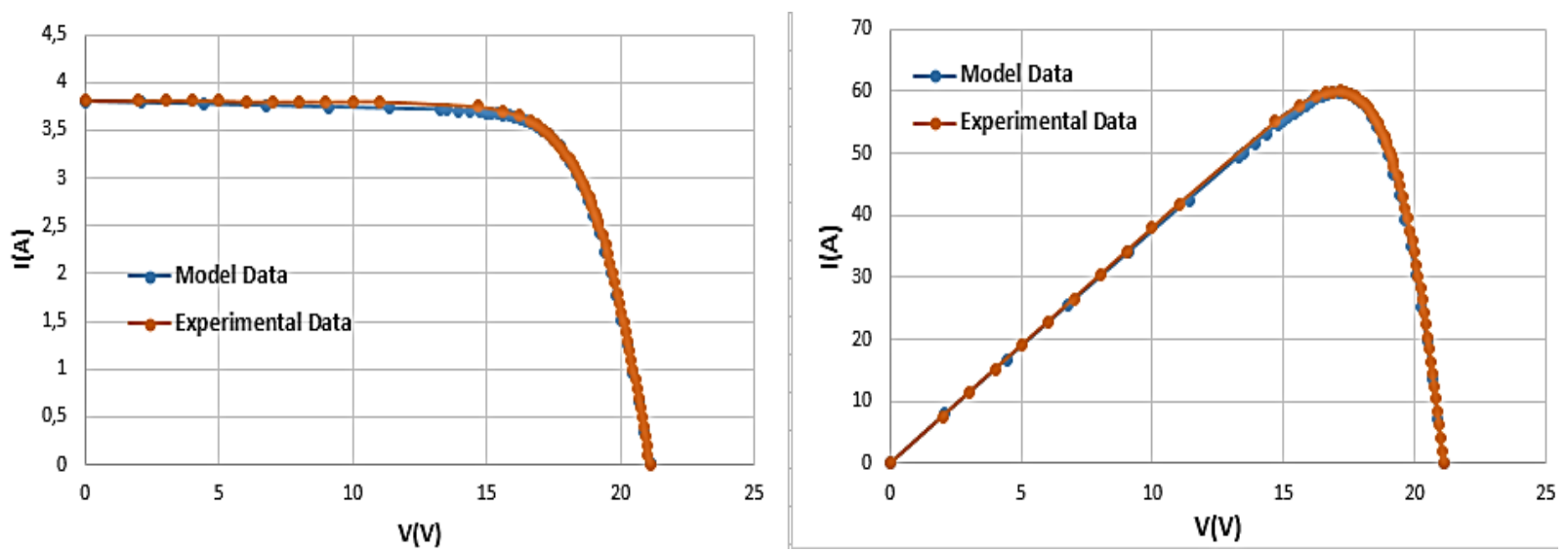

Figure 3.8. I-V and P-V characteristics of model and experimental data.

\subsection{Effect of solar irradiation variation}

Figure 3.7 contains the model of the three equations: one of these equations computes the photocurrent based on temperature and irradiance (equation (3.2)). The model of this equation is presented in Figure 3.9, and Figure 3.10 shows I-V and P-V curves of different solar irradiation values. 


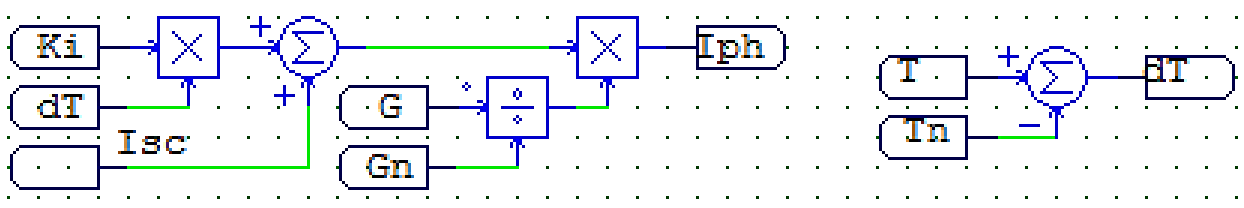

Figure 3.9. Model of the equation (3.2).
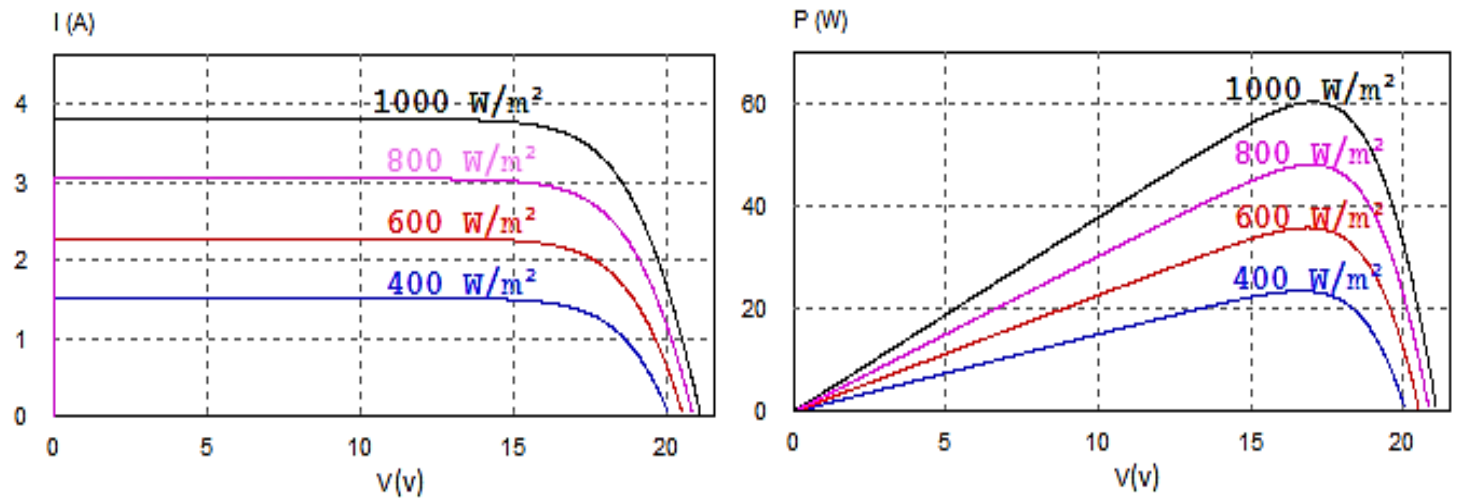

Figure 3.10. I-V and P-V characteristics for different values of irradiance.

As presented in Figure 3.10, the PV panel current depends heavily on solar irradiation. However, the voltage increases just by $1 \mathrm{~V}$ once the irradiance is increased from $400 \mathrm{~W} / \mathrm{m}^{2}$ to 1000 $\mathrm{W} / \mathrm{m}^{2}$. Therefore, the irradiance change affects heavily the PV panel current.

\subsection{Effect of the temperature variation}

Figure 3.7 also contains the modeling of the equation (3.3), which computes the diode saturation current based on the temperature. The model of this equation is shown in Figure 3.11, and Figure 3.12 shows the I-V and P-V characteristics for different values of temperature.

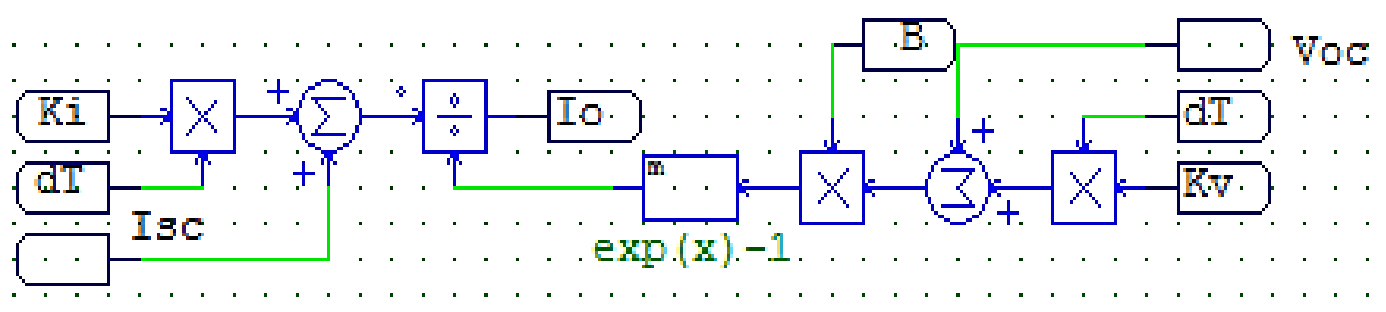

Figure 3.11. Model of equation (3.3).

Generally, as shown in Figure 3.12, for a fixed solar irradiation and when the temperature increases, the open-circuit voltage decreases and the short-circuit current increases with a little value. Therefore, the temperature change affects strongly the PV panel voltage. 

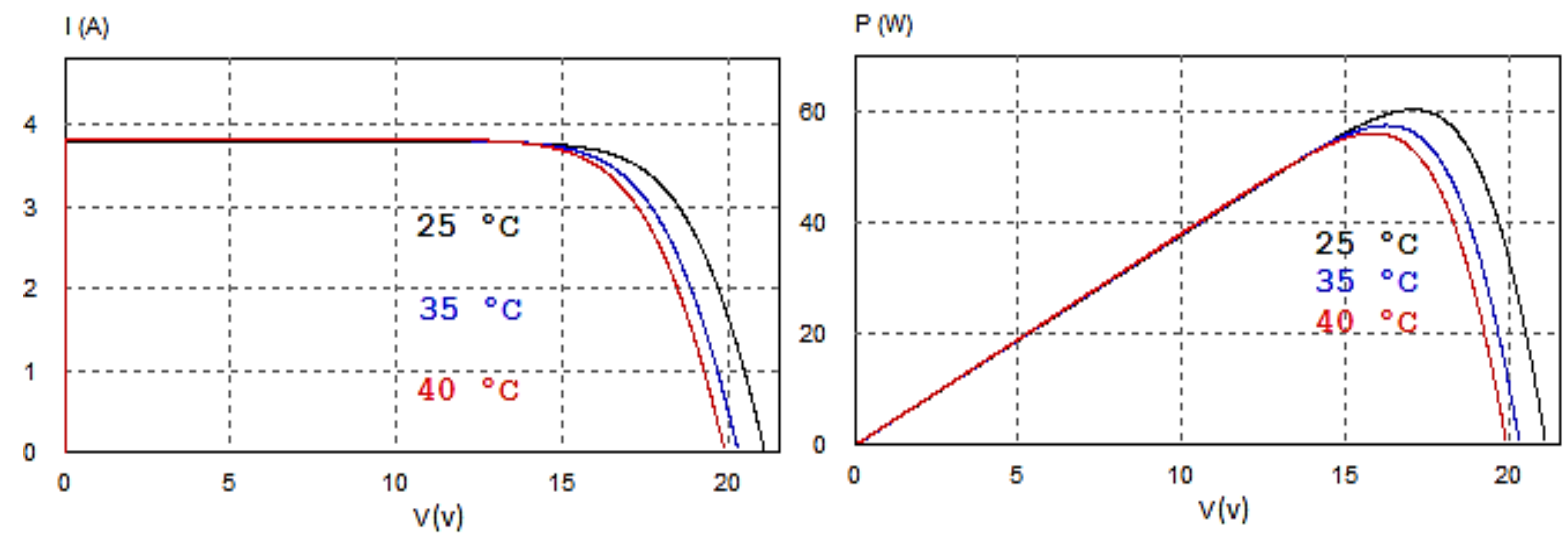

Figure 3.12. I-V and P-V curves for different values of temperature.

\subsection{Effect of series resistor variation}

The series resistor value is very small and it may be neglected in some cases. Nevertheless, to make the appropriate model for any PV panel, it is recommended to make a variation of this resistor and show its effect on the PV panel output. As shown in Figure 3.13, the change of the series resistor results on the deviation of the MPP.
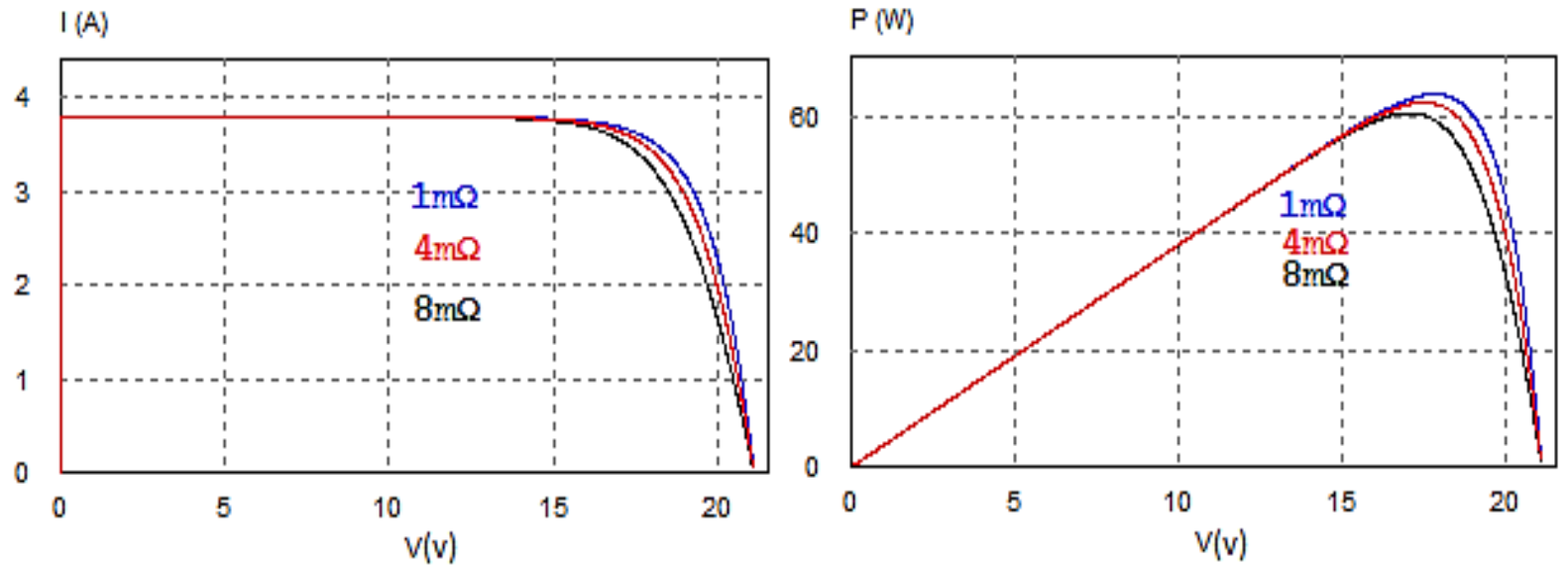

Figure 3.13. I-V and P-V curves for different values of $\mathbf{R}_{\mathbf{s}}$.

The simulation was made for three values of series resistance $(1 \mathrm{~m} \Omega, 4 \mathrm{~m} \Omega$, and $8 \mathrm{~m} \Omega$ ). Moreover, as shown in Figure 3.13, the upper values of series resistance decrease the output power. In addition, the fill factor presented by the equation (3.4) decreases as series resistance increases [71].

$$
F F=\frac{\mathrm{P}_{\max }}{\mathrm{V}_{\mathrm{oc}} I_{S C}}
$$




\subsection{Effect of shunt resistor variation}

As presented in Figure 3.14, the $R_{\text {sh }}$ should be quite large for a good fill factor. In fact, when $R_{S h}$ is small, the current collapses more strongly, then the loss of power is high and the fill factor is low. Therefore, the $R_{s h}$ of any PV panel should be large enough for an excellent efficiency.
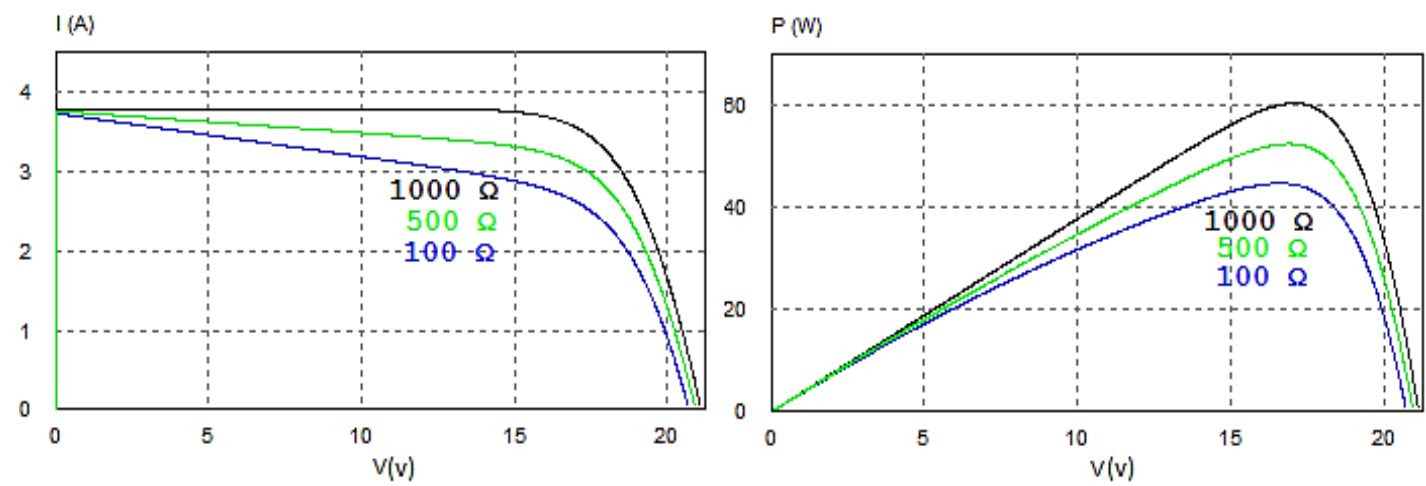

Figure 3.14. I-V and P-V curves for different values of $\mathbf{R}_{\mathbf{s h}}$

\subsection{Effect of shading}

Partial shading also presents a significant impact on PV output power. When the insolation received by a part of the PV panel (shaded cells) is less than the insolation received by another part (illuminated cells). Therefore the current generated by the illuminated cells is higher than the current produced by the shaded cells, this mismatch makes the diode of shaded cells reverse biased. As a result, the power will be lost in the shaded cells and that may cause a HOT SPOT problem which is the reason for permanent damage to the PV panel [14]. Hence to overcome this problem, the bypassdiodes can be connected in parallel with PV cells [14].

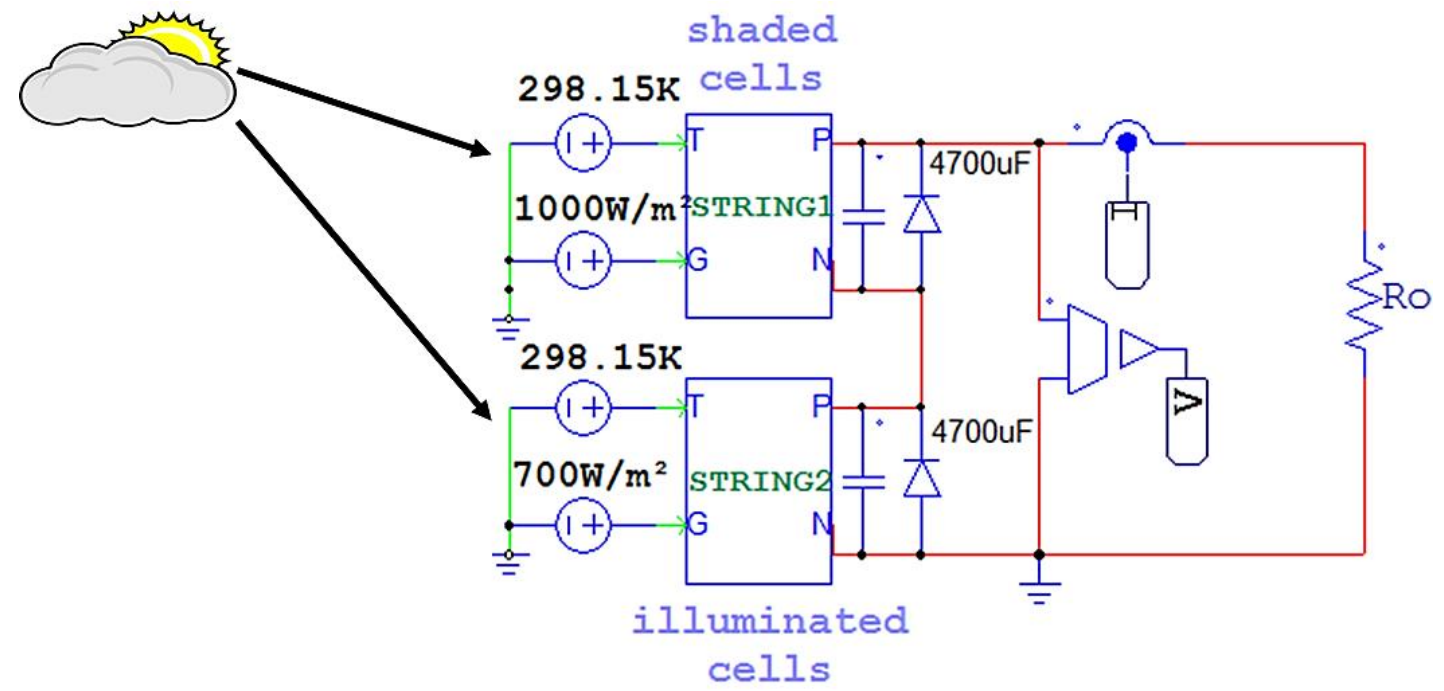

Figure 3.15. PV panel under non-uniform irradiation. 
To simulate the effect of shading, a bypass-diode is associated with each string of the panel, and it should be mentioned that the panel used includes two strings and each string is a set of 18 cells. Thus, as shown in Figure 3.15, the first string is exposed by $1000 \mathrm{~W} / \mathrm{m}^{2}$ and the second string by 700 $\mathrm{W} / \mathrm{m}^{2}$.

Under uniform irradiation, the bypass diodes have no impact because they are reverse biased. But under shading, the current flows through the diode instead of the shaded string because the bypass diode is directly biased. As a result, no power will be lost in the shaded cells and only the illuminated cells generate power. Figure 3.16 shows the effect of bypass diodes on the PV panel characteristics and as presented multiple peaks may occur on the P-V curve, there are two peaks, point $\mathrm{A}$ which is the global peak and point B which is the local peak. Therefore, conventional MPPT algorithms are unable to track the global peak which is real MPP [14].
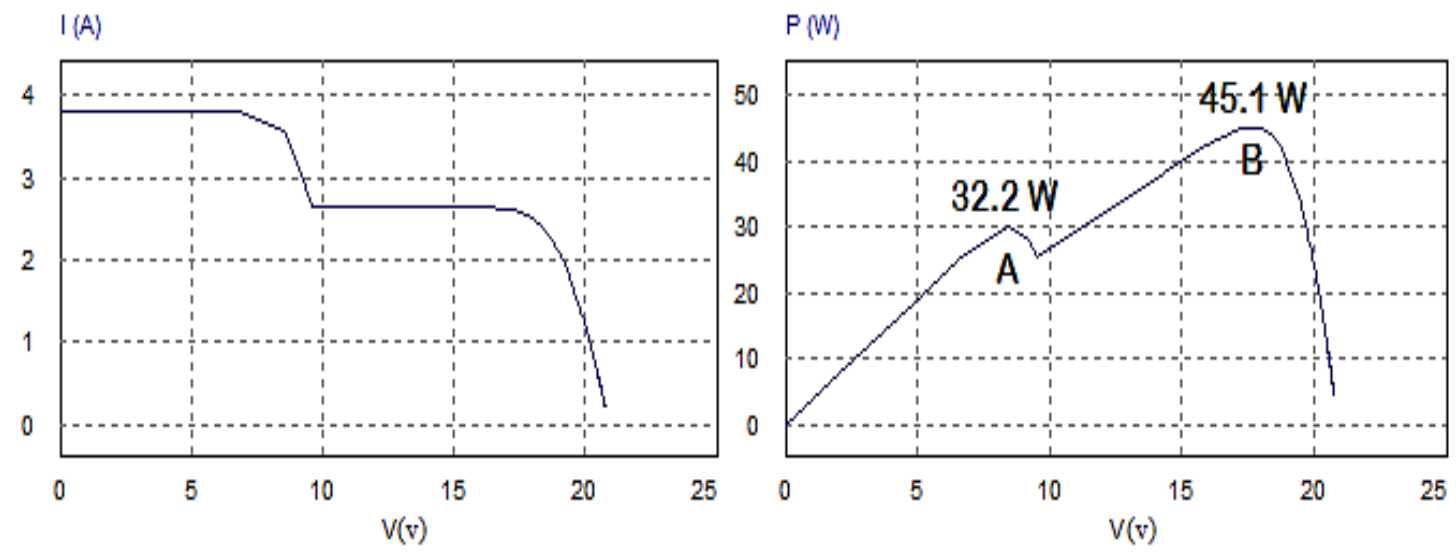

Figure 3.16. I-V and P-V characteristics of the PV panel under non-uniform irradiation.

\subsection{Photovoltaic Array}

To get benefit from the model developed, a PV array of 18 PV panels has been built to supply a Solar pumping station, not studied in this thesis. Therefore, as shown in Figure 3.17, three strings of six PV panels have been linked in parallel and each group is composed of six panels in series.

The model of the PV array has been achieved on PSIM, and simulation result obtained is presented in Figure 3.18. 

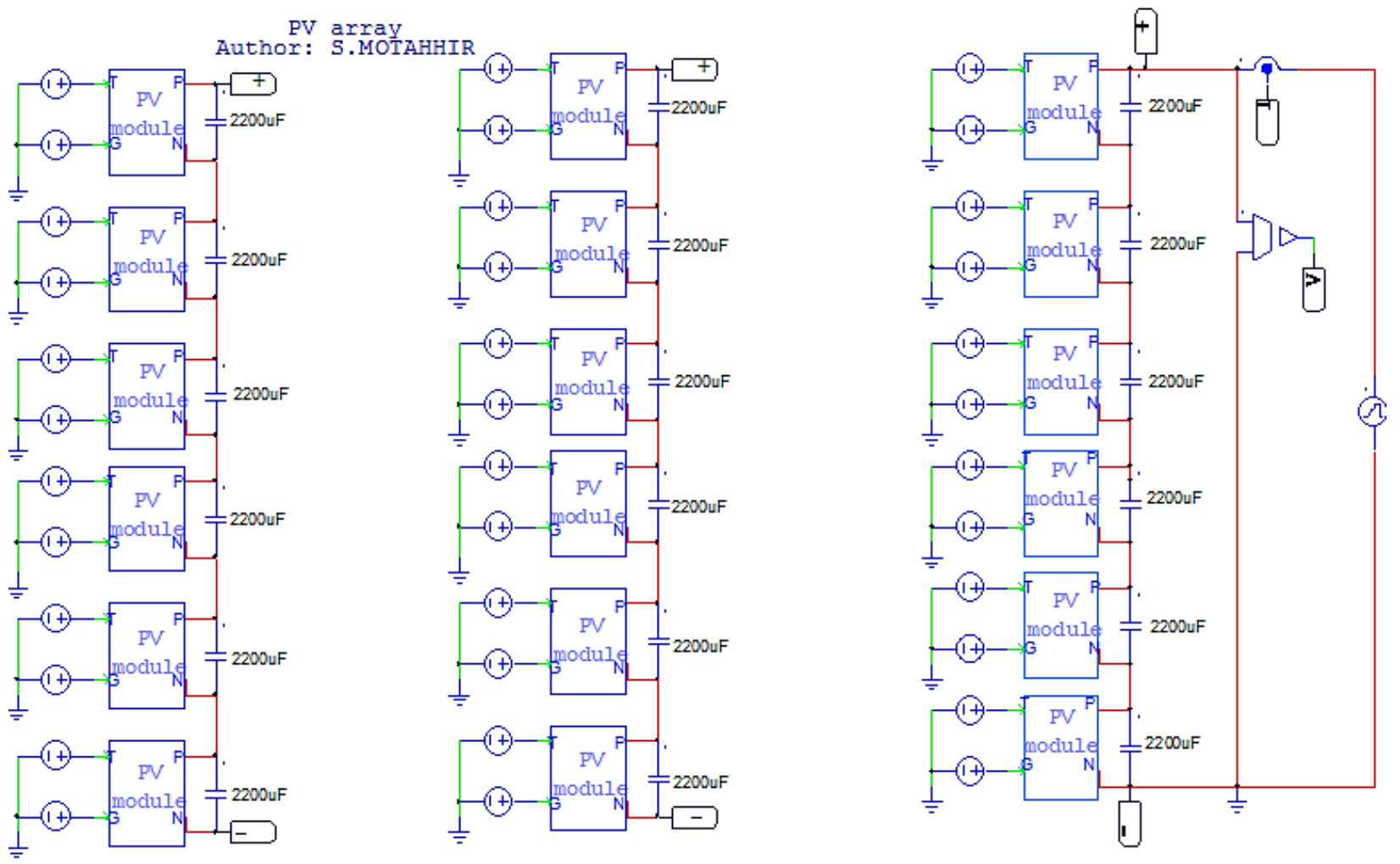

Figure 3.17. PV Array model.
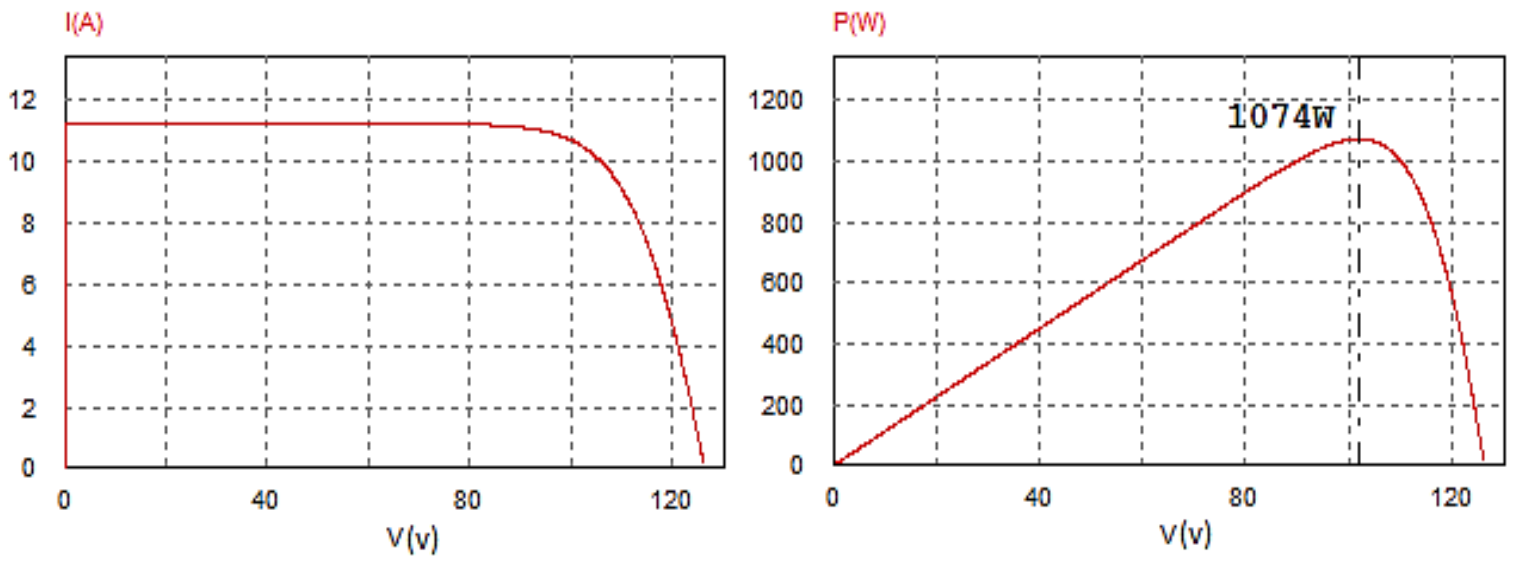

Figure 3.18. I-V and P-V curves of the PV Array.

As presented in Figure 3.18, the panels connected in parallel increase the current and the panels connected in series increase the voltage. However, as discussed in the previous section, this connection between panels can lead to HOT-SPOT problem when the insolation received by a part of the PV array (shaded panels) less than the insolation received by another part (illuminated panels).

\section{Proteus Based Modelling of Photovoltaic Panel}

\subsection{Proteus model of PV panel}


A PV panel is a device that can convert light from the sun into electrical energy by the photovoltaic effect. As presented in Figure 3.3, the equivalent circuit of the PV panel includes a current generator $I_{P h}$ connected in parallel with a diode that emulates the P-N junction, as well as a shunt resistor $R_{s h}$ and a series resistor $R_{S}$. Therefore, for modeling the PV panel in Proteus, its equivalent circuit is designed using a voltage-controlled current source, a diode with a Spice code based on the PV panel datasheet, and two resistances to model the shunt and the series resistors. Figure 3.19 shows the Proteus model and Spice code. Thus, Figure 3.20 presents the steps followed. The TDC-M20-36 panel is employed in this thesis and table 3.2 shows its characteristics.

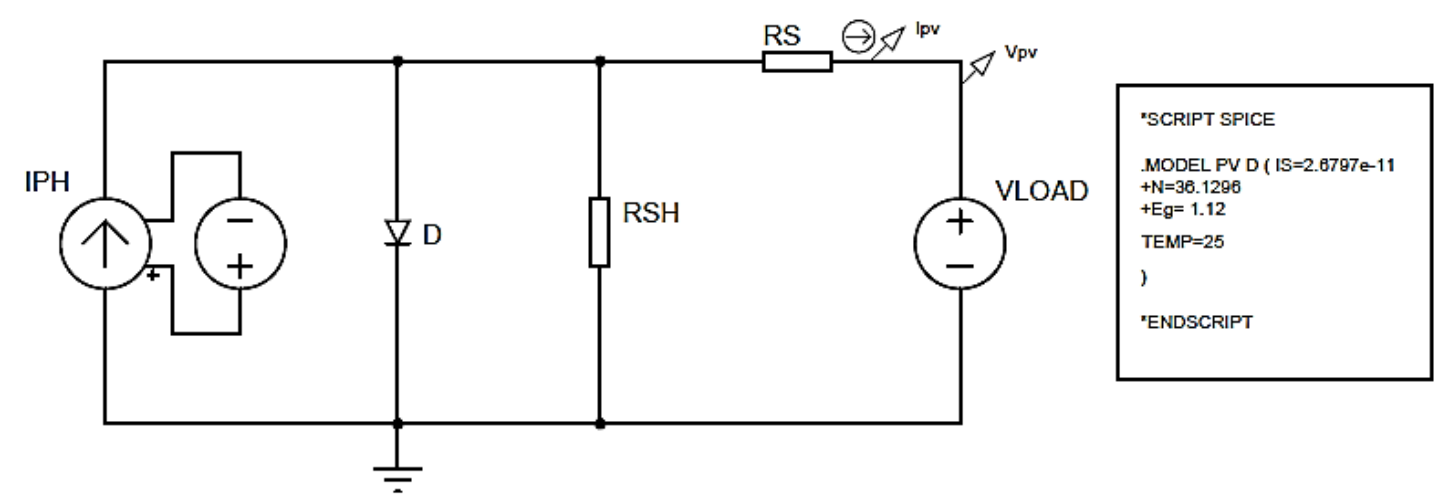

Figure 3.19. PV panel Proteus model.

Table 3.2. The TDC-M20-36 panel characteristics at STC.

\begin{tabular}{|l|c|}
\hline Characteristics & TDC-M20-36 \\
\hline Maximum power, $P_{\max }$ & $20 \mathrm{~W}$ \\
\hline Voltage at Pmax, $V_{m p}$ & $18.76 \mathrm{~V}$ \\
\hline Current at Pmax, $I_{m p}$ & $1.07 \mathrm{~A}$ \\
\hline Short-circuit current, $I_{S C}$ & $1.17 \mathrm{~A}$ \\
\hline Open-circuit voltage, $V_{O C}$ & $22.7 \mathrm{~V}$ \\
\hline $\begin{array}{l}\text { Temperature coefficient of } \\
\text { open-circuit voltage } V_{O C}, K_{v}\end{array}$ & $-0.35 \% /{ }^{\circ} \mathrm{C}$ \\
\hline $\begin{array}{l}\text { Temperature coefficient of } \\
\text { short-circuit current } I_{S C}, K_{i}\end{array}$ & $0.043 /{ }^{\circ} \mathrm{C}$ \\
\hline The number of cells & 36 \\
\hline Light-generated current $I_{p h}$ & $1.173 \mathrm{~A}$ \\
\hline Diode saturation current $I_{S}$ & $2.6797 \mathrm{e}-11 \mathrm{~A}$ \\
\hline Ideality factor & 1.0036 \\
\hline Shunt Resistance $R_{S h}$ & $405.96 \Omega$ \\
\hline Series Resistance $R_{S}$ & $1.0547 \Omega$ \\
\hline
\end{tabular}




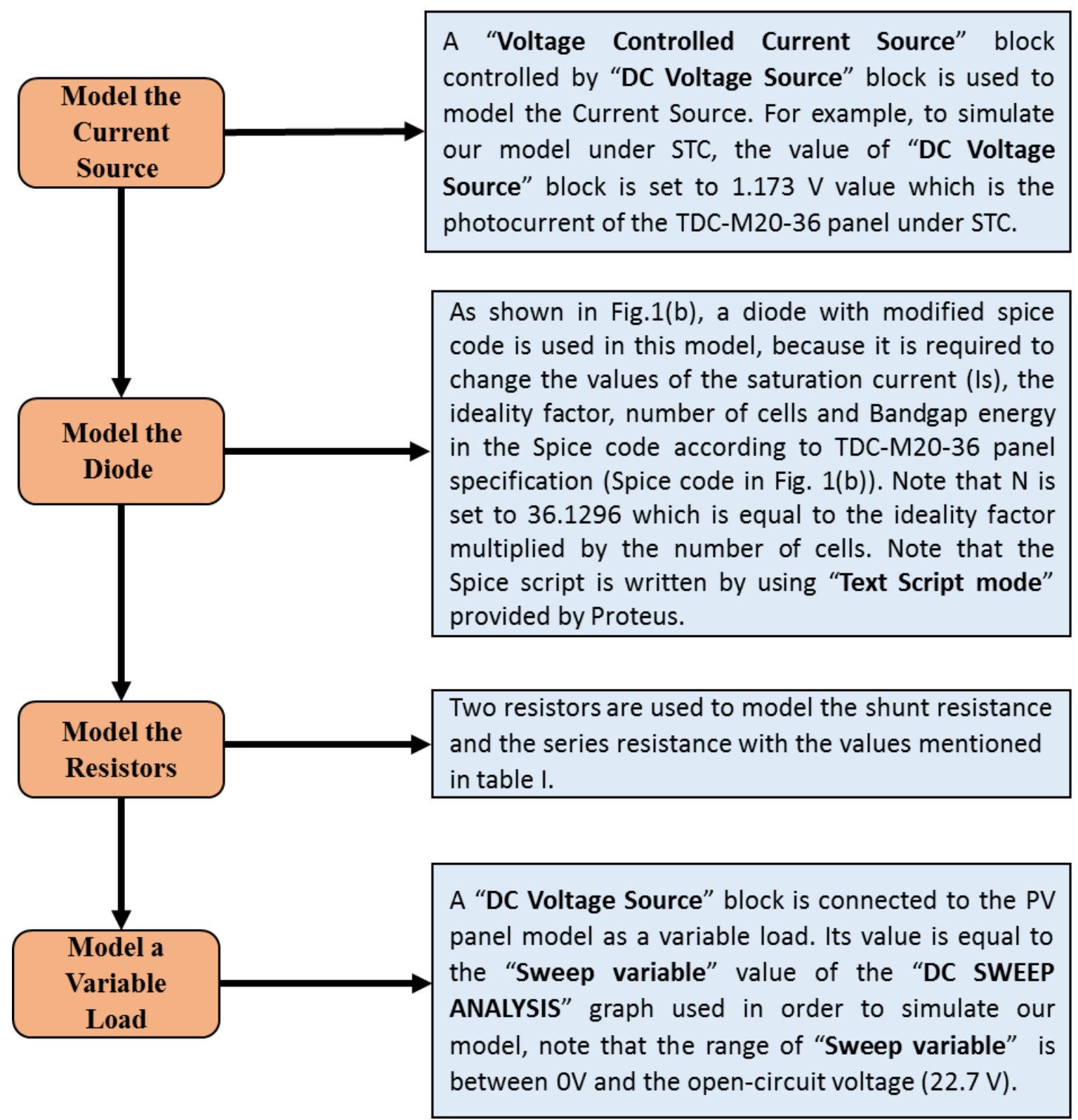

Figure 3.20. Steps for modeling PV Panel.

\subsection{Experimental validation of the Proteus model of PV panel}

In order to validate the Proteus model, the test bench of Figure 3.21 was used. It consists of a PV panel, a variable load, a Pyranometer to measure the solar radiation, a Multimeter to measure temperature, current and voltage sensors to measure PV current and voltage, and a computer to instrument the measured data by a virtual instrument made by LabVIEW tool. 


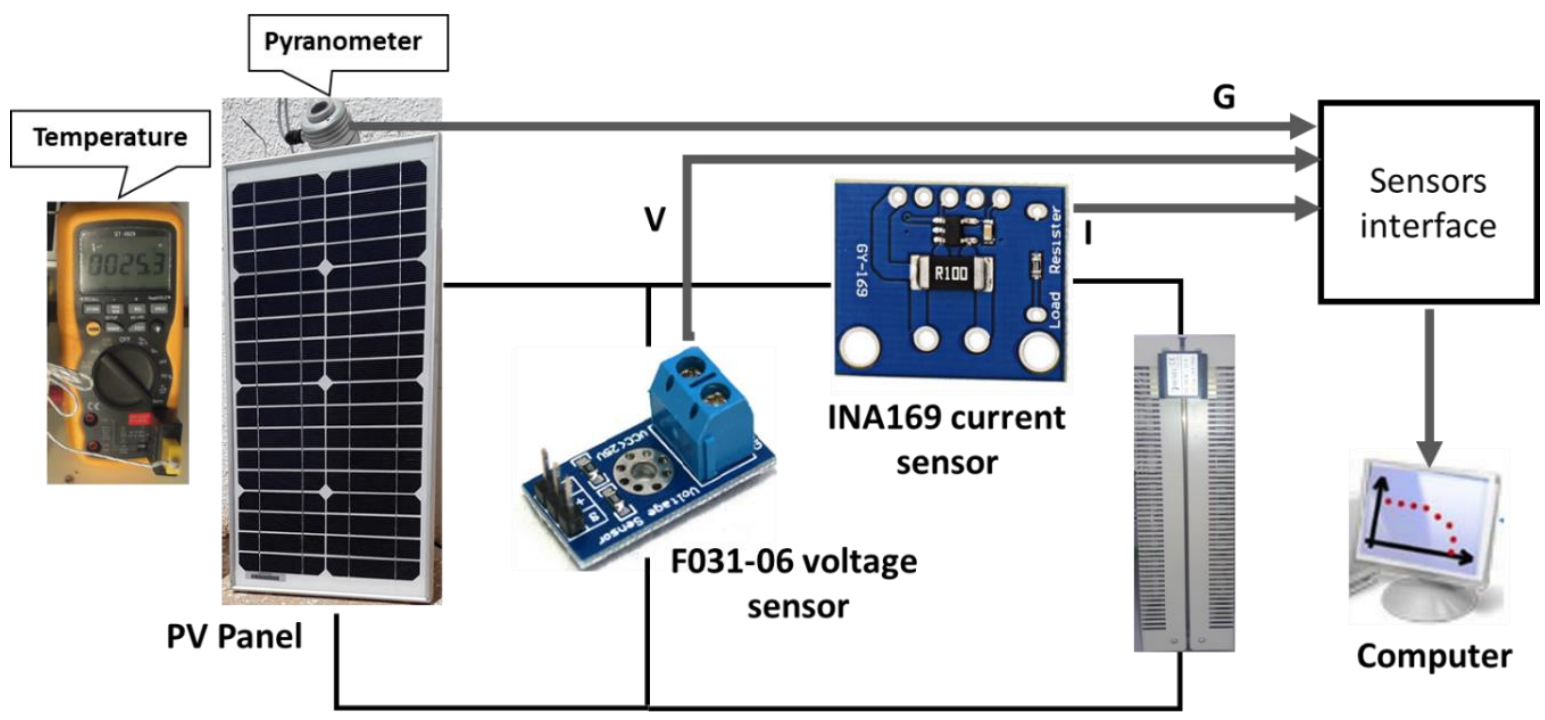

Figure 3.21. Measurement setup.
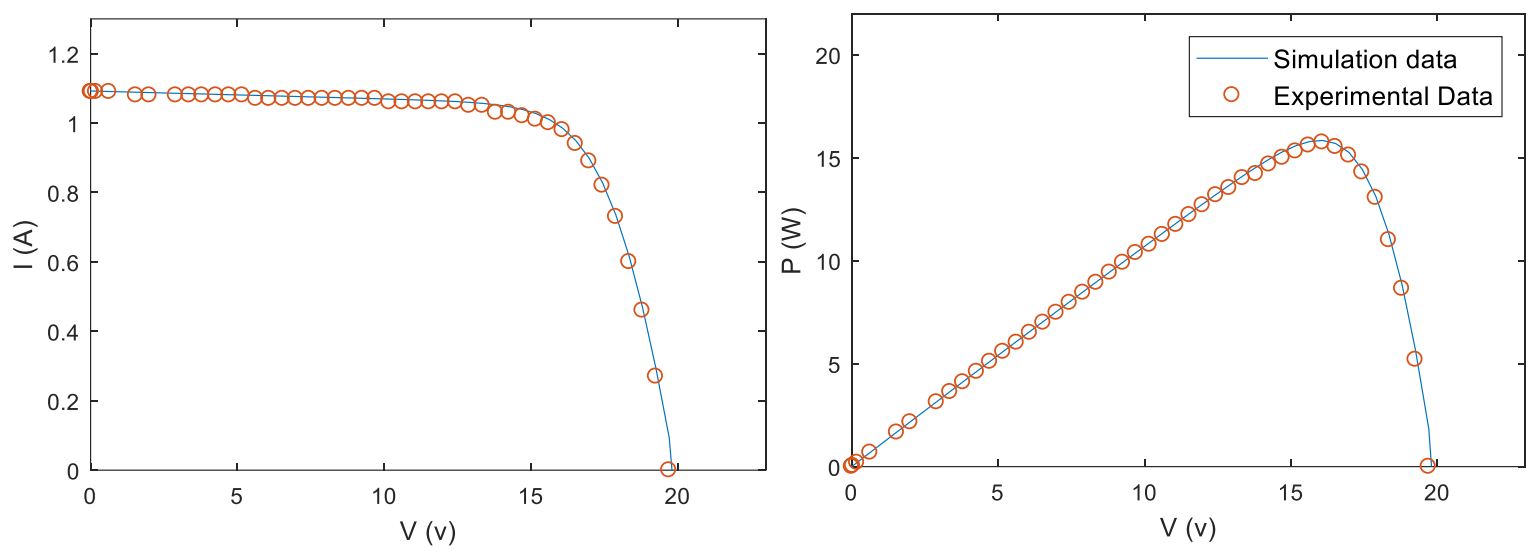

Figure 3.22. I-V and P-V model curves and experimental data.

Figure 3.22 shows the I-V and P-V characteristics obtained by the PV panel Proteus model and experimental data at $\mathrm{T}=59{ }^{\circ} \mathrm{C}$ and $\mathrm{G}=920 \mathrm{~W} / \mathrm{m}^{2}$. And as shown, the simulated data is in accordance with the experimental data both in the current and the power curves.

Once the PV panel is modeled and validated, and since Proteus provides in its library several microcontrollers, DSP, FPGA, and embedded boards as Arduino [53]. Therefore, this model can be used to design a PV system by implementing the MPPT algorithm in one of the controllers available in Proteus. Thus, it should be mentioned that the same MPPT C code implemented by Proteus will be used in the hardware test bench, and this is the advantage of Proteus in simulation compared to PSIM or Matlab/Simulink, because by using PSIM or Matlab we must rewrite the code of our algorithm once we start the hardware implementation. Hence, if our algorithm is tested in Proteus and 
it shows a good result, probably the hardware implementation will show the same result, due to the use of the same components in simulation and hardware implementation.

\section{Summary}

In this chapter, the PV panel's parameters are extracted using the Mathworks tool, hence by using these parameters a PV panel modeled on Matlab/Simulink and PSIM, and the results show that the model is in accordance with experimental data of used panel (MSX-60). In addition, A Proteus model of PV panel is developed and presented in this chapter, thus this model is validated by comparing its data with experimental data and consequently the model is in accordance with experimental data. As a result, this Proteus PV model and embedded boards available in Proteus can be used as a low-cost PV simulator to test the implementation of MPPT algorithm, this simulator makes future modifications on the system much more comfortable to achieve. 


\section{Chapter 4}

\section{Modified INC algorithm}

- Introduction

- MPPT system

- Modified Incremental Inductance algorithm for fast change of solar irradiance

- Low-cost PV system by using a proposed division-free Incremental conductance algorithm

- MIL and SIL and PIL Tests for a modified variable step size INC algorithm

- Summary 


\section{Introduction}

The maximization of the PV power always remains a significant challenge. Researchers have proposed different MPPT algorithms to maximize PV power, namely FSCC, FOCV, Fuzzy Logic, Neural Network, P\&O, and INC [10], [11]. FSCC and FOCV are the simplest MPPT algorithms, which are based on the linearity of short-circuit current or open-circuit voltage to the maximum power point current or voltage. However, these techniques isolate the PV panel to measure short-circuit current or open-circuit voltage. Therefore, the loss of energy is increased due to the periodic isolation of the panel [12]. On the other side, Fuzzy Logic and Artificial Neural Network are knowledge-based controllers where they require a detailed knowledge while implementing them. Fuzzy Logic and ANN are effective in tracking MPP and they obtain a consistent MPPT algorithm due to their ability to treat the nonlinearity of the PV Panel. But they require large memory for rules implementation (FLC) or training (ANN). In particular, the fuzzy logic method requires the designer to have some prior knowledge of how the output responds qualitatively to the inputs, and it suffers from a severe drawback that the rules cannot be changed, once it is defined. ANN presents many disadvantages like the fact that the data needed for the training process has to be specifically acquired for every PV panel and location, also the PV characteristics change with time, so the neural network has to be periodically trained. Hence, since the amount of training involved is quite high for this algorithm, it makes its implementation even more complex [13]. On the other hand, P\&O and INC are mostly used. These techniques use the (P-V) characteristic of the PV panel. For P\&O, steady-state oscillations occur after the MPP is found due to the perturbation made by this technique to maintain the MPP, which in turn increases the loss of power [14]. For INC, it is founded in the fact that slope of P-V characteristic is zero at the maximum power, and theoretically, there is no perturbation after the MPP is found. Therefore, oscillations are minimized. However, during the implementation, the zero value is hardly found on the slope of the P-V characteristic due to the truncation error in digital processing. Thus the INC technique can make an incorrect response when the irradiation is suddenly increased [15]. Therefore in this chapter, we will present and implement a modified INC algorithm, which can overcome the wrong response made by the conventional INC algorithm when the irradiance is suddenly increased. Therefore, this thesis presents an improved technique to detect the increase in solar irradiation. The variation of voltage $(\Delta \mathrm{V})$ and current $(\Delta \mathrm{I})$ are used to identify the increase in radiation instead of the slope $(\Delta \mathrm{P} / \Delta \mathrm{V})$ of the $\mathrm{P}-\mathrm{V}$ characteristic. The modified algorithm detects the increase of irradiance and makes a correct decision. Moreover, a mini error is accepted to admit that the slope is near to zero and minimize the steady-state oscillations. Nevertheless, INC is more complicated in structure compared to $\mathrm{P} \& \mathrm{O}$ since it contains several mathematical divisions that 
complicate the calculation process and require a stronger microcontroller which reduces the opportunity to use a low-cost development board [16]. Therefore, P\&O algorithm is extensively employed in PV autonomous systems for its simplicity [17]-[19]. In this kind of PV systems, it is preferred to implement MPPT algorithms by using a low-cost microcontroller to reduce the system cost. Thus, the P\&O algorithm, being an algorithm with no arithmetic-division [20]-[24], is a suitable choice to be implemented by a low-cost microcontroller. However, based on the above-mentioned analysis, INC is capable of tracking the MPP correctly with less steady-state oscillations and faster response when compared to $\mathrm{P} \& \mathrm{O}$ algorithm [25]-[28]. Therefore also in this chapter, the INC algorithm is modified by eliminating all division computations and make the algorithm structure simpler. This decreases the real-time processing which in turn enables the algorithm to be easily implemented by a low-cost embedded system. Hence, the modified algorithm is implemented by using Arduino Uno board in which the low-cost Atmega328 microcontroller is integrated; as a result, reduce the system cost.

On the other hand, to improve the efficiency of MPPT algorithm, a variable step-size is used [14]. However, this variable step can show poor performance in case of sudden irradiance variation. In addition, it can increase steady-state power oscillations [29]. Therefore, a modified variable stepsize is presented in this chapter. Then we offer guidelines to develop MPPT controller as automotive and aeronautical embedded systems are developed, by following the V-cycle development process, which means that our controller will be validated by using "Model In the Loop/ Software In the Loop/ Processor In the Loop" tests. In this sense, integrating the MPPT embedded system in the automotive or the aeronautical area will possible, and on the other hand to propose a low-cost option to test the hardware implementation of the MPPT algorithm. Therefore, the Model-based design of the modified variable step INC algorithm is developed and connected to the plant model (photovoltaic panel and Boost converter). Next, the system model is tested and validated by using "Model In the Loop" process. After that, the software of this algorithm is automatically generated for the host computer using embedded coder tool, and this software is connected to the plant model and tested using "Software In the Loop" process in the host computer. Finally, the software is generated from the MPPT model for the STM32F4 discovery board in order to create the Processor In the Loop block, which will be run in the STM32F4 discovery board, and the plant model will be simulated in the host computer, and the ST-LINK communication is used in order to connect the host computer and the embedded board.

\section{MPPT system}




\subsection{Need of MPPT controller}

PV panel provides I-V and P-V curves presented in Figure 4.1, these curves highlight one point where the power is maximum. As presented above, this point depends on solar irradiation and temperature. Moreover, as presented in Figure 4.1, in general, the load's characteristic is different from the MPP. Therefore, the Boost converter controlled by a duty cycle $(\alpha)$ generated by the MPPT controller is put between the panel and the load [16]. The interest of this addition is to remove the impedance mismatch between the panel and the load, and then the PV panel can operate at MPP.

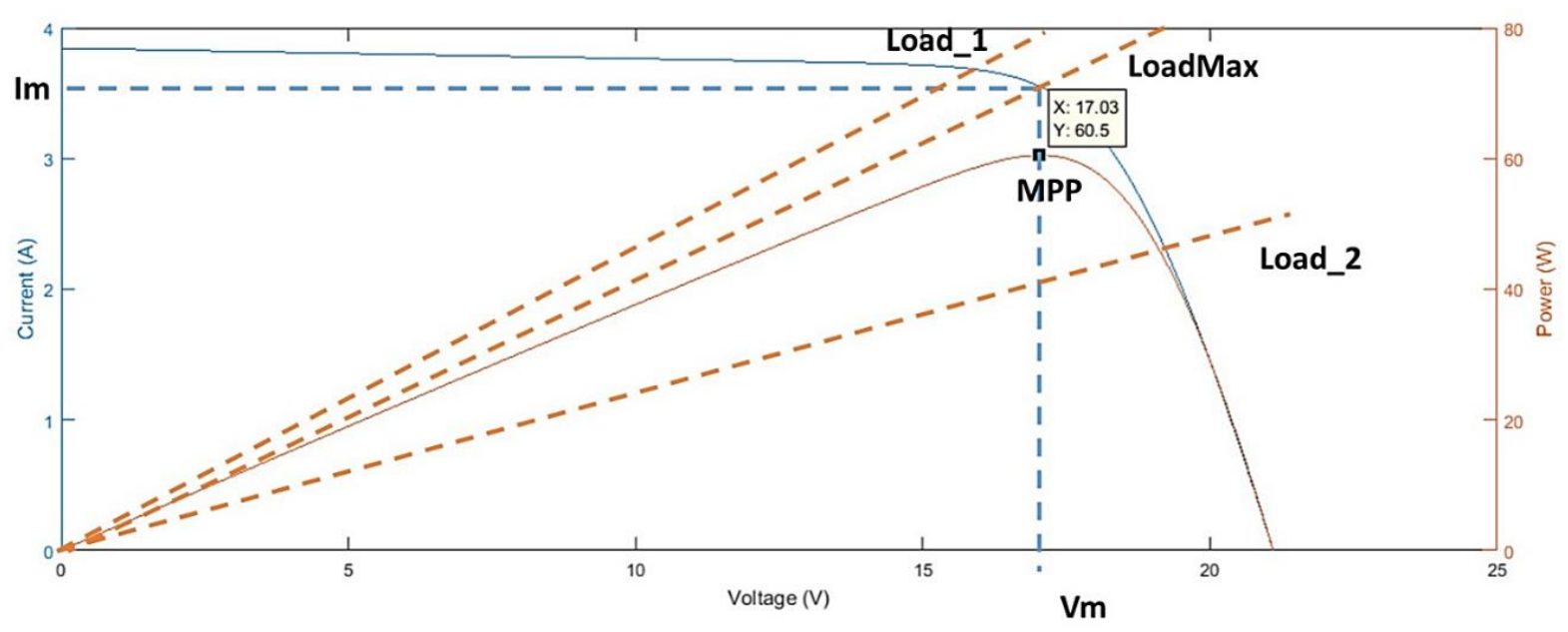

Figure 4. 1. The impact of load on I-V and P-V characteristics.

\subsection{Boost converter design}

It should be mentioned that the PV energy is not like a conventional energy source because in a conventional energy source, energy which is not delivered to the load is not consumed and remains in the source, in PV energy source the energy is wasted since it is available for free. Thus by using the Boost converter, current flows constantly into the input port due to the use of parallel switch in its topology, however by using Buck converter for example, there are times where current is not flowing into the input port due to the use of series switch. As a result, the energy is not delivered to the load when the switch is open and the energy is wasted since it is available for free. Hence, in PV system, the energy efficiency of the Boost converter may be higher than of the Buck converter [69].

The Boost converter is required to convert DC voltage $(V)$ to another DC voltage $\left(V_{o}\right)$. As shown in Figure 4.2, this converter contains a MOSFET switch, which is controlled by PWM signal. Once the switch is ON, the inductor stores energy from the PV panel, Moreover, the reverse-biased diode detaches the output from the PV generator and output capacitor provides current to the load. However, if the switch is OFF, the inductor is in a discharged state and the forward-biased diode 
connects the output to PV generator. The PV panel voltage and inductor voltage (discharging state) contribute together for the output voltage; therefore, it is always higher than input voltage [72]-[75].

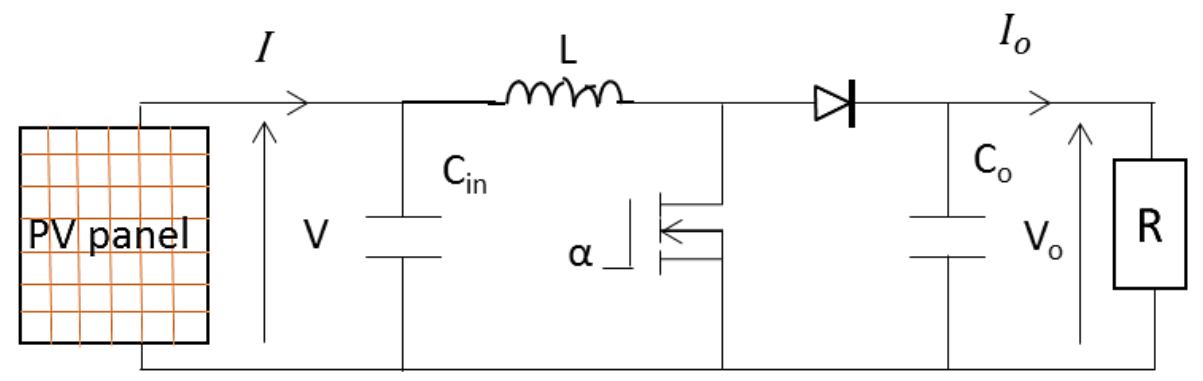

Figure 4. 2. Boost converter.

The operation principle of the Boost converter is described by the equations below [76]:

$$
\begin{gathered}
V_{O}=\frac{V}{(1-\alpha)} \\
I_{O}=I(1-\alpha)
\end{gathered}
$$

By using equations (4.1) and (4.2), equation (4.3) is obtained, which is the relationship between the resistance seen by the PV panel $\left(R_{e q}\right)$ and the load resistance $(R)$. Hence, based on this equation, the MPPT controller can find the optimum $\alpha$ to remove the mismatch between the load and MPP. Therefore, the boost converter is required to get maximum power available from the panel.

$$
R_{e q}=\frac{V}{I}=\frac{V_{O}(1-\alpha)^{2}}{I_{O}}=R(1-\alpha)^{2}
$$

\subsubsection{Selection of the inductor}

The choice of the inductor can directly influence the performance of the Boost converter. Moreover, the selection of the inductance is a trade-off between its cost, its size, and the inductor current ripple. A higher inductance value results in a minor inductance current ripple; however, that results in a higher cost and larger inductor's size, which means a larger PCB surface.

By the way, the inductance value can be given as:

During TON state:

$$
\begin{gathered}
V=L \frac{\Delta I_{L}}{T_{O N}} \\
L=\frac{V \alpha}{\Delta I_{L} F}
\end{gathered}
$$


Where $\Delta_{I L}$ can be computed as below, and $r$ is the inductor current ripple ratio, which is optimal in the range $[0.3,0.5][77]$ :

$$
\Delta I_{L}=r \times I
$$

Therefore, the optimum inductor value can be computed by using equation (10):

$$
L \geq \frac{V \alpha}{r I F}
$$

Based on Figure 4.3, to guarantee the performance of Boost converter in the continuous conduction mode, the following equation must be verified:

$$
I \geq \frac{\Delta I_{L}}{2}=>\Delta I_{L} \leq 2 I
$$

Therefore,

$$
L \geq \frac{\alpha(1-\alpha)^{2} R}{2 F}
$$

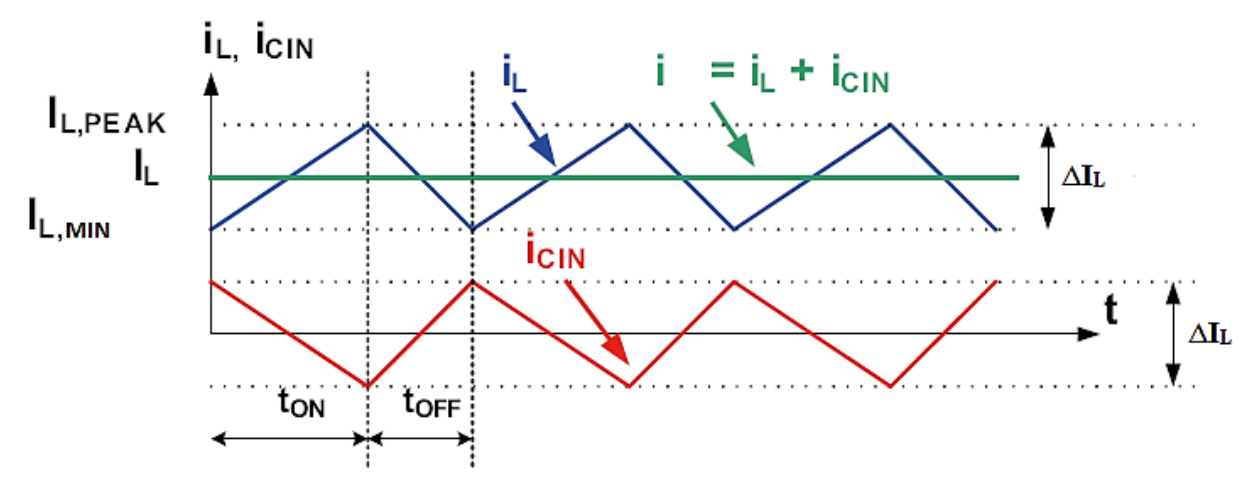

Figure 4. 3. Current waveforms of the input capacitor and inductor in CCM.

\subsubsection{Selection of the output capacitor}

The choice of the output capacitor is made by using output voltage ripple as follows:

During TON:

$$
I_{O}=C_{O} \frac{\Delta V_{O}}{T_{O N}}=>C_{O}=\frac{\alpha I_{O}}{\Delta V_{O} F}
$$

Therefore, the output capacitor value can be calculated as below, where the desired $\Delta V_{o}$ equals $2 \%$ of output voltage [76]:

$$
C_{O} \geq \frac{\alpha}{0.02 \times F \times R}
$$




\subsubsection{Selection of the input capacitor}

An input capacitor is used to decrease the input voltage ripple and to deliver an alternative current to the inductor. The input voltage ripple matches to the charge voltage during the charge phase of the capacitor, and during this phase, $I_{c i n}$ is greater than zero, so this phase is illustrated by the blue area in Figure 4.4, therefore this area is used to calculate the input capacitor as follows:

$$
I_{\text {Cin }}=C_{i n} \frac{\Delta V}{\Delta t} \Rightarrow \Delta V=\frac{I_{C i n} \Delta t}{C_{i n}}
$$

Based on Figure 4.4 and by using equation (4.12), equation (4.13) is found:

$$
\Delta V=\frac{\Delta I_{L}}{8 F C_{i n}} \Rightarrow>C_{i n}=\frac{\Delta I_{L}}{8 F \Delta V}=\frac{V \alpha}{8 F^{2} L \Delta V}
$$

Therefore, the input capacitor can be calculated by equation (4.14), where the desired $\Delta \mathrm{V}$ equals to $1 \%$ of input voltage [78]:

$$
C_{i n} \geq \frac{\alpha}{8 \times F^{2} \times L \times 0.01}
$$

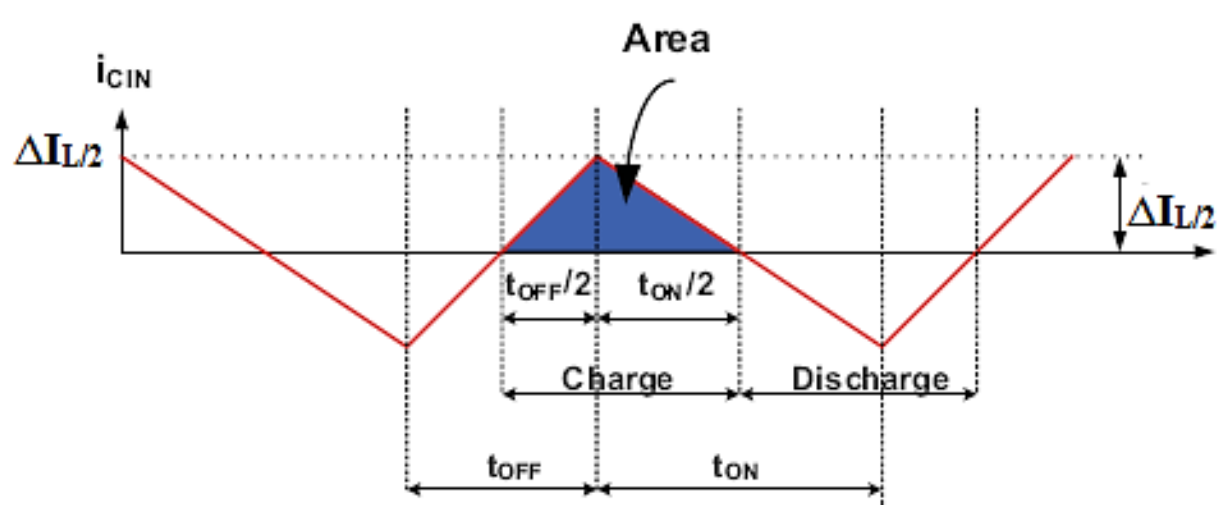

Figure 4. 4. Current waveforms of the input capacitor in CCM.

The design of the used Boost is presented in Table 4.1.

Table 4.1. Design of the Boost converter.

\begin{tabular}{|l|c|}
\hline Parameters & Values \\
\hline $\mathrm{L}$ & $1.2 \mathrm{mH}$ \\
\hline $\mathrm{C}_{\mathrm{in}}$ & $75 \mathrm{mF}$ \\
\hline $\mathrm{C}_{\mathrm{o}}$ & $75 \mathrm{mF}$ \\
\hline $\mathrm{F}$ & $10 \mathrm{kHz}$ \\
\hline $\mathrm{R}$ & $50 \Omega$ \\
\hline$\alpha_{\mathrm{MPP}}$ & 0.69 \\
\hline
\end{tabular}




\section{Modified Incremental Inductance algorithm for fast change of solar irradiance}

\subsection{Limitation of conventional INC algorithm}

A good MPPT algorithm balances between the tracking speed and steady-state performance. Following these requirements, the INC algorithm can be used even if it can fail in some cases [15], and in this study it will be modified to improve its performance. INC algorithm is founded in the fact that slope of P-V characteristic is zero at the MPP [79]. Therefore, this algorithm can be modeled as follows:

$$
\begin{aligned}
& \frac{d P}{d V}=0 \text { at MPP } \\
& \frac{d P}{d V}>0 \text { left to MPP } \\
& \frac{d P}{d V}<0 \text { right to MPP }
\end{aligned}
$$

Since:

$$
\frac{d P}{d V}=\frac{d(I V)}{d V}=V \frac{d I}{d V}+I
$$

Therefore:

$$
\begin{aligned}
& \frac{d I}{d V}=-\frac{I}{V} \text { at MPP } \\
& \frac{d I}{d V}>-\frac{I}{V} \text { left to MPP } \\
& \frac{d I}{d V}<-\frac{I}{V} \text { right to MPP }
\end{aligned}
$$

The flowchart of the INC algorithm is presented in Figure 4.5 [79]. This algorithm measures the current and voltage of the panel. If equation (4.21) is met, the duty cycle is increased, and vice versa if equation (4.22) is met. Then, there is nothing to do if equation (4.20) is met. Therefore, theoretically, if MPP is reached, no more perturbation of $\alpha$. Thus, steady-state oscillations are decreased and that is the main advantage of INC algorithm.

However, the conventional INC algorithm fails to make the right decision when the irradiance is sudden increased [15]. As presented in Figure 4.6, once the solar irradiance is at $500 \mathrm{~W} / \mathrm{m}^{2}$ and the PV system operates at load_2, the INC technique controls the PV system to reach the MPP (point B). When the irradiance is increased to $1000 \mathrm{~W} / \mathrm{m}^{2}$, Load_2 will lead the system to point G in I-V 
characteristic, which matches point $\mathrm{C}$ in $\mathrm{P}-\mathrm{V}$ characteristic. The INC technique calculates the slope between point $\mathrm{C}$ and point $\mathrm{B}$ which is positive. Therefore, the INC algorithm will decrease the duty cycle and consequently, the PV panel voltage will be increased. But since the MPP of $1000 \mathrm{~W} / \mathrm{m}^{2}$ is at point $\mathrm{A}$, and the slope between point $\mathrm{A}$ and $\mathrm{C}$ is negative, then the PV panel voltage should be decreased to reach point $\mathrm{A}$, instead of increasing voltage and recede from point $\mathrm{A}$ as made by the conventional INC algorithm. In addition, as presented in Figure 3.10, generally when the solar irradiance increases, the MPP moves to the right and consequently, the same problem will occur.

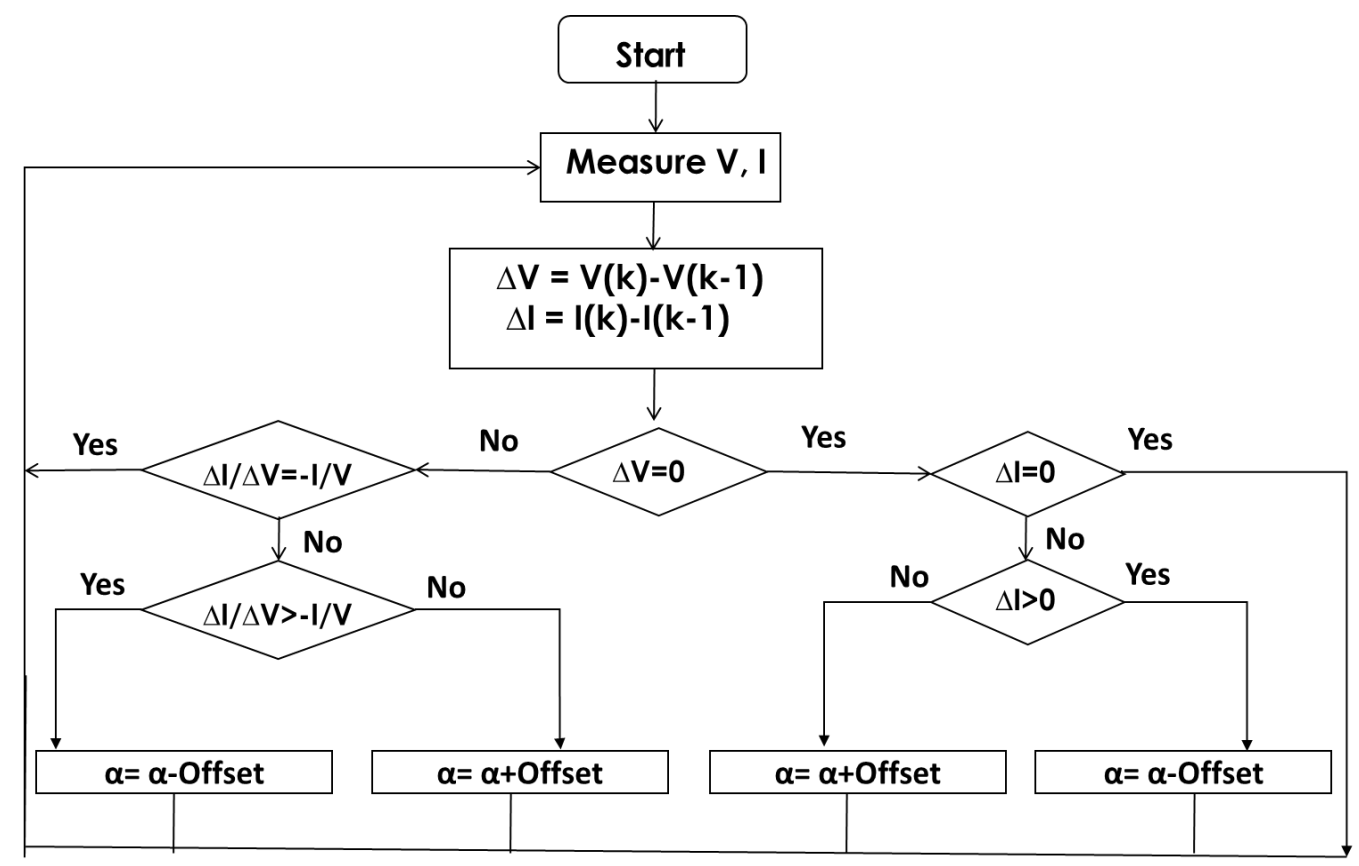

Figure 4. 5. Flowchart of INC algorithm.

Conversely, this weakness does not happen if the solar irradiation is decreased. Because as shown in Figure 4.6, the slope is positive between points A and D, and also between points B and H.

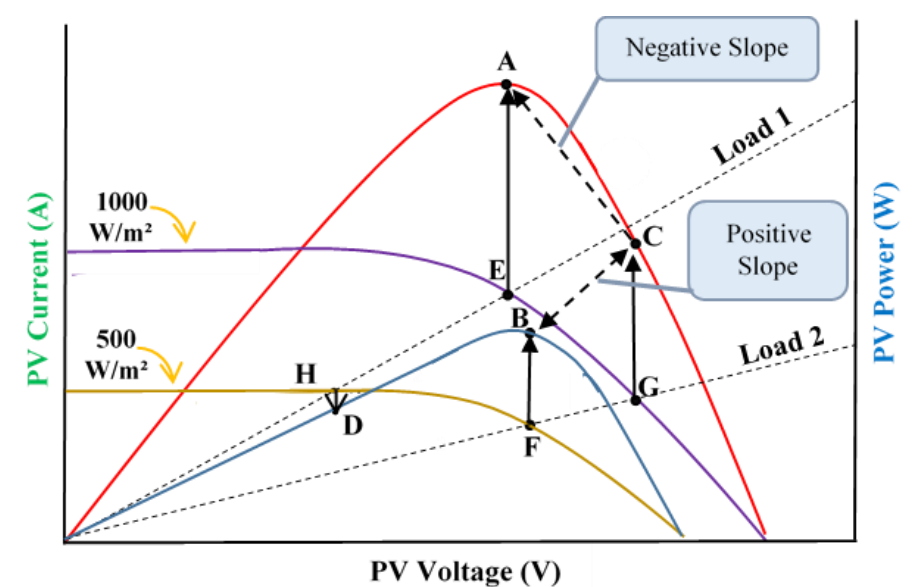

Figure 4. 6. P-V and I-V curves for solar irradiation $500 \mathrm{~W} / \mathrm{m}^{2}$ and $1000 \mathrm{~W} / \mathrm{m}^{2}$. 


\subsection{Modified INC algorithm for fast change in irradiance}

Based on the above analysis, it is noted that when the solar irradiance increases, both the voltage and the current are increased. Therefore, the sudden increase in solar irradiation can be detected, by checking if the MPP was reached and both the voltage and current are increased. Therefore, a permitted error is accepted (equation (4.23)) to stabilize our system around MPP and detect that the MPP is reached.

$$
\left|\frac{d I}{d V}+\frac{I}{V}\right|<0.07
$$

The modified algorithm is presented in Figure 4.7. So as shown, the addition is the check if the MPP was reached by using equation (4.23), then set Var to one. After that, when the equation (4.23) is not met and Var is one, the modified technique checks if both voltage and current are increased, in this case, the duty cycle is increased instead of decreased as made by the conventional algorithm. Hence, the INC algorithm is modified to overcome the incorrect decision made by the traditional algorithm when the irradiance is increased.

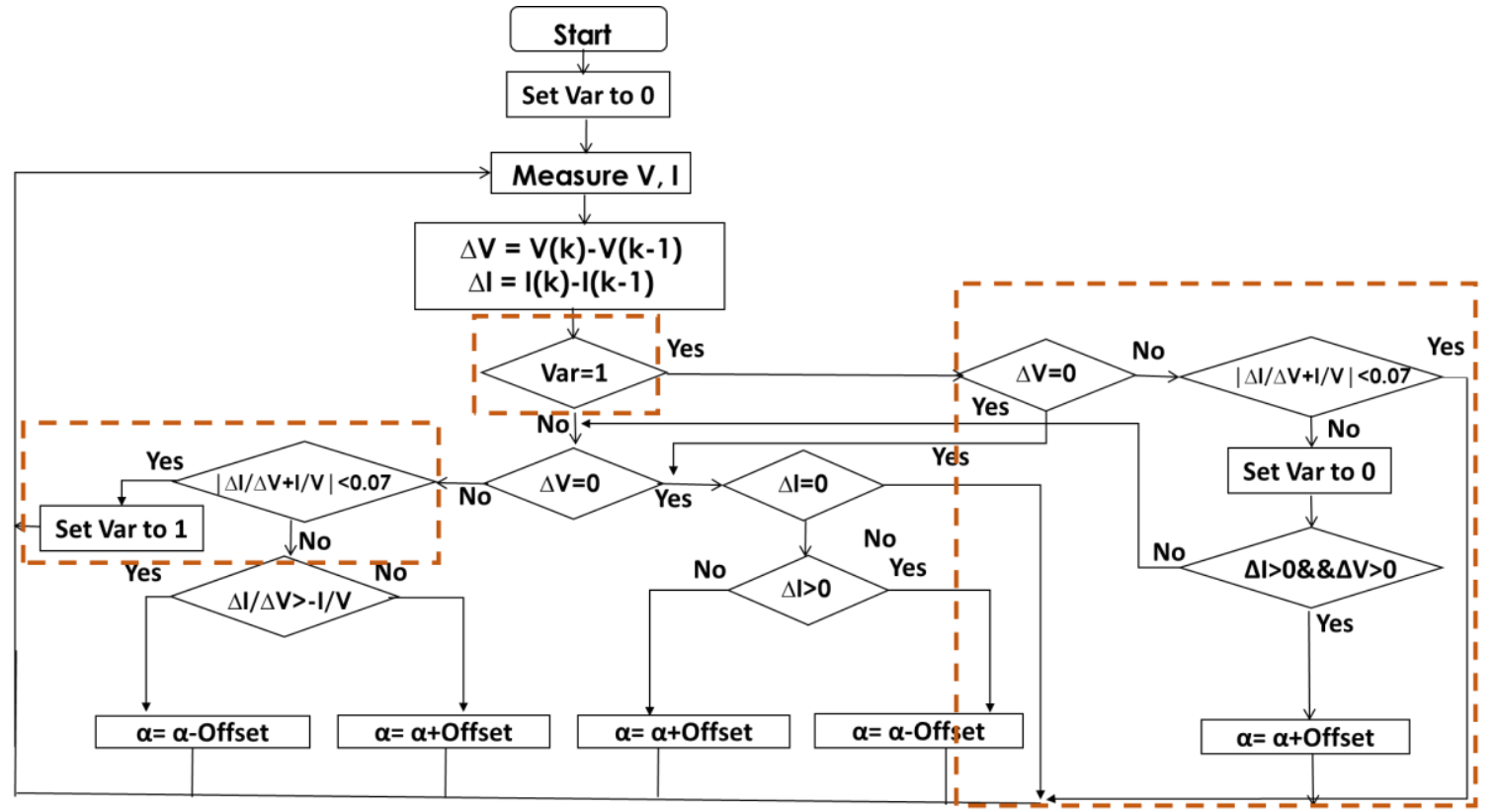

Figure 4. 7. Flowchart of the modified INC algorithm.

\subsection{Results and discussions}


'Software In the Loop' test was made for conventional and modified techniques and their dynamic and steady-state performances are examined through the irradiation changes covering different cases, which includes irradiation changes of 500 to $1000 \mathrm{~W} / \mathrm{m}^{2}, 1000$ to $800 \mathrm{~W} / \mathrm{m}^{2}, 800$ to $900 \mathrm{~W} / \mathrm{m}^{2}, 900$ to $600 \mathrm{~W} / \mathrm{m}^{2}$ and 600 to $200 \mathrm{~W} / \mathrm{m}^{2}$. Figure 2.8 presents the test result of the conventional INC algorithm and Figure 2.9 presents the test result of the modified algorithm. Therefore, as shown in these figures, the steady-state oscillations are minimized by using the modified algorithm and admit an error equal to 0.07 . Contrary to the conventional algorithm, which presents a high level of oscillations, as a result generate a loss of the PV energy. It is true that theoretically INC algorithm checks if the slope of the power curve is equal to zero (at MPP), and then there is no perturbation after the MPP is reached. However, during implementation, the zero value is rarely found on the slope of the P-V characteristic because real values cannot be precisely represented using binary floating-point numbers. Therefore, it is required to admit an error as done in the modified algorithm. Moreover as presented in these figures, when solar irradiation is suddenly increased, conventional algorithm leads the power to diverge with a large value from the new MPP. Correspondingly, the system requires a long time to obtain the new MPP due to the wrong decision made by the conventional algorithm. In addition, steady-state oscillations occur after the MPP is reached. On the other hand, as presented in Figure 2.9, the modified algorithm detects the fast increase of irradiation and performs a correct decision in duty cycle. Thus, the power converges to the new MPP from the first step and it is maintained at it. As a result, by using the modified INC, the power is converging faster compared with the response done by the conventional algorithm.

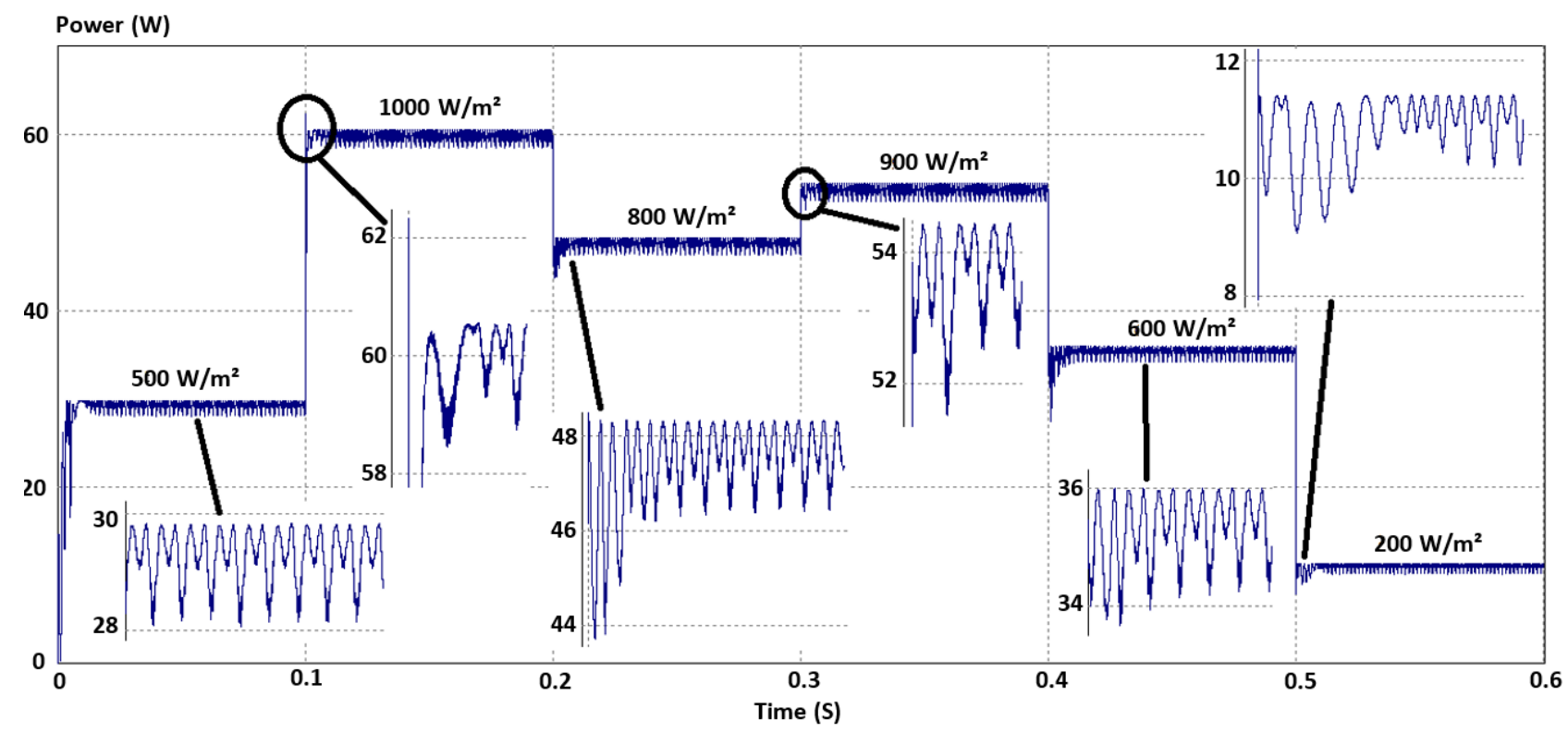

Figure 4. 8. Test result of the INC algorithm. 


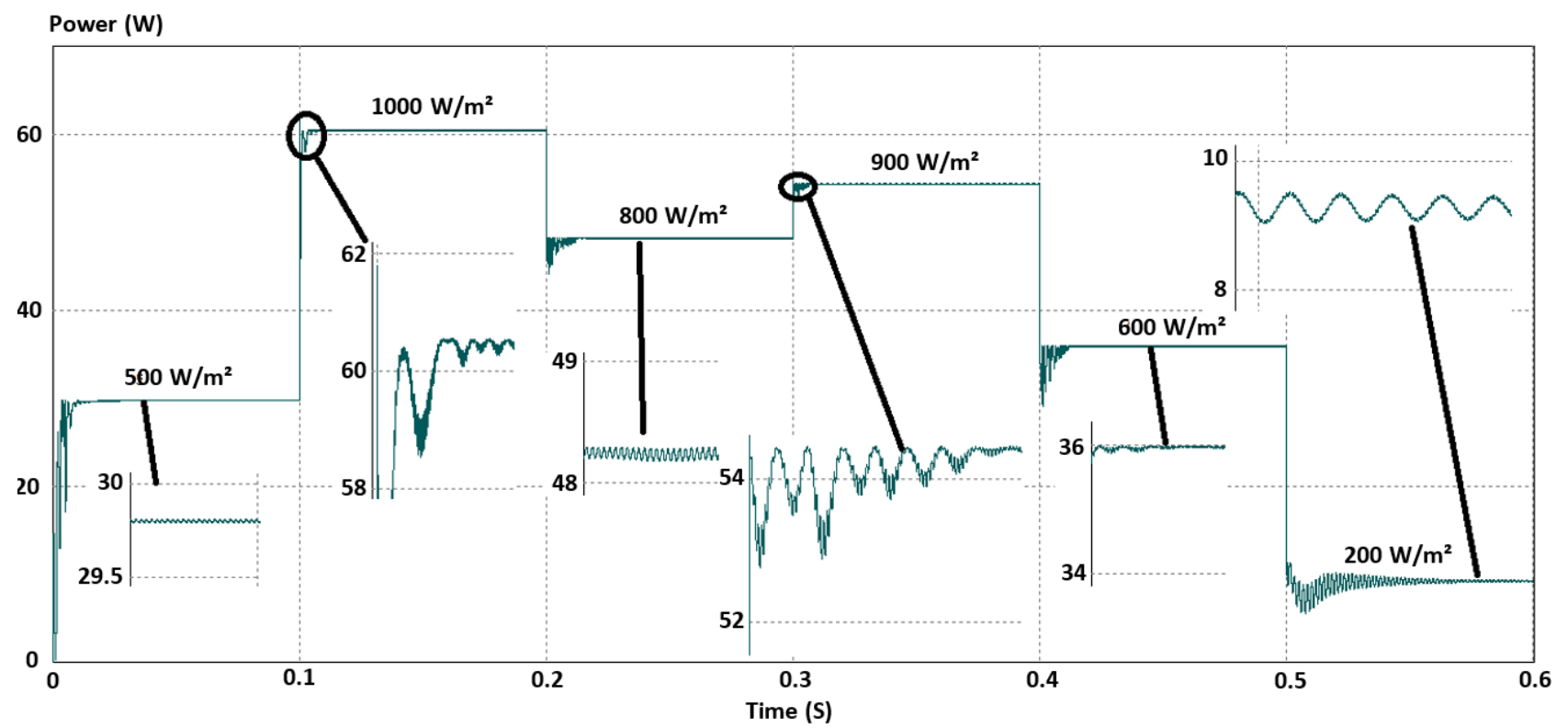

Figure 4. 9. Test result of the modified INC algorithm.

Table 4.2. Comparison of the proposed algorithm with other improved incremental conductance algorithms proposed in the scientific literature.

\begin{tabular}{|c|c|c|c|c|}
\hline Technique & $\begin{array}{c}\text { Oscillations } \\
\text { level }\end{array}$ & Efficiency & $\begin{array}{c}\text { Response time during } \\
\text { sudden increase in } \\
\text { irradiation }\end{array}$ & $\begin{array}{c}\text { Incorrect decision } \\
\text { under sudden increase } \\
\text { of irradiation }\end{array}$ \\
\hline Conventional & $2.5 \mathrm{~W}$ & $96 \%$ & Slow & Yes \\
\hline$[80]$ & $1 \mathrm{~W}$ & $96.40 \%$ & Fast & No \\
\hline$[81]$ & $1.5 \mathrm{~W}$ & $98.5 \%$ & Fast & Yes \\
\hline$[28]$ & $1 \mathrm{~W}$ & $97.5 \%$ & Medium & Nes \\
\hline Proposed & Neglected & $98.8 \%$ & Very fast & No \\
\hline
\end{tabular}

Table 4.2 summarizes a comparison of the proposed technique to other improved INC techniques introduced in the scientific literature in terms of the oscillation level, tracking efficiency, the response time during sudden increase in irradiation, and if the method makes an incorrect decision under sudden increase of radiation. As presented, the proposed technique shows a very fast-tracking speed, a higher efficiency, and neglected oscillations around the MPP compared to other methods. Thus only the proposed algorithm and that proposed in [29] make a correct decision under sudden increase of irradiation, contrary to the conventional technique and those proposed in [30], [31] which make an incorrect decision.

\subsection{Problem of MPPT algorithm under partial shading}

The bypass diodes are used to reduce the loss of energy in the shaded cells. However, as shown in Figure 3.16, a multiple maxima can occur on P-V characteristic using this solution (bypass diodes), like in our case there are two maximum power points, point A (global) and point B (local), therefore MPPT algorithm can fail to track the real MPP that depends on the value of the load [82]. 
In order to present this problematic, the simulation was performed for two values of the load. Note that the second string is exposed by higher irradiance $\left(1000 \mathrm{~W} / \mathrm{m}^{2}\right)$ than the first $\left(700 \mathrm{~W} / \mathrm{m}^{2}\right)$.

As shown in Figure 4.10, the first value (50 $\Omega$ ) leads the PV system to the global MPP; however, as shown in Figure 4.11, the second value (20 $\Omega$ ) leads the photovoltaic system to the local MPP.

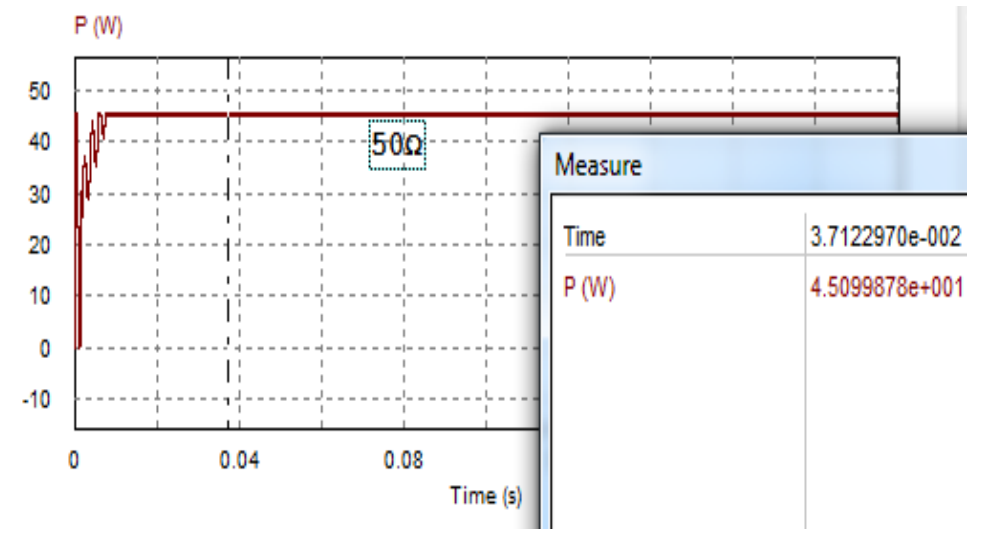

Figure 4. 10. Output power of PV system in case of load equals to $50 \Omega$.

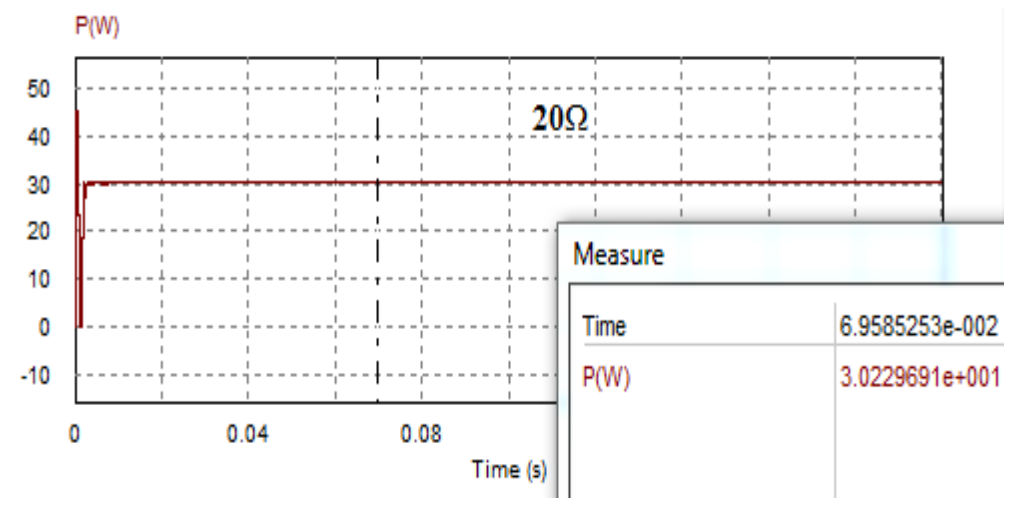

Figure 4. 11. Output power of PV system in case of load equals to $20 \Omega$.

As shown in Figure 4.10, when the load used leads the PV system to the local MPP, the MPPT command gets stuck on this point. Therefore to solve this problematic, the DMPPT method is used [83], [84].

\subsection{Distributed MPPT}

DMPP represented by the sum of the string MPP. Therefore To obtain the DMPP, each PV string can be joined to a Boost to extract the MPP of each string and the output power is the sum of the powers generated by the two strings. This kind of solution is called the Distributed Maximum Power Point Tracking (DMPPT). Figure 4.12 demonstrates a DMPPT method structure established on DC/DC converters (Boost), whereas the outputs of the Boosts are in series. 
PV panel

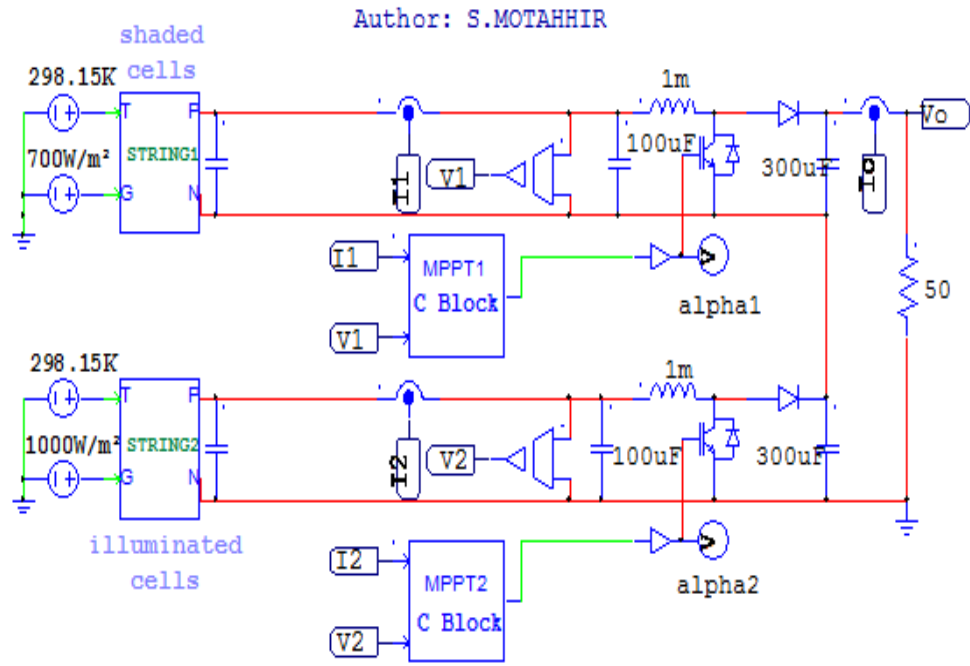

Figure 4. 12. The simulation of improved system.

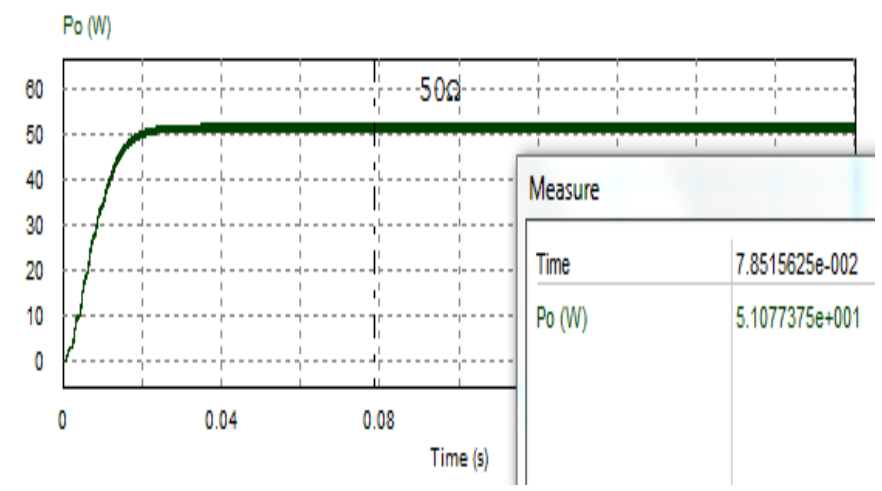

Figure 4. 13. Output power of PV system in case of load equals to $50 \Omega$ using DMPPT.

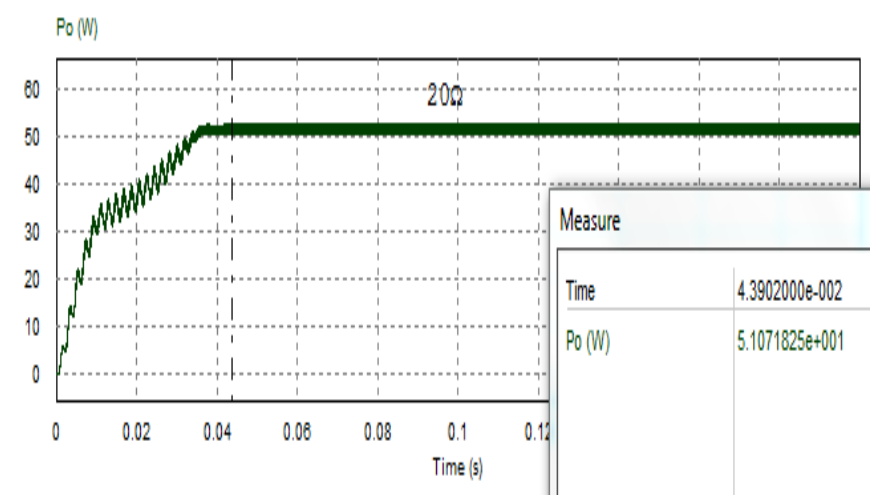

Figure 4. 14. Output power of PV system in case of load equals to $20 \Omega$ using DMPPT.

As presented in Figures 4.13 and 4.14, by using the same values of load tested with bypass diodes and conventional MPPT (50 $\Omega$ and $20 \Omega$ ), the power dissipated by the two loads is identical $(51.07 \mathrm{~W})$ instead of $45.1 \mathrm{~W}$ (global maxima) or $30.2 \mathrm{~W}$ (local maxima). Therefore, by adopting the 
DMPPT method, the problem due to the multiple local peaks is solved, because, in the improved system, the output power is the sum of the powers generated by the two strings. So, as a result using DMPPT, we gained in terms of power $5.97 \mathrm{~W}$ in case of $50 \Omega$ as load and $20.87 \mathrm{~W}$ in case of $20 \Omega$ as a load.

It should be mentioned that using this method, there is no risk to have the load current higher than the shaded cells current, because the two strings are not connected directly. The DC/DC converter connected to the shaded cells adapts their current to the current absorbed by the load.

Note that by using this method we extract a power value's higher than the global MPP. However, this method needs more resources compared with GMPPT (two Boosts and two microcontrollers are used), but the power gained by using DMPPT method merits these added resources. However, as mentioned in the introduction, the most solution is to use a GMPPT command in each Boost of the DMPPT architecture, in order to avoid also the case when a string is partially shaded, therefore at first in this thesis we have studied and implemented the DMPPT method, and as a perspective, it would of interest to design and implement a DMPPT method by using a GMPPT command in each DC/DC converter.

\section{Low-cost Embedded system based control for PV system by using a modified division-free} Incremental conductance algorithm

\subsection{Complexity of INC algorithm and the modified algorithm}

The conventional INC algorithm uses the incremental conductance $(\Delta \mathrm{I} / \Delta \mathrm{V})$ of the PV panel to find the sign of $\mathrm{P}-\mathrm{V}$ curve slope $(\Delta \mathrm{P} / \Delta \mathrm{V})$ and its structure can be presented as follows [43]:

$$
\begin{aligned}
& \frac{\Delta P}{\Delta V}=0 \text { at MPP } \\
& \frac{\Delta P}{\Delta V}>0 \text { left to MPP } \\
& \frac{\Delta P}{\Delta V}<0 \text { right to MPP }
\end{aligned}
$$

Since,

$$
\frac{\Delta P}{\Delta V}=\frac{\Delta(I V)}{\Delta V}=V \frac{\Delta I}{\Delta V}+I
$$

Therefore, 


$$
\begin{aligned}
& \frac{\Delta I}{\Delta V}=-\frac{I}{V} \text { at MPP } \\
& \frac{\Delta I}{\Delta V}>-\frac{I}{V} \text { left to MPP } \\
& \frac{\Delta I}{\Delta V}<-\frac{I}{V} \text { right to MPP }
\end{aligned}
$$

Based on equations (4.28)-(4.30), the flowchart of the conventional INC algorithm is presented in Figure 4.15 [85].

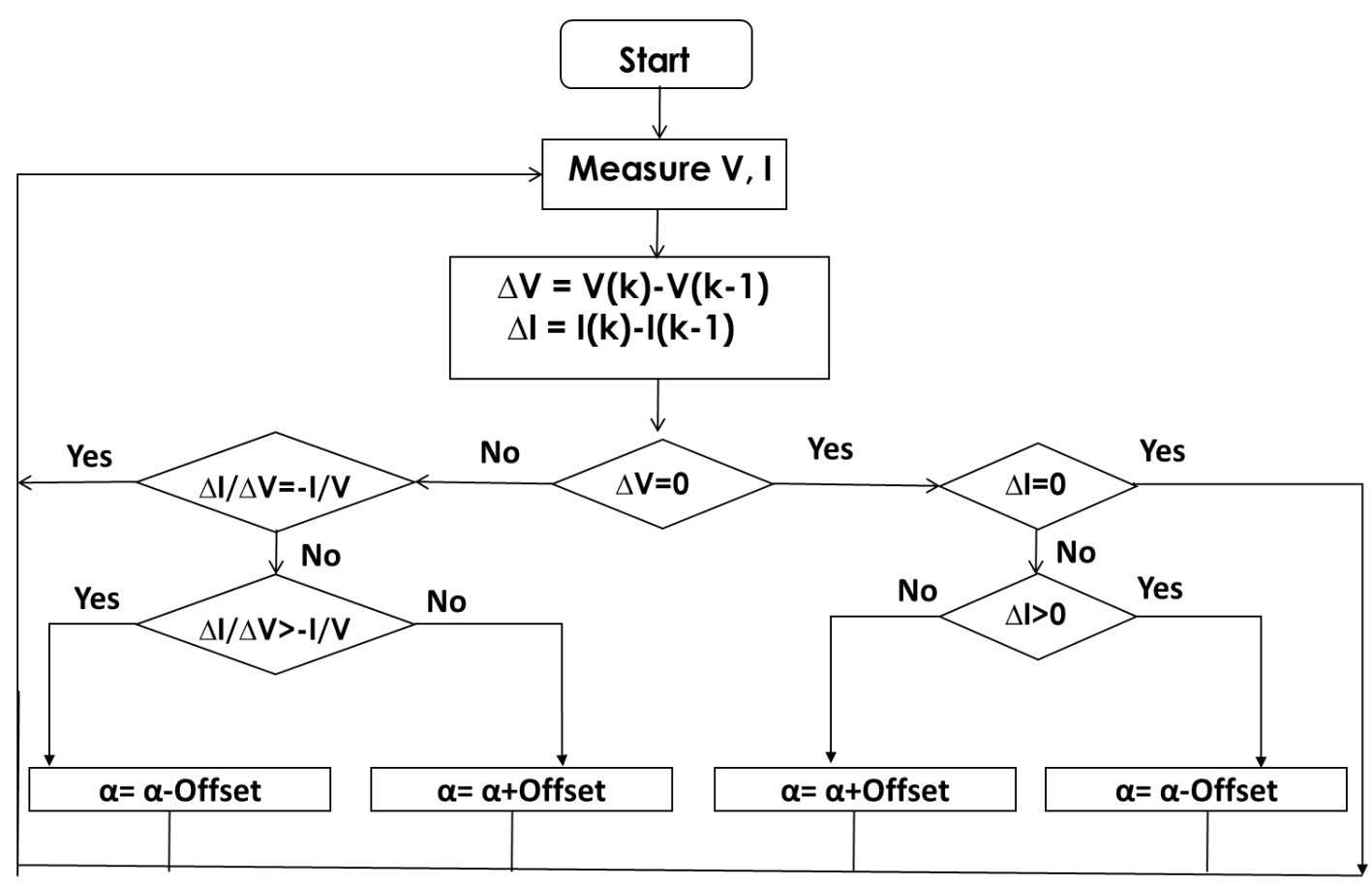

Figure 4. 15. Flowchart of conventional INC algorithm.

As presented in Figure 4.15, the conventional INC technique contains several division computations that require a stronger microcontroller including a great memory, a high clock frequency, and floating-point computation, and this reduces the opportunity to use a low-cost development board [16].

Therefore in this thesis, a modification is made in the structure of the conventional INC algorithm to remove all its division calculations to make simpler its implementation and then a lowcost embedded system can be used to minimize the system cost; therefore the equations (4.28)-(4.30) are modified to be as follows:

$$
[(V \times \Delta I)+(I \times \Delta V)] /(V \times \Delta V)=0 \text { at MPP }
$$




$$
\begin{aligned}
& {[(V \times \Delta I)+(I \times \Delta V)] /(V \times \Delta V)>0 \text { left to MPP }} \\
& {[(V \times \Delta I)+(I \times \Delta V)] /(V \times \Delta V)<0 \text { right to MPP }}
\end{aligned}
$$

As the denominator in (4.31)-(4.33) is equal to $\mathrm{V}^{*} \Delta \mathrm{V}$, so for equation (4.31), this denominator can be removed since this equation is equal to zero. While only $\mathrm{V}$ can be removed in equations (4.32) and (4.33) since it is always greater than zero and its sign does not influence these equations. As a result, the equations (4.34)-(4.36) are found:

$$
\begin{aligned}
& (V \times \Delta I)+(I \times \Delta V)=0 \text { at MPP } \\
& (V \times \Delta I)+(I \times \Delta V) / \Delta V>0 \text { left to MPP } \\
& (V \times \Delta I)+(I \times \Delta V) / \Delta V<0 \text { right to MPP }
\end{aligned}
$$

Therefore, to avoid the division calculations, the INC algorithm instructions are represented as below:

$$
\begin{aligned}
& (V \times \Delta I)+(I \times \Delta V)=0 \text { at MPP } \\
& (V \times \Delta I)+(I \times \Delta V)>0 \text { and } \Delta V>0 \text { left to MPP } \\
& (V \times \Delta I)+(I \times \Delta V)<0 \text { and } \Delta V<0 \text { left to MPP } \\
& (V \times \Delta I)+(I \times \Delta V)>0 \text { and } \Delta V<0 \text { right to MPP } \\
& (V \times \Delta I)+(I \times \Delta V)<0 \text { and } \Delta V>0 \text { right to MPP }
\end{aligned}
$$

The flowchart of the modified algorithm is presented in Figure 4.16, where the elimination of all division calculations is made by using mathematical operations. As a result, algorithm structure complication is reduced which in turn minimizes processing real-time and hence the algorithm can be implemented by low-cost embedded board. 


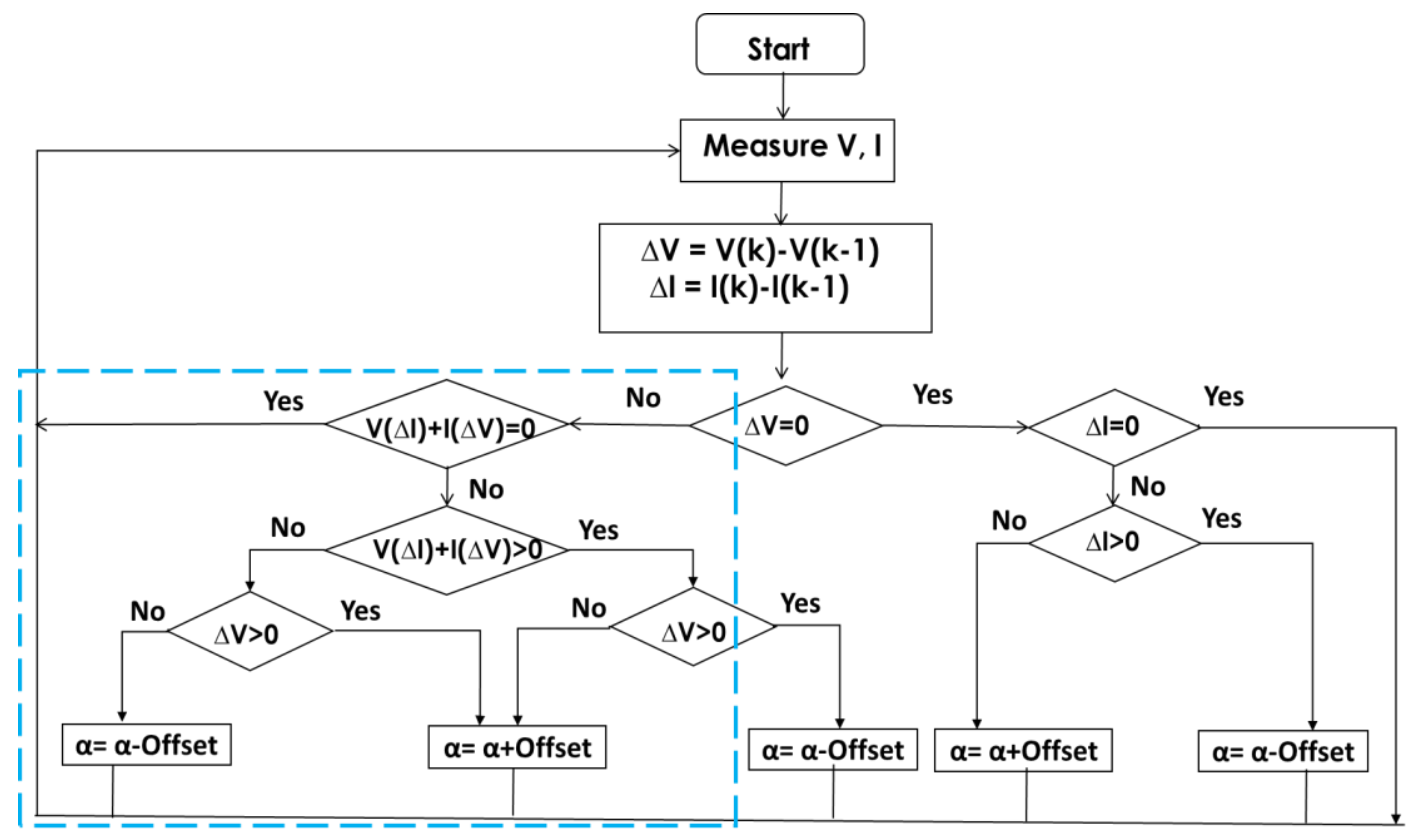

Figure 4. 16. Flowchart of the modified INC algorithm.

\subsection{Implementation}

In order to implement the MPPT algorithm, different components are required such as current sensor, voltage sensor, development board, Boost converter, and driver.

- Board: the embedded board employed in this work is Arduino UNO, based on the low-cost ATMega328 microcontroller [53].

- Voltage sensor: is required to adapt the higher PV voltage to the Arduino analog input voltage which is limited to 5V. The sensor used in this work is "B25 Voltage Sensor Module" [86].

- Current sensor: is required to sense the PV panel current. The sensor used in this work is "INA169 Analog DC Current Sensor" and note that the output voltage value of this sensor is equal to the value of the current that through it [87].

- Boost converter: is presented in Figure 4.17; it is used as an interface between the panel and the load in order to adapt the impedance to operate at MPP [80], [88].

The parameters of the used converter are chosen as $\mathrm{L}=20 \mathrm{mH}, C_{i n}=220 \mu \mathrm{F}, C_{o}=470 \mu \mathrm{F}, \mathrm{F}=1$ $\mathrm{kHz}$, and $\mathrm{R}$ of the load is $70 \Omega$. It should be mentioned that the switch used in the designed Boost is IRFP250N transistor because it has a low value of $R_{d s}$ (on) which is equal to $0.075 \Omega$. Therefore, by using this switch the loss of power is minimized. Thus the Diode used is Schottky diode because the latter is suggested to increase the efficiency of the Boost converter thanks to its low forward voltage and its fast recovery time. 
- Driver: is used for controlling the MOSFET transistor by a microcontroller. The driver used in this work is TC4420, the latter is manufactured in CMOS for low consumption and more efficient working versus bipolar driver [89].

As presented in Figure 4.17, for clarity reasons the PV panel Proteus model is put in a subcircuit, then it is connected to the load through the Boost converter. The Arduino board acquires the PV voltage and current through voltage and current sensors to use them by the MPPT algorithm implemented on this board, and the latter controls the Boost converter through the driver by using the duty cycle computed by MPPT algorithm to reach the maximum power. In addition, the PV power, PV voltage, and PV current are displayed on the LCD screen.

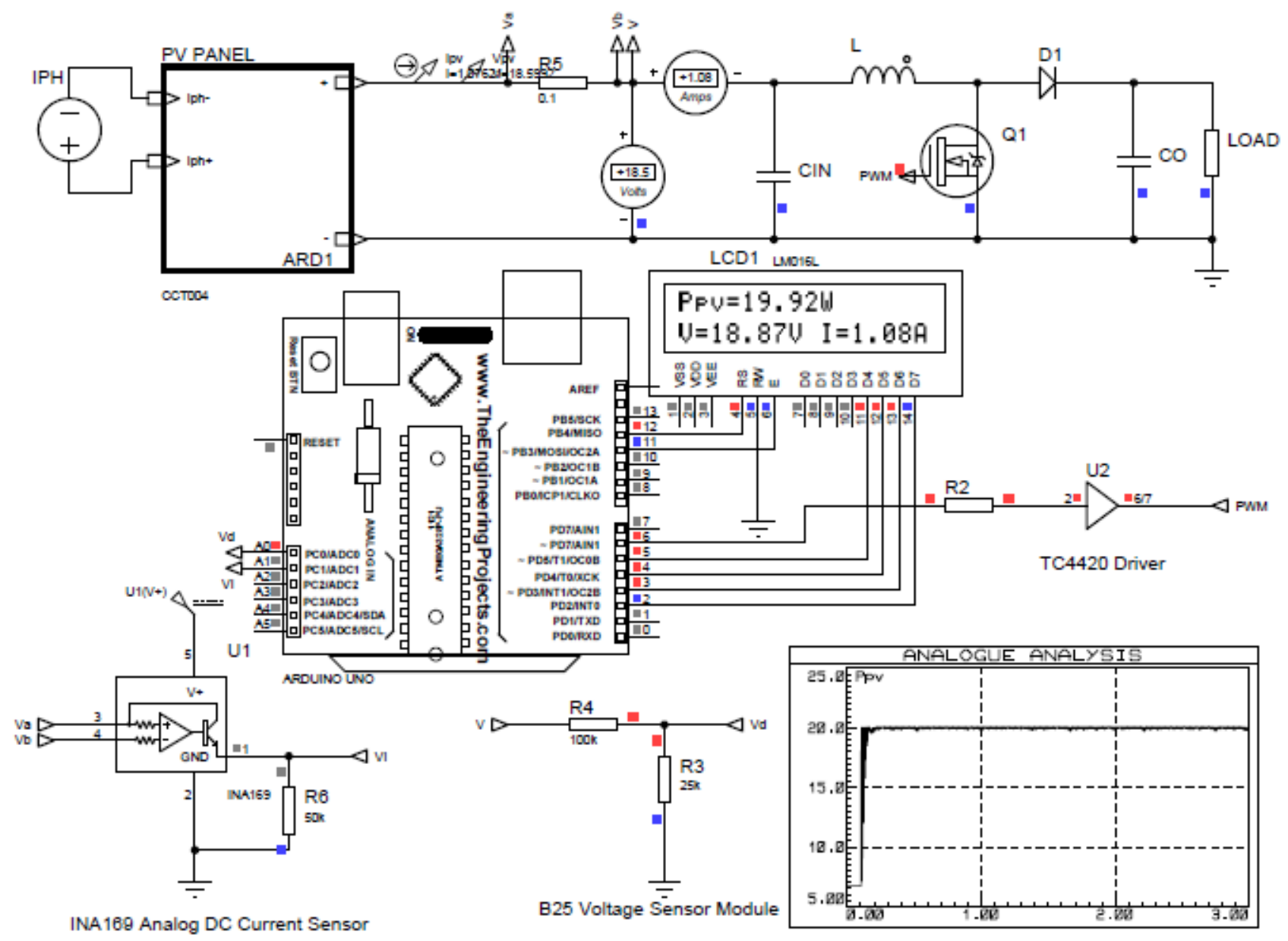

Figure 4. 17. Low-cost embedded system-based control Proteus for PV system on Proteus.

\subsection{Simulation result}

The simulation was made to compare the steady-state and transient performance of the conventional and the modified algorithms. Also, the execution time for both algorithms has to be compared to show the impact of eliminating all division calculations in the modified algorithm. Therefore, Figure 4.18(a) presents the execution time of the conventional algorithm program which 
is $480 \mu \mathrm{s}$ and Figure 4.18(b) shows the execution time of the modified algorithm which is $300 \mu \mathrm{s}$. Hence, the elimination of all division computations in the modified algorithm reduces the execution time and as a result, makes simple the controller process.
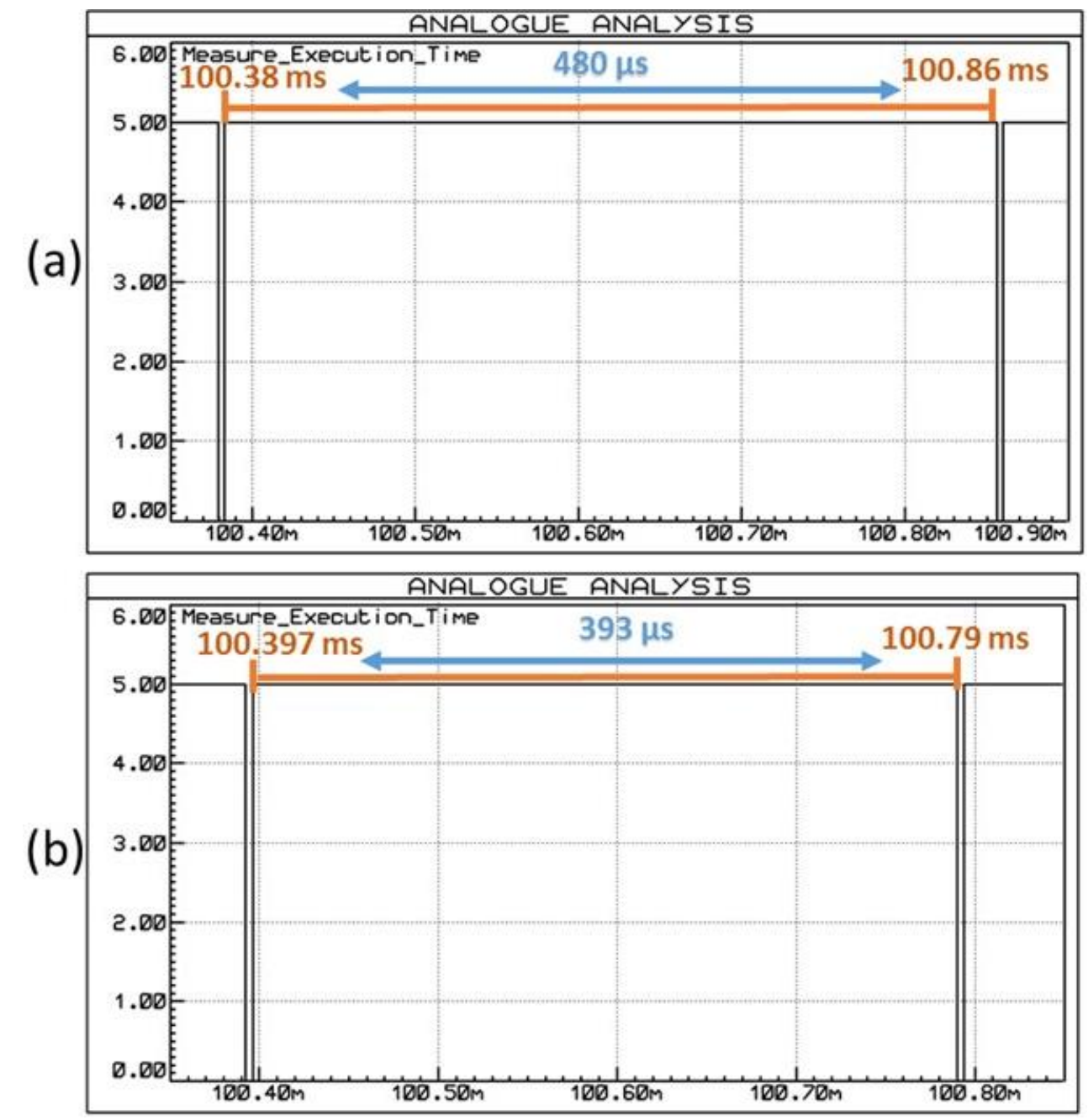

Figure 4. 18. (a): Execution time of the conventional algorithm program, (b): Execution time of the modified algorithm program.

The solar irradiation is suddenly modified from $1000 \mathrm{~W} / \mathrm{m}^{2}$ to $500 \mathrm{~W} / \mathrm{m}^{2}$ at $\mathrm{t}=1.5 \mathrm{~s}$. Figure 4.19(a) presents simulation results of the conventional algorithm and Figure 4.19(b) shows simulation results of the modified algorithm. As a result, as presented in these figures, the steady-state oscillation is decreased by using the modified algorithm. Also, when the solar irradiation is suddenly modified from $1000 \mathrm{~W} / \mathrm{m}^{2}$ to $500 \mathrm{~W} / \mathrm{m}^{2}$, the response time is $0.37 \mathrm{~s}$ for the conventional algorithm and $0.1 \mathrm{~s}$ for the modified algorithm because the elimination of all division computation in the modified algorithm reduces the execution time, and consequently the performance is enhanced with less steadystate oscillations and faster response during change. 

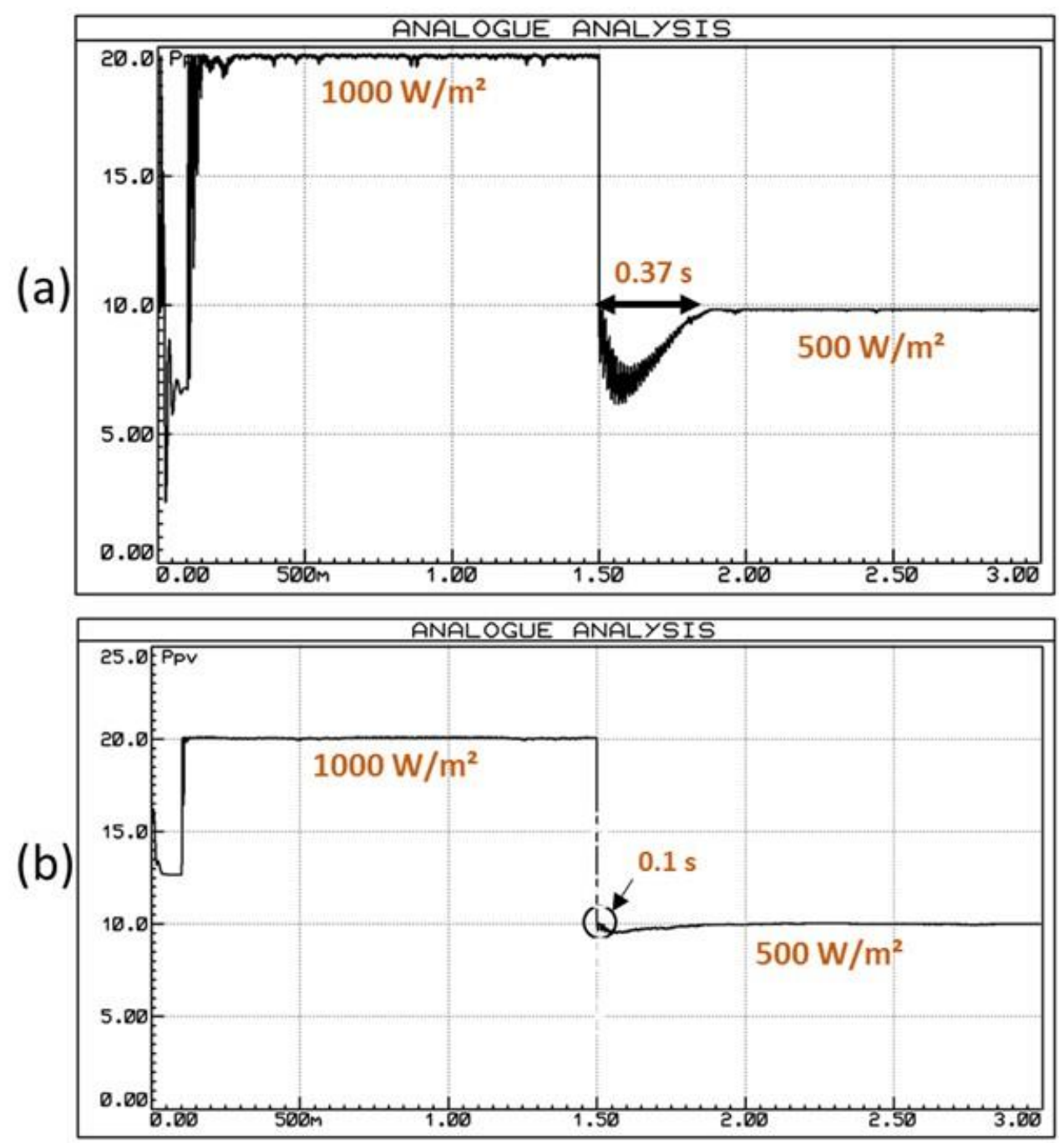

Figure 4. 19. (a): Simulation result of the conventional INC algorithm, (b): Simulation result of the modified INC algorithm.

\subsection{Experimental result}

The elimination of all division computations in the modified algorithm results in simplifying its design and enabling it to be easily implemented by low-cost microcontrollers with enhancing its performance. To validate that, a test bench using hardware components is employed.

The conventional INC algorithm and the modified INC algorithm are both implemented using the Atmega328 microcontroller. Figure 4.20 shows the experimental setup, and as presented in it, a computer is used to instrument the PV power by using a virtual instrument made by "Instrument Control Toolbox" of Matlab/Simulink. In addition, to compare the performance of both algorithms under sudden changes, a brutal decrease in solar irradiance should be made. But PV panel is unable 
to produce this test due to the randomly fluctuating atmospheric conditions. Hence, as presented in Figure 4.20, it is required to replace PV panel by PV Emulator [116].

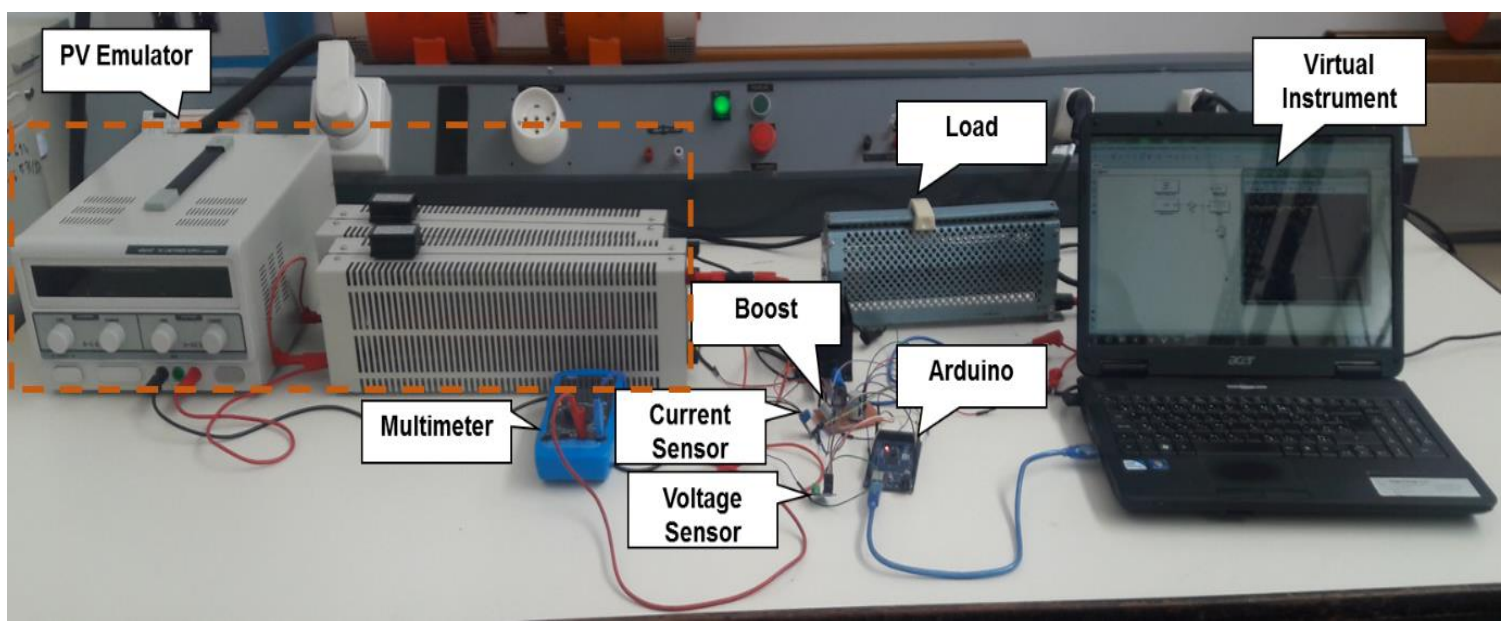

Figure 4. 20. Experimental setup.

Figures 4.21(a) and (b) present the experimental results of both techniques, under a sudden change in the solar irradiation (from $1000 \mathrm{~W} / \mathrm{m}^{2}$ to $500 \mathrm{~W} / \mathrm{m}^{2}$ ). A zoom in the results is made, as shown in Figure 4.21(a), the conventional technique generates more steady-state oscillation around the MPP compared with the modified method presented in Figure 4.21(b). On the other hand, the modified technique offers faster response with response time equals to $0.1 \mathrm{~s}$ which is very lower than the response time obtained by the conventional method $(0.36 \mathrm{~s})$.

In summary, experimental results validate that the modified technique decreases the execution time of the program, which results in the best compromise between steady-state performance and faster response. As shown in Table 4.3, our work is compared with some experimental works published recently. If we compare our proposal with low-cost microcontrollers' implementation [26], [28], our solution presents a faster response during sudden change. Whereas, prototypes with more rapid response use an expensive controller (FPGA or DSP) [90], [91]. Thus, in [92] a costly controller (dSPACE) is used; nevertheless, this work presents a slower response time compared to our proposal. In addition, our system presents a neglected steady-state oscillation. Moreover, it presents one of the highest efficiencies of more than $98 \%$.

Consequently, the modified INC algorithm implemented by the low-cost Atmega328 microcontroller results in the best compromise between steady-state performance and faster response. Hence, the proposed system is validated to be a suitable low-cost solution for PV systems. 

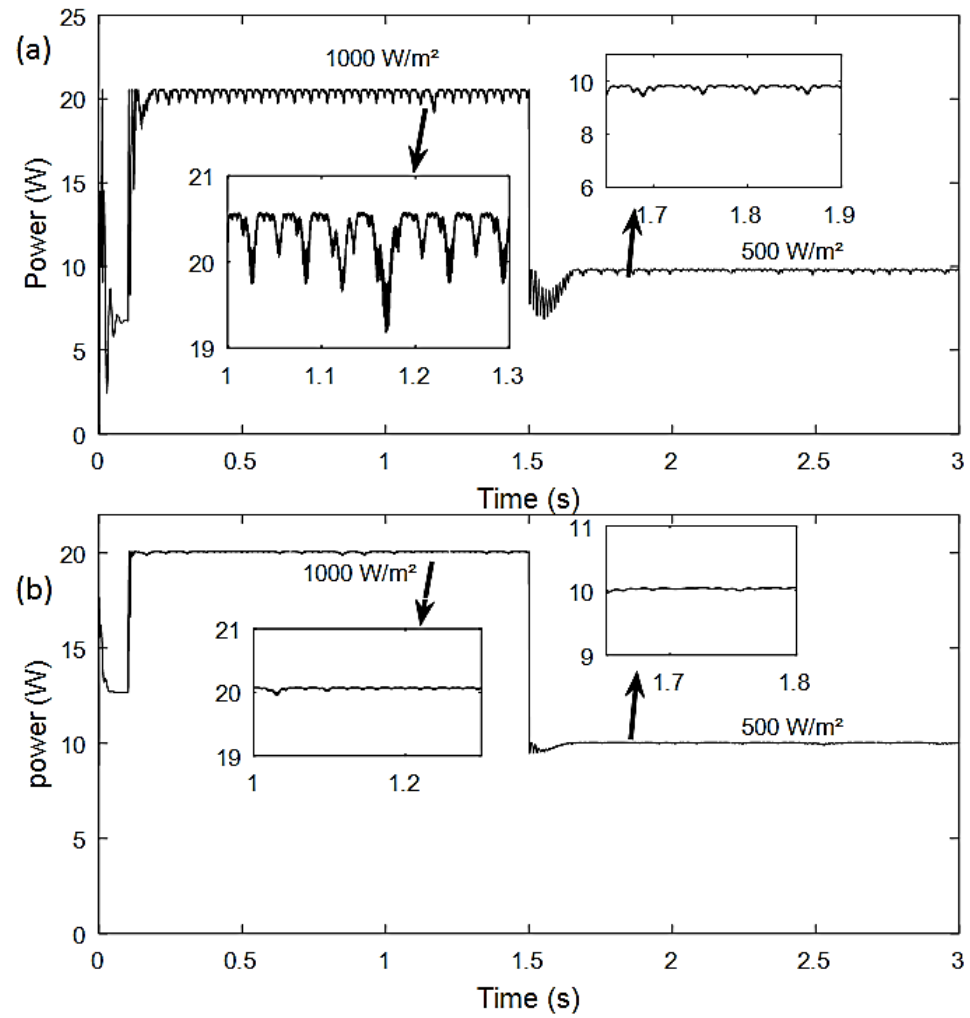

Figure 4. 21. Experimental result of the conventional INC algorithm, (b): Experimental result of the modified INC algorithm.

Table 4.3. Comparison between our proposal and some experimental works published recently.

\begin{tabular}{|c|c|c|c|c|c|c|c|}
\hline $\begin{array}{c}\text { Paper, } \\
\text { Publication } \\
\text { year }\end{array}$ & $\begin{array}{c}\text { PV } \\
\text { Power } \\
\text { at STC }\end{array}$ & $\begin{array}{c}\text { MPPT } \\
\text { algorithm }\end{array}$ & Controller used & $\begin{array}{c}\text { Power } \\
\text { ripples }\end{array}$ & Efficiency & $\begin{array}{c}\text { Response } \\
\text { time }\end{array}$ & $\begin{array}{c}\text { Cost of } \\
\text { controller }\end{array}$ \\
\hline [90], (2014) & $80 \mathrm{~W}$ & $\begin{array}{c}\text { Modified } \\
\text { INC }\end{array}$ & $\begin{array}{c}\text { Xilinx XC3S400 } \\
\text { FPGA }\end{array}$ & $2.7 \mathrm{~W}$ & $98.8 \%$ & $2.5 \mathrm{~ms}$ & $38.5 \$$ \\
\hline [91], (2014) & $210 \mathrm{~W}$ & $\begin{array}{c}\text { Adaptive } \\
\text { P\&O-fuzzy } \\
\text { MPPT }\end{array}$ & $\begin{array}{c}\text { DSP } \\
\text { TMS320F28335 }\end{array}$ & $1 \mathrm{~W}$ & $95.2 \%$ & $20 \mathrm{~ms}$ & $21.17 \$$ \\
\hline [28], (2014) & $40 \mathrm{~W}$ & $\begin{array}{c}\text { TS fuzzy- } \\
\text { based INC } \\
\text { dsPIC33fJ128M } \\
\text { C802 }\end{array}$ & $1 \mathrm{~W}$ & $97.5 \%$ & $2 \mathrm{~s}$ & $4.46 \$$ \\
\hline [26], (2015) & $87 \mathrm{~W}$ & $\begin{array}{c}\text { Modified } \\
\text { INC }\end{array}$ & $\begin{array}{c}\text { Microcontroller } \\
\text { PIC18f4520 }\end{array}$ & $1.3 \mathrm{~W}$ & $99 \%$ & $0.275 \mathrm{~s}$ & $4.26 \$$ \\
\hline [92], (2017) & $10 \mathrm{~W}$ & $\begin{array}{c}\text { FLC } \\
\text { MPPT }\end{array}$ & dSPACE-1103 & $0.9 \mathrm{~W}$ & $97.295 \%$ & $0.264 \mathrm{~s}$ & $38 \$$ \\
\hline [92], (2017) & $10 \mathrm{~W}$ & $\begin{array}{c}\text { Improved } \\
\text { INC }\end{array}$ & dSPACE-1103 & $1 \mathrm{~W}$ & $91.93 \%$ & $0.254 \mathrm{~s}$ & $38 \$$ \\
\hline Proposed & $20 \mathrm{~W}$ & $\begin{array}{c}\text { Modified } \\
\text { INC }\end{array}$ & Atmega 328 & $0.5 \mathrm{~W}$ & $98.5 \%$ & $0.1 \mathrm{~s}$ & $2 \$$ \\
\hline
\end{tabular}




\section{MIL and SIL and PIL Tests for a modified variable step size INC algorithm}

\subsection{Motivation}

The hardware implementation of these solutions is not easy, especially the MPPT algorithm, even if the MPPT algorithm is implemented by simulation tools like Simulink or PSIM. But, once we start the hardware implementation of MPPT algorithm in digital devices like microcontroller, microprocessor, DSP and FPGA, several problems can occur due to either the mismatches which can appear between the software and the requirements during the development process, or the fact that all the components used are real (PV panel, DC/DC converter, sensors, actuators and microcontroller). Hence when a bug occurs, it is difficult to know precisely the responsible component of this bug. That can increase the time spent in debugging runtime errors. Therefore in other fields, like automotive and aeronautical, the software can be generated from the model tested and validated by simulation, and there are different steps between simulation and hardware implementation step. For instance, generally the automotive and aeronautical embedded software follows the V-cycle development process [93], [94], and as shown in Figure 4.22, there are three tests mostly used in these areas, MIL, SIL and PIL tests, and in each one, there is an aim to be checked. For MIL, the objective is to check the model developed from the algorithm requirements; in other words, check that the model is in accordance with the algorithm requirements. For SIL, the aim is to check the software generated from the model on the host computer. For PIL, the objective is to check the software generated from the model in the embedded target. That can avoid redundant testing activities while improving software quality.

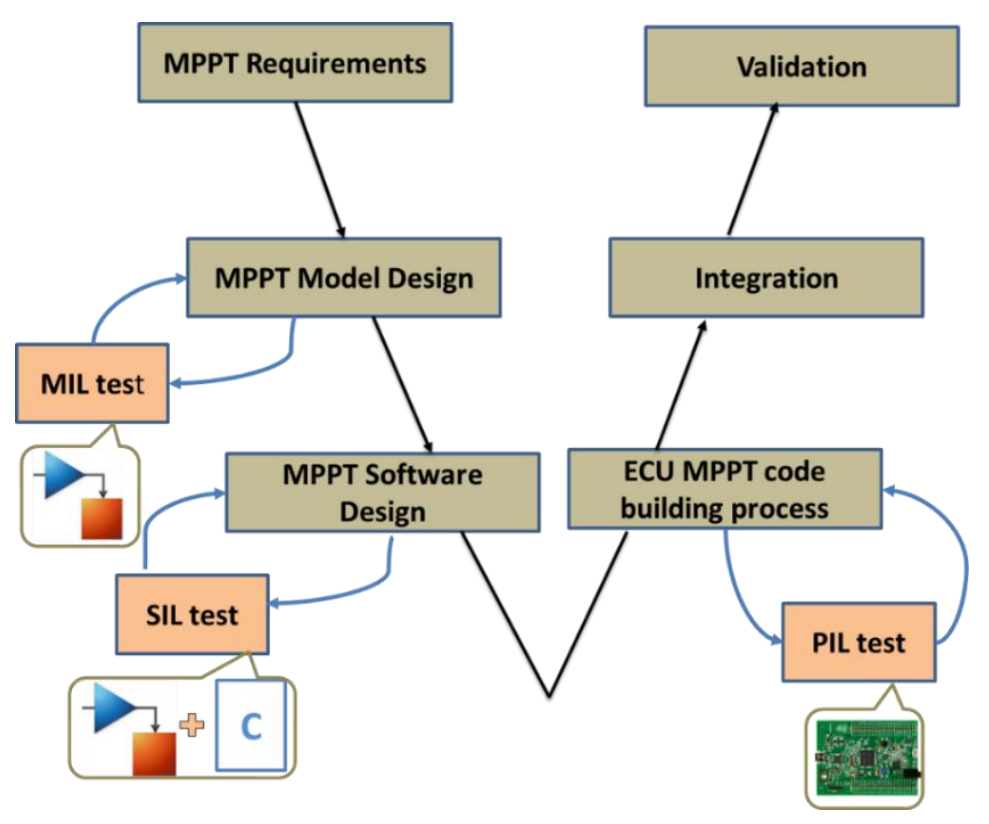

Figure 4. 22. MIL, SIL and PIL tests in V-Cycle development process. 
For instance, the use of a development cycle is recommended by the standard applied in the aeronautical (DO-178C norm) and automotive (ISO 26262 standard) areas [94], [95]. They recommend that the embedded software should follow a development cycle to achieve the objective of these standards, which is developing software in accordance with its requirements (MPPT algorithm requirements in our case). Since good processes make good software, a V-cycle development process is a suitable choice due to its accuracy, because it contains a verification process for each design process. As a result, an error may be detected through several verification activities. Consequently, we can remove a maximum of errors. If the objective is not attained, the software will not be certified [94], [95]; hence the software cannot be integrated in the aircraft. Therefore, when PV energy is used in hybrid electric aircraft, the MIL/SIL/PIL tests are suitable to be made by following the V-cycle development process for the MPPT software, that to check if this software is in accordance with its requirements and contribute to certify it. In addition, the tools used to generate and validate the software must be qualified by DO-178C standard [95]. Therefore, Matlab/Simulink is used in this work as a qualified tool [96].

Moreover, the choice of such MPPT algorithm is based on its tracking speed, steady-state performance and its ability to be implemented in embedded board ensuring high robustness. Hence, the most used are P\&O and INC algorithms; in particular, the INC algorithm which is a new version of $\mathrm{P} \& \mathrm{O}$, and it is used extensively due to its ability to reduce the steady-state oscillations [97]. Consequently, to improve its efficiency, a variable step-size is used [14]. However, this variable step can show poor performance in case of sudden irradiance variation. In addition, it can increase steadystate power oscillations [29]. Therefore, this work proposes a modified variable step-size.

On the other hand, the MPPT implementation step is required to test our algorithm under controlled conditions of temperature and irradiation. PV panels are unable to reproduce power desired by the tester due to the randomly fluctuating atmospheric conditions. Therefore, solar panel simulators are frequently used in place of actual PV panels [62]. Kok Soon Tey and Saad Mekhilef have used an Agilent solar array simulator for implementing a Modified incremental conductance MPPT algorithm [15]. Also, PV emulators by using programmable DC power supply are already proposed [98], [99]. However, solar array simulators or programmable DC power supply are expensive instruments and they are not always affordable. Therefore, the PIL test can be used as a low-cost solution to test the hardware implementation of the MPPT algorithm under different conditions of irradiation and temperature. 
Hence in this work, a modified variable step INC algorithm is used, which can reduce the steady-state oscillations and improve the tracking speed under sudden irradiance variation. In addition, this work aims to develop the proposed MPPT technique by following the V-cycle development process and using MIL/SIL/PIL tests, that for two reasons. Firstly, to take advantage of these kinds of tests and to provide a low-cost solution for testing MPPT. Secondly, to have a possibility of integrating the MPPT embedded software in the automotive or the aeronautical field. And as a result, use it for example in hybrid electric vehicles or aircraft.

\subsection{Modified variable step Incremental Conductance algorithm}

As shown in Figure 4.24, the used MPPT algorithm is based on the conventional INC algorithm, in which the controller gauges incremental variations in PV current and voltage to predict the impact of the command [26], [27]. This algorithm needs more calculation but can follow changing conditions faster than P\&O method [26]. However, like P\&O algorithm, INC can produce oscillations in the output power since the oscillations in steady-state are proportional to the step-size (Offset). If the step-size is high, then oscillations are high. Otherwise, the oscillations would be low, but the variation of the duty cycle $(\alpha)$ will be very low; this may slow down the tracking process. As a result, by using fixed step-size a trade-off problem exists between faster response and steady-state oscillations. Hence to improve MPPT algorithm performance a variable step-size was used as mentioned by equation (4.42) [14], where Ofsset , $_{0}$ is the scaling factor.

$$
\text { Offset }=\operatorname{Ofsset}_{0} \times a b s\left(\frac{\Delta P}{\Delta V}\right)
$$

However, this conventional variable step-size shown in (4.42) depends on the change of the PV power and PV voltage. Consequently, this traditional step-size can increase steady-state power oscillations. In addition, it can show poor performance in case of sudden irradiance variation. We can explain that as follows:

\section{- In case of stable irradiance:}

As shown in Figure 3.6, in the area near to MPP and voltage source region, the PV voltage change $(\Delta \mathrm{V})$ is very low; as a result, the $\Delta \mathrm{P} / \Delta \mathrm{V}$ steps will be large. Therefore, these large step-sizes can increase steady-state power oscillations; as a result, the algorithm efficiency is decreased.

Moreover, the $\mathrm{dP} / \mathrm{dV}$ term cannot achieve adaptive stepping at current source region and it is mathematically proven as follows. The $\mathrm{dP} / \mathrm{dV}$ term can be expanded into (4.43): 


$$
\frac{d P}{d V}=I+V \frac{d I}{d V}
$$

In the constant current source region, $\mathrm{I}_{\mathrm{PV}}$ approximately equal to $\mathrm{I}_{\mathrm{sc}}$, which is a constant. Consecutively the $\mathrm{dI} / \mathrm{dV}$ term becomes zero, and (4.43) can simplified into (4.44):

$$
\frac{d P}{d V}=I_{S C}
$$

This implies that $\mathrm{dP} / \mathrm{dV}$ term is a constant at constant current source region, and hence is unable to achieve adaptive stepping. As a result, the performance of the MPPT deteriorates.

- In case of irradiance variation: The conventional variable step can decrease the performance in case of sudden irradiance variation. During the variation in irradiance, mostly when it varies slowly and when the load is battery (Figure 4.23), the PV voltage change $(\Delta \mathrm{V})$ is very low whereas there is a significant PV power variation $(\Delta \mathrm{P})$ because of the change in irradiance affects PV current more than the PV voltage. Consequently, the $\Delta \mathrm{P} / \Delta \mathrm{V}$ steps will be large. Therefore, this moves the operating point far away from the new MPP, which in turn increases the time to reach the new MPP. Therefore, the algorithm efficiency is decreased.

In order to overcome this problem, a modified variable step-size (equation (4.45)) is used in this work, which depends only on the PV power change $(\Delta \mathrm{P})$ :

$$
\text { Offset }=\text { Ofsset }_{0} \times a b s(\Delta P)
$$

Where Ofsset ${ }_{1}$ is the scaling factor that is adjusted to compromise between the response time and reducing the steady-state oscillations.
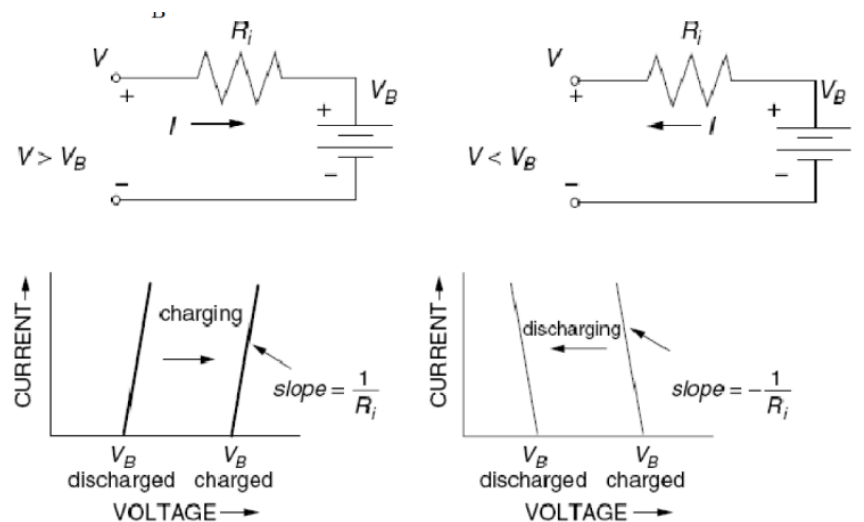

Figure 4. 23. Equivalent circuit of battery and I-V characteristic graph. 


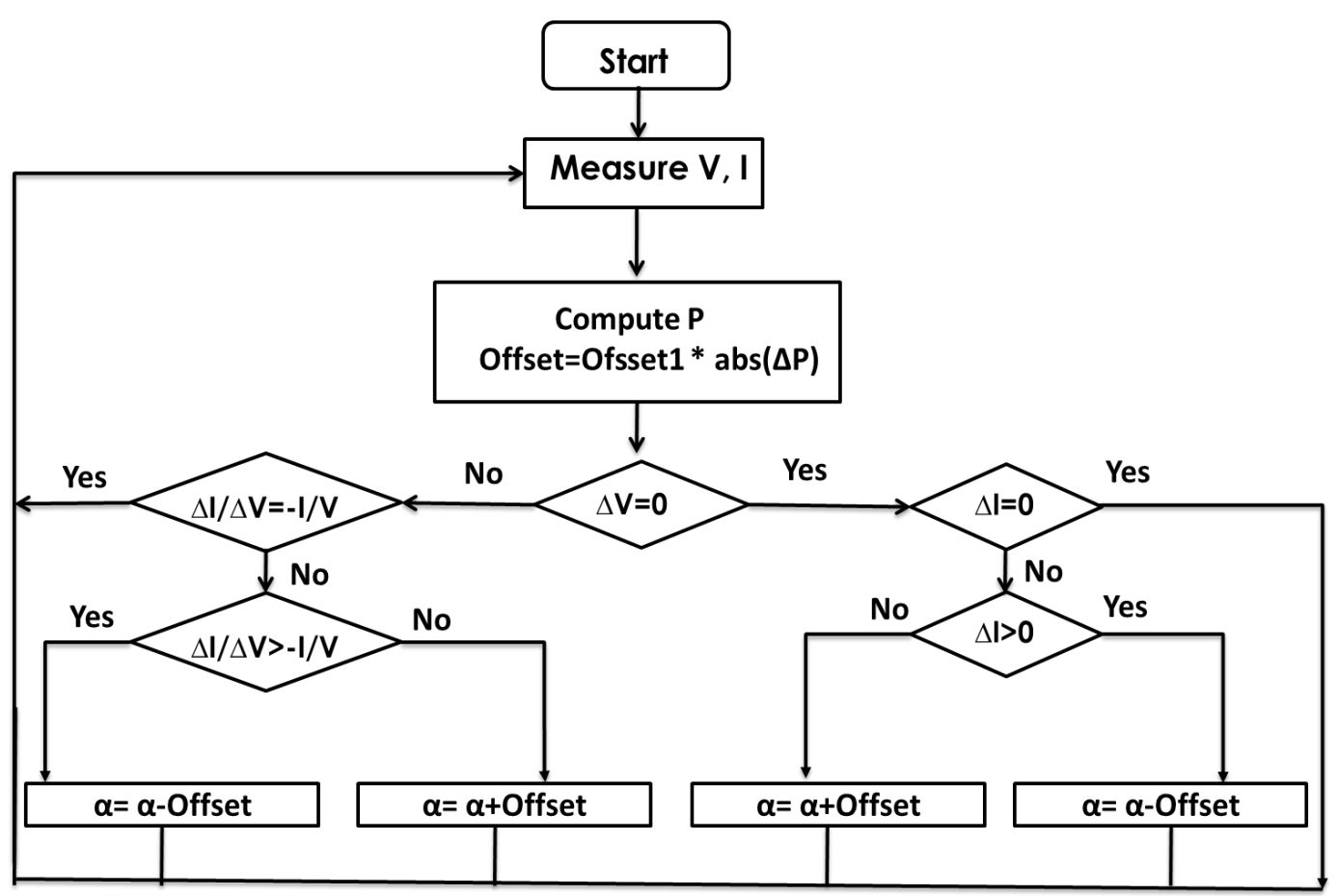

Figure 4. 24. Flow process diagram of modified INC control method for Boost.

As well, the Figure 4.25 describes the PV system implementing the modified variable stepsize INC algorithm using Model-Based Design in order to control the Boost converter:

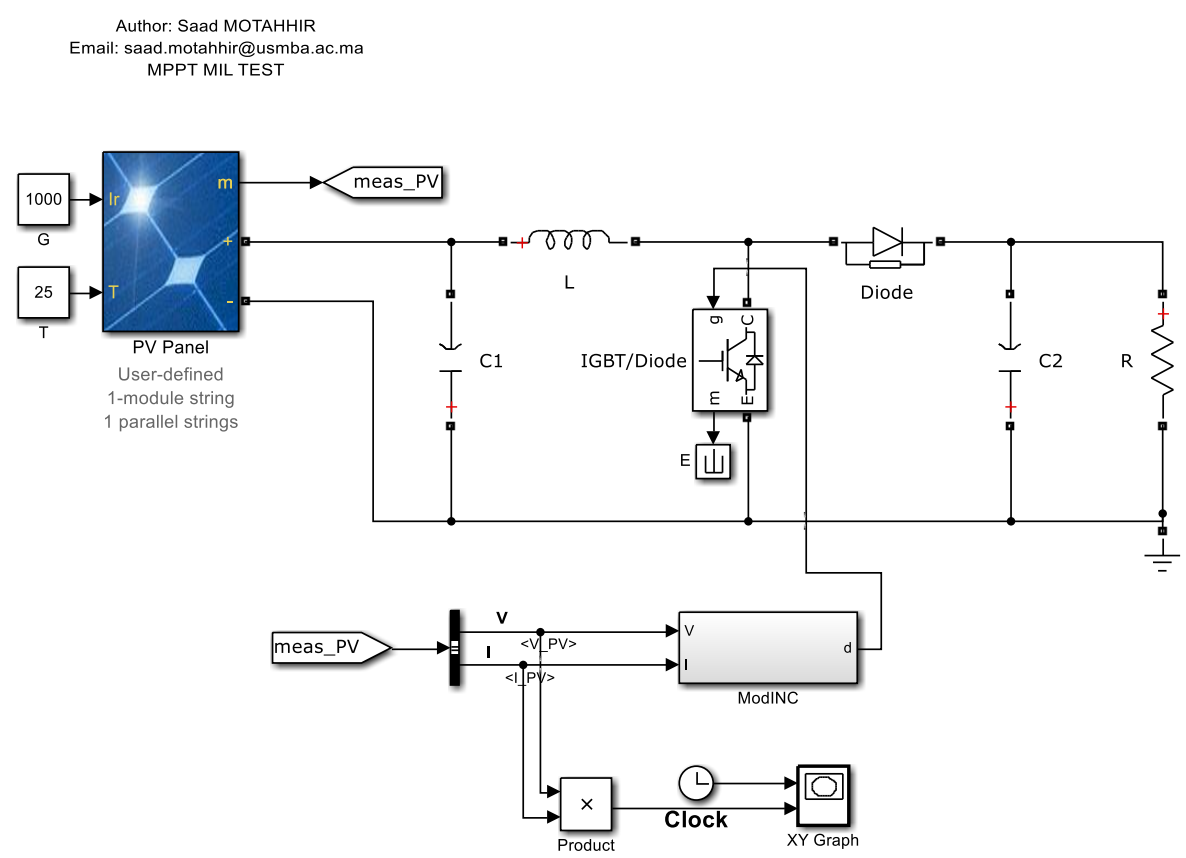

Figure 4. 25. The PV generation system.

The parameters of the designed Boost converter used in this work are given in the table below: 
Table 4.4. Parameters of the boost converter.

\begin{tabular}{|l|c|}
\hline Parameter & Value \\
\hline $\mathrm{L}$ & $3 \mathrm{mH}$ \\
\hline $\mathrm{C} 1$ & $100 \mu \mathrm{F}$ \\
\hline $\mathrm{C} 2$ & $100 \mu \mathrm{F}$ \\
\hline $\mathrm{F}$ & $10 \mathrm{kHz}$ \\
\hline $\mathrm{R}$ & $30 \Omega$ \\
\hline $\mathrm{A}$ & 0.6 \\
\hline
\end{tabular}

\subsection{MIL/SIL/PIL tests}

\subsubsection{Model in the Loop test}

The INC algorithm with the modified variable step is modeled and it is connected to the plant model (PV panel and Boost converter). In this step, the MPPT model is tested in a simulation environment (Simulink) and this process is called MIL test. This means that the controller model and the plant model are simulated on the host computer without any real hardware components [100].

The result obtained using MIL test under STC is presented in Figure 4.26, and as shown in the steady-state, the PV power is equal to $60.54 \mathrm{~W}$, which is the maximum power of the Solarex MSX60 panel under STC $\left(1000 \mathrm{~W} / \mathrm{m}^{2}\right.$ and $\left.25^{\circ} \mathrm{C}\right)$. Also, as shown the variable step-size used gives a fast response without steady-state oscillations.

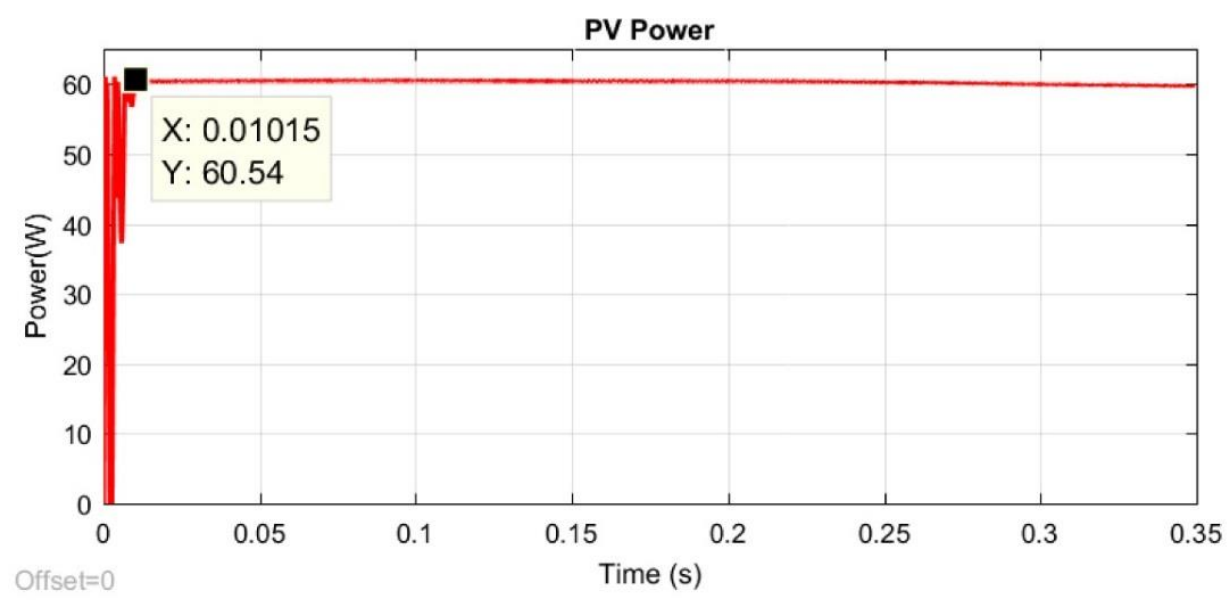

Figure 4. 26. Output power of PV system using MIL test under STC. 
Secondly, the MIL test is made under sudden irradiance variation, Firstly, the solar irradiation is suddenly modified from $500 \mathrm{~W} / \mathrm{m}^{2}$ to $1000 \mathrm{~W} / \mathrm{m}^{2}$, and next from $1000 \mathrm{~W} / \mathrm{m}^{2}$ to $800 \mathrm{~W} / \mathrm{m}^{2}$, and finally from $800 \mathrm{~W} / \mathrm{m}^{2}$ to $600 \mathrm{~W} / \mathrm{m}^{2}$. Figure 4.27 presents the test result, and as shown the modified algorithm presents faster response during irradiance changes and the steady-state oscillations are almost neglected.

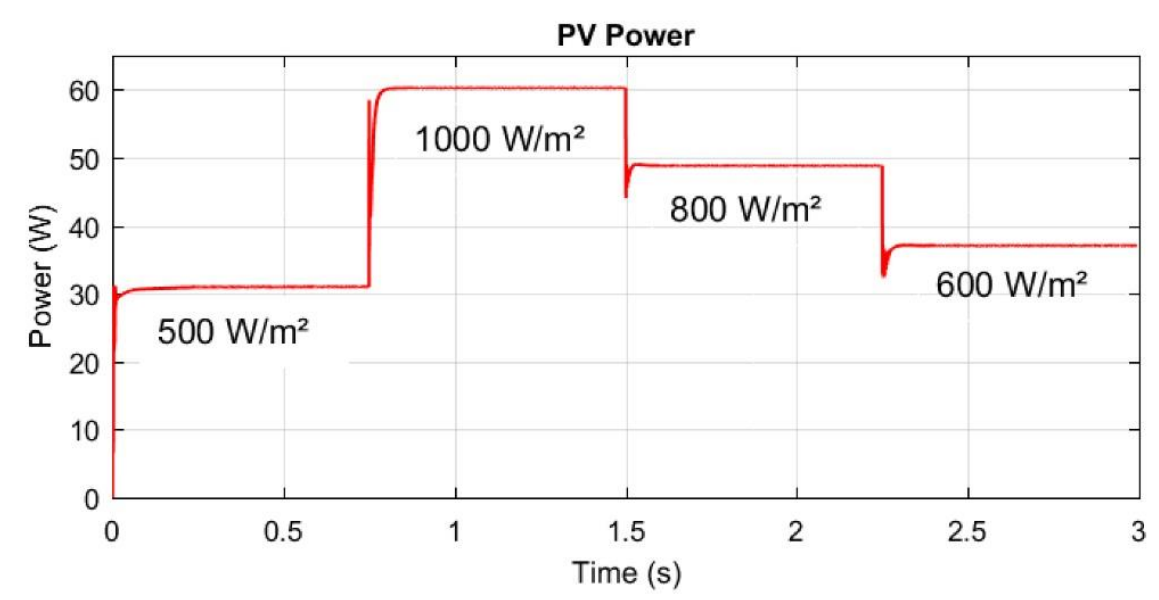

Figure 4. 27. Output power of PV system using MIL test under irradiance change.

\subsubsection{Software in the Loop test}

Once the model of the modified INC algorithm is validated using MIL method, the SIL method is the next step to check the code automatically generated from the MPPT model. SIL test means that the code is generated from the model for x86 target using Microsoft Windows SDK (Software Development Kit) and embedded coder tools as shown in Figure 4.28. That to test this code on the host computer without any hardware [100].

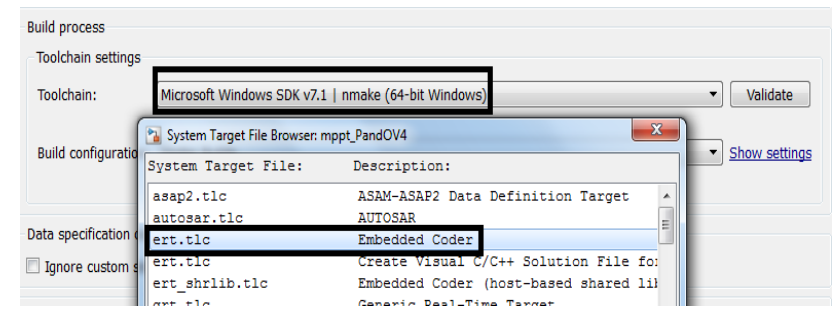

Figure 4. 28. Configuration interface.

As shown in Figure 4.29, to generate the SIL block, the option "Create Software-in-the-loop (SIL) block" must be selected before building the modified variable step INC model. 


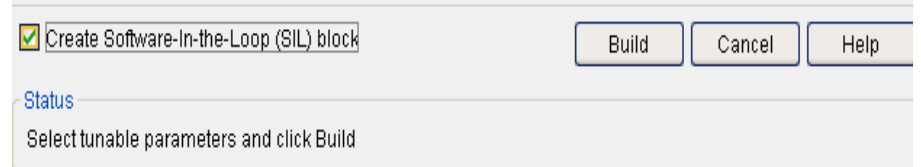

Figure 4. 29. Panel for generating the software.

As displayed in Figure 4.30, the code generated is implemented in the S-function block provided by Simulink, and this block is connected to the plant model (PV panel and the Boost).

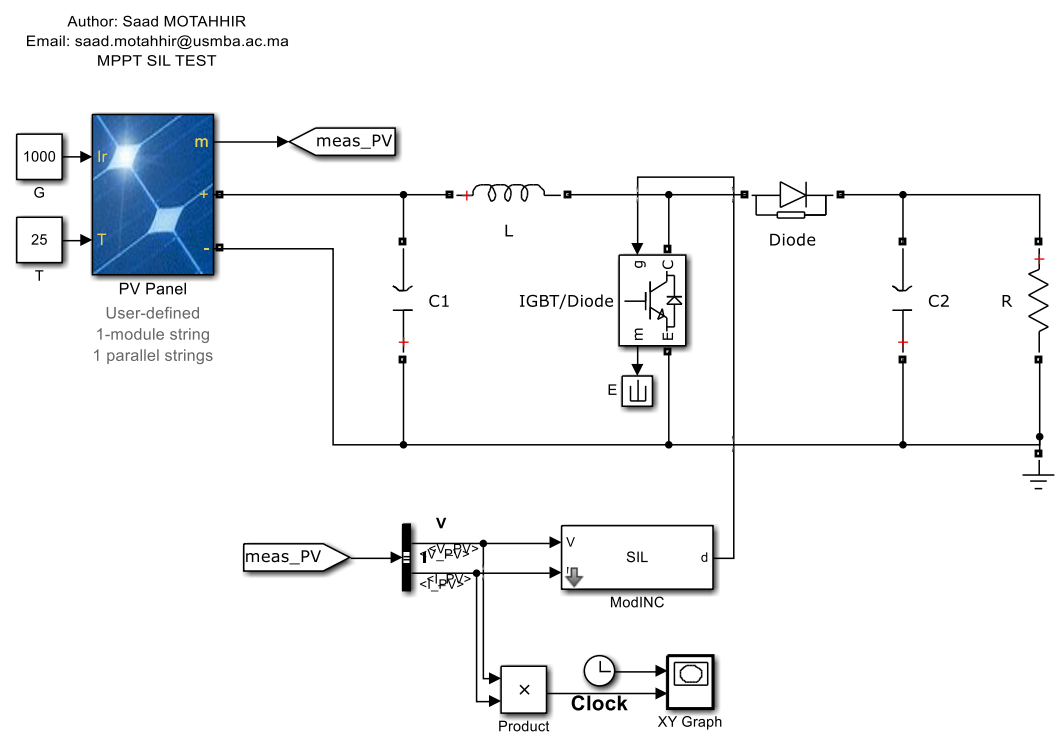

Figure 4. 30. The PV generation system using SIL block.

The result obtained using SIL test is presented in Figure 4.31. The result of this test is compared with that of the MIL test. And as shown, the SIL result is in accordance with MIL result.

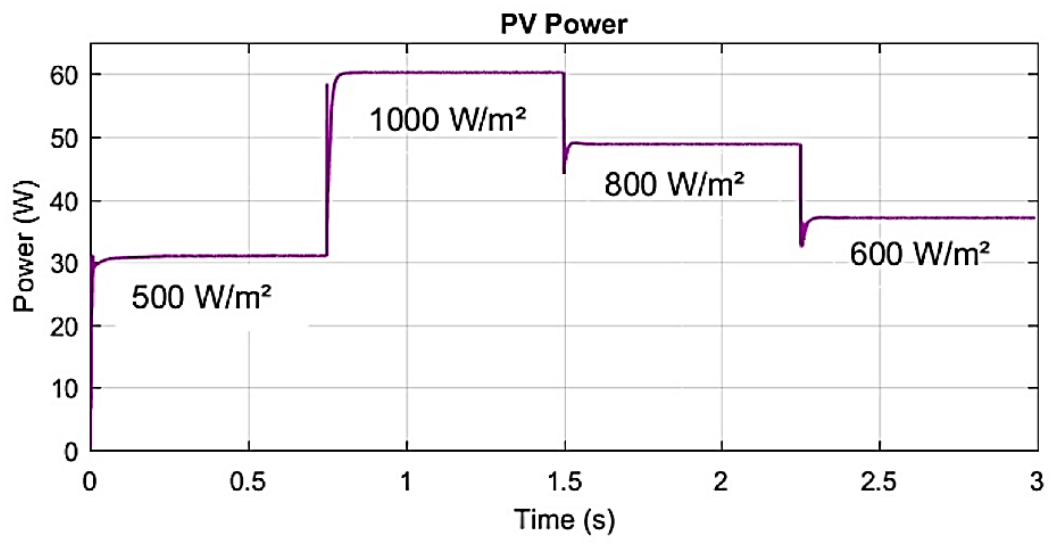

Figure 4. 31. Output power of PV system using SIL test under irradiance change.

\subsubsection{Processor in the Loop test}


Once the software of the modified variable step INC algorithm is validated using SIL method, the PIL method is the next step to check the automatically generated embedded software and to test the implementation of our MPPT algorithm.

PIL test means that the code is generated from the model for the embedded target by using the target's compiler and embedded coder tool, in order to load and run the generated hex file on the embedded board. However, the plant model is simulated on the host computer. And they are connected by USB cable. The PIL test process is a fundamental step of the development cycle to check that the comportment of the deployment code covers the requirements of our algorithm [100], [101].

The embedded board used in this test is STMicroelectronics STM32F4 Discovery board as shown in Figure 4.32. The microcontroller integrated into this board is STM32F407VG from ST Microelectronics. This microcontroller contains a 32-bit ARM Cortex-M4F CPU with 1 Mbyte flash memory, 192 Kbytes SRAM and a maximum clock frequency of $168 \mathrm{MHz}$, and with FPU (Floating Point Unit) and DSP instructions. It also provides communication interfaces like CAN/USB [102]. So the more calculation needed by the modified INC algorithm can be covered by this board due to the hardware resources it contains.

So the hex file is generated from the Simulink model for this board by using its toolchain (GNU Tools for ARM Embedded Processors) and embedded coder tools.

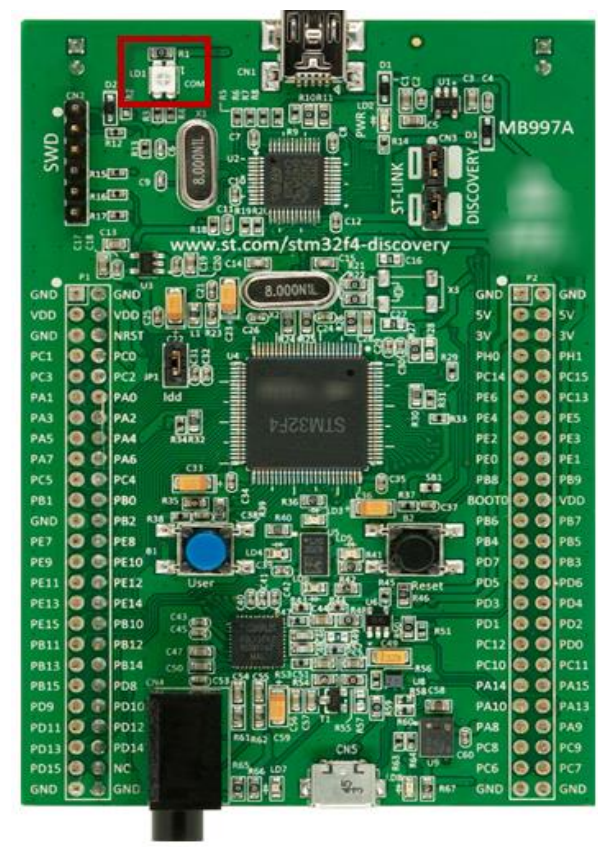

Figure 4. 32. STMicroelectronics STM32F4 Discovery board. 
Since the PIL test means that the MPPT software will be run on the STM32F4 Discovery board, and the plant model will be simulated on the host computer, the communication interface between the two parts is needed. Therefore, the ST-LINK communication is used as shown in Figure 4.33, which does not require any additional cables or hardware besides a USB type A to Mini-B cable.

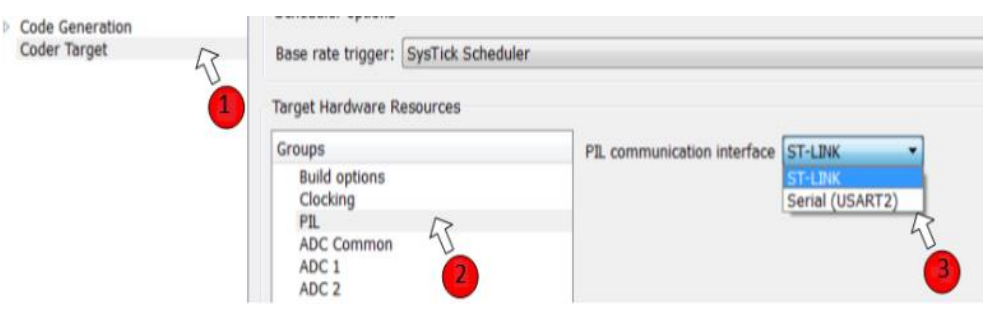

Figure 4. 33. Select the ST-LINK communication.

To configure Simulink to run PIL test, we have to enable PIL verification as shown in Figure 4.34.

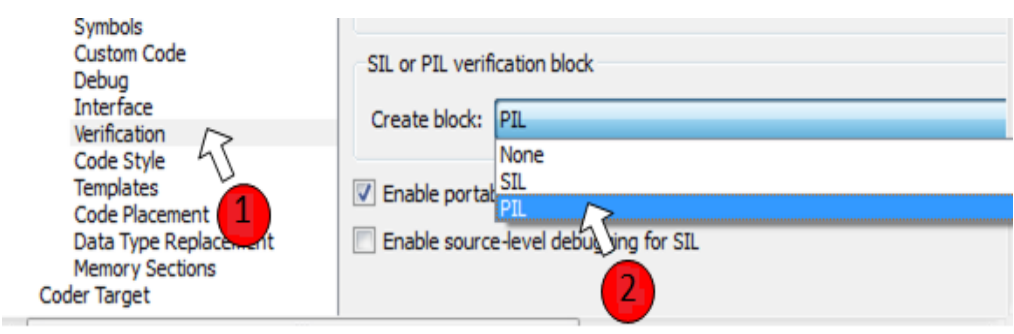

Figure 4. 34. Configure a Simulink model to run PIL.

As shown in Figure 4.35, in order to create a PIL block for the MPPT Controller, the STM32F4 Discovery is selected as a target hardware.
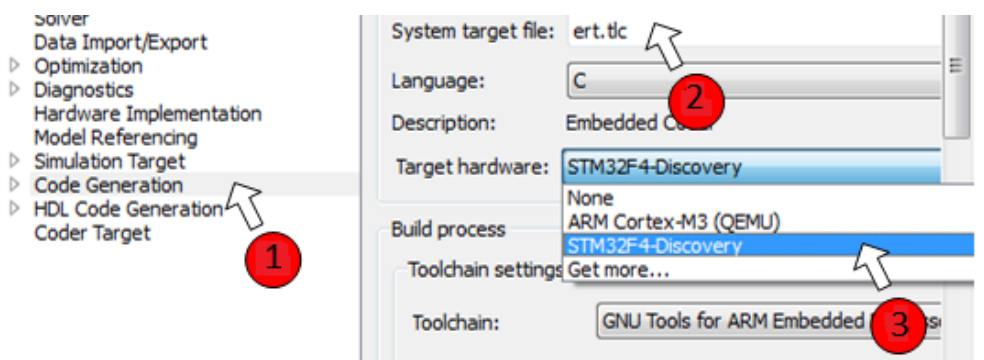

Figure 4. 35. Select STMicroelectronics STM32F4 Discovery board.

As shown in Figure 4.36, Baremetal or CMSIS-RTOS RTX can be used as an operating system (OS). Both OS will offer similar performance; however, each OS use different scheduling algorithm. For efficiency and full visibility of the scheduler code choose Baremetal, and prefer CMSIS-RTOS RTX to generate code compatible with legacy code. 


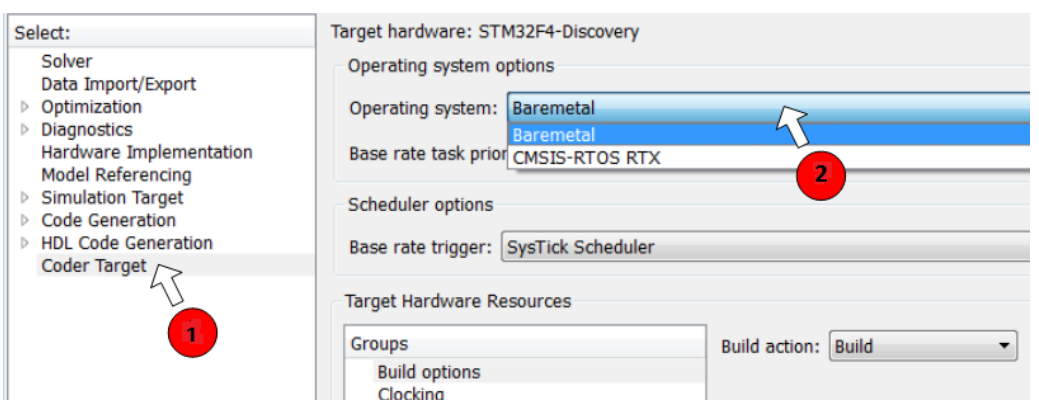

Figure 4. 36. Choose the operating system.

As presented in Figure 4.37, the PIL block is generated and connected to the plant model so as to acquire the PV voltage and current, after that the PIL block will compute the duty cycle by using the modified algorithm and send it to the plant model through the ST-Link interface.

The result obtained using PIL test is presented in Figure 4.38. And it is compared with that of the MIL and SIL tests, and as shown the PIL result is in accordance with MIL and SIL results.

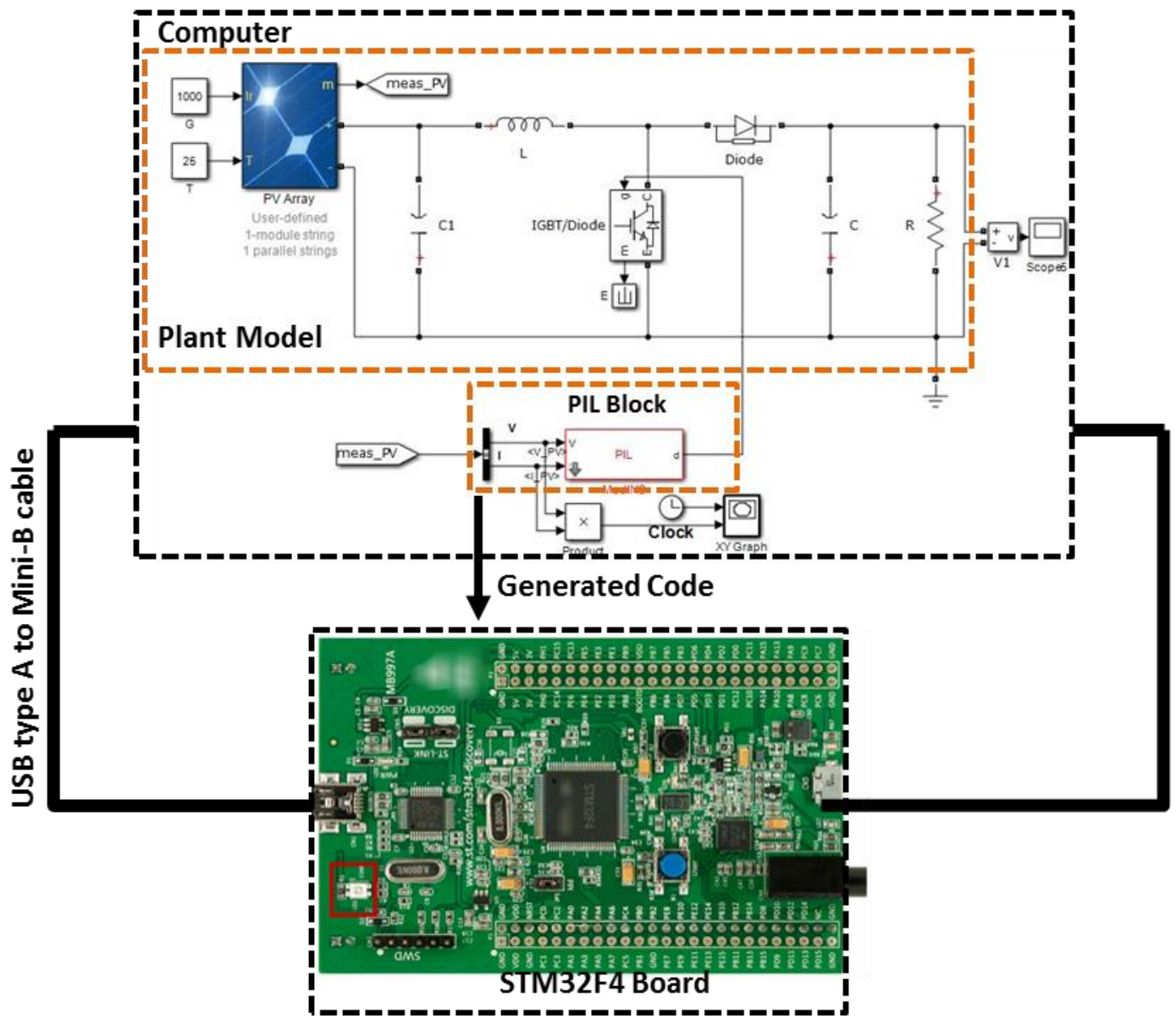

Figure 4. 37. The PV generation system using PIL block. 


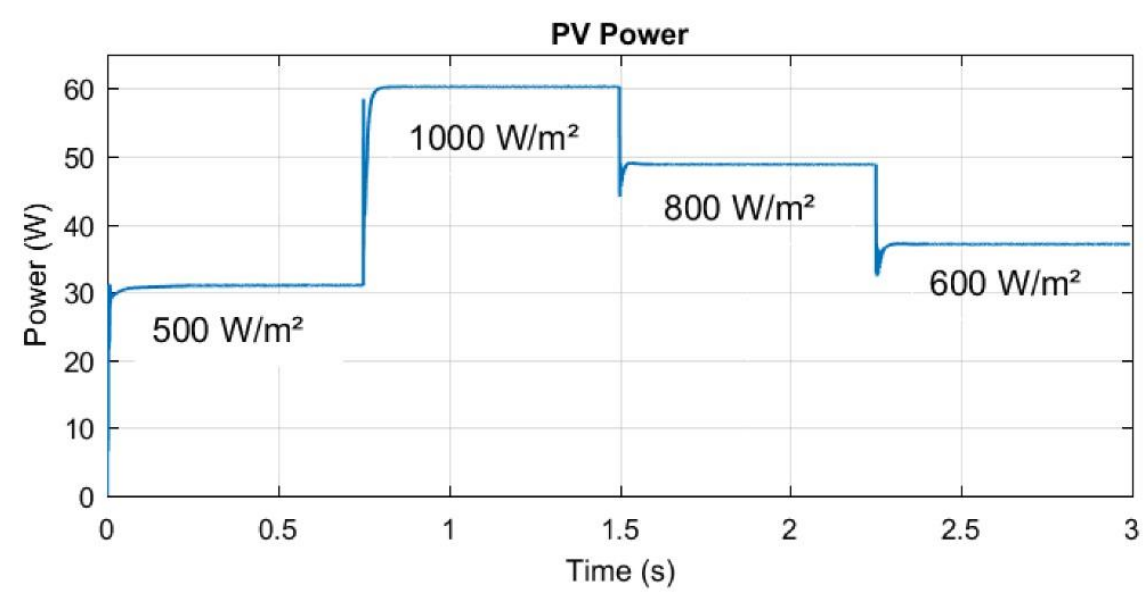

Figure 4. 38. Output power of PV system using PIL test under irradiance change.

By using PIL test, both Simulink and STM32F4 board will run at the same time and will exchange data based on the modified MPPT algorithm implemented by the PIL block. Therefore, PIL test can be used as a low-cost solution to test the hardware implementation of MPPT algorithm under different conditions of irradiation and temperature.

\subsection{Recapitulation}

Note that, if the tests' results (MIL/SIL/PIL) are different or they are not in accordance with the algorithm requirements, it means that somewhere in the process there is a problem. For example, if MIL behavior is not in accordance with the algorithm requirements, it means that there is a mismatch between Simulink model and algorithm. Therefore, it is required to correct the model according to the algorithm requirements. Thus, if SIL result is not in accordance with MIL result, that means that the software generated from the model for the host computer is not in accordance with the model. Therefore, it is required to correct the software according to the algorithm requirements. The same for PIL, if its result is not in accordance with MIL and SIL results, it means that the software generated from the model for the STM32F4 Board is not in accordance with the model. Therefore, it is required to correct the software according to the algorithm requirements. Furthermore, according to DO-178C, the objective is to produce software that is compliant with its requirements (MPPT algorithm) [95].

On the other hand, the performances of the modified variable step INC algorithm are compared to the achievements of different variable step INC algorithms proposed in some existing works in Table 4.5. As shown, our proposed presents the faster response and one of the highest efficiencies of more than $98 \%$, thus the power ripples are almost neglected. 
Table 4.5. Comparison between the proposed work and some existing works in the area of PV systems.

\begin{tabular}{|c|c|c|c|c|c|}
\hline $\begin{array}{c}\text { Reference, } \\
\text { Publication } \\
\text { year }\end{array}$ & Variable step & Controller used & $\begin{array}{c}\text { Power } \\
\text { ripples }\end{array}$ & Efficiency & $\begin{array}{c}\text { Response } \\
\text { time }\end{array}$ \\
\hline$[90],(2014)$ & $\begin{array}{c}\text { Choose between } \Delta \mathrm{D}_{1} \\
\text { and } \Delta \mathrm{D}_{2}\end{array}$ & $\begin{array}{c}\text { Xilinx XC3S400 } \\
\text { FPGA }\end{array}$ & $2.7 \mathrm{~W}$ & $98.8 \%$ & $2.5 \mathrm{~ms}$ \\
\hline$[26],(2015)$ & $\begin{array}{c}\text { Step=N* abs } \\
(\Delta \mathrm{P} / \Delta \mathrm{V})\end{array}$ & PIC18F4520 & $2 \mathrm{~W}$ & $97.97 \%$ & $0.4 \mathrm{~s}$ \\
\hline$[79],(2015)$ & $\begin{array}{c}\mathrm{Step}=\mathrm{N}^{*} \text { abs } \\
(\Delta \mathrm{P} /(\Delta \mathrm{V}-\Delta \mathrm{I}))\end{array}$ & dsPIC30F4011 & $2 \mathrm{~W}$ & $98 \%$ & $0.5 \mathrm{~s}$ \\
\hline Our work & $\begin{array}{c}\text { Offset=Offset } t_{1} \text { abs } \\
(\Delta \mathrm{P})\end{array}$ & STM32F407VG & neglected & $98.8 \%$ & $0.02 \mathrm{~s}$ \\
\hline
\end{tabular}

\section{Summary}

In this chapter, a modified INC algorithm that can overcome the confusion faced by the conventional INC algorithm is proposed. As a result, the tests show that the modified algorithm detects the fast increase of irradiation and makes a correct decision, contrary to the conventional algorithm. Moreover, by using the modified algorithm steady-state oscillations are almost neglected. Hence, the loss of energy is minimized. As a result, the efficiency is equal to $98.8 \%$ instead of $96 \%$ obtained by the conventional technique. In addition, another modification is made in the modified INC algorithm which is the elimination of all division computations found in the conventional INC algorithm. This has rendered the algorithm structure simpler and has decreased the required real processing time. Hence, the modified algorithm can be easily implemented by low-cost microcontrollers (as Atmega328 in our case) in order to propose a low-cost embedded board and then minimize system cost. In addition, simulation and experimental results show that the modified algorithm reduces the execution time and as a result makes simple the controller process. As a result compared to the conventional INC algorithm, the modified algorithm can track the MPP correctly with faster response and less steady-state oscillations during sudden changes, and that is thanks to the simple structure of the modified algorithm. Note that the result obtained by Proteus simulation is nearly the same obtained by experimental work. As a result, we can base on this Proteus test bench to check the excellent performance of such MPPT algorithm.

On the other hand in this chapter, a modified variable step-size is presented. To perform correctly in case of sudden irradiance variation. Then, three manners of tests (MIL/SIL/PIL) mostly used for automotive and aeronautical embedded systems are employed to validate the functionality 
and robustness of the modified variable step INC algorithm. As a result, the responses of the three tests are in accordance with the MPPT algorithm requirements. Hence this work contributes to achieve the objective of DO-178C and ISO 26262 standards. In addition, the results show that the modified algorithm avoids the steady-state oscillations and increases the tracking speed under sudden irradiance variation. In light of that, the MPPT is tested on STM32F4 Discovery board; therefore the performance obtained will be the same by using a real PV panel. Consequently, the PIL test can be used as a low-cost solution to test the hardware implementation of MPPT algorithm under different conditions of irradiation and temperature. So by using these kinds of tests, we took advantage of safety level integrated in automotive and aeronautical embedded systems. And In this sense, integrating the MPPT embedded system in the automotive or the aeronautical area will possible 


\section{Chapter 5}

\section{Kalman Filter based MPPT}

- Introduction

- Kalman filter based MPPT

- Results and discussions

- Summary 


\section{Introduction}

As presented in chapter 2, MPPT algorithms differ in many aspects such as cost, efficiency, response time, required sensors, accurate tracking in case of temperature or solar irradiance change, and implementation complexity [103]. The most commonly used algorithms are fuzzy logic control, neural networks, Perturb and observe, and Incremental Conductance [12], [104]. For fuzzy logic control, it has some advantages like dealing with imprecise inputs, handling nonlinearity, and fast convergence. However, this algorithm requires hardware with high specifications, high on complexity, and the effectiveness of this algorithm depends a lot on choosing the correct error computation and an appropriate rule base [104]. The neural networks can track the MPP accurately and rapidly. Nevertheless, this technique presents many disadvantages like the fact that the data needed for the training process has to be specifically acquired for every PV panel and location, also the PV characteristics change with time, so the neural network has to be periodically trained [104]. On the other hand, P\&O and INC are the most used due to their easy implementation and their low requirements in hardware and number of sensors [14], [16]. However, $\mathrm{P} \& \mathrm{O}$ algorithm presents some disadvantages such as high oscillation around the MPP because the perturbation continuously changes in both directions to maintain the MPP [14]. Therefore, INC algorithm was proposed to minimize the steady-state oscillation by comparing the slope of the P-V curve with zero, theoretically, when the peak of the P-V curve is found, no further perturbation of duty cycle or no oscillation in the output power [16]. However, the algorithm speed is slow when fixed step size is used. Therefore, the variable step size in INC algorithm was proposed in [105], which means, the fixed step size is multiplied with the slope of the P-V curve. Thus, the duty cycle step size becomes smaller when the PV system operates near to the MPP (peak of the P-V curve). Meanwhile, the step size is larger and possesses faster-tracking speed when the PV system operates far from the MPP.

However, INC and variable step size INC algorithms are unable to respond accurately to the first step change in the duty cycle under rapid environmental changes [15]. Therefore, a powerful method to predict the new position of MPP under rapid environmental changes must be used to resolve this problem. Since Kalman filter can provide an efficient computational (recursive) solution of the least-squares method. The filter is very powerful in several aspects: it supports estimations of past, present, and even future states, and it can do so even when the precise nature of the modeled system is unknown [30]. Hence, this filter can be used to respond accurately to rapid environmental changes. Thus, in [106], [107] the Kalman filter was designed to find the MPP, but their design may not be practical in all situations of rapid environmental changes, because it is not tested under 
temperature and solar irradiance variation. Therefore, Kalman filter based MPPT is designed in this chapter, this proposed method responds accurately to all situations of rapid environmental changes. On the other hand, the proposed method is compared with INC algorithm to verify and evaluate its performance, because based on the analysis above, INC algorithm balances between admitted response time and excellent steady-state performance. The architecture of the PV system used in this work is presented in Figure 5.1. As shown, a Boost converter controlled by the MPPT algorithm is inserted between the PV panel and the load; this addition is required to remove the impedance mismatch between the panel and the load, and then the PV system can operate at MPP. The MPPT algorithms (Kalman filter or INC) are implemented in C language by using C block provided by PSIM tool and they are tested using 'Software In the Loop' method.

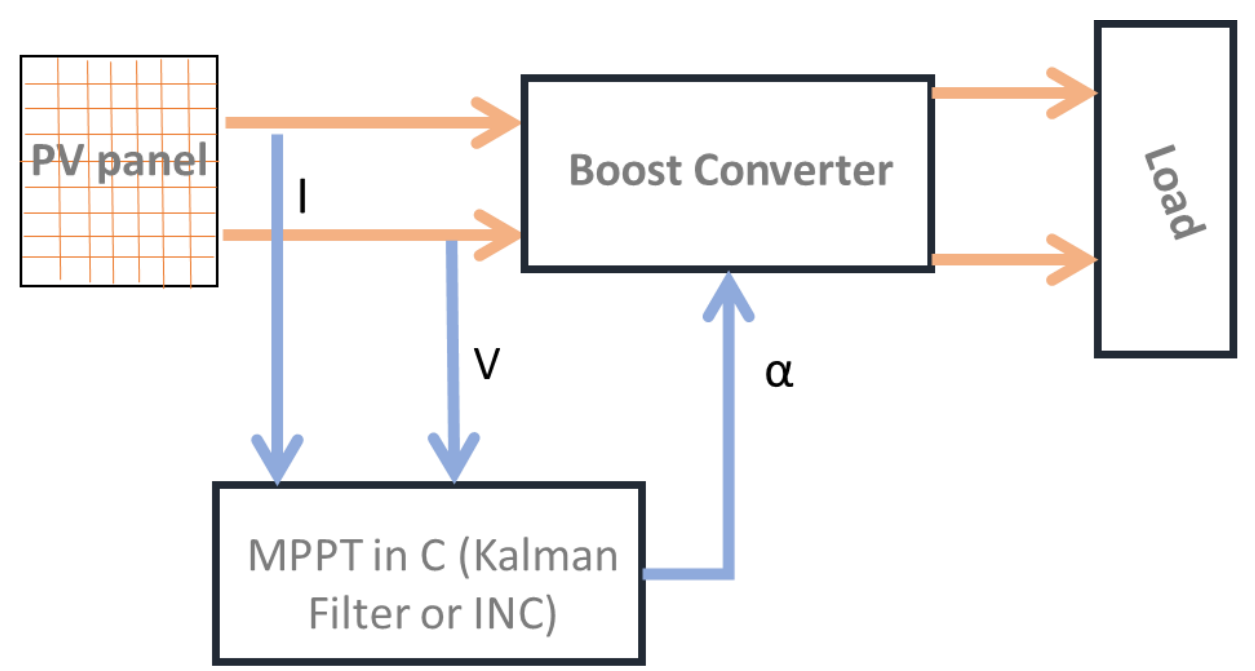

Figure 5.1. The architecture of the PV system.

\section{Kalman filter based MPPT}

\subsection{Kalman filter design}

The Kalman filter is a set of mathematical equations that provides an efficient computational (recursive) solution of the least-squares method. The filter is very powerful in several aspects: it supports estimations of past, present, and even future states, and it can do so even when the precise nature of the modeled system is unknown [106]. In 1960, R.E. Kalman published his famous paper describing a recursive solution to the discrete data linear filtering problem [30]. Since that time, due in large part to advances in digital computing; the Kalman filter has been the subject of extensive research and application, particularly in the area of autonomous or assisted navigation. 
In this filter, two set of equations are used during each iteration. The first set is called "the time update" or also "the prediction state"; it is composed of two equations. The first equation is used to project the state ahead [108], [114].

$$
\hat{x}_{k}^{-}=A \hat{x_{k-1}}+B u_{k-1}
$$

Where:

- $\quad x_{k}$ is the state estimate at iteration $\mathrm{k}$ calculated from previous iteration.

- $\quad x_{k-1}$ is the state corrected at iteration k-1 given by the measurement output $z_{k-1}$.

- $\quad u_{k-1}$ is the control process at the iteration $\mathrm{k}-1$.

- $A$ is a constant that depends on the system in which the Kalman filter is used; it is the state transition model that is applied to the previous state.

- $\quad B$ is a constant that depends on the system in which the Kalman filter is used; it is the control input model that is applied to the control process.

The second equation is used to project the error covariance ahead [108]:

$$
P_{k}^{-}=A P_{k-1} A^{T}+Q
$$

Where:

- $Q$ is the process noise covariance. It is a covariance matrix associated with the noise in states, it is generally constructed intuitively but there are some points that need to be regarded choosing it. Unmodeled dynamics and parameter uncertainties are modeled as process noise generally.

- $\quad P_{k}^{-}$is the priori error covariance at iteration $\mathrm{k}$.

- $\quad P_{k-1}$ is the posteriori error covariance at iteration k-1.

The second set of equation is called "the measurement update" or also the "correction state" and it is used to correct the value predicted during "the time update" step. This set of equations is constituted from three equations presented below [108]:

First, we compute the Kalman gain:

$$
K_{k}=P_{k}^{-} C^{T}\left(\mathrm{C} P_{k}^{-} C^{T}+R\right)^{-1}
$$


Then we update the estimate $x_{k}$ via the measurement output $z_{k}$ :

$$
\hat{x_{k}}=\hat{x}_{k}^{-}+\mathrm{K}_{k}\left(\mathrm{z}_{k}-C \hat{x_{k}}\right)
$$

The last equation updates the error covariance:

$$
P_{k}=\left(1-\mathrm{K}_{k} C\right) P_{k}^{-}
$$

Where:

- $\quad x_{k}$ is the state corrected at iteration k given by the measurement output $z_{k}$.

- $\quad P_{k}$ is the posteriori error covariance at iteration $\mathrm{k}$.

- $K_{k}$ is the Kalman gain.

- $R$ is the measurement noise covariance. It can be found by processing the measurement while the output of the system is held constant. In this case, only noise remains in the data after its mean is removed.

- $\quad z_{k}$ is the measurement value.

- $\quad C$ is a constant that depends on the system in which the Kalman filter is used; it is the observation model which maps the true state space into the observed space.

These two steps "the time update" and "the measurement update" are repeated during each iteration which causes noise to reduce and the error covariance to become zero [108].

\subsection{Design the MPPT algorithm using Kalman filter}

In order to find the MPP using the Kalman filter, we need to design this filter to look for the voltage at the MPP. Therefore, based on the P-V curve shown in Figure 3.6, the power increases with a gradual positive slope until reaches one optimal point then after that it decreases with a negative slope. Using this analysis, the voltage at MPP can be predicted using equation (5.6) and the priori error covariance is computed by equation (5.7), where $\mathrm{A}$ is 1 and $\mathrm{B}$ is $\mathrm{M}$.

- The prediction state:

$$
\begin{aligned}
& \hat{V}_{k}^{-}=\hat{V}_{k-1}+M \frac{\Delta P_{k-1}}{\Delta V_{k-1}} \\
& P_{k}^{-}=P_{k-1}+Q
\end{aligned}
$$


Where:

$-\hat{V}_{k}^{-}$is the value of voltage estimated by the Kalman filter based MPPT at iteration $\mathrm{k} . \hat{V}_{k}^{-}$is analogous to $\hat{x}_{k}$.

- $\quad M$ is the scaling factor, it is analogous to $B$.

- $\Delta P_{k-1} / \Delta V_{k-1}$ is the slope of the P-V curve at iteration $\mathrm{k}-1$. This slope is analogous to the control unit $u_{k-1}$.

- The measurement update:

Using the error covariance from the prediction state, the Kalman gain $K_{k}$ is calculated by equation (5.8), where $C$ is 1 :

$$
K_{k}=P_{k}^{-}\left(P_{k}^{-}+R\right)^{-1}
$$

The measurement update equations correct the state and covariance predicted with the measurement PV voltage $V_{i n, k}$.

$$
\begin{aligned}
& \hat{V_{k}}=\hat{V}_{k}^{-}+K_{k}\left(\mathrm{~V}_{\mathrm{in}, k}-\hat{V}_{k}^{-}\right) \\
& P_{k}=\left(1-K_{k}\right) P_{k}^{-}
\end{aligned}
$$

Where $\hat{V}_{k}$ is the value of voltage corrected by the Kalman filter based MPPT at iteration k given by the measurement PV voltage $V_{i n, k}$.

Figure 5.2 shows the PV panel model connected to the Boost converter controlled by embedded software running Kalman filter based MPPT developed using C language and C block provided by PSIM tool. This kind of simulation is called 'software-in-the-loop' test, it is used to test the software of the algorithm ( $\mathrm{C}$ code in our case) within a modeling environment (PV panel and Boost converter in our case) that can help prove or test the software of the controller (MPPT algorithm in our case). SIL testing and simulation can thus be a useful technique for software proving at earlier stages of the design. 


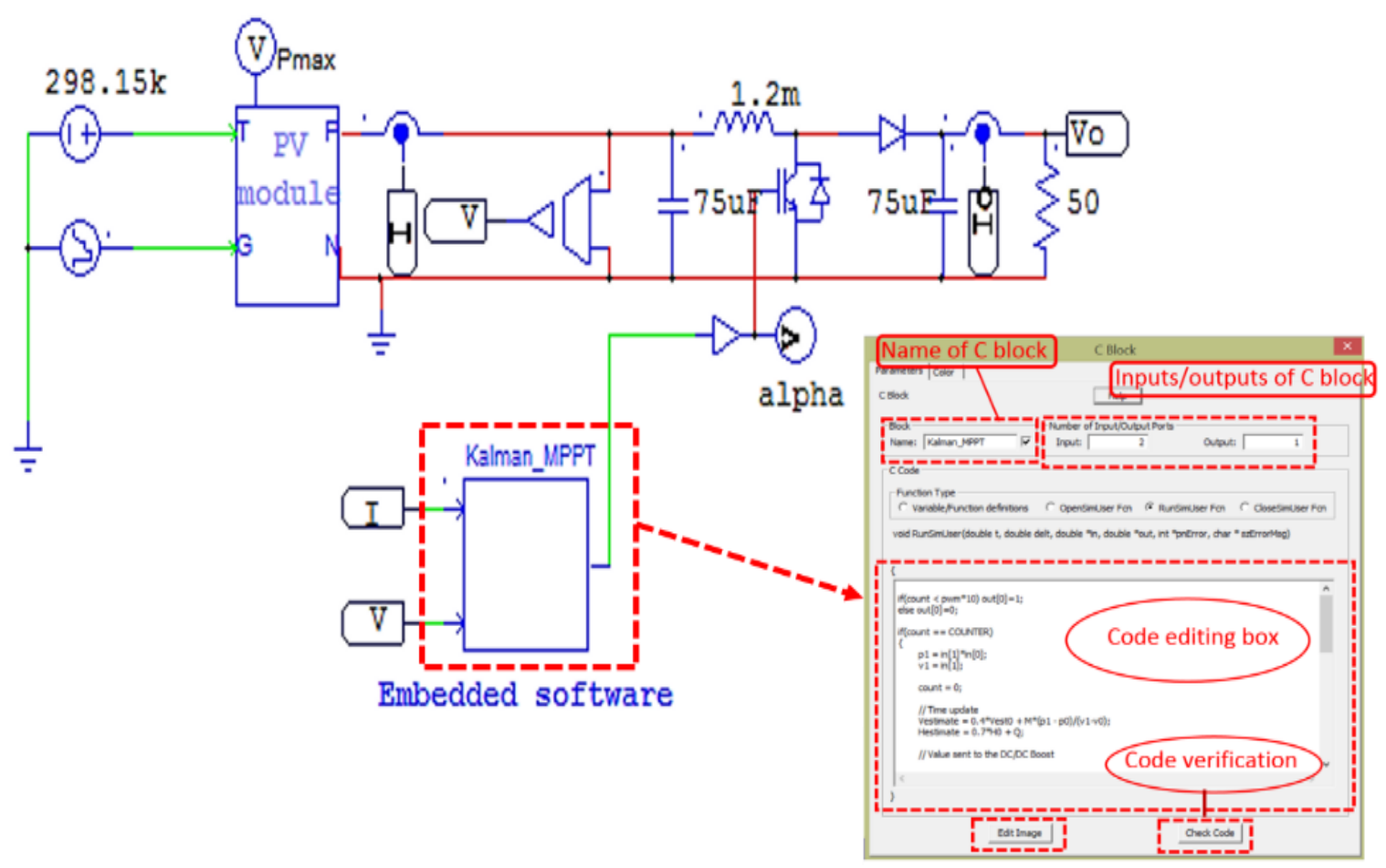

Figure 5.2. Software-in-the-loop test for the Kalman filter based MPPT on PSIM.

\section{Results and discussions}

In this section, the results obtained from simulating both methods under different values of temperature and solar irradiance are presented. The first simulation is done under STC. The second is done under variable solar irradiance and then variable temperature. A comparison of results obtained by these two methods is done and a summary of the results is shown in Tables 5.1 and 5.2.

\subsection{Tests under standard test conditions}

\subsubsection{INC algorithm}

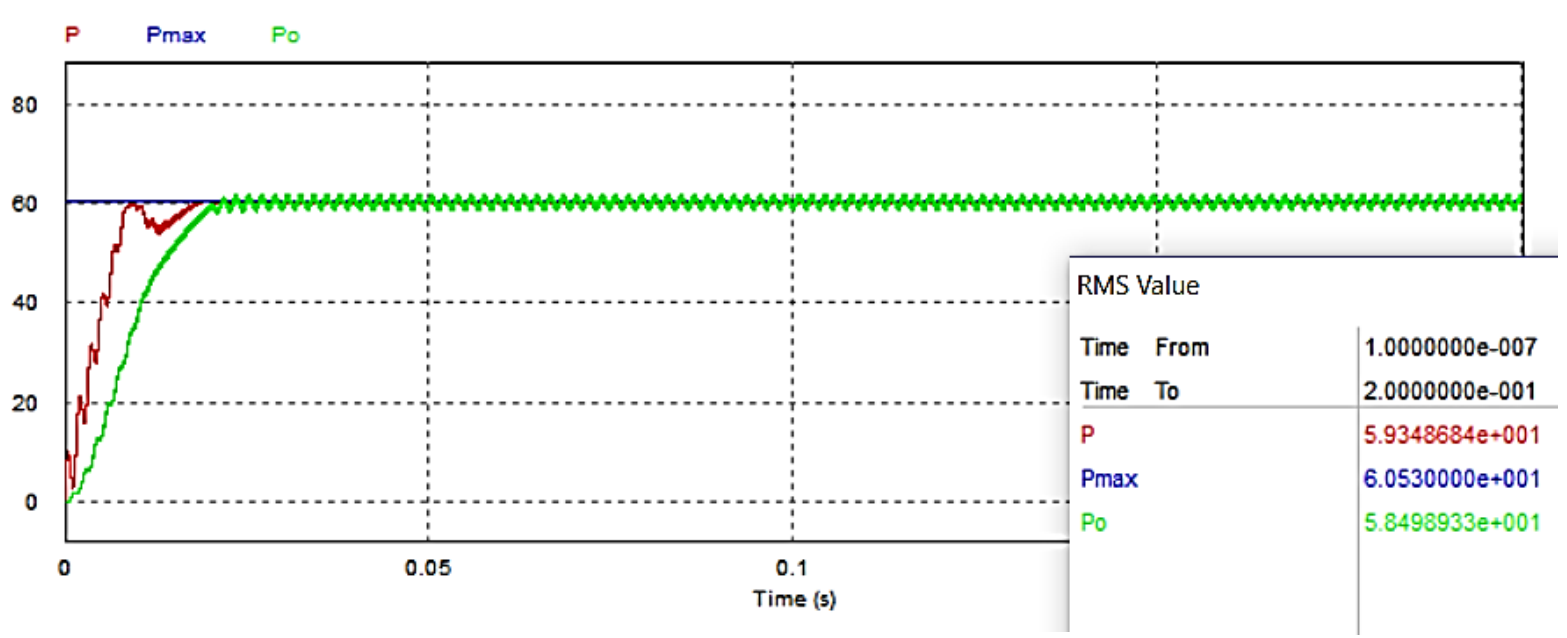

Figure 5.3. The output powers for INC algorithm under STC. 


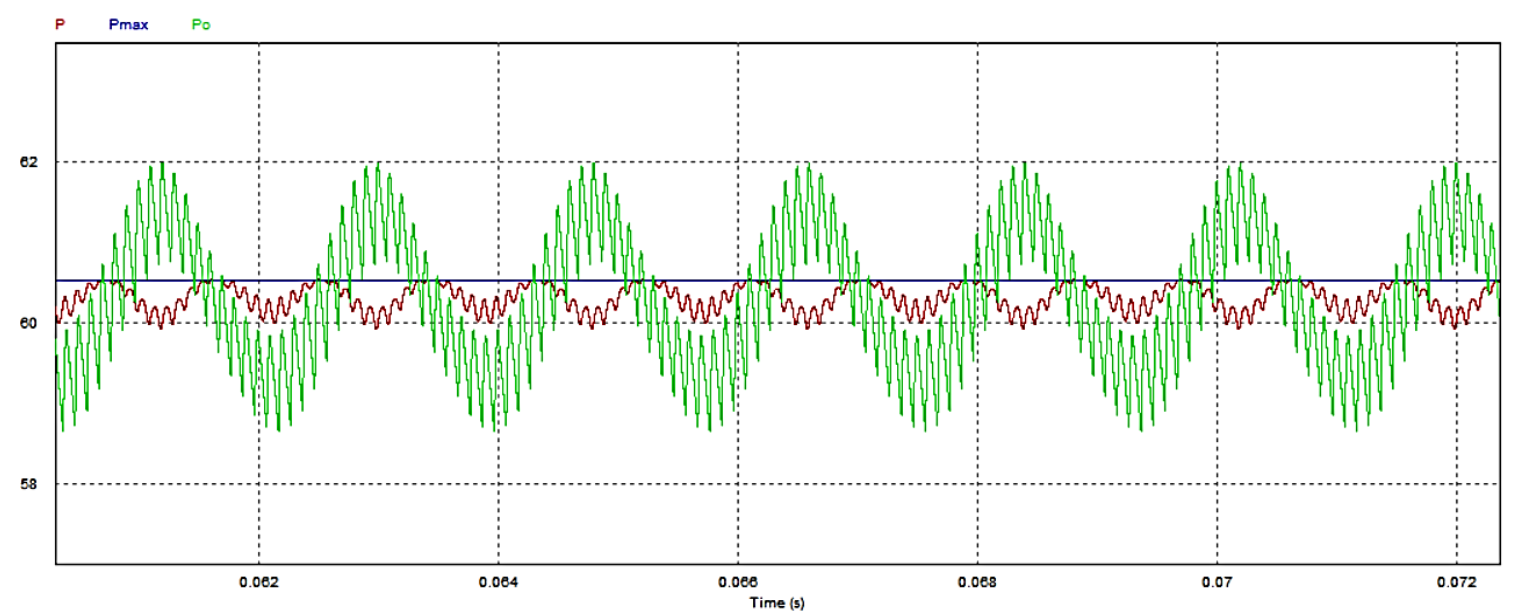

Figure 5.4. Zoom in the output powers for INC algorithm under STC.

Figure 5.3 shows the results obtained by INC algorithm under STC, a zoom in these results done and presented in Figure 5.4. These results show the power generated by the PV panel (P), the power absorbed by the load (Po), and the power available from the PV panel (Pmax) and this is the target which must be reached by the MPPT algorithm.

As shown in the figures above, by using the INC algorithm, the system takes $20 \mathrm{~ms}$ to stabilize around the MPP with an efficiency of $96.64 \%$. Also, the power ripple is more than $3 \mathrm{~W}$, which leads to high oscillations around the MPP.

\subsubsection{Kalman filter based MPPT}

Figure 5.5 shows the results obtained by Kalman filter based MPPT under STC, a zoom in these results done and presented in Figure 5.6, the efficiency obtained is around $99.38 \%$ and the response time is less than $5 \mathrm{~ms}$, Also the power ripple is less than $0.8 \mathrm{~W}$. Hence under STC, the proposed method presents a faster response with a good efficiency and oscillations are almost neglected.

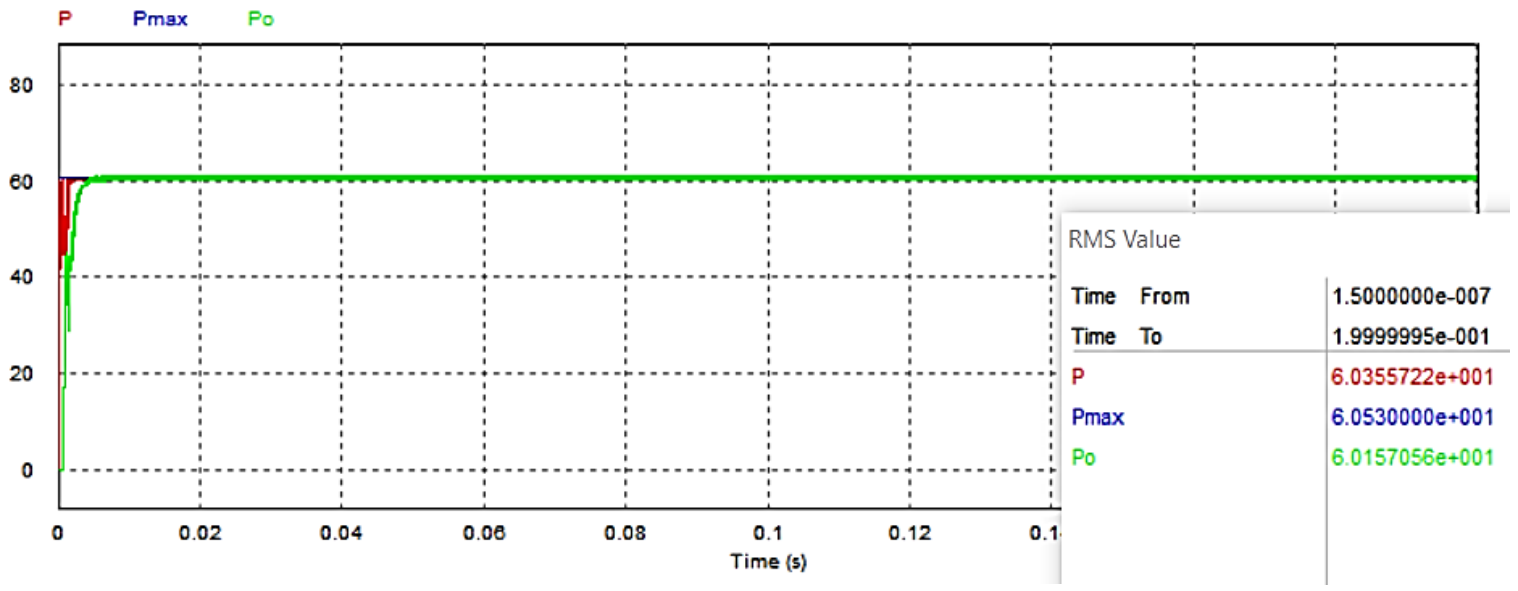

Figure 5.5. The output powers for Kalman filter based MPPT under STC. 


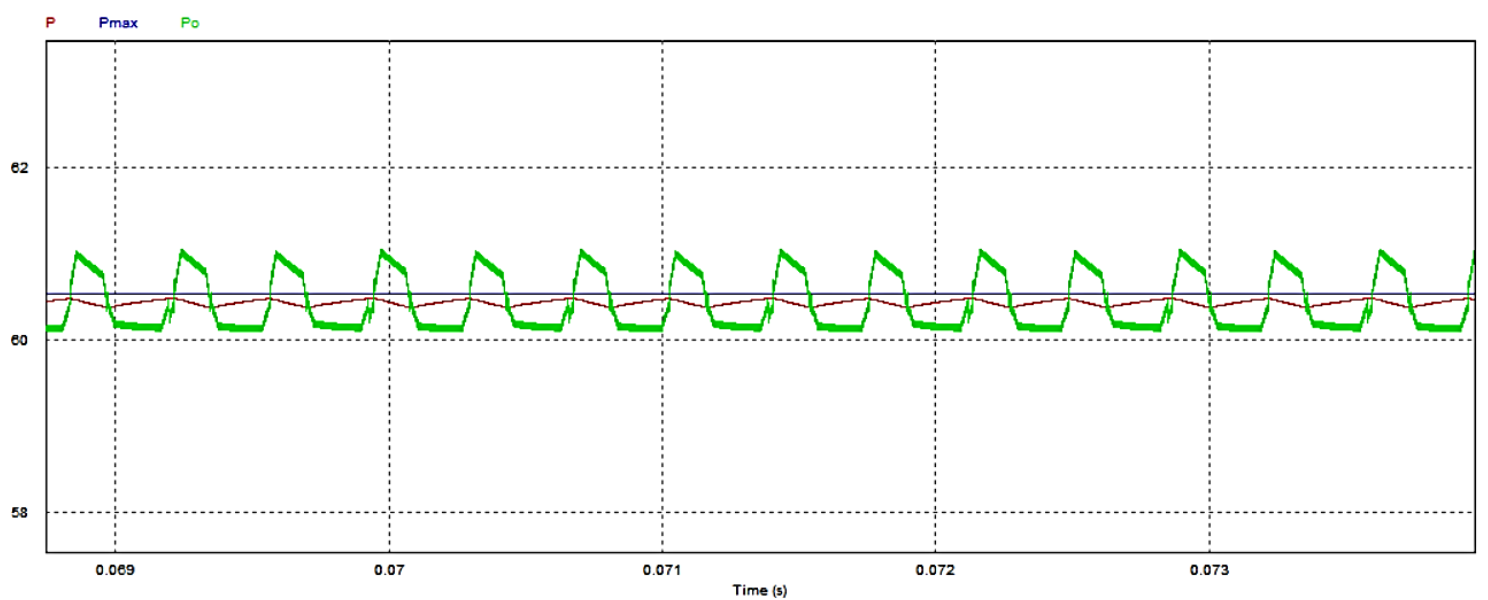

Figure 5.6. Zoom in the output powers for Kalman filter based MPPT under STC.

\subsection{Tests under variable solar irradiance}

\subsubsection{INC algorithm}

As shown in Figure 5.7, the INC algorithm takes longer to reach the new MPP in case of a sudden change in solar irradiance. Hence, the efficiency of this system under variable solar irradiance is low, which is equal to $96.10 \%$.

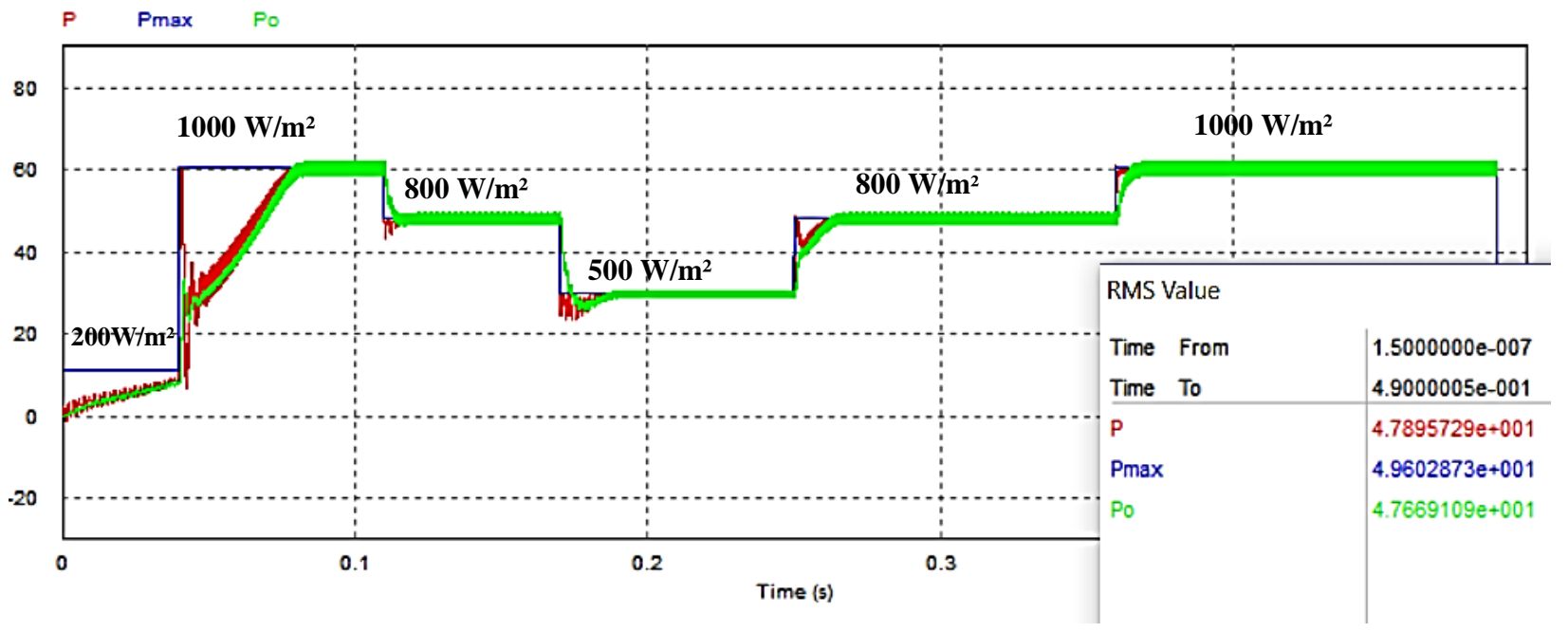

Figure 5.7. The output powers for INC algorithm under variable solar irradiance.

\subsubsection{Kalman filter based MPPT}

As shown in Figure 5.8, the proposed method presents a faster response to reach the new MPP in case of a sudden change in solar irradiance; the oscillations of the output powers are almost neglected. Also, this method shows an excellent efficiency which is equal to $99.29 \%$. 


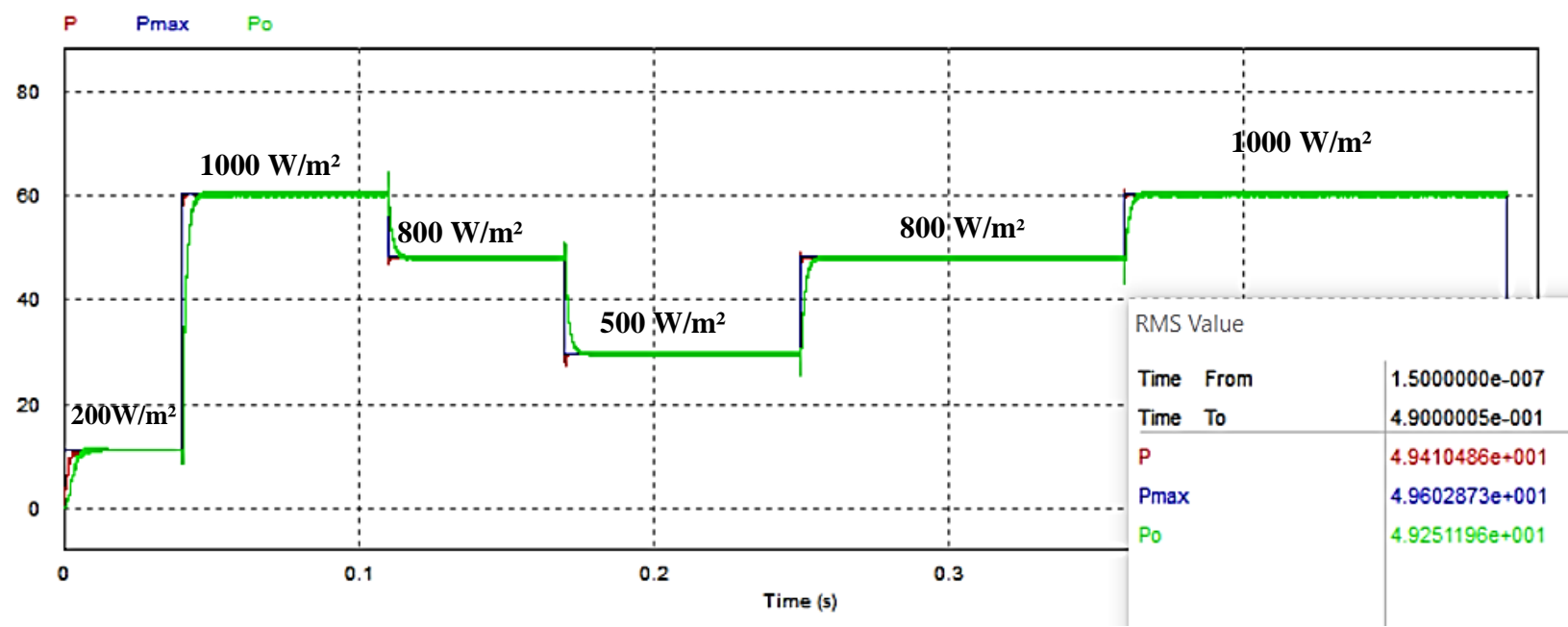

Figure 5.8. The output powers for Kalman filter based MPPT under variable solar irradiance.

\subsection{Tests under variable temperature and fixed solar irradiance $\left(500 \mathrm{~W} / \mathrm{m}^{2}\right)$}

\subsubsection{INC algorithm}

As shown in Figure 5.9, under variable temperature, the INC algorithm presents an admitted efficiency of $98.34 \%$, but the power ripple is more than $3 \mathrm{~W}$, which leads to high oscillations around the MPP.

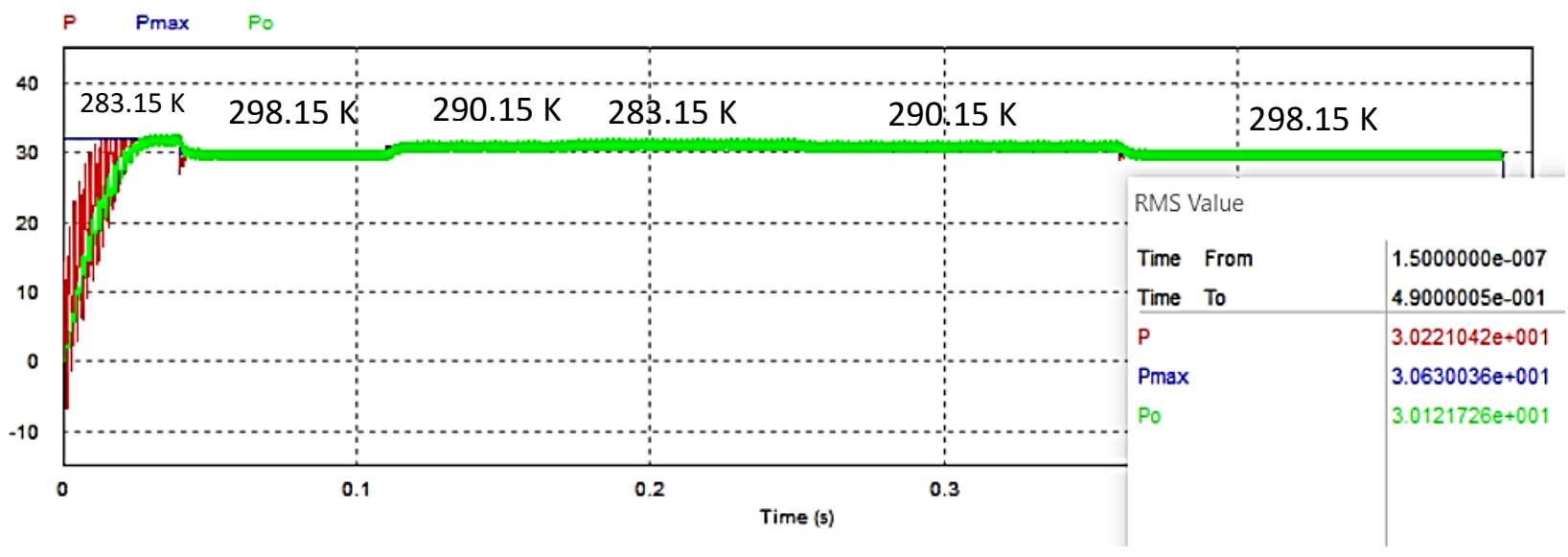

Figure 5.9. The output powers for INC algorithm under variable temperature.

\subsubsection{Kalman filter based MPPT}

As shown in Figure 5.10, under variable temperature, the proposed method presents a faster response to reach the new MPP and the oscillations are almost neglected. Also, this method shows a good efficiency which is equal to $99.42 \%$. 


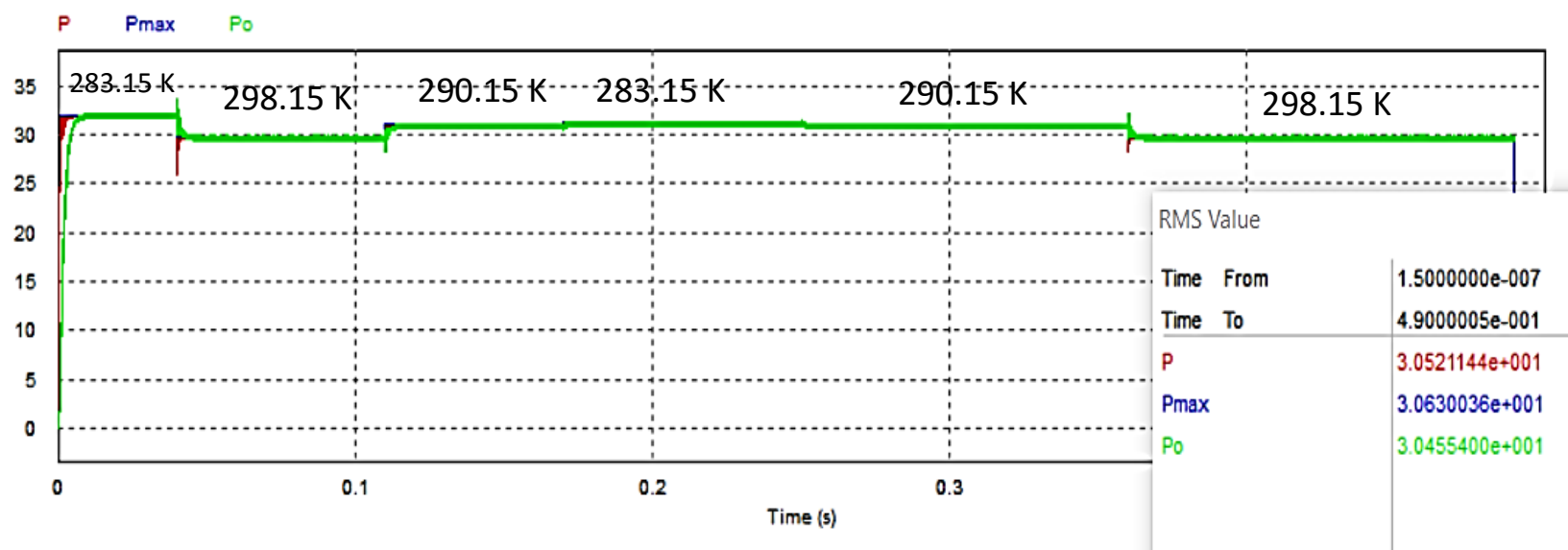

Figure 5.10. The output powers for Kalman filter based MPPT under variable temperature.

\subsection{Recapitulation}

After presenting the results obtained by the INC algorithm and Kalman filter based MPPT, these results are summarized in Tables 5.1 and 5.2.

Table 5.1. Results comparison between the proposed method and INC algorithm at temperature 298.15 K.

\begin{tabular}{|c|c|c|c|c|c|c|}
\hline \multirow{2}{*}{$\begin{array}{c}\text { Irradiance } \\
\left(\mathbf{W} / \mathbf{m}^{\mathbf{2}}\right)\end{array}$} & \multicolumn{3}{|c|}{ Kalman filter based MPPT } & \multicolumn{3}{c|}{ INC algorithm } \\
\cline { 2 - 7 } & Response & Efficiency & Oscillations & Response & Efficiency & Oscillations \\
$(\%)$ & $(\mathrm{W})$ & 0.8 & 30 & 96.64 & 3 \\
\hline 1000 & 5 & 99.38 & 0.4 & 24 & 96.72 & 1.6 \\
\hline 500 & 4 & 99.25 & 0.7 & 29 & 96.62 & 2.7 \\
\hline
\end{tabular}

Table 5.2. Results comparison between the proposed method and INC algorithm at irradiance $500 \mathrm{~W} / \mathrm{m}^{2}$.

\begin{tabular}{|c|c|c|c|c|c|c|}
\hline \multirow{2}{*}{$\begin{array}{c}\text { Temperature } \\
(\mathbf{K})\end{array}$} & \multicolumn{3}{|c|}{ Kalman filter based MPPT } & \multicolumn{3}{c|}{ INC algorithm } \\
\cline { 2 - 7 } & $\begin{array}{c}\text { Response } \\
\text { time (ms) }\end{array}$ & $\begin{array}{c}\text { Efficiency } \\
(\%)\end{array}$ & $\begin{array}{c}\text { Oscillations } \\
(\mathrm{W})\end{array}$ & $\begin{array}{c}\text { Response } \\
\text { time (ms) }\end{array}$ & $\begin{array}{c}\text { Efficiency } \\
(\%)\end{array}$ & $\begin{array}{c}\text { Oscillations } \\
(\mathrm{W})\end{array}$ \\
\hline 298.15 & 4 & 99.40 & 0.4 & 30 & 96.98 & 2 \\
\hline 283.15 & 4 & 99.49 & 0.4 & 28 & 96.92 & 1.6 \\
\hline 290.15 & 4 & 99.42 & 0.45 & 28 & 96.96 & 1.8 \\
\hline
\end{tabular}

In these tables, we compared the two methods based on three criteria which are:

(i) The response time: is the time needed by the method to achieve the maximum power.

(ii) The efficiency: is a factor that defines how close the results obtained to the ideal maximum power. 
(iii) Oscillations: are how much the power oscillates when the MPP is reached.

Based on the results obtained in this work and the criteria cited before, we can see that the proposed method presents better results than the conventional INC algorithm. From the tables above, we notice that the response time of the proposed method is 6 times lower than the INC algorithm response time. Kalman filter based MPPT presents better efficiency around $99.38 \%$ and the oscillations are 5 times smaller. These results show that Kalman filter based MPPT presents better performances than INC algorithm. Therefore, the latter can be considered as one of the powerful MPPT algorithms.

\section{Summary}

In this chapter, we compared the Kalman filter based MPPT with the conventional INC algorithm to prove Kalman efficiency under stable and variable environmental conditions. The results obtained showed a better performance for the proposed method when compared to the INC algorithm. The efficiency obtained by Kalman is better than the obtained by the INC. The oscillations generated by the INC are high compared to Kalman. We can conclude that Kalman filter is better when it is used as MPPT than the INC algorithm. It is true that to implement Kalman filter based MPPT, a stronger microcontroller including a great memory, a high clock frequency, and floating-point computation is required and this increases the cost of our PV system. But the high performance obtained by this method merits that. Therefore, if minimizing the price is not important than guarantying a very high level of robustness and efficiency of our PV system, the proposed method is a suitable choice to be used. 


\section{Chapter 6}

\section{Summary, conclusion and future work}

- Summary of Work and Conclusion

- Suggestions for Future Work 


\section{Summary of Work and Conclusion}

The thesis begins with a critical review of several MPPT techniques used to track the maximum power point (MPP) of PV system. They are categorized into three groups. First, the conventional methods namely perturb and observe (P\&O), incremental conductance (INC) and direct duty cycle control methods are discussed. The second group comprises of techniques that utilize the PV array and power converter characteristics. The last group is based on soft computing approaches. These include methods such as fuzzy logic control (FLC), artificial neural network (ANN) and partial swarm optimization (PSO) algorithm. The merits and drawbacks of each method are highlighted. Then, INC algorithm is found suitable to propose a low-cost PV system with several improvements.

To simulate our proposed methods, the PV panel is modeled. Therefore, the PV panel's parameters are extracted using Mathworks tool "PV Array", hence by using these parameters a PV panel and a PV array are modeled on Matlab/Simulink and PSIM, and the results show that the model is in accordance with experimental data of the used panel (MSX-60). In addition, A Proteus model of PV panel is developed and presented in this thesis, thus this model is validated by comparing its data with experimental data and consequently the model is in accordance with experimental data. As a result, this Proteus PV model and electronic boards available in Proteus can be used as a low-cost PV simulator to test the implementation of MPPT algorithm, this simulator makes future modifications on the system much easier to achieve.

Then a modified INC algorithm that can overcome the confusion faced by the conventional INC algorithm is proposed in this thesis. As a result, the tests show that the modified algorithm detects the fast increase of irradiation and makes a correct decision, contrary to the conventional algorithm. Moreover, by using the modified algorithm steady-state oscillations are almost neglected. Hence, the loss of energy is minimized and the efficiency is equal to $98.8 \%$ instead of $96 \%$ obtained by the conventional technique. In addition, another modification is made in the modified INC algorithm, which is the elimination of all division computations found in the conventional INC algorithm. This has rendered the algorithm structure simpler and has decreased the required real processing time. Hence, the modified algorithm can be easily implemented by low-cost microcontrollers (as Atmega328 in our case) to minimize system costs. In addition, simulation and experimental results show that the modified algorithm reduces the execution time and as a result make simple the controller process. Consequently, the modified algorithm can track the MPP correctly with faster response and less steady-state oscillations during sudden changes compared to conventional INC algorithm, and 
that is thanks to the simple structure of the modified algorithm. Note that the result obtained by Proteus simulation is nearly the same obtained by experimental work. As a result, we can base on this Proteus test bench to check the excellent performance of such MPPT algorithm.

On the other hand in this thesis, a modified variable step-size is presented to perform correctly in case of sudden irradiance variation. Then, three manners of tests (MIL/SIL/PIL) mostly used for automotive and aeronautical embedded system are employed to validate the functionality and robustness of the modified variable step INC algorithm. As a result, the responses of the three tests are in accordance with the MPPT algorithm requirements. Hence this work contributes to achieve the objective of DO-178C and ISO 26262 standards. In addition, the results show that the modified algorithm avoids the steady-state oscillations and increases the tracking speed under sudden irradiance variation. In light of that, the MPPT is tested on STM32F4 Discovery board; therefore, the performance obtained will be the same by using a real PV panel. Consequently, the PIL test can be used as a low-cost solution to test the hardware implementation of MPPT algorithm under different conditions of irradiation and temperature. So, by using these kinds of tests, we took advantage of safety level integrated in automotive and aeronautical embedded systems. And In this sense, integrating the MPPT embedded system in the automotive or the aeronautical area will possible.

On the other side, for a very high level of robustness and efficiency of our PV system, it is required to use a powerful method. Therefore in this thesis, Kalman filter based MPPT algorithm is proposed. Then, we compared the proposed method with the conventional INC algorithm to prove Kalman efficiency under stable and variable environmental conditions. The results obtained showed a better performance for the proposed method when compared to the conventional INC algorithm. The efficiency obtained by Kalman is better than the obtained by the INC. The oscillations generated by the INC are high compared to Kalman. We can conclude that Kalman filter is better when it is used as MPPT than the conventional INC algorithm. It is true that to implement Kalman filter based MPPT, a stronger microcontroller including a great memory, a high clock frequency, and floatingpoint computation is required and this increases the cost of our PV system. But the high performance obtained by this method merits that. Therefore, if minimizing the cost is not important than guarantying a very high level of robustness and efficiency of our PV system, the proposed method is a suitable choice to be used.

In a nutshell, this thesis proposed two solutions, the first one is for low-cost applications with a good performance by using the modified INC, and the second is for higher performance and critical applications by using Kalman filter. 


\section{Suggestions for Future Works}

In this thesis, several contributions are presented. However, there remain potentially new findings in the area of MPPT control and solar energy that can still be explored. These can be summarized in the following section.

\subsection{Design an improved MPPT method for tracking the MPP under partial shading condition}

When a PV Panel is subjected to partial shading, its P-V curves exhibit multiple peaks with several local and one global peak (GP). The drawback with the conventional MPPT, is that for the majority of the cases, the algorithm is likely to trap at the local peak, simply because it could not differentiate the local with the GP. Consequently, it oscillates around the vicinity of the local peak and will remain in that location indefinitely. As a result, output power is reduced. Therefore, it would be of interest to design an improved MPPT method which is capable of tracking the MPP under partial shading condition

\subsection{Extended Kalman filter based MPPT}

Chapter 5 describes the design and implementation of Kalman filter based MPPT algorithm, but the hardware implementation of this method is not made. Therefore, it would be of interest to implement this method in a microcontroller or a DSP. In addition, it would be of interest to design the MPPT algorithm using the extended Kalman filter (EKF) which can handle the nonlinearity of the PV characteristics.

\subsection{Automatic cleaning system for the PV panel, solar tracker and PV system as a connected object}

Other methods that can be used to optimize the PV energy are: Solar tracker and Automatic cleaning system for the PV panel. Therefore, it would be exciting to propose a PV system with the following functionalities:
(i) Automatic cleaning system.
(ii) Sun Tracker system.
(iii) MPPT controller.

On the other hand, make the PV panel as a connected object by using the Internet of Things (IoT) technology, this can present several benefits such as remote control of PV system and monitor the PV energy as well as the fault detection. 


\section{REFERENCES}

[1] Great Britain. Department of Trade and Industry, Meeting the energy challenge - A white paper on energy (2007), TSO, ISBN: 9780101712422.

[2] Darnell, J., \& Jefferson, M. (1994). New renewable energy resources: a guide to the future. World Energy Council, London, England.

[3] Cacciato, M., Consoli, A., Attanasio, R., \& Gennaro, F. (2010). Soft-switching converter with HF transformer for grid-connected photovoltaic systems. IEEE Transactions on Industrial Electronics, 57(5), 1678-1686.

[4] Rahim, N. A., Chaniago, K., \& Selvaraj, J. (2011). Single-phase seven-level grid-connected inverter for photovoltaic system. IEEE transactions on industrial electronics, 58(6), 2435-2443.

[5] Bruendlinger, R., Bletterie, B., Milde, M., \& Oldenkamp, H. (2006). Maximum power point tracking performance under partially shaded PV array conditions. Proc. 21st EUPVSEC, 2157-2160.

[6] Han, X., Wang, Y., \& Zhu, L. (2011). Electrical and thermal performance of silicon concentrator solar cells immersed in dielectric liquids. Applied energy, 88(12), 4481-4489.

[7] Kuznetsov, I. A., Greenfield, M. J., Mehta, Y. U., Merchan-Merchan, W., Salkar, G., \& Saveliev, A. V. (2011). Increasing the solar cell power output by coating with transition metal-oxide nanorods. Applied energy, 88(11), 4218-4221.

[8] Li, M., Ji, X., Li, G., Wei, S., Li, Y., \& Shi, F. (2011). Performance study of solar cell arrays based on a trough concentrating photovoltaic/thermal system. Applied Energy, 88(9), 3218-3227.

[9] Badescu, V. (2006). Simple optimization procedure for silicon-based solar cell interconnection in a series-parallel PV module. Energy Conversion and Management, 47(9), 1146-1158.

[10] Amir, A., Selvaraj, J., \& Rahim, N. A. (2016). Study of the MPP tracking algorithms: Focusing the numerical method techniques. Renewable and Sustainable Energy Reviews, 62, 350-371.

[11] Gupta, A., Chauhan, Y. K., \& Pachauri, R. K. (2016). A comparative investigation of maximum power point tracking methods for solar PV system. Solar Energy, 136, 236-253.

[12] Verma, D., Nema, S., Shandilya, A. M., \& Dash, S. K. (2016). Maximum power point tracking (MPPT) techniques: Recapitulation in solar photovoltaic systems. Renewable and Sustainable Energy Reviews, 54, 1018-1034.

[13] Ram, J. P., Babu, T. S., \& Rajasekar, N. (2017). A comprehensive review on solar PV maximum power point tracking techniques. Renewable and Sustainable Energy Reviews, 67, 826-847.

[14] Motahhir, S., El Ghzizal, A., Sebti, S., \& Derouich, A. (2016). Shading effect to energy withdrawn from the photovoltaic panel and implementation of DMPPT using C language. International review of automatic control, 9(2), 88-94.

[15] Tey, K. S., \& Mekhilef, S. (2014). Modified incremental conductance MPPT algorithm to mitigate inaccurate responses under fastchanging solar irradiation level. Solar Energy, 101, 333-342.

[16] Motahhir, S., El Ghzizal, A., Sebti, S., \& Derouich, A. (2017). MIL and SIL and PIL tests for MPPT algorithm, Cogent Engineering, 4: 1378475 .

[17] Elbaset, A. A., Ali, H., Abd-El Sattar, M., \& Khaled, M. (2016). Implementation of a modified perturb and observe maximum power point tracking algorithm for photovoltaic system using an embedded microcontroller. IET Renewable Power Generation, 10(4), 551-560.

[18] Al Nabulsi, A., \& Dhaouadi, R. (2012). Efficiency optimization of a DSP-based standalone PV system using fuzzy logic and dual-MPPT control. IEEE Transactions on Industrial Informatics, 8(3), 573-584.

[19] Elgendy, M. A., Zahawi, B., \& Atkinson, D. J. (2012). Assessment of perturb and observe MPPT algorithm implementation techniques for PV pumping applications. IEEE transactions on sustainable energy, 3(1), 21-33.

[20] Motahhir, S., El Ghzizal, A., Sebti, S., \& Derouich, A. (2015). Proposal and Implementation of a novel perturb and observe algorithm using embedded software. 3rd International Renewable and Sustainable Energy Conference (IRSEC), (pp. 1-5). IEEE.

[21] Piegari, L., \& Rizzo, R. (2010). Adaptive perturb and observe algorithm for photovoltaic maximum power point tracking. IET Renewable Power Generation, 4(4), 317-328.

[22] Femia, N., Petrone, G., Spagnuolo, G., \& Vitelli, M. (2005). Optimization of perturb and observe maximum power point tracking method. IEEE transactions on power electronics, 20(4), 963-973.

[23] Fermia, N., Granozio, D., Petrone, G., \& Vitelli, M. (2007). Predictive \& adaptive MPPT perturb and observe method. IEEE Transactions on Aerospace and Electronic Systems, 43(3).

[24] Abdelsalam, A. K., Massoud, A. M., Ahmed, S., \& Enjeti, P. N. (2011). High-performance adaptive perturb and observe MPPT technique for photovoltaic-based microgrids. IEEE Transactions on Power Electronics, 26(4), 1010-1021.

[25] Ishaque, K., Salam, Z., \& Lauss, G. (2014). The performance of perturb and observe and incremental conductance maximum power point tracking method under dynamic weather conditions. Applied Energy, 119, 228-236.

[26] Soon, T. K., \& Mekhilef, S. (2015). A fast-converging MPPT technique for photovoltaic system under fast-varying solar irradiation and load resistance. IEEE transactions on industrial informatics, 11(1), 176-186

[27] Radjai, T., Rahmani, L., Mekhilef, S., \& Gaubert, J. P. (2014). Implementation of a modified incremental conductance MPPT algorithm with direct control based on a fuzzy duty cycle change estimator using dSPACE. Solar Energy, 110, 325-337.

[28] Sekhar, P. C., \& Mishra, S. (2014). Takagi-Sugeno fuzzy-based incremental conductance algorithm for maximum power point tracking of a photovoltaic generating system. IET Renewable Power Generation, 8(8), 900-914.

[29] Zakzouk, N. E., Elsaharty, M. A., Abdelsalam, A. K., Helal, A. A., \& Williams, B. W. (2016). Improved performance low-cost incremental conductance PV MPPT technique. IET Renewable Power Generation, 10(4), 561-574.

[30] Kalman, R. E. (1960). A new approach to linear filtering and prediction problems. Journal of basic Engineering, 82(1), 35-45.

[31] Motahhir, S., El Ghzizal, A., Sebti, S., \& Derouich, A. (2017). Modeling of Photovoltaic System with modified Incremental Conductance Algorithm for fast changes of irradiance. International Journal of Photoenergy, in press.

[32] Ishaque, K. (2012). Deterministic Particle Swarm Optimization Method for Maximum Power Point Tracking of Photovoltaic System (Doctoral dissertation, Universiti Teknologi Malaysia).

[33] Ishaque, K., \& Salam, Z. (2013). A review of maximum power point tracking techniques of PV system for uniform insolation and partial shading condition. Renewable and Sustainable Energy Reviews, 19, 475-488.

[34] Wasynezuk, O. (1983). Dynamic behavior of a class of photovoltaic power systems. IEEE transactions on power apparatus and systems, (9), 30313037.

[35] Hart, G. W., Branz, H. M., \& Cox, C. H. (1984). Experimental tests of open-loop maximum-power-point tracking techniques for photovoltaic arrays. Solar cells, 13(2), 185-195. 
[36] Yuvarajan, S., \& Xu, S. (2003). Photovoltaic power converter with a simple maximum-power-point-tracker. Proceedings of the International Symposium In Circuits and Systems, (Vol. 3, pp. III-III). IEEE.

[37] Mutoh, N., Matuo, T., Okada, K., \& Sakai, M. (2002). Prediction-data-based maximum-power-point-tracking method for photovoltaic power generation systems. IEEE 33rd Annual Power Electronics Specialists Conference, (Vol. 3, pp. 1489-1494). IEEE.

[38] Noguchi, T., Togashi, S., \& Nakamoto, R. (2001). Short-current-pulse based adaptive maximum-power-point tracking for photovoltaic power generation system. IEEJ Transactions on Industry Applications, 121(1), 78-83.

[39] Kobayashi, K., Matsuo, H., \& Sekine, Y. (2004, June). A novel optimum operating point tracker of the solar cell power supply system. In Power Electronics Specialists Conference, 2004. PESC 04. 2004 IEEE 35th Annual (Vol. 3, pp. 2147-2151). IEEE.

[40] Patterson, D. J. (1990, June). Electrical system design for a solar powered vehicle. In Power Electronics Specialists Conference, 1990. PESC'90 Record, 21st Annual IEEE (pp. 618-622). IEEE.

[41] Noh, H. J., Lee, D. Y., \& Hyun, D. S. (2002, November). An improved MPPT converter with current compensation method for small scaled PVapplications. In IECON 02 IEEE 2002 28th Annual Conference of the Industrial Electronics Society (Vol. 2, pp. 1113-1118). IEEE.

[42] Enslin, J. H., \& Snyman, D. B. (1992, November). Simplified feed-forward control of the maximum power point in PV installations. In Industrial Electronics, Control, Instrumentation, and Automation, 1992. Power Electronics and Motion Control, Proceedings of the 1992 International Conference on (pp. 548-553). IEEE.

[43] Karatepe, E., \& Hiyama, T. (2009). Polar coordinated fuzzy controller based real-time maximum-power point control of photovoltaic system. Renewable Energy, 34(12), 2597-2606.

[44] Hohm, D. P., \& Ropp, M. E. (2003). Comparative study of maximum power point tracking algorithms. Progress in photovoltaics: Research and Applications, 11(1), 47-62.

[45] Peng, Y. F., Wai, R. J., \& Lin, C. M. (2004). Implementation of LLCC-resonant driving circuit and adaptive CMAC neural network control for linear piezoelectric ceramic motor. IEEE Transactions on Industrial Electronics, 51(1), 35-48.

[46] Ishaque, K., Abdullah, S. S., Ayob, S. M., \& Salam, Z. (2010). Single input fuzzy logic controller for unmanned underwater vehicle. Journal of Intelligent and Robotic Systems, 59(1), 87-100.

[47] Ishaque, K., Abdullah, S. S., Ayob, S. M., \& Salam, Z. (2011). A simplified approach to design fuzzy logic controller for an underwater vehicle. Ocean Engineering, 38(1), 271-284.

[48] Ishaque, K., \& Salam, Z. (2011). An improved modeling method to determine the model parameters of photovoltaic (PV) modules using differential evolution (DE). Solar Energy, 85(9), 2349-2359.

[49] Ishaque, K., Salam, Z., Taheri, H., \& Shamsudin, A. (2011). A critical evaluation of EA computational methods for Photovoltaic cell parameter extraction based on two diode model. Solar Energy, 85(9), 1768-1779.

[50] Ishaque, K., Salam, Z., Amjad, M., \& Mekhilef, S. (2012). An improved particle swarm optimization (PSO)-based MPPT for PV with reduced steady-state oscillation. IEEE transactions on Power Electronics, 27(8), 3627-3638.

[51] Eberhart, R., \& Kennedy, J. (1995, October). A new optimizer using particle swarm theory. In Micro Machine and Human Science, 1995. MHS'95, Proceedings of the Sixth International Symposium on (pp. 39-43). IEEE.

[52] Patel, H., \& Agarwal, V. (2008). MATLAB-based modeling to study the effects of partial shading on PV array characteristics. IEEE transactions on energy conversion, 23(1), 302-310.

[53] Motahhir, S., Chalh, A., Ghzizal, A., Sebti, S., \& Derouich, A. (2017). Modeling of Photovoltaic Panel by using Proteus. Journal of Engineering Science and Technology Review, 10 (2), 8-13.

[54] Rauschenbach, H. S. (1980). „Solar Cell Array Design Handbook "Van Nostrand Reinhold Co. New York.

[55] Barth, N., Jovanovic, R., Ahzi, S., \& Khaleel, M. A. (2016). PV panel single and double diode models: optimization of the parameters and temperature dependence. Solar Energy Materials and Solar Cells, 148, 87-98.

[56] Nishioka, K., Sakitani, N., Uraoka, Y., \& Fuyuki, T. (2007). Analysis of multicrystalline silicon solar cells by modified 3-diode equivalent circuit model taking leakage current through periphery into consideration. Solar Energy Materials and Solar Cells, 91(13), $1222-1227$.

[57] Yildiran, N., \& Tacer, E. (2016). Identification of photovoltaic cell single diode discrete model parameters based on datasheet values. Solar Energy, 127, 175-183.

[58] Ishaque, K., Salam, Z., Mekhilef, S., \& Shamsudin, A. (2012). Parameter extraction of solar photovoltaic modules using penalty-based differential evolution. Applied Energy, 99, 297-308.

[59] AlHajri, M. F., El-Naggar, K. M., AlRashidi, M. R., \& Al-Othman, A. K. (2012). Optimal extraction of solar cell parameters using pattern search. Renewable Energy, 44, 238-245.

[60] Mathworks (2015). PV Array. https://fr.mathworks.com/help/physmod/sps/powersys/ref/pvarray.html. Accessed 04 Mai 2017.

[61] Carrero, C., Amador, J., \& Arnaltes, S. (2007). A single procedure for helping PV designers to select silicon PV modules and evaluate the loss resistances. Renewable Energy, 32(15), 2579-2589.

[62] Ahmed, J., \& Salam, Z. (2016). A Modified P\&O Maximum Power Point Tracking Method with Reduced Steady-State Oscillation and Improved Tracking Efficiency. IEEE Transactions on Sustainable Energy, 7(4), 1506-1515.

[63] Motahhir, S., El Ghzizal, A., Sebti, S., \& Derouich, A. (2015, November). Une ressource pédagogique pour l'enseignement par simulation: cas des panneaux photovoltaïques. International Workshop on Pedagogic Approaches \& E-Learning.

[64] Villalva, M. G., Gazoli, J. R., \& Ruppert Filho, E. (2009, September). Modeling and circuit-based simulation of photovoltaic arrays. In Power Electronics Conference, 2009. COBEP'09. Brazilian (pp. 1244-1254). IEEE.

[65] Drissi, H., Khediri, J., Zaafrane, W., \& Braiek, E. B. (2017). Critical factors affecting the photovoltaic characteristic and comparative study between two maximum power point tracking algorithms. International Journal of Hydrogen Energy, 42(13), 8689-8702.

[66] Mertens, K. (2013). Photovoltaics: fundamentals, technology and practice. John Wiley \& Sons.

[67] McEvoy, A., Markvart, T., Castañer, L., Markvart, T., \& Castaner, L. (Eds.). (2003). Practical handbook of photovoltaics: fundamentals and applications. Elsevier.

[68] Villalva, M. G., Gazoli, J. R., \& Ruppert Filho, E. (2009). Comprehensive approach to modeling and simulation of photovoltaic arrays. IEEE Transactions on power electronics, 24(5), 1198-1208.

[69] Glasner, I., \& Appelbaum, J. (1996). Advantage of boost vs. buck topology for maximum power point tracker in photovoltaic systems. Nineteenth Convention of Electrical and Electronics Engineers in Palestine, (pp. 355-358). IEEE.

[70] Solarex MSX60 and MSX64 photovoltaic panel, datasheet (1998). https://www.solarelectricsupply.com/media/custom/upload/SolarexMSX64.pdf. Accessed 21 April 2017

[71] Motahhir, S., El Ghzizal, A., \& Derouich, A. (2015, May). Modélisation et commande d'un panneau photovoltaïque dans l'environnement PSIM. Congrès International de Génie Industriel et Management des Systèmes.

[72] Fathabadi, H. (2016). Novel high efficiency DC/DC boost converter for using in photovoltaic systems. Solar Energy, 125, 22-31. 
[73] Du, Y., \& Lu, D. D. C. (2011). Battery-integrated boost converter utilizing distributed MPPT configuration for photovoltaic systems. Solar energy, 85(9), 1992-2002.

[74] Abusorrah, A., Al-Hindawi, M. M., Al-Turki, Y., Mandal, K., Giaouris, D., Banerjee, S., \& Papadopoulou, S. (2013). Stability of a boost converter fed from photovoltaic source. Solar energy, 98, 458-471.

[75] Santos, J. L., Antunes, F., Chehab, A., \& Cruz, C. (2006). A maximum power point tracker for PV systems using a high performance boost converter. Solar Energy, 80 (7), 772-778.

[76] Mohan, N., \& Undeland, T. M. (2007). Power electronics: converters, applications, and design. John Wiley \& Sons.

[77] Maniktala, S. (2012). Switching Power Supplies A-Z. Elsevier

[78] Rashid, M. H. (2009). Power electronics: circuits, devices, and applications. Pearson Education India.

[79] Loukriz, A., Haddadi, M., \& Messalti, S. (2016). Simulation and experimental design of a new advanced variable step size Incremental Conductance MPPT algorithm for PV systems. ISA Transactions, 62, 30-38.

[80] Belkaid, A., Colak, I., \& Isik, O. (2016). Photovoltaic maximum power point tracking under fast varying of solar radiation. Applied Energy, 179, 523-530.

[81] De Brito, M. A. G., Galotto, L., Sampaio, L. P., e Melo, G. D. A., \& Canesin, C. A. (2013). Evaluation of the main MPPT techniques for photovoltaic applications. IEEE transactions on industrial electronics, 60(3), 1156-1167.

[82] Kim, R. Y., \& Kim, J. H. (2013). An improved global maximum power point tracking scheme under partial shading conditions. Journal of International Conference on Electrical Machines and Systems, 2 (1), pp. 65-68.

[83] Qin, S., Cady, S. T., Dominguez-Garcia, A. D., \& Pilawa-Podgurski, R. C. N. (2015). A distributed approach to maximum power point tracking for photovoltaic submodule differential power processing. IEEE Transactions on Power Electronics, 30(4), 2024-2040.

[84] Solórzano, J., \& Egido, M. A. (2014). Hot-spot mitigation in PV arrays with distributed MPPT (DMPPT). Solar Energy, 101, $131-137$.

[85] Lin, C. H., Huang, C. H., Du, Y. C., \& Chen, J. L. (2011). Maximum photovoltaic power tracking for the PV array using the fractional-order incremental conductance method. Applied Energy, 88(12), 4840-4847.

[86] Voltage Sensor Module Arduino Compatible. 2017. [Online]. Available: http://www.emartee.com/product/42082/Voltage\%20Sensor\%20.

[87] INA169 Datasheet. 2017. [Online]. Available: http://www.ti.com/lit/ds/symlink/ina169.pdf?HQS=TI-null-null-alldatasheets-df-pf-SEP-wwe.pdf

[88] Montoya, D. G., Ramos-Paja, C. A., \& Giral, R. (2016). Improved design of sliding-mode controllers based on the requirements of MPPT techniques. IEEE transactions on Power Electronics, 31(1), 235-247.

[89] TC4420 Driver Datasheet. 2017. [Online]. Available: http://ww1.microchip.com/downloads/en/DeviceDoc/21419D.pdf

[90] Faraji, R., Rouholamini, A., Naji, H. R., Fadaeinedjad, R., \& Chavoshian, M. R. (2014). FPGA-based real time incremental conductance maximum power point tracking controller for photovoltaic systems. IET Power Electronics, 7(5), 1294-1304.

[91] Zainuri, M. A. A. M., Radzi, M. A. M., Soh, A. C., \& Rahim, N. A. (2013). Development of adaptive perturb and observe-fuzzy control maximum power point tracking for photovoltaic boost dc-dc converter. IET Renewable Power Generation, 8(2), 183-194.

[92] Boukenoui, R., Ghanes, M., Barbot, J. P., Bradai, R., Mellit, A., \& Salhi, H. (2017). Experimental assessment of Maximum Power Point Tracking methods for photovoltaic systems. Energy, 132, 324-340.

[93] Dubois, H., Peraldi-Frati, M. A., \& Lakhal, F. (2010). A model for requirements traceability in a heterogeneous model-based design process: Application to automotive embedded systems. 15th IEEE international conference in Engineering of complex computer systems, (pp. 233-242). IEEE.

[94] Moy, Y., Ledinot, E., Delseny, H., Wiels, V., \& Monate, B. (2013). Testing or formal verification: Do-178C alternatives and industrial experience. IEEE software, 30(3), 50-57.

[95] RTCA. (2011). DO-178C. Software considerations in airborne systems and equipment certification.

[96] Mathworks (2016). Supported Standards and Products. https://www.mathworks.com/products/do-178/supported.html. Accessed 04 September 2017.

[97] Sivakumar, P., Kader, A. A., Kaliavaradhan, Y., \& Arutchelvi, M. (2015). Analysis and enhancement of PV efficiency with incremental conductance MPPT technique under non-linear loading conditions. Renewable Energy, 81, 543-550.

[98] Zhou, Z., Holland, P. M., \& Igic, P. (2014). MPPT algorithm test on a photovoltaic emulating system constructed by a DC power supply and an indoor solar panel. Energy Conversion and Management, 85, 460-469.

[99] Kadri, R., Andrei, H., Gaubert, J. P., Ivanovici, T., Champenois, G., \& Andrei, P. (2012). Modeling of the photovoltaic cell circuit parameters for optimum connection model and real-time emulator with partial shadow conditions. Energy, 42(1), 57-67.

[100]Bringmann, E., \& Krämer, A. (2008). Model-based testing of automotive systems. 1st International Conference In Software Testing, Verification, and Validation, (pp. 485-493). IEEE.

[101]Hu, M., Zeng, G., Yao, H., \& Tang, Y. (2010). Processor-in-the-loop demonstration of coordination control algorithms for distributed spacecraft. IEEE International Conference in Information and Automation (ICIA), (pp. 1008-1011). IEEE.

[102] Von Maurich, I., \& Güneysu, T. (2014). Towards Side-Channel Resistant Implementations of QC-MDPC McEliece Encryption on Constrained Devices. PQCrypto, 2014, 266-282.

[103]El-Khozondar, H. J., El-Khozondar, R. J., Matter, K., \& Suntio, T. (2016). A review study of photovoltaic array maximum power tracking algorithms. Renewables: Wind, Water, and Solar, 3(1), 3

[104]Reisi, A. R., Moradi, M. H., \& Jamasb, S. (2013). Classification and comparison of maximum power point tracking techniques for photovoltaic system: A review. Renewable and Sustainable Energy Reviews, 19, 433-443.

[105]Liu, F., Duan, S., Liu, F., Liu, B., \& Kang, Y. (2008). A variable step size INC MPPT method for PV systems. IEEE Transactions on industrial electronics, 55(7), 2622-2628.

[106] Ramchandani, V., Pamarthi, K., \& Chowdhury, S. R. (2012). Comparative study of maximum power point tracking using linear Kalman filter \& unscented kalman filter for solar photovoltaic array on field programmable gate array. International Journal on Smart Sensing \& Intelligent Systems, 5(3), 152-158.

[107]Kang, B. O., \& Park, J. H. (2011). Kalman filter MPPT method for a solar inverter. IEEE Power and Energy Conference at Illinois, (pp. 1-5). IEEE.

[108] Aoune, A., Motahhir, S., El Ghzizal, A., Sebti, S., \& Derouich, A. (2016). Determination of the maximum power point in a photovoltaic panel using Kalman Filter on the environment PSIM. International Conference on Information Technology for Organizations Development, (pp. 1-4). IEEE.

[109]Lyden, S., \& Haque, M. E. (2015). Maximum Power Point Tracking techniques for photovoltaic systems: A comprehensive review and comparative analysis. Renewable and Sustainable Energy Reviews, 52, 1504-1518.

[110]Mohanty, P., Bhuvaneswari, G., Balasubramanian, R., \& Dhaliwal, N. K. (2014). MATLAB based modeling to study the performance of different MPPT techniques used for solar PV system under various operating conditions. Renewable and Sustainable Energy Reviews, $38,581-593$.

[111]Gupta, A., Chauhan, Y. K., \& Pachauri, R. K. (2016). A comparative investigation of maximum power point tracking methods for solar PV system. Solar Energy, 136, 236-253. 


\section{Contribution to the optimization of energy withdrawn from a PV panel using an Embedded System}

[112]Bendib, B., Belmili, H., \& Krim, F. (2015). A survey of the most used MPPT methods: Conventional and advanced algorithms applied for photovoltaic systems. Renewable and Sustainable Energy Reviews, 45, 637-648.

[113] Amir, A., Amir, A., Selvaraj, J., Rahim, N. A., \& Abusorrah, A. M. (2017). Conventional and modified MPPT techniques with direct control and dual scaled adaptive step-size. Solar Energy, 157, 1017-1031.

[114]Motahhir, S., Aoune, A., El Ghzizal, A., Sebti, S., \& Derouich, A. (2017). Comparison between Kalman filter and incremental conductance algorithm for optimizing photovoltaic energy. Renewables: Wind, Water, and Solar, 4(1), 8.

[115]Mukerjee, A. K., \& Dasgupta, N. (2007). DC power supply used as photovoltaic simulator for testing MPPT algorithms. Renewable Energy, 32(4), 587-592. 


\section{APPENDIX A}

\section{List of Data}

- MATLAB/Simulink Model of Photovoltaic Cell, Panel and Array:

https://github.com/motahhir/MATLAB-Simulink-Model-of-Photovoltaic-Cell-Panel-and-Array-

- MPPT in PSIM Software:

https://github.com/motahhir/MPPT-in-PSIM-Software

- PV Panel in Proteus:

https://github.com/motahhir/PV-Panel-in-Proteus

- PV panel under shading and implementation of DMPPT:

https://github.com/motahhir/PV-panel-under-shading-and-implementation-of-DMPPT

- Data for: MIL and SIL and PIL tests for MPPT algorithm Paper:

https://github.com/motahhir/Data-for-MIL-and-SIL-and-PIL-tests-for-MPPT-algorithm-Paper

- Data for: Development of a low-cost PV system using an improved INC algorithm and a PV panel Proteus model:

https://github.com/motahhir/MPPT-in-Proteus

- Data for: Photovoltaic system with quantitative comparative between an improved MPPT and existing INC and P\&O methods under fast varying of solar irradiation:

https://github.com/motahhir/Data-for-Photovoltaic-system-with-quantitative-comparative-between-animproved-MPPT-and-existing-IN 


\section{APPENDIX B}

\section{List of publications}

\section{Patents application (OMPIC)}

1. Motahhir, S., El Majid, B., \& El Ghzizal, A. Rideaux avec des barres solaires lumineuses autonomes, mobiles et modulables.

2. Motahhir, S., El Majid, B., \& El Ghzizal, A. Collecteur solaire parabolique à double face avec système de refroidissement.

\section{PUBLICATIONS}

\section{- Papers published in international and indexed journals}

1. Motahhir, S., El Hammoumi, A., \& El Ghzizal, A. (2019). The Most Used MPPT Algorithms: Review and the Suitable Low-cost Embedded Board for Each Algorithm. Journal of Cleaner Production (Elsevier), 118983.

2. M. Boussetta, S. Motahhir, R. El Bachtiri, A. Allouhi, M. Khanfara, and Y. Chaibi, (2019). Design and Embedded Implementation of a Power Management Controller for Wind-PV-Diesel Microgrid System. International Journal of Photoenergy (Hindawi), In press.

3.

4. El Majid, B., Motahhir, S., \& El Ghzizal, A. (2019). Parabolic bifacial solar panel with the cooling system: concept and challenges. SN Applied Sciences (Springer Nature), 1(10), 1176.

5. Errouha, M., Derouich, A., Nahid-Mobarakeh, B., Motahhir, S., \& El Ghzizal, A. (2019). Improvement control of photovoltaic based water pumping system without energy storage. Solar Energy (Elsevier), 190, 319-328.

6. Errouha, M., Derouich, A., Motahhir, S., Zamzoum, O., El Ouanjli, N., \& El Ghzizal, A. (2019). Optimization and control of water pumping PV systems using fuzzy logic controller. Energy Reports (Elsevier), 5, 853-865.

7. El Ouanjli, N., Derouich, A., El Ghzizal, A., Motahhir, S., Chebabhi, A., El Mourabit, Y., \& Taoussi, M. (2019). Modern improvement techniques of direct torque control for induction motor drives-a review. Protection and Control of Modern Power Systems (Springer Nature), 4(1), 11.

8. El Ouanjli, N., Motahhir, S., Derouich, A., El Ghzizal, A., Chebabhi, A., \& Taoussi, M. (2019). Improved DTC strategy of doubly fed induction motor using fuzzy logic controller. Energy Reports (Elsevier), 5, 271-279. 
9. Motahhir, S., Hammoumi, A. E., Ghzizal, A. E., \& Derouich, A. (2019). Open hardware/software test bench for solar tracker with virtual instrumentation. Sustainable Energy Technologies and Assessments (Elsevier), 31, 9-16.

10. Motahhir, S., Chalh, A., El Ghzizal, A., \& Derouich, A. (2018). Development of a Low-cost PV System using an improved INC algorithm and a PV panel Proteus model. Journal of Cleaner Production (Elsevier), 204, 355-365.

11. EL Hammoumi A., Motahhir S., EL Ghzizal A., Chalh A., Derouich A. (2018). A simple and low-cost active dual-axis solar tracker. Energy Science \& Engineering (Wiley). 6(5), 607-620.

12. Chalh, A., Motahhir, S., El Hammoumi, A., El Ghzizal, A., \& Derouich, A. (2018). Study of a Low-Cost PV Emulator for Testing MPPT Algorithm under Fast Irradiation and Temperature Change. Technology and Economics of Smart Grids and Sustainable Energy (Springer Nature), 3(1), 11.

13. Motahhir, S., El Hammoumi, A., \& El Ghzizal, A. (2018). Photovoltaic system with quantitative comparative between an improved MPPT and existing INC and P\&O methods under fast varying of solar irradiation. Energy Reports (Elsevier), 4, 341-350.

14. Motahhir, S., Aoune, A., El Ghzizal, A., Sebti, S., \& Derouich, A. (2017). Comparison between Kalman filter and incremental conductance algorithm for optimizing photovoltaic energy. Renewables: Wind, Water, and Solar (Springer Nature), 4(1), 8.

15. El Hammoumi, A., Motahhir, S., Chalh, A., El Ghzizal, A., \& Derouich, A. (2018). Low-cost virtual instrumentation of PV panel characteristics using Excel and Arduino in comparison with traditional instrumentation. Renewables: Wind, Water, and Solar (Springer Nature), 5(1), 3.

16. Motahhir, S., El Ghzizal, A., Sebti, S., \& Derouich, A (2017). Modeling of Photovoltaic System with modified Incremental Conductance Algorithm for fast changes of irradiance. International Journal of Photoenergy (Hindawi), vol. 2018, Article ID 3286479, 13 pages.

17. Motahhir, S., El Ghzizal, A., Sebti, S., \& Derouich, A. (2017). MIL and SIL and PIL tests for MPPT algorithm, Cogent Engineering (Taylor \& Francis), 4: 1378475.

18. Motahhir, S., Chalh, A., Ghzizal, A., Sebti, S., \& Derouich, A. (2017). Modeling of Photovoltaic Panel by using Proteus. Journal of Engineering Science and Technology Review, 10 (2), 8-13.

19. Motahhir, S., El Ghzizal, A., Sebti, S., \& Derouich, A. (2016). Shading effect to energy withdrawn from the photovoltaic panel and implementation of DMPPT using $C$ language. International review of automatic control, 9(2), 88-94.

- IOP conference publications (Indexed in Scopus and Web of Science) 
20. Chalh, A., Motahhir, S., El Hammoumi, A., El Ghzizal, A., \& Derouich, A. (2018, June). A low-cost PV Emulator for testing MPPT algorithm. In IOP Conference Series: Earth and Environmental Science (Vol. 161, No. 1, p. 012018). IOP Publishing.

21. El Hammoumi, A., Motahhir, S., Chalh, A., El Ghzizal, A., \& Derouich, A. (2018, June). Real-time virtual instrumentation of Arduino and LabVIEW based PV panel characteristics. In IOP Conference Series: Earth and Environmental Science (Vol. 161, No. 1, p. 012019). IOP Publishing.

22. Choudhary, P., Srivastava, R. K., Mahendra, S. N., \& Motahhir, S. (2017, August). Sustainable Solution for Crude Oil and Natural Gas Separation using Concentrated Solar Power Technology. In IOP Conference Series: Materials Science and Engineering (Vol. 225, No. 1, p. 012134). IOP Publishing (international Collaboration).

\section{- IEEE conference publications (Indexed in Scopus and Web of Science)}

23. Motahhir, S., El Ghzizal, A., Sebti, S., \& Derouich, A. (2015, December). Proposal and Implementation of a novel perturb and observe algorithm using embedded software. 3rd International in Renewable and Sustainable Energy Conference (IRSEC), (pp. 1-5). IEEE inclusion.

24. Aoune, A., Motahhir, S., El Ghzizal, A., Sebti, S., \& Derouich, A. (2016, March). Determination of the maximum power point in a photovoltaic panel using Kalman filter on the environment PSIM. International Conference in Information Technology for Organizations Development (IT4OD) (pp. 14). IEEE inclusion. 


\section{APPENDIX C}

\section{Thesis presentation:}

https://fr.slideshare.net/saadmotahhir/presentation-soutenance-v5-148007693 